RFPFIVED

FEB 011998

OSTI

\title{
Re-Evaluation of a Subsurface Injection Experiment for Testing Flow and Transport Models
}
M. J. Fayer
R. E. Lewis
R. E. Engelman
A. L. Pearson
C. J. Murray

J. L. Smoot

R. R. Randall W. H. Wegener

A. H. Lu

December 1995

Prepared for the U.S. Department of Energy under Contract DE-AC06-76RLO 1830

Pacific Northwest National Laboratory Operated for the U.S. Department of Energy by Battelle Memorial Institute 


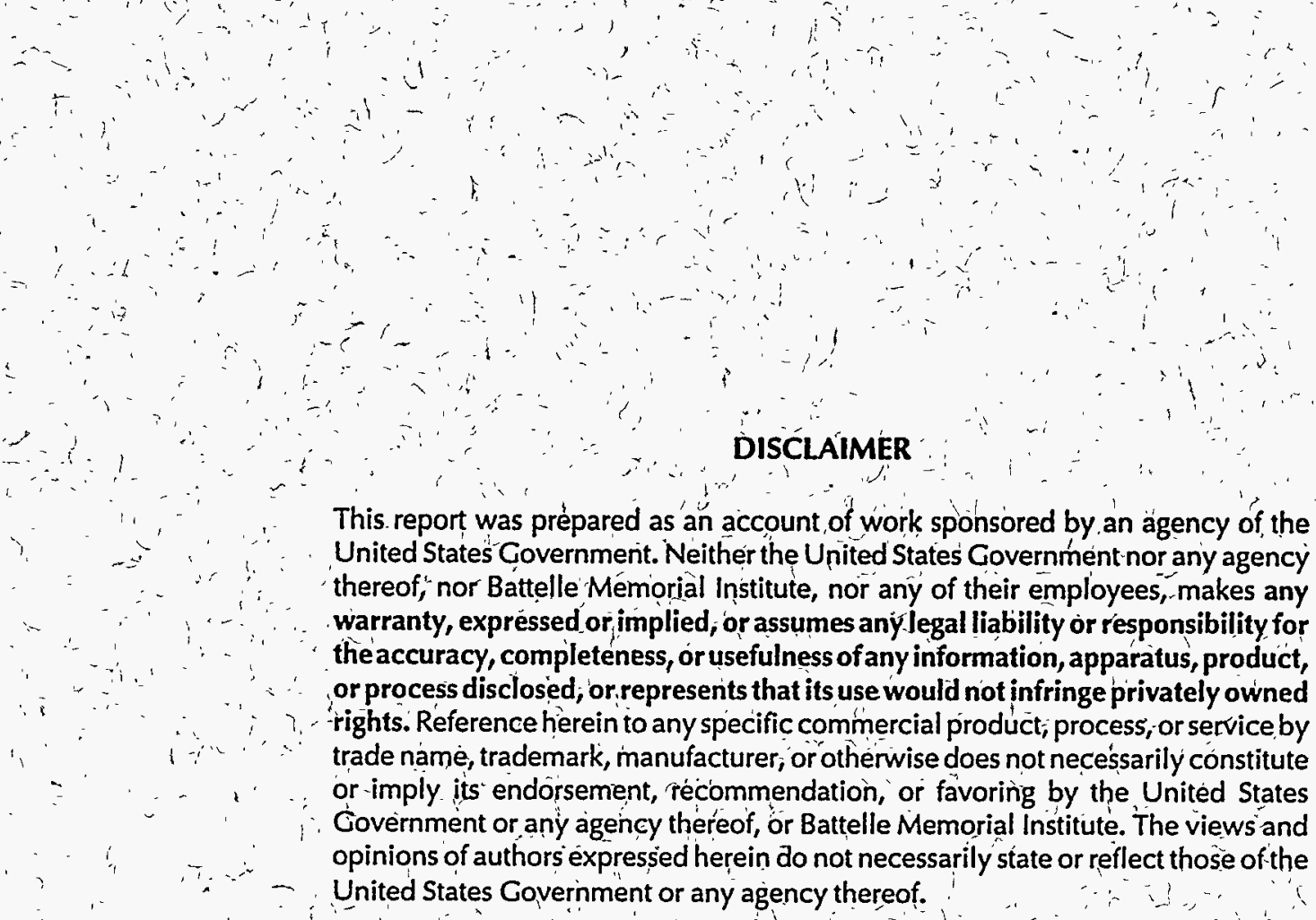

This report was prépared as an account of work sponsored by an àgency of the United States Government. Neither the United States Government nor any agency thereof,' nor Battelle Memorial Institute, nor any of their employees,-makes any warranty, expressed or implied, or assumes any legal liability or responsibility for the accuracy, completeness, or usefulness of any information, apparatus, product, or process disclosed; or represents that its use would not infringe privately owned rights. Reference herein to any specific commercial product, process, or service by trade name, trademark, manufacturer, or otherwise does not necessarily constitute or -imply its endorsement, récommendation, or favoring by the United States Government or any agency thereof, or Battelle Memorial Institute. The views and opinions of authors expressied herein do not necessarily state or reflect those of the

\section{PACIFIC NORTHWEST LABORATORY operated by \\ BATTELLE MEMORIAL INSTITUTE \\ for the \\ UNITED STATES DEPARTMENT ÓF ENERGY ¿ under Contráct DE-ACO6-76RLO 1830}

Printed in the United States of America

Available to DOE and DOE contractors from the

Office of Scientific and Technical Informátion, P.O. Box 62, Oak Ridge, TN 37831;

$\therefore$ prices available from (615) 576-8401. FTS 626-8401.

Available to the public from the National Technical Information Service,

U.S. Department of Cómmerce, 5285 Port Royal Rd., Springfield, VA 22161. 


\title{
Re-Evaluation of a Subsurface Injection Experiment for Testing Flow and Transport Models
}

\author{
M. J. Fayer \\ R. E. Lewis \\ R. E. Engelman \\ A. L. Pearson \\ C. J. Murray \\ J. L. Smoot \\ R. R. Randall(a) \\ W. H. Wegener(b) \\ A. H. Lu
}

December 1995

Prepared for the U.S. Department of Energy under Contract DE-AC06-76RLO 1830

Pacific Northwest National Laboratory

Richland, Washington 99352

(a) Three Rivers Scientific, Richland, Washington

(b) Hoquiam High School, Hoquiam, Washington 



\section{Summary}

The current preferred method for disposal of low-level radioactive waste (LLW) at the Hanford Site is to vitrify the wastes so they can be stored in a near-surface, shallow-land burial facility (Shord 1995). Pacific Northwest Laboratory (PNL) managed the PNL Vitrification Technology Development (PVTD) Project to assist Westinghouse Hanford Company (WHC) in designing and assessing the performance of a disposal facility for the vitrified LLW. Vadose zone flow and transport models are recognized as necessary tools for baseline risk assessments of stored waste forms.

The objective of the Controlled Field Testing task of the PVTD Project is to perform and analyze field experiments to demonstrate the appropriateness of conceptual models for the performance assessment. The most convincing way to demonstrate appropriateness is to show that the model can reproduce the movement of water and contaminants in the field. Before expensive new experiments are initiated, an injection experiment conducted at the Hanford Site in 1980 (designated the "Sisson and the Lu experiment") should be completely analyzed and understood. Briefly, in that test, a solution containing multiple tracers was injected at a single point into the subsurface sediments. The resulting spread of the water and tracers was monitored in wells surrounding the injection point. Given the advances in knowledge, computational capabilities, and models over the last 15 years, it is important to re-analyze the data before proceeding to other experiments and history-matching exercises.

The objective of this task in FY 1995 was to log the injection site with the latest geophysical tools to provide better estimates of water contents, refine the stratigraphic conceptual model, and ultimately provide a data set that is sufficiently complete, detailed, and accurate to enable effective testing of models. The objectives of this report are to 1) document the 1995 geophysical data; 2) interpret the data relative to the mass of injected water, the original geologic conceptual model, and the predicted movement of water and ${ }^{134} \mathrm{Cs}$; and 3) determine the direction of future model testing. In FY 1995, four wells at the injection site were logged with two of the original neutron probes. These probes were also calibrated in moisture calibration standards. All of the wells at the injection site also were logged for water content, density, and gamma emissions by a logging vender. Three wells near the injection point were logged specifically for the tracer ${ }^{134} \mathrm{Cs}$.

With the 1995 data, new calibration equations were calculated for all three neutron probes used during the experiment. The revised equations were sufficiently different to affect calculations in some past studies. For Probe 1 (the most frequently used probe), the estimated error in water content for the 1980 data was 3.2 vol\%. The error in water content caused by probe positioning (i.e., centered versus eccentered) was estimated to be no more than $2.2 \mathrm{vol} \%$. In future experiments, prior to each injection, the entire set of wells should be logged to serve as a baseline. Also, all of the probes should be run in several wells for field verification before, during, and after the experiment.

The temporal spread of neutron probe measurements made it difficult to analyze the experiment during and immediately after an injection when fluxes were highest. However, this time during the experiment may not be the most important time to analyze. Performance assessments are more concerned with what happens over many years. Monitoring activities in future experiments should be focused less on the injection period and more on the long-term movement of the injected water and tracers.

As analysts strive to discern details at $15 \mathrm{~cm}(6 \mathrm{in}$.) or shorter spacings, knowledge of the actual depth location of each measurement will be critical. The centers of measurement for the different 
geophysical tools should be more clearly defined and referenced to an established datum. To extract the most value from the data during the analyses, the well casings should be surveyed to eliminate elevation differences and verify how parallel the wells actually are.

Calculation of the volume of water in the domain during the experiment showed that the neutron probe data tracked the injected volume within an amount roughly equivalent to one injection volume. This exercise revealed that the calibration equation for each probe, rather than an average equation, should be used.

Geophysical logging data indicated that the injected $85 \mathrm{Sr}$ was not detectable and the ${ }^{134 \mathrm{Cs}}$ was barely detectable within $2 \mathrm{~m}(6.6 \mathrm{ft})$ of the injection point. These results are consistent with these tracers' radioactive half-lives. The fact that $134 \mathrm{Cs}$ was detected after 15 years only near the injection point is an indication of that tracer's high sorption potential. The radioactive tracers were shown to be viable for in situ (nondestructive) measurements. These and similar tracers should be considered for use in future.experiments.

The geophysical data are the subject of ongoing analyses. To date, the results show strong horizontal features (i.e., layers) that aren't always truly horizontal, continuous, or of constant thickness. This variability is consistent with the attempts by Smoot and Lu (1994) and Smoot (1995) to incorporate three-dimensional features in their geologic model. Some of the geophysical data will be used to infer the lithology of the sediments. Once this analysis effort is completed, a field sampling effort should be undertaken to collect sediment samples to verify the resulting lithologic model and calibrate the geophysical tools. This sampling effort can be coordinated with other PVTD sampling efforts to optimize the investment.

The depth profiles of tracer concentrations appeared incomplete because not all depths or wells were logged, making. it difficult to understand the movement of the tracers. A complete set of gross gamma logs from 1983 was acquired for these wells. These logs should be processed and compared to the total gamma emissions in 1995 to estimate the ${ }^{134} \mathrm{Cs}$ distribution in 1983 . This information could be used to clarify whether the original tracer scans covered the entire ${ }^{134} \mathrm{Cs}$ plume or were . incomplete.

Tracer profiles constructed from 1980 data show steep vertical concentration gradients, sometimes with significant concentration differences over $0.15 \mathrm{~m}(6 \mathrm{in}$.). The short spacing of these differences implies that the detail of the geologic model may be important at a similar scale. To date, the finest model detail has been a $0.5-\mathrm{m}$ (1.6-ft) vertical spacing. The 1995 geophysical data were collected at vertical spacings ranging from 0.025 to $0.15 \mathrm{~m}$ (1 to 6 in.). A As these data are analyzed, similarly detailed geologic conceptual models can be generated and tested.

Based on the preliminary analyses, much remains to be learned from the Sisson and Lu experiment. The recommended steps include these: 1) construct a geologic model that is consistent with the $1995^{-}$geophysical data, 2) define a modeling grid that is aligned with the spatial orientation of the monitoring data, 3) determine measures of model goodness-of-fit, 4) use a flow and transport model to simulate the injection experiment using the multiple geologic conceptual models proposed during the past 15 years, 5) test the quantitative capability of the flow and transport model to reproduce the injection experiment, and 6) evaluate the benefits derived from using the progressively more detailed, more expensive, and computationally intensive geologic models.

A significant amount of geophysical data were collected in 1995. Although analyses of these data and the experiment are ongoing, the results so far have highlighted several recommendations 
necessary to complete the evaluation of the Sisson and Lu experiment. These recommendations include analyzing the 1983 gross gamma logs, field sampling to calibrate the geophysical logging tools and to verify the geologic conceptual model, and testing of flow and transport models.

The potential of the Sisson and Lu data set for demonstrating model confidence has not yet been realized. Until it is, the best course of action is to exhaust the probative value of the experiment before proposing additional tests. The exceptions to this recommendation are those tests designed with objectives for which it is known the Sisson and Lu experiment cannot address. 


\section{Acknowledgments}

We want to thank Tyler Gilmore, David Stromswold, Pat Hays, and Kathy Blanchard for reviewing this report and providing helpful comments. This work was supported by the U.S. Department of Energy, Richland Operations Office. Pacific Northwest National Laboratory is operated for the U.S. Department of Energy by Battelle under Contract DE-AC06-76RLO 1830. 



\section{Contents}

Summary $\ldots \ldots \ldots \ldots \ldots \ldots \ldots \ldots \ldots \ldots \ldots \ldots \ldots \ldots \ldots \ldots \ldots \ldots \ldots \ldots \ldots \ldots \ldots \ldots \ldots$

Acknowledgments $\ldots \ldots \ldots \ldots \ldots \ldots \ldots \ldots \ldots \ldots \ldots \ldots \ldots \ldots \ldots \ldots \ldots \ldots$ vii

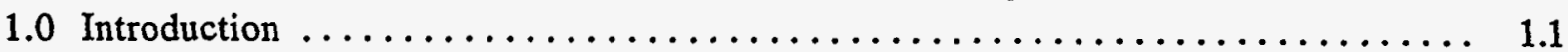

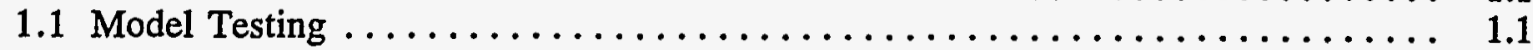

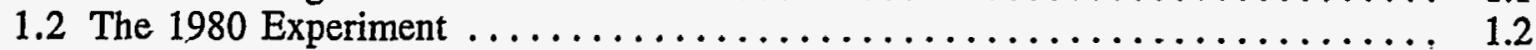

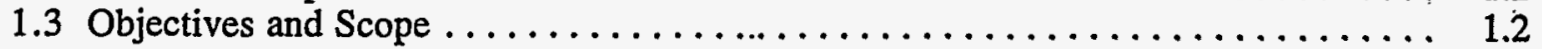

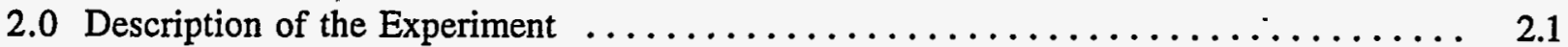

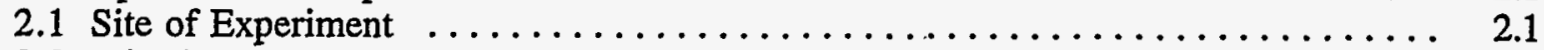

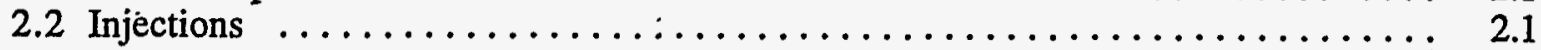

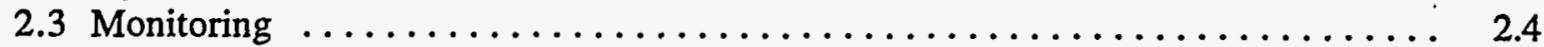

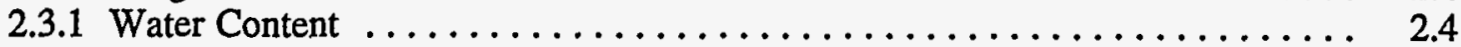

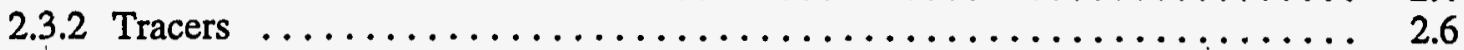

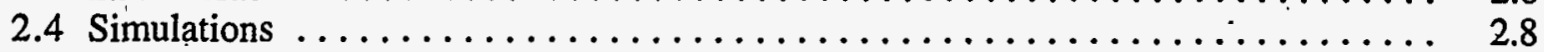

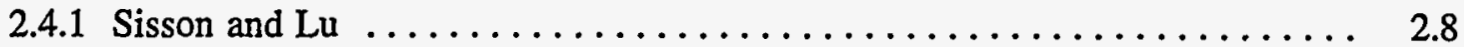

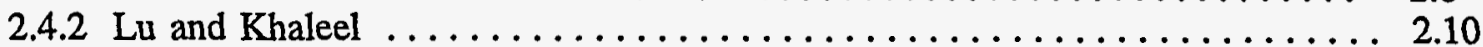

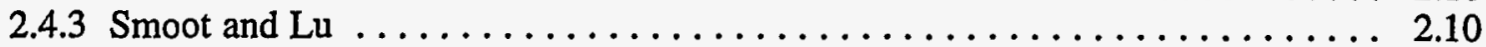

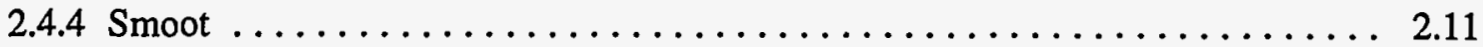

3.0 Measurement Tools Used in FY $1995 \ldots \ldots \ldots \ldots \ldots \ldots \ldots \ldots \ldots \ldots \ldots \ldots \ldots \ldots \ldots$

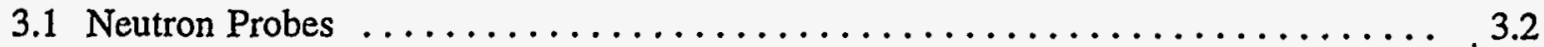

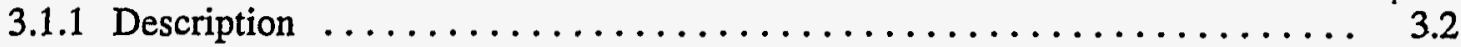

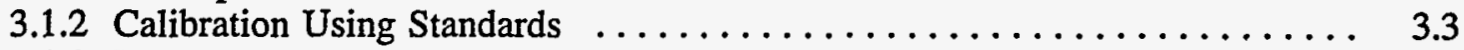

3.1 .3 Field Measurements . . . . . . . . . . . . . . . . . . . . 3.3

3.1.4 Final Calibration Using Standards and Field Data . . . . . . . . . . 3.5

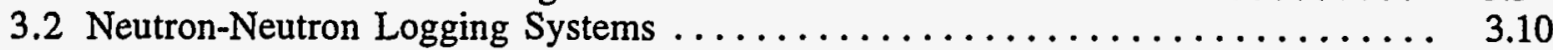

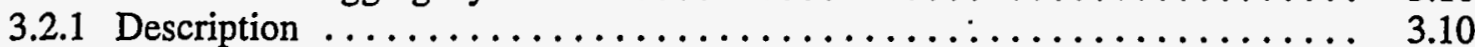

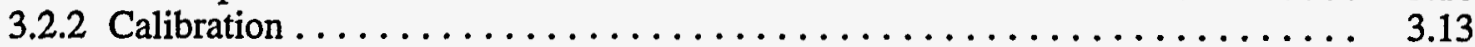

3.3 Gamma-Gamma Density Logging System .................... 3.14

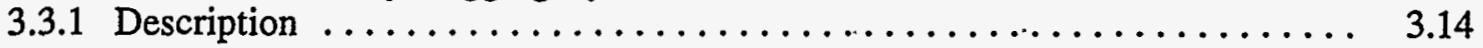

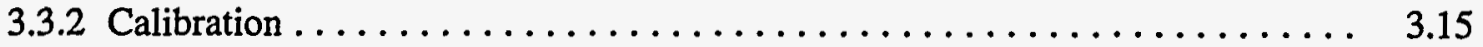

3.4 Spectral Gamma Logging Systems $\ldots \ldots \ldots \ldots \ldots \ldots \ldots \ldots \ldots \ldots \ldots \ldots \ldots \ldots \ldots \ldots \ldots \ldots .16$

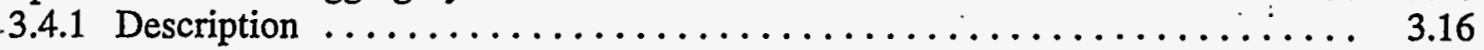

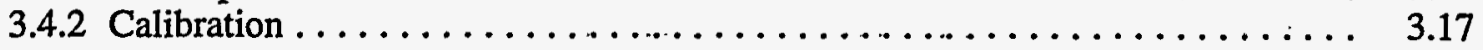

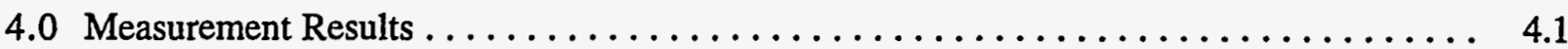

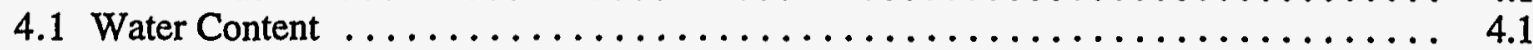

4.1 .1 Comparison Among Tools . . . . . . . . . . . . . . . . . .

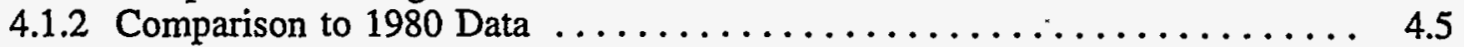

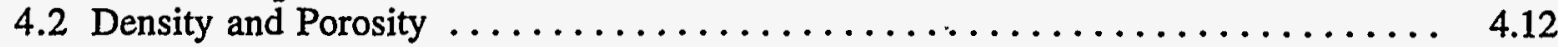

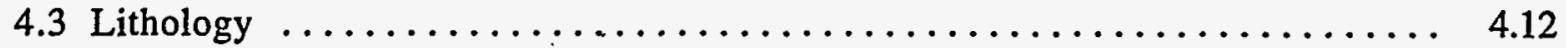

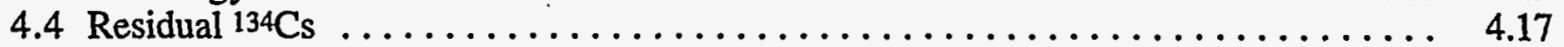

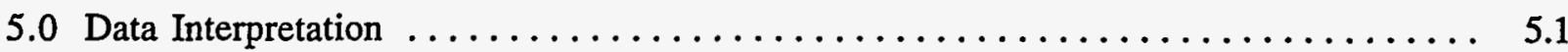

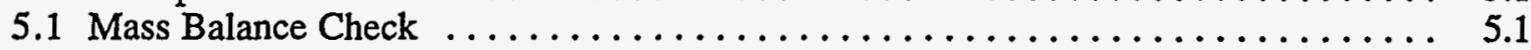




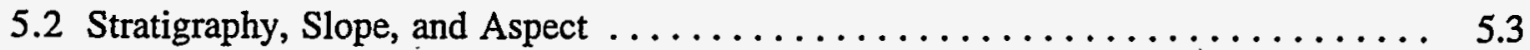

5.3 Findings Relative to Previous Geologic Models $\ldots \ldots \ldots \ldots \ldots \ldots \ldots \ldots \ldots . \ldots \ldots$

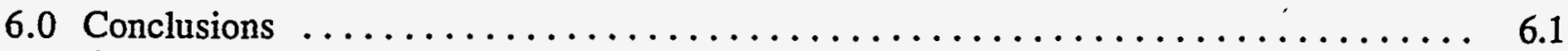

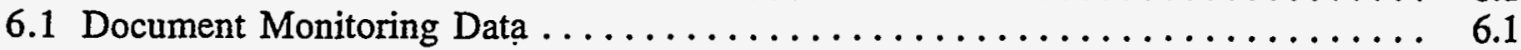

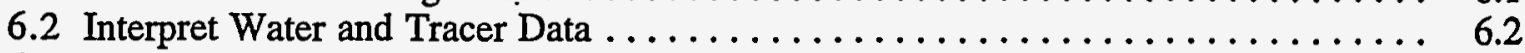

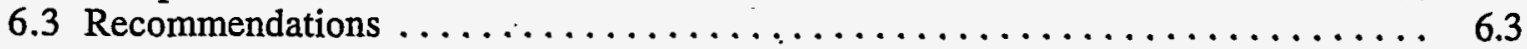

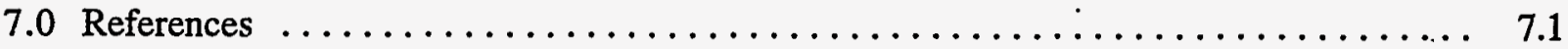

Appendix A - Neutron Probe Data $\ldots \ldots \ldots \ldots \ldots \ldots \ldots \ldots \ldots \ldots \ldots \ldots \ldots \ldots \ldots \ldots \ldots \ldots$

Appendix B - Schlumberger Data . . . . . . . . . . . . .

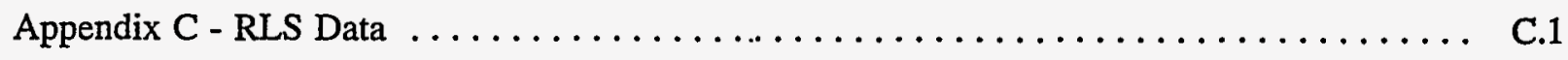




\section{Figures}

1.1 Hanford Site Map Showing Location of the Proposed LLTWDS $\ldots \ldots \ldots \ldots \ldots$

1.2 200 East Area Map Showing Location of the Proposed LLTWDS Relative to the

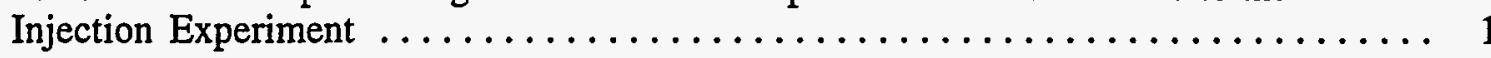

2.1 Cutaway View of the Injection Experiment Showing the Well Placement, the Tank for Mixing the Injection Solution, and the Connection Between the Tank and the

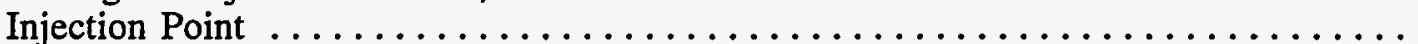

2.2 Plan View of Monitoring and Injection Well Placement and the Corresponding Local and Hanford Well Identification Numbers $\ldots \ldots \ldots \ldots \ldots \ldots \ldots \ldots \ldots \ldots \ldots \ldots \ldots$

2.3 Monitoring, Injection, and Sampling Dates $\ldots \ldots \ldots \ldots \ldots \ldots \ldots \ldots \ldots \ldots \ldots$

2.4 Water Content Changes Demonstrating that Monitoring with Neutron Probes Did Not Completely Capture the Wetting Front as It Moved Laterally Beyond $4.0 \mathrm{~m}(13.1 \mathrm{ft}) \ldots$

2.5 Depth Profiles of ${ }^{85 \mathrm{Sr},}{ }^{134} \mathrm{Cs}$, and Water Content for Selected Dates . . . . . . . . . .

3.1 Neutron Probe Calibration Equations Fitted to the Moisture Calibration Standards .....

3.2 Water Content Profiles for the CNT-G Probe and the Two Neutron Probes Used in 1980

3.3 Comparison of Water Content Profiles from the CNT-G Tool and the Two Neutron

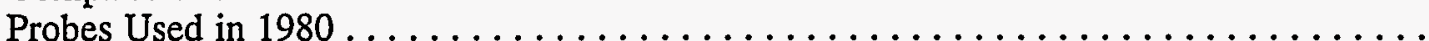

3.4 New Calibration Equations for the Neutron Probes

3.5 Water Content Differences Between the New Calibration Equations and the Original

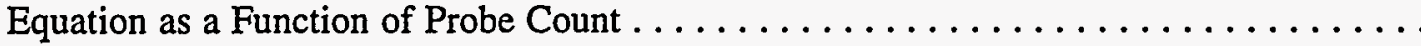

3.6 Schematic Diagram of the CNT-G Tool

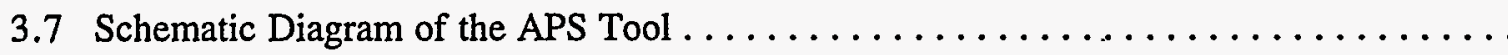

3.8 Density Correction as a Function of Compensated Bulk Density for Well E-1 . . . . . 3.15

3.9 Schematic Diagram of the HNGS Tool $\ldots \ldots \ldots \ldots \ldots \ldots \ldots \ldots \ldots \ldots \ldots \ldots$

3.10 Schematic Diagram of the RLS Tool $\ldots \ldots \ldots \ldots \ldots \ldots \ldots \ldots \ldots \ldots \ldots$

4.1 Comparison of Water Contents in Well A-7 (E24-79) Determined with Two Neutron

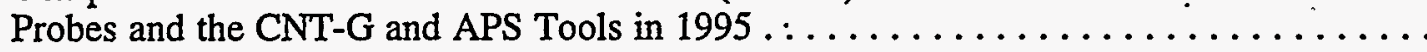

4.2 Comparison of Water Contents in Well E-1 (E24-92) Determined with the CNT-G and

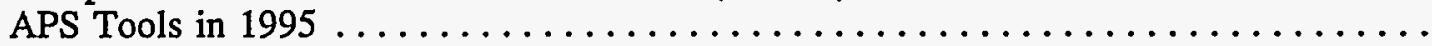


4.3 Comparison of Water Contents in Well E-7 (E24-95) Determined with Two Neutron Probes and the CNT-G and APS Tools in $1995 \ldots \ldots \ldots \ldots \ldots \ldots \ldots \ldots \ldots \ldots . \ldots \ldots$

4.4 Comparison of Water Contents in Wells A-7, E-1, and E-7 Determined with the APS Operating at High Resolution Mode with a Value Every 0.05 m (1.9 in.) in 1995 . . . . 4.6

4.5 Comparison of Water Contents in Well A-7 Determined with Probe 1 in 1980, 1981,

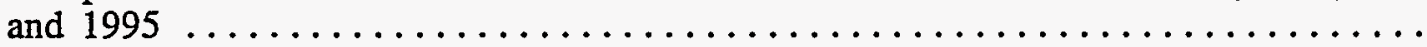

4.6 Comparison of Water Contents in Well E-7 Determined with Probe 1 in 1980, 1981,

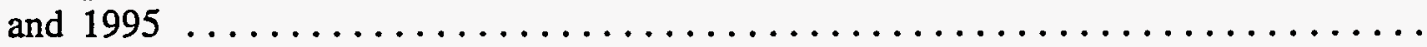

4.7 Comparison of Water Contents in Well-H-4 Determined with Probe 1 in 1980, 1981, and 1995

4.8 Comparison of Water Contents in Well H-6 Determined with Probe 1 in 1980, 1981, and 1995

4.9 Comparison of Water Contents in Well E-1 Determined with Probe 1 in 1980 and 1981, and with the CNT-G in 1995

4.10 Depth Profiles of Wet Bulk Density and Water Content Measured with the LDS and CNT-G Tools at 0.15-m (5.9-in.) Intervals in Well E-1

4.11 Wet Bulk Density as a Function of Water Content Measured with the CNT-G Tool for Well E-1. . . . . . . . . . . . . . . . . . . . . . . . . . .

4.12 Depth Profiles of Bulk Density and Water Content Measured with the LDS Tool at $0.025-\mathrm{m}(0.98-\mathrm{in}$.) Intervals and the APS Tool at $0.05-\mathrm{m}(1.9-\mathrm{in}$.$) Intervals$ in Well E-1

4.13 Spectral Gamma Data Collected with the RLS System in Well E-1 in $1995 \ldots \ldots \ldots . .4$

4.14 Gamma Data Collected with the HNGS Tool in Well C-1 in 1995 . . . . . . . . . . . . 4.19

4.15 Gamma Data Collected with the HNGS Tool in Well G-1 in $1995 \ldots \ldots \ldots \ldots \ldots$

4.16 Spectral Gamma Data Collected with the RLS System in Well G-1 in 1995 . . . . . . . 4.22

5.1 Plan View of Model Grid Showing Locations of Wells and Associated Cells $\ldots \ldots .2$

5.2 Comparison of Injected Volume of Water and the In Situ Increase in Water Content

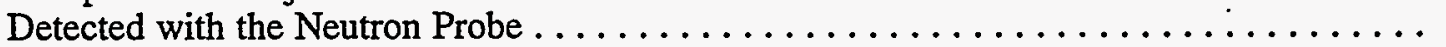

5.3 Water Content Profiles for all 32 Wells Using the 1995 CNT-G Data Every $15 \mathrm{~cm}(6 \mathrm{in}$.

5.4 Potassium Profiles for all 32 Wells Using the 1995 HNGS Data Every $15 \mathrm{~cm}$ (6 in.) ... 
5.5 Three-Dimensional View of Water Content Using the 1995 CNT-G 15-cm (6-in.)

Data Along a Transect Through the A and E Wells (east-west)

5.6 Three-Dimensional View of Bulk Density Using the 1995 LDS $15-\mathrm{cm}$ (6-in.)

Data Along a Transect Through the A and $\mathrm{E}$ Wells (east-west)

5.7 Three-Dimensional View of Gross Gamma Using the 1995 HNGS 15-cm (6-in.)

Data Along a Transect Through the A and E Wells (east-west) 


\section{Tables}

2.1 Information about Tracers in the Injection Fluid $\ldots \ldots \ldots \ldots \ldots \ldots \ldots \ldots$

2.2 Information for Neutron Probes Used by Sisson and $\mathrm{Lu} \ldots \ldots \ldots \ldots \ldots \ldots$

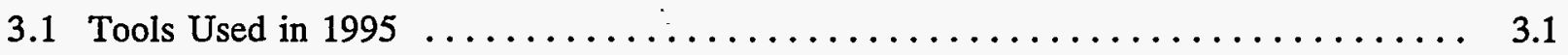

3.2 Fitting Statistics for Calibration of the Neutron Probes Using the

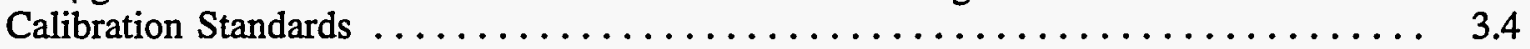

3.3 Identification of Data Set of Neutron Probe Counts Used to Cross-Calibrate

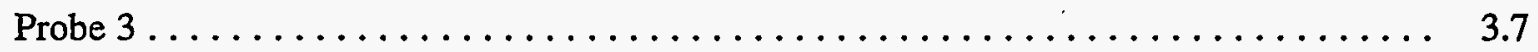

3.4 Fitting Statistics for Calibration of the Neutron Probes Using both the Calibration

Standards and the CNT-G Data for Depths Between 1.2 and $16.8 \mathrm{~m} \ldots \ldots \ldots \ldots .7$

3.5 DQOs and Results for the Neutron-Neutron Moisture Logging Systems in Models with 15-cm- (6-in.-) ID Steel Casing . . . . . . . . . . . . . . . . . . 3.13

3.6 DQOs and Results for the Scintillation Spectral Gamma Logging System . . . . . . . . 3.19

4.1 Statistical Parameters of Th, U, and K Data from HNGS Log of Well E-1 . . . . . 4.16

5.1 Summary Statistics for all 32 Wells Using the 1995 Geophysical Data . . . . . . . . . 5.9 


\subsection{Introduction}

From the mid 1940's to mid 1980's, the U.S. government constructed and operated facilities at the Hanford Site in southeastern Washington to produce nuclear materials for defense purposes. During that 40-year period, large quantities of radioactive and chemical wastes were produced. Some wastes entered and contaminated the environment; the remainder is stored in various containers across the Hanford Site. Much of the low-level radioactive waste (LLW) at Hanford is currently stored in single- and double-shell tanks on the Site.

The U.S. Department of Energy (DOE) Order 5820.2A (DOE 1988) mandates that site-specific radiological performance assessments be conducted before emplacing LLW in disposal facilities. These performance assessments must provide "reasonable assurance" that the disposal activities will protect long-term human health and safety before the facilities will be approved by DOE. Westinghouse Hanford Company has initiated performance assessment activities to evaluate disposal of vitrified LLWs. Pacific Northwest Laboratory (PNL) provided technology support to this performance assessment effort through its PNL Vitrification Technology Development (PVTD) Project. The Controlled Field Testing task within the PVTD Project is focused on the flow and transport models used in the performance assessment. Below are descriptions of the model testing objective of this task, a brief history of an injection experiment conducted in 1980 upon which much of this task's work is based, and the objectives and scope of this report.

\subsection{Model Testing}

The objective of the Controlled Field Testing task is to perform and analyze field experiments to demonstrate the appropriateness of the conceptual model for the performance assessment. Vadose zone flow and transport models are recognized as necessary tools for baseline risk assessments. The purpose of these models is, in part, to "...evaluate the potential migration of contaminants within vadose zone soils to the water table..." (DOE 1991). Confidence in the predictions of these models improves progressively as the models are repeatedly shown to represent reality.

The most convincing way to demonstrate model appropriateness is to show that the model can reproduce reality (i.e., the movement of water and contaminants in the field). Demonstrating that models represent reality is generally called "validation." Bredehoeft and Konikow (1993) suggest calling the usual model validation process "history matching" because it is based largely on comparisons to existing data. Van Genuchten suggested that models "are the most effective tools for getting a better understanding of the unsaturated zone at the Hanford Site" (Khaleel 1993). The sentiment that models are best used for understanding was echoed by Bredehoeft and Hall (1995). Clearly, any attempt to evaluate the potential migration of contaminants necessitates as much understanding as possible, recognizing the admonition of van Genuchten that "no model, however sophisticated, will ever represent reality since a model, by definition, is an approximation of reality" (Khaleel 1993).

For a history-matching exercise to be useful, the available characterization and monitoring information must be sufficient to enable an accurate evaluation of the model predictions. While new experiments can be designed with the appropriate objectives to provide the needed information, historical experiments may not have enough information with which to judge the accuracy of the model. Fortunately at the Hanford Site, an experiment was conducted during which significant quantities of information were collected. The continuing value of the 1980 experiment for model testing was noted during a vadose zone modeling workshop held at Hanford (Khaleel 1993). Given 
the advances in knowledge, computational capabilities, and models over the last 15 years, it was important that a present-day analysis of the data be completed before proceeding to other experiments and history-matching exercises.

\subsection{The 1980 Experiment}

In 1980, an injection experiment was conducted in the 200 East Area of the Hanford Site (Sisson and Lu 1984). The purpose of the experiment was to collect field data with which to test a flow and transport model. Section 2.0 describes the experiment methods and resulting data in more detail. Sisson and $\mathrm{Lu}(1984)$ conducted limited testing, but a thorough analysis of the data was never completed and published. Fayer et al. (1993) reviewed the data set for possible model testing. They published soil characterization data that were not contained in the original report and indicated concerns about the neutron probe calibration. Subsequently, Lu and Khaleel (Khaleel 1993), Smoot and Lu (1994), and Smoot (1995) attempted to test various models (Section 2.4 discusses these studies more fully). All of these studies used water content to test their models. None of these studies addressed solute transport.

Figure 1.1 shows the location of the Low-Level Tank Waste Disposal Site (LLTWDS) at the Hanford Site (Shord 1995). Figure 1.2 shows the location of the LLTWDS relative to the site of the Sisson and $\mathrm{Lu}$ injection experiment. Because of the proximity of the injection experiment site to the LLTWDS, using the injection experiment to test models adds value to the PVTD Project. Furthermore, any geophysical data collected at the Sisson and Lu site can be used directly to characterize the subsurface sediments within the LLTWDS.

\subsection{Objectives and Scope}

The objective of this.task in FY 1995 was to log the injection site with the latest geophysical tools to provide better estimates of water contents, refine the stratigraphic conceptual model, and ultimately provide a data set that is sufficiently complete, detailed, and accurate to effectively test models. The objectives of this report are to 1 ) document these geophysical data; 2) interpret the data relative to the mass of injected water, the original geologic conceptual model, and the predicted movement of water and ${ }^{134} \mathrm{Cs}$; and 3) determine whether it would be fruitful to continue studies at the injection site, propose a new site, or cease testing altogether.

The scope of the report includes the measurements conducted in FY 1995, with comparisons as appropriate to the 1980 injection experiment. Four wells at the site were logged with two of the original neutron probes. These probes were also calibrated in moisture calibration standards. All of the wells at the injection site were logged for water content, density, and natural gamma emissions by a logging vender. Three wells near the injection point were logged specifically for ${ }^{134} \mathrm{Cs}$. The appendices provide more detailed information about the logging tools and methods used. 


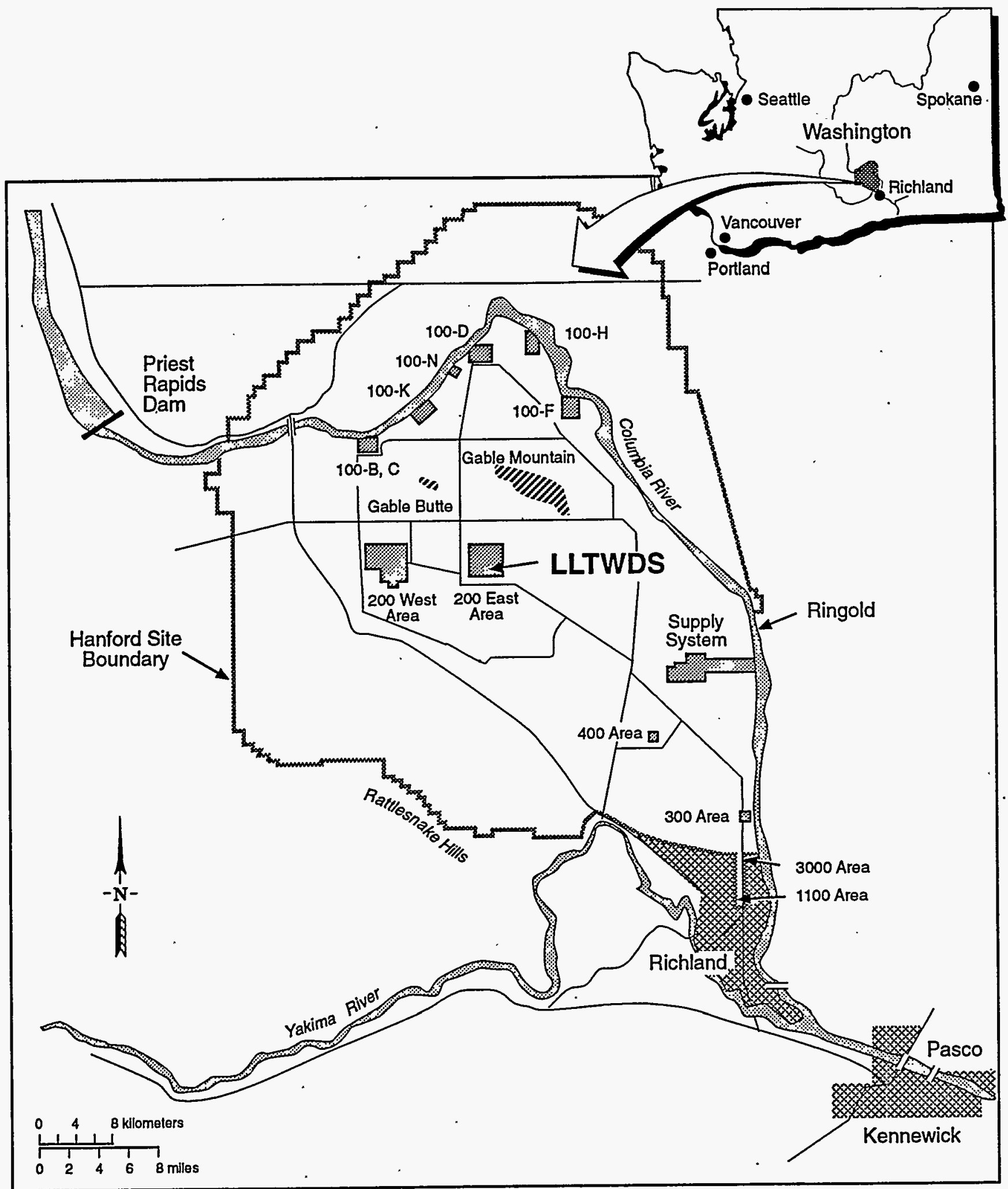

SG95110016.1

Figure 1.1. Hanford Site Map Showing Location of the Proposed LLTWDS 


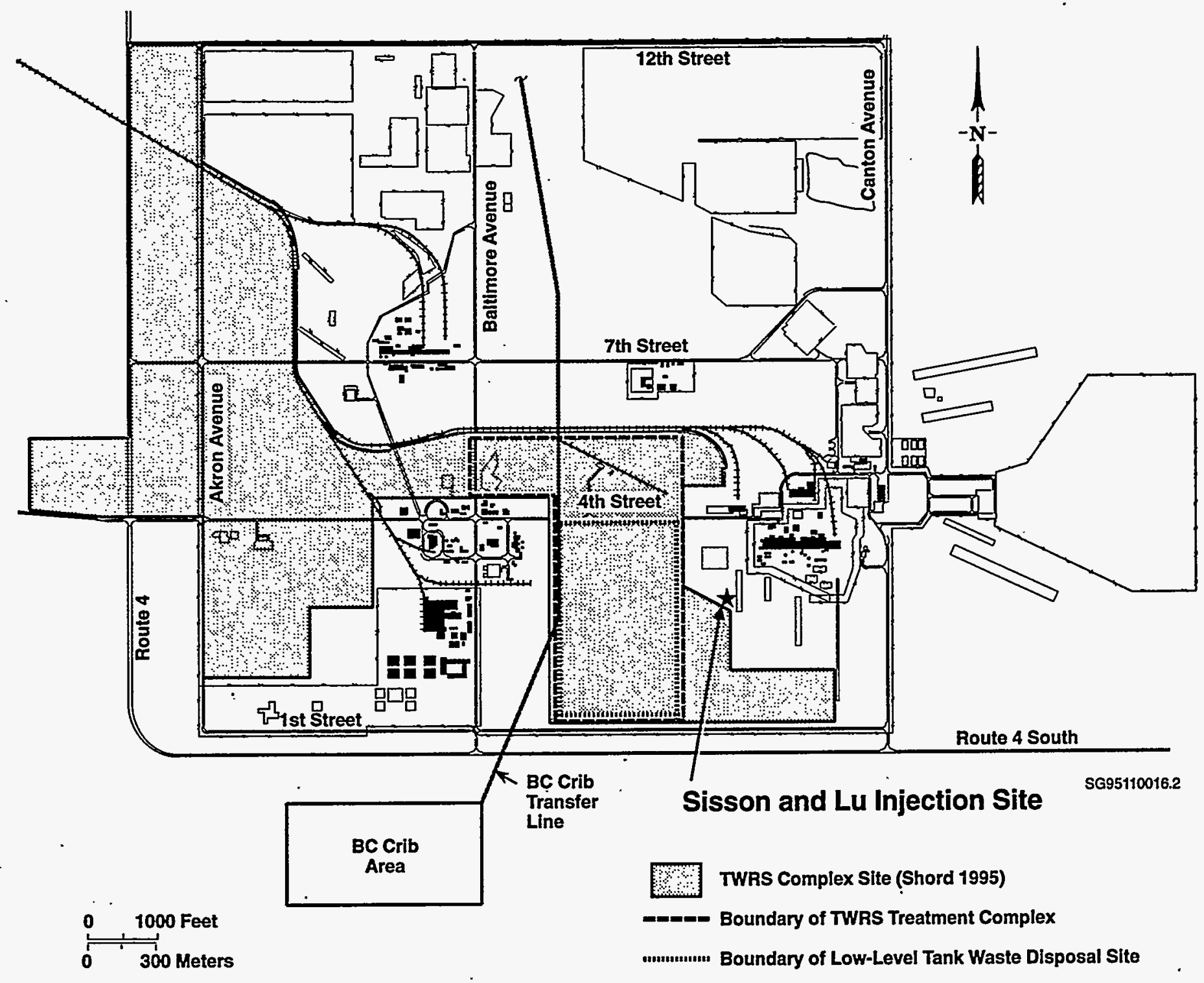

Figure 1.2. 200 East Area Map Showing Location of the Proposed LLTWDS Relative to the Injection Experiment 


\subsection{Description of the Experiment}

In 1980 , an injection experiment was conducted at the Hanford Site. A solution containing multiple tracers was injected at a single point into the subsurface sediments. The resulting spread of the water and tracers was monitored in wells that surrounded the injection point. The monitoring data were used to test flow and transport models of the vadose zone. The injection experiment was carried out during a 16-month period from June 1980 to October 1981. The only published report from the original investigators was Sisson and $\mathrm{Lu}$ (1984). Fayer et al. (1993) reviewed the experiment and reported additional characterization data for the sediments. Lu and Khaleel (1993), Smoot and Lu (1994), and Smoot (1995) tested different unsaturated flow models with the data. The following subsections provide a synopsis of the experiment and model testing activities. For specific details, see the original reports.

\subsection{Site of Experiment}

Figure 1.1 shows where the experiment was conducted in the 200 East Area. The injection site is on the edge of the proposed LLTWDS and should provide valuable information for the performance assessment. The climate is semiarid; weather summaries are available in Hoitink and Burk (1994). The soil is classified as a Rupert Sand (Hajek 1966). Geologically, the sediments are flood deposits known as the Hanford formation. All aspects of the injection and monitoring occurred within this formation.

Typical vegetation is cheatgrass, tumblemustard, and tumbleweed. At one time, the site was mostly covered with sagebrush. Sisson and Lu (1984) did not mention the status of the vegetation. Fayer et al. (1993) reported that the site was grubbed (i.e., shrubs and other vegetation were removed) prior to the experiment. However, aerial photographs in 1973 and 1976 show no shrubs, indicating that shrubs were removed from the site prior to 1973 . The shrubs probably were removed during construction of crib 216-A-38-1 in 1967, the date indicated on construction drawing H-2-62875.

Figure 2.1 shows a cutaway view of the experiment. Each injection solution was mixed in the tank located outside the monitoring area and delivered by pipe to the injection point. Figure 2.2 shows the monitoring well placement and numbering scheme, including both local and Hanford well identification numbers. In all, 32 monitoring wells surrounded the central injection well. The injection point was $4.57 \mathrm{~m}(15 \mathrm{ft})$ below the ground surface. The monitoring wells extended from the surface to a depth of $18.3 \mathrm{~m}(60 \mathrm{ft})$.

\subsection{Injections}

For each of the eleven injection tests, the injection solution was prepared in the above-ground tank shown in Figure 2.1. The components of the solutions included calcium chloride, calcium nitrate, barium chloride, rubidium nitrate, and two radioactive ions, ${ }^{134} \mathrm{Cs}$ and $85 \mathrm{Sr}$. Table 2.1 shows the tracer information, including estimated $R_{d}$ values (i.e., an empirically determined.sorption parameter) and the average solution concentrations.

Eleven injection tests were performed. The first eight injections occurred on a weekly basis from September 22 to November 10 of 1980 . These injections included the radioactive tracers. The remaining three injections occurred on November 18 and 24, 1980, and February 2, 1981, and did not include radioactive tracers. The solution was delivered from the tank to the injection well point 


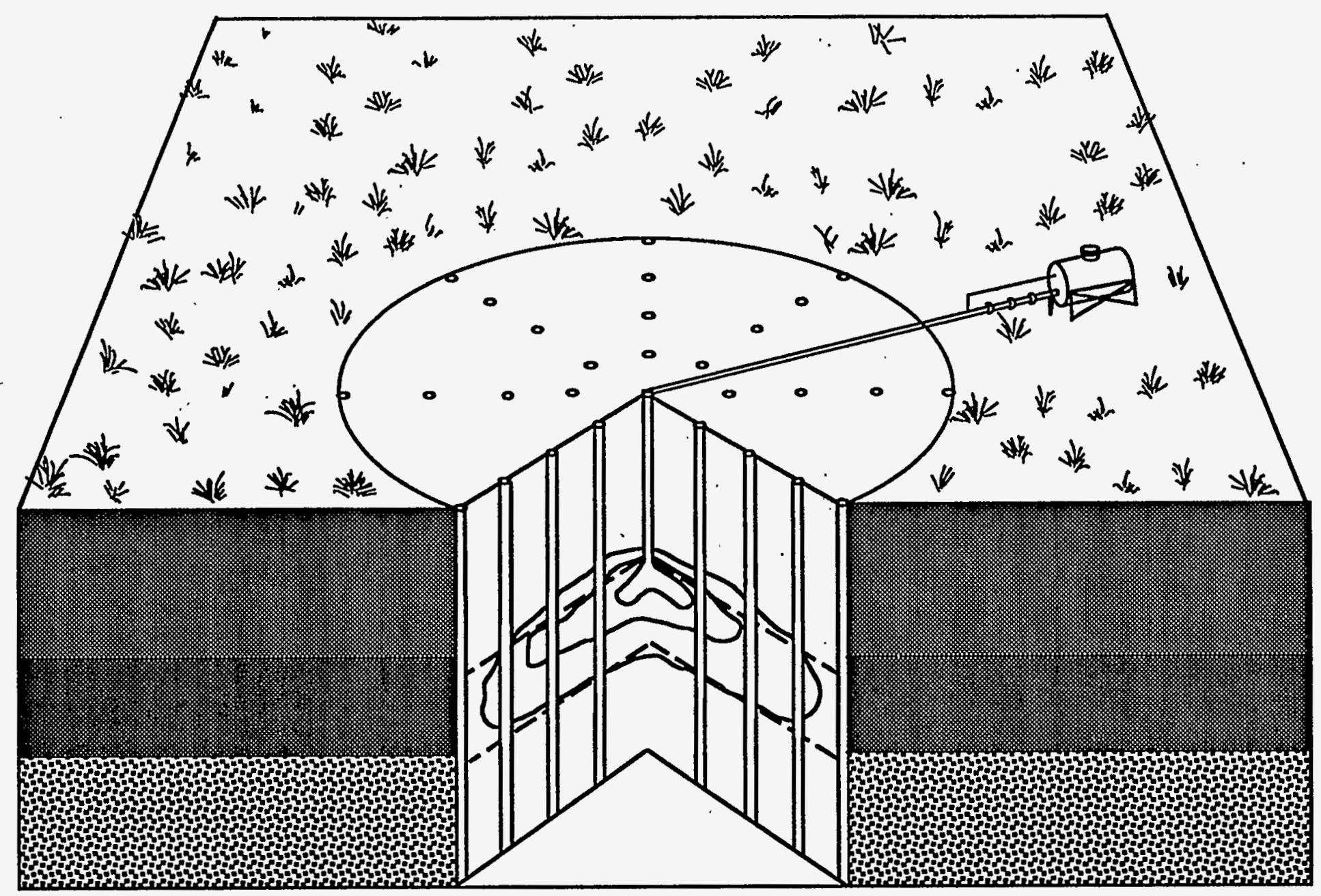

Figure 2.1. Cutaway View of the Injection Experiment Showing the Well Placement, the Tank for Mixing the Injection Solution, and the Connection Between the Tank and the Injection Point 


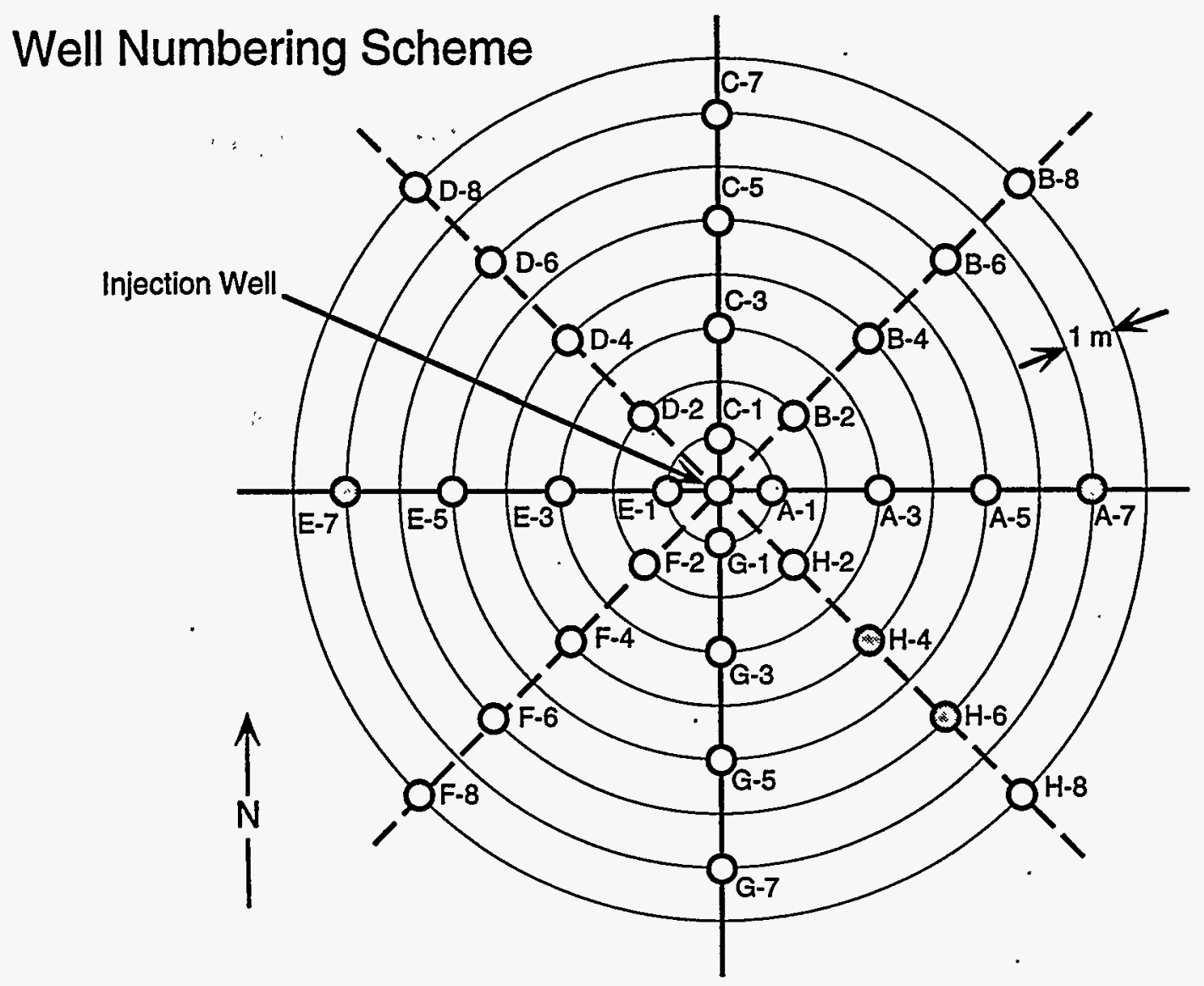

Well Identification Numbers

\begin{tabular}{|c|c|c|c|c|c|c|c|}
\hline Local & Hanford & Local & Hanford & Local & Hanford & Local & Hanford \\
\hline$A-1$ & E24-76 & $C-1$ & E24-84 & $E-1$ & E24-92 & G-1 & E24-100 \\
\hline A-3 & E24:77 & C-3 & E24-85 & E-3 & E24-93 & G-3 & E24-101 \\
\hline A-5 & E24-78 & C. -5 & E24-86 & E-5 & E24-94 & G-5 & E24-102 \\
\hline A-7 & E24-79 & C-7 & E24-87 & E-7 & E24-95 & G-7 & E24-103 \\
\hline B-2 & E24-80 & D-2 & E24-88 & $F-2$ & E24-96 & $\mathrm{H}-2$ & E24-104 \\
\hline B-4 & E24-81 & D-4 & E24-89 & $\mathrm{F}-4$ & E24-97 & $\mathrm{H}-4$ & E24-105 \\
\hline B-6 & E24-82 & D-6 & E24-90 & F-6 & E24-98 & $H-6$ & E24-106 \\
\hline B-8 & E24-83 & D-8 & E24-91 & F-8 & E24-99 & $\mathrm{H}-8$ & E24-107 \\
\hline
\end{tabular}

Figure 2.2. Plan View of Monitoring and Injection Well Placement and the Corresponding Local and Hanford Well Identification Numbers. Shaded wells were logged with neutron probes in 1995. 
Table 2.1. Information about Tracers in the Injection Fluid. Average $R_{d}$ Values for Hanford sediments are from Serne and Wood (1990). Suggested $R_{d}$ values for ${ }^{134} \mathrm{Cs}$ and ${ }^{85} \mathrm{Sr}$ are for neutral-to-high $\mathrm{pH}$, high salt (ionic strength $>0.01 \mathrm{M}$ ), low organic, oxic solutions (Kaplan et al. 1995). The last three of the eleven injections did not contain radioactive components.

\begin{tabular}{|c|c|c|c|c|c|c||}
\hline Tracer & $\begin{array}{c}\text { Atomic } \\
\text { Weight }\end{array}$ & Valence & $\begin{array}{c}\text { Half } \\
\text { Life }\end{array}$ & $\begin{array}{c}\text { Average } \\
R_{d} \text { for } \\
\text { Hanford } \\
(\mathrm{mL} / \mathrm{g})\end{array}$ & $\begin{array}{c}\text { Suggested } \\
\mathrm{R}_{\mathrm{d}} \text { Range } \\
\text { (mL/g) }\end{array}$ & $\begin{array}{c}\text { Average } \\
\text { Injection } \\
\text { Concentration } \\
\text { (Activity) }\end{array}$ \\
\hline $\mathrm{Ba}$ & 137.3 & +2 & - & 50 & - & $2.1 \times 10-5 \mathrm{M}$ \\
\hline $\mathrm{Ca}$ & 40.1 & +2 & - & 10 & - & $6.0 \times 10-3 \mathrm{M}$ \\
\hline $\mathrm{Cl}$ & 35.5 & -1 & - & 0 & - & $164 \mathrm{ppm}$ \\
\hline $134 \mathrm{Cs}$ & 132.9 & +1 & $2.05 \mathrm{yr}$ & 50 & 64 to 1360 & $\begin{array}{c}1.6 \times 10-11 \mathrm{M} \\
(2.8 \mu \mathrm{Ci} / \mathrm{L})\end{array}$ \\
\hline $\mathrm{NO} 3$ & 62.0 & -1 & - & 0 & - & $320 \mathrm{ppm}$ \\
\hline $\mathrm{Rb}$ & 85.5 & +1 & - & unknown & - & $1.0 \times 10-5 \mathrm{M}$ \\
\hline $85 \mathrm{Sr}$ & 87.6 & +2 & $64 \mathrm{~d}$ & 10 & 0.3 to 42 & $\begin{array}{c}1.2 \times 10-11 \mathrm{M} \\
(24 \mu \mathrm{Ci} / \mathrm{L})\end{array}$ \\
\hline
\end{tabular}

using a stainless steel gear pump that controlled the delivery rate. The volume of solution injected during a test ranged from 3000 to $5500 \mathrm{~L}$ (795 to $1458 \mathrm{gal}$ ). The injection rates ranged from 270 to $420 \mathrm{~L} / \mathrm{h}(2.5$ to $3.9 \mathrm{gal} / \mathrm{h})$.

\subsection{Monitoring}

Water content and tracer concentration were the two variables that were monitored throughout the experiment. Water content was measured with neutron probes and the concentrations of the two radioactive tracers were measured with a gamma energy analysis probe. After the experiment, sediment samples were collected at three locations and analyzed for chloride, nitrate, and water content. Figure 2.3 shows the monitoring, injection, and sampling dates.

\subsubsection{Water Content}

Table 2.2 provides information about the three neutron probes used during the experiment. Three months prior to the start of the experiment, water contents were measured with Probe 1 at intervals of $0.3 \mathrm{~m}$ (12 in.). Measurement depths ranged from 0.3 to $18.3 \mathrm{~m}$ (1 to $60 \mathrm{ft}$ ), for 


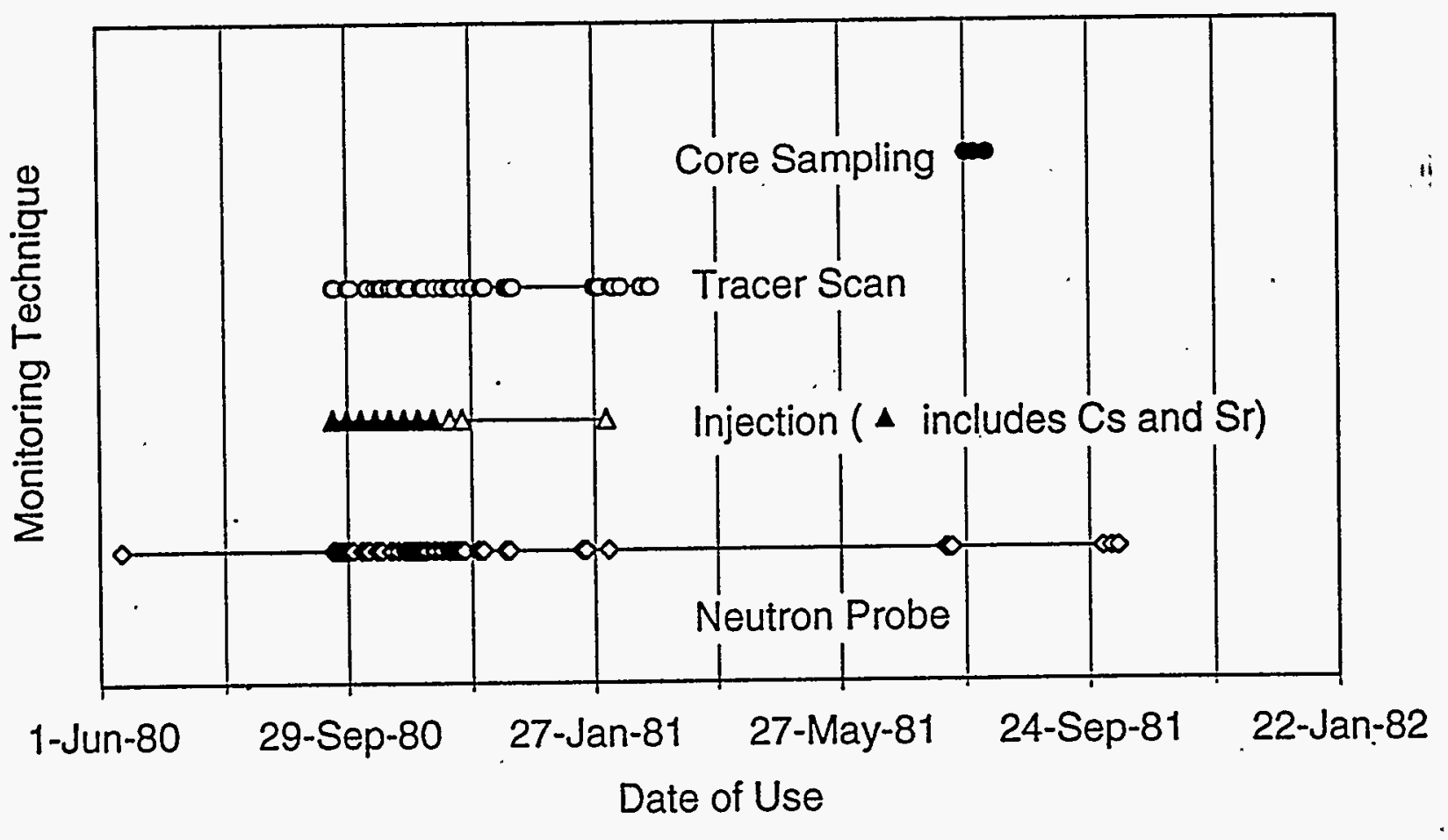

Figure 2.3. Monitoring, Injection, and Sampling Dates

Table 2.2. Information for Neutron Probes Used by Sisson and Lu (1984)

\begin{tabular}{||c|c|c|c|c||}
\hline \hline Probe No. & Serial No. & CPN Model No. & Probe Type & $\begin{array}{c}\text { Relative } \\
\text { Frequency } \\
\text { of Use }\end{array}$ \\
\hline 1 & H38092510 & 503 & Moisture & Highest \\
\hline 2 & D79102971 & 501 & Moisture-Density & Medium \\
\hline 3 & H36011607 & 503 & Moisture & Lowest \\
\hline
\end{tabular}

a total of 60 depths in every well and 1920 measurements overall. Note that Sisson and Lu (1984) actually logged every foot but reported the results as being at every $0.3 \mathrm{~m}$, the implicit assumption being that $0.3 \mathrm{~m}$ equalled $1 \mathrm{ft}$.

During and after the injection experiment (i.e., from September 22, 1980, to October 8, 1981), Sisson and Lu used all three probes listed in Table 2.2. Probe 1, which was used for the initial conditions in June 1980, was used most frequently. Probe 2 was used less frequently than Probe 1. Probe 3 was used the least, with dates ranging from October 27 to December 17, 1980. 
Regarding the monitoring depths and frequency, Sisson and Lu (1984) stated "The depths and radii of moisture probe readings were determined ad hoc." The reason is simple: With one or two probes in operation at any one time (probes were shared with other projects), it was physically impossible to read all 1920 depth locations quickly. Even if all three probes were available, it would still take more than three hours to complete a single sweep of all depths. During days when an injection test was taking place, Sisson and Lu tried to read the inner wells every 1 to 2 hours. They concentrated their readings around the injection point and moved to the outer monitoring wells only when they determined it necessary to stay "...immediately outside the wetted volume."

Other than the data collected to establish initial conditions, no data were collected above $3.0 \mathrm{~m}$ $(10 \mathrm{ft})$ and only a scattering at 3.0 and $3.4 \mathrm{~m}(10$ and $11 \mathrm{ft})$ near the end of September 1980. Follow-

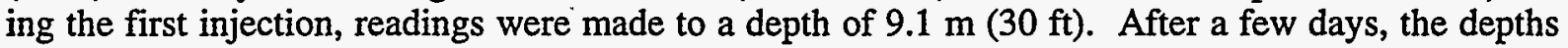
were extended to $12.2 \mathrm{~m}$ (40 ft). During October and November, readings in most wells were extended to depths from 12.2 to $13.7 \mathrm{~m}$ (40 to $45 \mathrm{ft}$ ). Data were not collected below $13.7 \mathrm{~m} \mathrm{(45} \mathrm{ft)}$ until December 1980. The frequency of data collection in the outer wells was sparse. The data from Sisson and Lu appear to show that water had already reached some of these wells (Figure 2.4) by the first logging on October 14, 1980, making it difficult to know when the wetting front had reached the well and thus difficult to calculate a mass balance during the experiment.

Sisson and Lu (1984) reported a single calibration equation for all three probes, but Fayer et al. (1993) indicated some uncertainty in the equation.

\subsubsection{Tracers}

Of the tracers listed in Table 2.1, only the radioactive tracers were monitored throughout the experiment. Activity of the tracers ${ }^{134} \mathrm{Cs}$ and ${ }^{85} \mathrm{Sr}$ was determined by analyzing the spectrum of the gamma energy emissions detected in the wells. Figure 2.3 shows the monitoring schedule for the tracers. As they did for the neutron probe data, Sisson and Lu (1984) logged at 1 -ft intervals, but reported the results as being at $0.3-\mathrm{m}$ intervals using the conversion factor of $1 \mathrm{ft}=0.3 \mathrm{~m}$.

Sisson and $\mathrm{Lu}(1984)$ reported activity of $85 \mathrm{Sr}$ for the eight wells nearest the injection point. For the wells $1 \mathrm{~m}$ ( $3.3 \mathrm{ft}$ ) from the injection point, the depths ranged from 3.9 to $8.4 \mathrm{~m}(13$ to $28 \mathrm{ft})$. For the wells $2 \mathrm{~m}(6.6 \mathrm{ft}$ ) from the injection point, the depths ranged from 4.9 to $7.3 \mathrm{~m} \mathrm{(16} \mathrm{to} 24 \mathrm{ft})$. Sisson and Lu (1984) did not indicate whether other depths and other wells contained ${ }^{85 \mathrm{Sr}}$.

Figure 2.5 shows that the peak activity of $85 \mathrm{Sr}$ in well E-1 occurred at a depth around $5.74 \mathrm{~m}$ (18.8 ft). Over time, the peak broadened vertically both upward and downward. Interestingly, the depth of this peak was about $1.0 \mathrm{~m}(3.3 \mathrm{ft})$ below the injection depth and $1.0 \mathrm{~m}(3.3 \mathrm{ft})$ away horizontally. The available data appear to show that $85 \mathrm{Sr}$ moved beyond the $2-\mathrm{m}(6.6-\mathrm{ft})$ wells. For example, elevated levels of $85 \mathrm{Sr}$ were detected as early as October 20,1980 , the day of the fifth injection. Three injections with $85 \mathrm{Sr}$ occurred subsequent to that measurement date and were followed by three injections without ${ }^{85 \mathrm{Sr}}$.

The ${ }^{85} \mathrm{Sr}$ in the first injection decayed by $77 \%$ by February 5,1981 , the date of the last tracer measurement displayed in Figure 2.5. The $85 \mathrm{Sr}$ in the eighth injection (the last injection with $85 \mathrm{Sr}$ ) decayed by $61 \%$ by that date. The ${ }^{85} \mathrm{Sr}$ profiles in Figure 2.5 were not corrected for decay. 


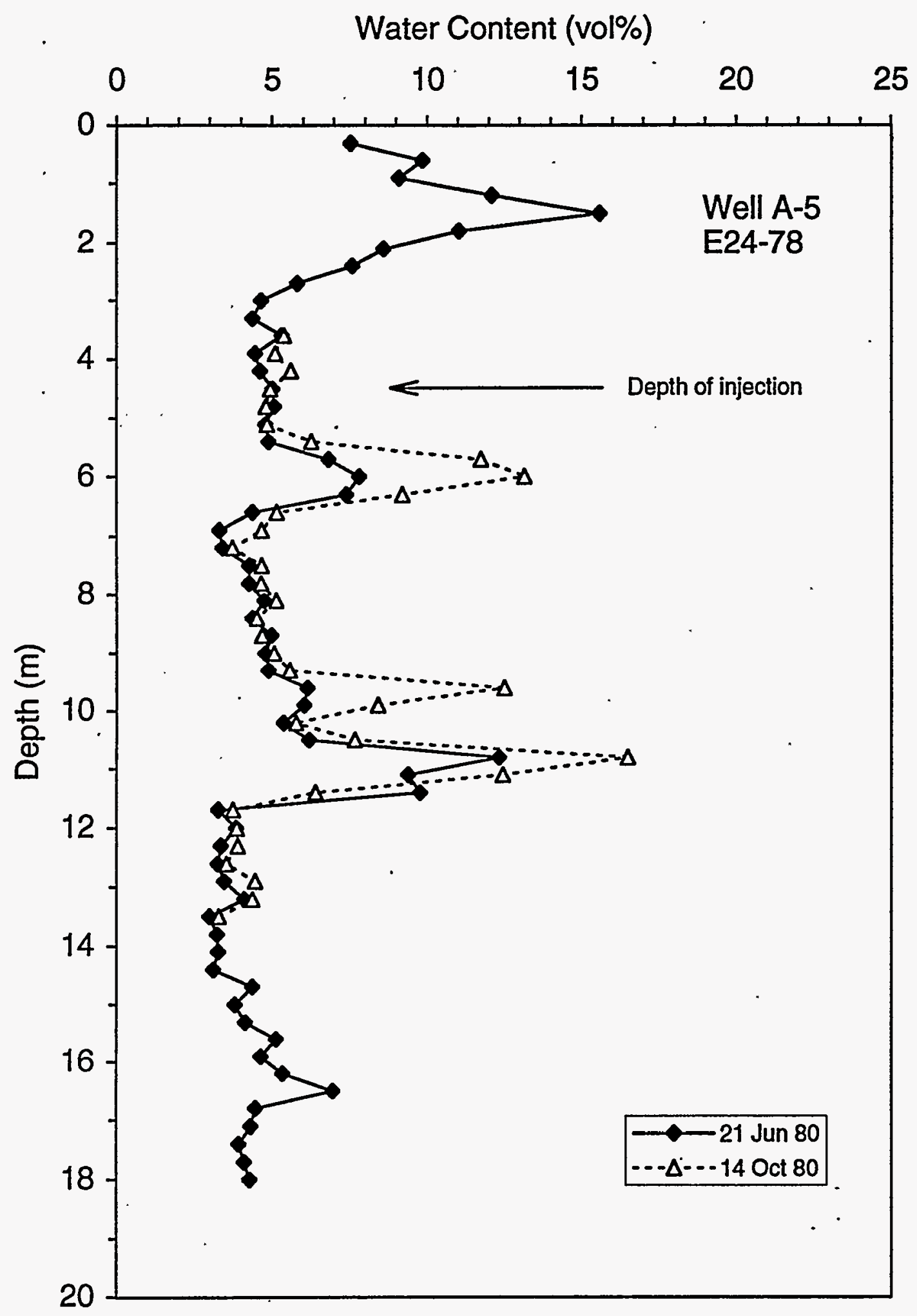

Figure 2.4. Water Content Changes Demonstrating that Monitoring with Neutron Probes Did Not Completely Capture the Wetting Front as It Moved Laterally Beyond $4.0 \mathrm{~m}$ (13.1 ft) 
Sisson and $\mathrm{Lu}(1984)$ reported ${ }^{134} \mathrm{Cs}$ activity for only three wells: C-1, E-1, and G-1. The depths of observation ranged mostly from 4.0 to $4.9 \mathrm{~m}$ (13 to $16 \mathrm{ft}$ ), except that well E-1 also showed ${ }^{134} \mathrm{Cs}$ at $5.5 \mathrm{~m}(18 \mathrm{ft})$. This measurement may have been an observation of preferential flow. Sisson and $\mathrm{Lu}$ did not indicate whether other depths and/or other wells contained ${ }^{134} \mathrm{Cs}$. In particular, well A-1 was the same radial distance from the injection point as the other wells, but no ${ }^{134} \mathrm{Cs}$ was reported ( $85 \mathrm{Sr}$ was reported for this well and the four surrounding wells: B-2, E-1, G-1, and H-2).

Figure 2.5 shows the peak activity of ${ }^{134} \mathrm{Cs}$ in well E-1 was at a depth of $4.6 \mathrm{~m}$ (15 ft). However, it seems clear from the data that the monitoring scheme did not capture the ${ }^{134}$ Cs profile com-

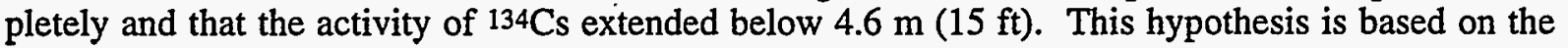
incomplete ${ }^{134} \mathrm{Cs}$ profile, the ${ }^{85} \mathrm{Sr}$ peak at a depth of $5.74 \mathrm{~m}(18.8 \mathrm{ft})$, and the water content peak at a depth of $5.5 \mathrm{~m}(18 \mathrm{ft})$.

Cesium-134, with its 2.05 -year half life, is longer lived than ${ }^{85} \mathrm{Sr}$. The ${ }^{134} \mathrm{Cs}$ in the first injection decayed by $13 \%$ by February 19,1981 , the date of the last reported tracer measurement. Cesium134 in the eighth injection (the last injection with ${ }^{134} \mathrm{Cs}$ ) would have decayed by only $9 \%$ by that date. The ${ }^{134} \mathrm{Cs}$ profiles in Figure 2.5 were not corrected for decay.

Sisson and $\mathrm{Lu}$ (1984) did not report the activity units for the radioactive tracers. The tracer units were likely $\mu \mathrm{Ci} / \mathrm{L}$, based on the average input concentration of $85 \mathrm{Sr}(24 \mu \mathrm{Ci} / \mathrm{L})$ and the observed plateau of $85 \mathrm{Sr}$ activity in the wells (between 20 and 30 units). Assuming the units to be $\mu \mathrm{Ci} / \mathrm{L}$, the minimum and maximum activities reported for ${ }^{85} \mathrm{Sr}$ were 0.00082 and 51.8 , although most of the reported peak activities ranged between 20 and $30 \mu \mathrm{Ci} / \mathrm{L}$. The minimum and maximum activities reported for ${ }^{134} \mathrm{Cs}$ were 0.0006 and $0.25 \mu \mathrm{Ci} / \mathrm{L}$. No calibration data were provided for the gamma energy analyses.

In the summer of 1981 , roughly 7 months after the last injection, three wells were drilled to collect sediment samples for analyses of chloride, nitrate, and water content (Fayer et al. 1993). The wells were located at distances of $1.4,2.32$, and $3.73 \mathrm{~m}(4.6,7.6$, and $12.2 \mathrm{ft})$ from the injection well. Sample depths ranged from 4.7 to $15.2 \mathrm{~m}(15.5$ to $50 \mathrm{ft})$. Although clear, consistent trends are not evident in the data, average values decreased with increasing distance from the injection. For example, the average chloride concentration in the nearest well was $13.1 \mathrm{ppm}$, whereas it was $10.6 \mathrm{ppm}$ in the farthest sampling well. Similar relations were observed for nitrate and water content.

\subsection{Simulations}

Four distinct attempts have been made to simulate the injection experiment. These efforts are summarized below.

\subsubsection{Sisson and Lu (1984)}

Sisson and Lu (1984) conducted the first simulations of the injection experiment. Their concepual geologic model consisted of four sediment types arranged in 13 horizontal layers with alternating hydraulic properties. Their numerical model was an axisymmetric finite element grid in which the smallest element was $0.4 \mathrm{~m}(1.3 \mathrm{ft})$ radially and $0.6 \mathrm{~m}(1.9 \mathrm{ft})$ vertically. The largest element size was $2.0 \mathrm{~m}(6.5 \mathrm{ft})$ radially and $3.6 \mathrm{~m}(11.8 \mathrm{ft})$ vertically. Other than at the injection point, all boundary fluxes were set to zero. 

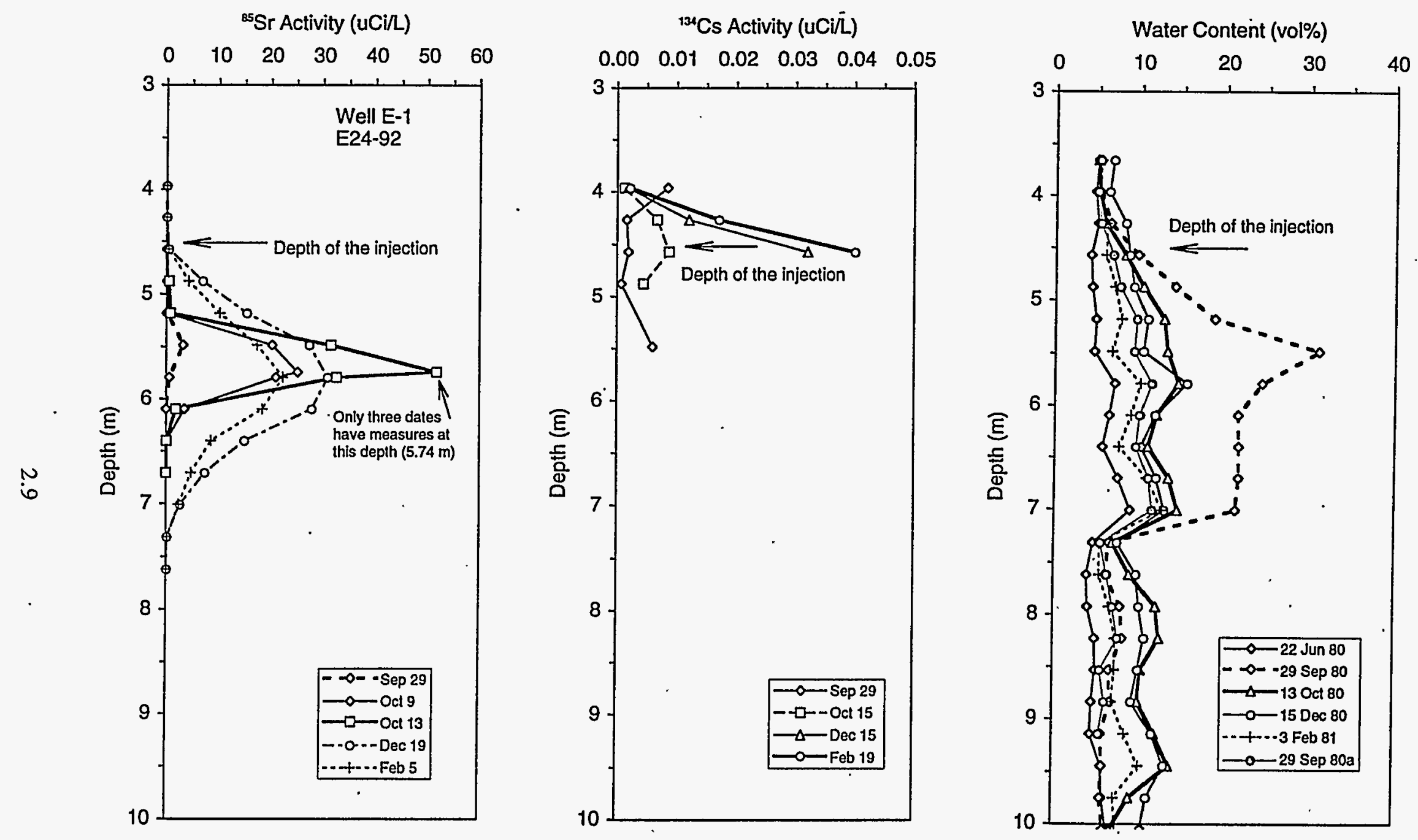

Figure 2.5. Depth Profiles of ${ }^{85 S r},{ }^{134} \mathrm{Cs}$, and Water Content for Selected Dates 
Sisson and $\mathrm{Lu}$ (1984) compared their model predictions of water content to measured values at three depths [4.7, 5.7, and $6.6 \mathrm{~m}(15.4,18.7$, and $21.6 \mathrm{ft})]$ and two radial distances [ 1 and $2 \mathrm{~m}$ $(3.3$ and $6.5 \mathrm{ft}$ )]. They had to include anisotropy ratios of from 2 to 8 to achieve sufficient lateral spreading of the wetting front: After adjusting the soil hydraulic properties, they were able to get "good agreement" between the observed and predicted water contents. They noted model bias when . compared to individual wells, but little to no bias when average values as a function of radial distance were used. One of their significant recommendations was to use the natural pre-experiment water contents to predict the site lithology. They also recommended using a spatial interpolation procedure like kriging to transform point measurements of water content to the modeling grid.

\subsubsection{Lu and Khaleel (1993)}

$\mathrm{Lu}$ and Khaleel (1993) simulated the experiment in an attempt to understand the impact of layered sediments, saturation-dependent anisotropy, and hysteresis. Two geologic models were used: uniform soil and nonuniform soil consisting of 10 soil layers. Each of these geologic models was tested under three conditions: isotropic hydraulic properties, saturation-dependent anisotropic hydraulic properties, and hysteresis. Their numerical model was an axisymmetric finite element grid in which the smallest element was $0.5 \mathrm{~m}(1.6 \mathrm{ft})$ radially and $0.6 \mathrm{~m}(1.9 \mathrm{ft})$ vertically. The largest element size was $1.2 \mathrm{~m}(3.9 \mathrm{ft})$ radially and $1.8 \mathrm{~m}(5.9 \mathrm{ft})$ vertically. A recharge flux of $20 \mathrm{~mm} / \mathrm{yr}$ ( $0.79 \mathrm{in} . / \mathrm{yr})$ was determined based on the soil hydraulic properties, the initial water contents, and assuming a unit gradient condition throughout the domain. Other than at the injection point, the boundary fluxes were zero at the vertical boundaries, $20 \mathrm{~mm} / \mathrm{yr}(0.79 \mathrm{in} . / \mathrm{yr})$ at the top boundary, and a unit gradient condition at the bottom boundary. The initial conditions were determined by running the model for 20 years with a recharge flux of $20 \mathrm{~mm} / \mathrm{yr}(0.79 \mathrm{in} . / \mathrm{yr})$ (starting with the initial measured wàter contents) and using the final simulated water content distribution as the initial condition.

The model evaluation criteria used by $\mathrm{Lu}$ and Khaleel were visual comparisons of water contents [as was done by Sisson and Lu (1984)] and spatial moments analyses. Published documentation is limited to viewgraphs presented at a workshop, with no discussion of the results and no summary. The viewgraphs show plots of predicted and measured water contents. The moment analyses were documented in an internal memo. The results indicated that the integrated mass for the fieldmeasured data was consistently higher by up to $35 \%$ compared to what was injected. Reasons offered for the discrepancy were calibration error for the neutron probes, measurement errors, and overrepresentation of the preferential flow region. The authors concluded that structural layering in the geologic model and saturation-dependent anisotropy were significant processes and hysteresis was not significant.

\subsubsection{Smoot and Lu (1994)}

Smoot and Lu (1994) simulated the experiment to demonstrate how multi-dimensional geologic information would impact flow and transport simulations. Specifically, they wanted to show whether a fully three-dimensional geologic conceptual model would cause the simulation to produce the observed degree of lateral spreading of the injected water without having to use anisotropy ratios. They constructed the geologic model using the observations of the geologist as recorded in the drilling logs for the 32 wells. This method allowed lenses and discontinuous layers to be included in the model. The numerical model, which used the integrated finite difference technique; consisted of uniform rectangular cells that were $0.5 \mathrm{~m}(1.6 \mathrm{ft})$ on a side. Simulations were conducted with different recharge rates to determine the best upper boundary condition. A rate of $50 \mathrm{~mm} / \mathrm{yr}$ (1.97 in./yr) provided a water content distribution that most closely matched the pre-injection measured distribution. A 20-year simulation with the $50-\mathrm{mm} / \mathrm{yr}(1.97 \mathrm{in} . / \mathrm{yr})$ rate established the initial 
conditions for the subsequent simulation. The lateral boundary fluxes were zero. The bottom boundary was specified as a unit gradient condition. An internal source was used to represent the injection point.

Smoot and Lu used the initial neutron probe data to determine spatial correlation lengths. They used the resulting variograms to interpret the water content measurements onto their modeling grid, thereby enabling the calculation of differences between predicted and interpolated measured water contents. The variograms derived from the initial conditions were used for interpolation during all subsequent measurement times. Smoot and Lu assessed the simulation model's performance by using the water content differences to indicate model bias and by visually inspecting the differences in three dimensions. The paper did not contain any three-dimensional images, graphs, or summary statistics to indicate model performance. The authors claimed an improvement in their model results based on the visual observation of lateral spreading similar to that observed. They attributed the improvement to the incorporation of heterogeneity.

\subsubsection{Smoot (1995)}

Smoot (1995) simulated the experiment with the same objective and numerical model as Smoot and $\mathrm{Lu}$ (1994). The numerical model grid was coarser than the one used by Smoot and Lu (1994). Each finite difference cell had the same vertical dimension $[0.5 \mathrm{~m}(1.6 \mathrm{ft})]$, but the other two dimensions were $0.9 \mathrm{~m}(2.9 \mathrm{ft})$ rather than $0.5 \mathrm{~m}(1.6 \mathrm{ft})$. The geologic conceptual model was the same, although on a coarser grid in accordance with the numerical model. Boundary and initial conditions were as in Smoot and Lu (1994), except for the recharge rate. Smoot (1995) used $50 \mathrm{~mm} / \mathrm{yr}$ (1.97 in./yr) because this rate had been. "...commonly used in modeling studies at the Hanford Site..."

Smoot (1995) determined model performance by examining the differences between the simulated and interpolated measured water contents of the model cells. Smoot looked at the average error for various combinations of cells, including all cells, cells near measurement locations, cells within soil types, and cells in the top and bottom halves of the domain. He noted that the differences appeared to be invariant in time and that the model consistently over-predicted water contents (by as much as $14 \mathrm{vol} \%$ in the silt). Smoot concluded that the average error in the model output predictions of water content was within the measurement error of the neutron probe, showing that the model bias was low. While the overall average differences may have been low, according to Appendix I in Smoot (1995), the overall root-mean-square (RMS) error at various times during the simulation ranged from 3.9 to $4.5 \mathrm{vol} \%$, values which are much higher than the typically claimed probe errors of 1 to 2 vol\%. Because no comparison was made with previous simulations (i.e., Lu and Khaleel 1993; Smoot and Lu 1994), a definitive statement cannot be made regarding which simulation effort was more successful at reproducing the observations. 



\subsection{Measurement Tools Used in FY 1995}

The Sisson and Lu injection site was logged with a suite of tools in early 1995 to calibrate the neutron probes used during the experiment in 1980, document the water distribution 15 years after the injections, and refine the geologic conceptual model. Except for the neutron probes, the measurement systems represent borehole geophysical logging (Ellis 1987, Hearst and Nelson 1985), a mature technology that has been used since the 1920s to support mineral exploration and provide geophysical data for the petroleum industry. Nuclear borehole geophysical techniques, including the techniques used in this experiment, have been used commercially since the $1960 \mathrm{~s}$.

Table 3.1 lists the tools used, the variables measured by each, and the well sampling details. Water content, bulk density, and gamma activity were measured in the 32 Sisson and Lu wells using borehole geophysical systems provided by Schlumberger Well Services. The water content and natural gamma activity systems have been adapted for the unsaturated Hanford borehole environment (Ellis et al. 1995) and the bulk density system is currently undergoing calibration. In addition, water content was measured in four of these wells with four different neutron probes, and in three of these four wells using another adapted oil-field service. High-purity germanium (HPGe) measurements were acquired in three wells where anomalous gamma activities were identified by the instrumentation. The remainder of this section provides a technical description and pedigree of each measurement system deployed, and discusses the calibration methods used and the resulting precision and accuracy measured.

Table 3.1. Tools Used in 1995

\begin{tabular}{||l|c|c|c|c||}
\hline \hline \multicolumn{1}{|c|}{ Tool Name } & Tool ID & Variables Measured & $\begin{array}{c}\text { Number of } \\
\text { Wells Sampled }\end{array}$ & $\begin{array}{c}\text { Sampling Depth } \\
\text { Interval (m) }\end{array}$ \\
\hline $\begin{array}{l}\text { Neutron Probe } \\
\begin{array}{l}\text { Compensated } \\
\text { Neutron Tool }\end{array}\end{array}$ & NNT-G(a) & Water content & 4 & 0.3 \\
\hline $\begin{array}{l}\text { Accelerator } \\
\text { Porosity Sonde }\end{array}$ & APS(a) & Water content & 32 & 0.15 \\
\hline $\begin{array}{l}\text { Litho-Density } \\
\text { Sonde }\end{array}$ & LDS(a) & Bulk density & 32 & 0.025 and 0.15 \\
\hline $\begin{array}{l}\text { Hostile } \\
\text { Environment } \\
\text { Natural Gamma } \\
\text { Ray Sonde }\end{array}$ & HNGS(a) & $\begin{array}{l}\text { Activity of gamma } \\
\text { emitters }\end{array}$ & 32 & 0.15 \\
\hline $\begin{array}{l}\text { Radionuclide } \\
\text { Logging System }\end{array}$ & RLS & $\begin{array}{l}\text { Activity of gamma } \\
\text { emitters }\end{array}$ & 3 & -0.15 \\
\hline \begin{tabular}{l} 
(a) Mark of Schlumberger Well Services. \\
\hline
\end{tabular}
\end{tabular}




\subsection{Neutron Probes}

During the injection experiment in 1980 , three neutron probes were used to monitor water content. Fayer et al. (1993) indicated some uncertainty with the probe calibration reported by Sisson and $\mathrm{Lu}$ (1984). Confidence in the measurement is necessary if the data set is to be used for model testing. Two of the probes (Probes 1 and 2 in Table 2.2) were located in 1995 for calibration. Two additional probes that were used by other projects at the Hanford Site were included in the calibration exercise because they could be used in future experiments. However, they were not considered in the analysis of the injection experiment that is contained in this report:

\subsubsection{Description}

Goodspeed (1981) describes quite well the theory of neutron probe operation. Basically, the neutron probe operates on the principle of thermalization of fast neutrons by water. Fast neutrons are emitted from a small source, typically a composite of ${ }^{241} \mathrm{Am}$ and $\mathrm{Be}$. The $241 \mathrm{Am}$ emits alpha particles and gamma radiation. The $\mathrm{Be}$ target absorbs the alpha particles and emits fast neutrons with energies mostly around $4 \mathrm{MeV}$, but ranging as high as $11 \mathrm{MeV}$. The source of fast neutrons in all four probes in Table 2.2 is $50 \mathrm{mCi}$ of $241 \mathrm{AmBe}$. The half life of $241 \mathrm{Am}$ is 458 years, so decay during the last 15 years reduced the source strength by only $2 \%$.

As fast. neutrons collide with atoms, they lose energy and are eventually slowed to thermal energies (i.e., $<0.1 \mathrm{eV}$ ) where they are readily absorbed by certain nuclei. Because a neutron and hydrogen have equivalent mass, hydrogen is very effective at slowing neutrons during a collision. Water.is the dominant source of hydrogen in sediments; clays are a secondary source if present in sufficient quantity. Thus, the thermal neutron count can be used as an indicator of water content after correcting for the clay content. The detector counts the number of thermal neutrons that are reflected back to the detector. A higher number of thermal neutrons detected indicates a higher water content.

Typically, neutron probes are used in 5.08 -cm-ID aluminum casing to maximize sensitivity. However, these probes can be used in larger boreholes with steel casing (Hearst and Carlson 1994). The wells at the injection site were made of steel casing with a $15-\mathrm{cm} \mathrm{ID.}$

Neutron probes have limitations that include their radius of influence, thermal neutron absorption, and counting time (Williams et al. 1981). Their radius of influence, i.e., the volume of sediment sensed, is a function of water content; the lower the water content, the larger the volume sensed. Hearst and Carlson (1993) stated that the radius likely varies from 14 to $20 \mathrm{~cm}$ over the range of water contents in typical unsaturated sediments. This limitation causes the probe to smooth steep gradients in water content, particularly when the gradient is over distances on the order of the size of the sensed volume or less. Williams et al. (1981) pointed out this limitation relative to "...studies at a scale requiring the location and movement of wetting fronts..." Tracking a moving wetting front was what Sisson and Lu (1984) tried to do.

Thermal neutron absorption can limit the effectiveness of a neutron probe. Elements such as B, $\mathrm{Cl}$, and $\mathrm{Fe}$, when present in sufficient quantity, can absorb a high number of thermalized neutrons and decrease the number reaching the detectors. If the probe operator is unaware of the presence of these absorbers, then the water content will be underestimated. Finally, the probe requires a finite amount of time to obtain a number of counts sufficient to produce a statistically significant reading. Longer counting times yield more precise readings. During experiments where water contents are changing rapidly, the neutron probe may not be able to measure precisely. The counting time of $15 \mathrm{~s}$ used by Sisson and Lu (1984) was about as short as it could be and still yield acceptable results. 


\subsubsection{Calibration Using Standards}

As part of another project, three calibration standards of 5, 12, and 20 vol\% water content were constructed (Engelman et al. 1995). The standards, or moisture tanks, contain a mixture of sand and alumina trihydrate in proportions necessary to yield the specified water contents. Each standard has a 15-cm-ID steel casing similar to the casing at the Sisson and Lu site.

The diameters of the probes are much smaller than the diameter of the casing and there was concern that the readings would depend on the probe position relative to the casing wall. Other studies have shown that centering the probe has no significant effect (Hearst and Carlson 1994). To demonstrate the impact of centering the probes in the calibration standards, two sets of readings were taken: one set with the probes centered and another with the probes eccentered (i.e., held against the north side of the casing). The results in Appendix A show a high correlation between the centered and eccentered positions $\left(r^{2}>0.98\right)$. During the experiment in 1980 , no attempt was made to center or eccenter the probes. At most depths, the position of the probe laterally was likely more eccentered than centered. Therefore, for the remainder of these analyses, the eccentered values were used.

Appendix A describes the procedure whereby the probes were calibrated. Water content was correlated against neutron probe counts using a linear calibration equation of the form

$$
W C=m C+b
$$

$$
\text { where } \quad \begin{aligned}
W C & =\text { water content }(\text { vol\%) } \\
m & =\text { slope, a curve-fitting parameter } \\
C & =\text { neutron probe counts } \\
b & =\text { intercept, a curve-fitting parameter }
\end{aligned}
$$

A linear equation usually provides adequate calibration (e.g., CPN Manual 1984; Greacen et al. 1981; Hearst and Carlson 1994). To minimize the effects of source decay and electronic aging, $C$ is generally replaced with the count ratio, which is the ratio of the counts to the standard count. The standard count is a measure of the number of counts in a well-defined and invariant material. The probe housing is typically used, although special barrels of wax or water can be used. The newer probes ' have a software function that automatically takes 32 8-s readings and determines the standard count. The count ratio was not used in Eq. 3.1 because standard counts were not recorded during the 1980 injection experiment.

Figure 3.1 shows the fit for the two probes used in the experiment. Table 3.2 shows that the fits for all four probes were very good $\left(r^{2}>0.98\right)$ and the standard errors were less than $1 \%$ water content. A good linear relationship was not unexpected given only three water content standards. However, the strength of the linear fit implies that the third-order polynomial used by Sisson and Lu (1984) may not have been necessary to describe the neutron probe response to water content.

\subsubsection{Field Measurements}

Four of the monitoring wells at the injection site were logged with the neutron probes in February 1995. The wells were A-7 (E24-79), E-7 (E24-95), H-4 (E24-105), and H-6 (E24-106). Each well was logged at depths from 0.3 to $18.3 \mathrm{~m}$ (1 to $60 \mathrm{ft}$ ) at intervals of $0.3 \mathrm{~m}(1 \mathrm{ft})$. These depths corresponded to the depths logged by Sisson and Lu (1984), as described in Section 2.3.1 of this report. 

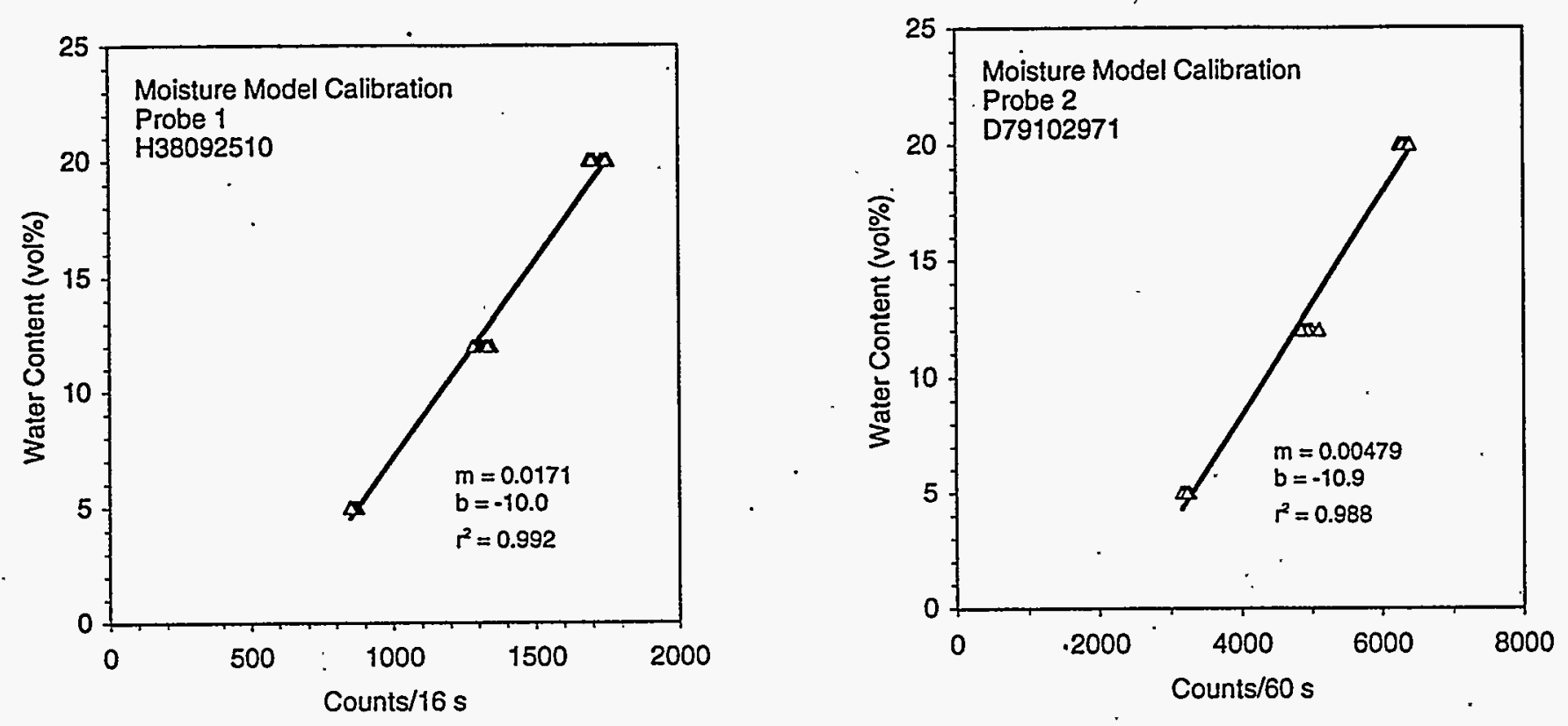

Figure 3.1. Neutron Probe Calibration Equations Fitted to the Moisture Calibration Standards

Table 3.2. Fitting Statistics for Calibration of the Neutron Probes Using the Calibration Standards $(n=27)$. The hydroprobe (serial numbers starting with the letter $H$ ) software converted all readings to a 16-s basis.

\begin{tabular}{|c|c|c|c|c|c||}
\hline $\begin{array}{c}\text { Probe Serial } \\
\text { No. }\end{array}$ & Counting Time (s) & Slope & Intercept & $\begin{array}{c}\text { Standard } \\
\text { Error in Water } \\
\text { Content }\end{array}$ & $r^{2}$ \\
\hline D72024328 & 60 & 0.0115 & -11.3 & 0.83 & 0.983 \\
\hline D79102971 & 60 & 0.00479 & -10.9 & 0.68 & 0.988 \\
\hline H33115410 & 64, but reported as 16 & 0.00559 & -13.0 & 0.65 & 0.990 \\
\hline H38092510 & 64, but reported as 16 & 0.0171 & -1010 & 0.57 & 0.992 \\
\hline
\end{tabular}


As mentioned earlier, there was a concern about the lateral position of the probes within the borehole. To demonstrate the impact of centering the probe in the field, two sets of readings were taken: one set with the probes centered and another with the probes eccentered (i.e., held against the borehole casing but without controlling the azimuthal direction). The results in Appendix A showed a high correlation between the centered and eccentered positions $\left(r^{2}>0.91\right)$. As indicated earlier, for the remainder of these analyses, the eccentered values were used.

The four wells were also logged with the Compensated Neutron Tool (CNT-G) tool (see Section 3.2) to provide an independent determination of in situ water content. Figure 3.2 shows that the neutron probe data did not match the CNT-G data very well. This result was the same for all four wells. Linear correlation of the CNT-G water contents to the neutron probe counts showed that the slopes were very similar but the intercepts were significantly different. A number of reasons for the differences were explored and discarded, including cable lengths, temperature, and operator error. Because the error was in the intercept and not the slope, the only credible reason was that the formation and/or borehole contained a significant amount of thermal neutron absorbers. The epithermal detector used in the CNT-G is not sensitive to thermal neutron absorption, but the neutron probes are.

Typical thermal neutron absorbers like $\mathrm{B}$ and $\mathrm{Cl}$ are not present in sufficient quantity to measurably affect thermal neutron counts. A check of the average Hanford sediments revealed a significant quantity, $6.5 \mathrm{wt} \%$, of natural $\mathrm{Fe}$ (Bjornstad 1990), which has a relatively high thermal neutron capture cross section. An analysis of thermal neutron diffusion showed that the presence of the Fe could indeed explain the differences seen in Figure 3.2. Well casings also have Fe. The well casing in the field was $0.635 \mathrm{~cm}(0.25 \mathrm{in}$.) thick; whereas, the casing in the calibration standards was $0.818 \mathrm{~cm}$ ( 0.322 in.) thick. The presence of in situ thermal neutron absorbers can be addressed by collecting in situ calibration data, as will be demonstrated in the next section.

The third probe used in the experiment, Probe 3, was not available for calibration in 1995. In fact, very little is known about this probe other than the limited data in the calibration plot in Sisson and Lu (1984). Fortunately, within the set of monitoring data published by Sisson and Lu, there exists several sets of data that were collected with Probes 2 and 3 on the same date. Table 3.3 shows that the times between readings were short and the depths were $5 \mathrm{~m}(16.4 \mathrm{ft})$ or more below the injection point. Based on these observations and a review of the surrounding data, we determined that water contents were not changing noticeably during the readings and that a cross-correlation would be acceptable. Correlating the counts from Probe 2 against the counts from Probe 3 produced the relationship

$$
{ }^{\mathrm{D} 79} C_{15}=1.05 \mathrm{H} 36 C_{15}-123
$$

where the superscript of $C$ is the first three symbols of the probe serial number and the subscript is the counting time in seconds. The relationship, which was strong $\left(r^{2}=0.974\right)$, was used to infer the calibration for Probe 3 using the calibration for Probe 2 determined below.

\subsubsection{Final Calibration Using Standards and Field Data}

To compensate for the naturally occurring thermal neutron absorbers in the formation, the final calibrations were determined by using the slopes from the calibration standards (Table 3.2) and determining the intercept by fitting to the lumped field data collected from the four. wells in January 1995. Table 3.4 shows that the final correlations for the two probes used at the injection site were good $\left(r^{2}>0.8\right)$ and that the standard errors were less than 2 vol\% water content. Figure 3.3 shows the improved fit relative to the fit in Figure 3.2. 


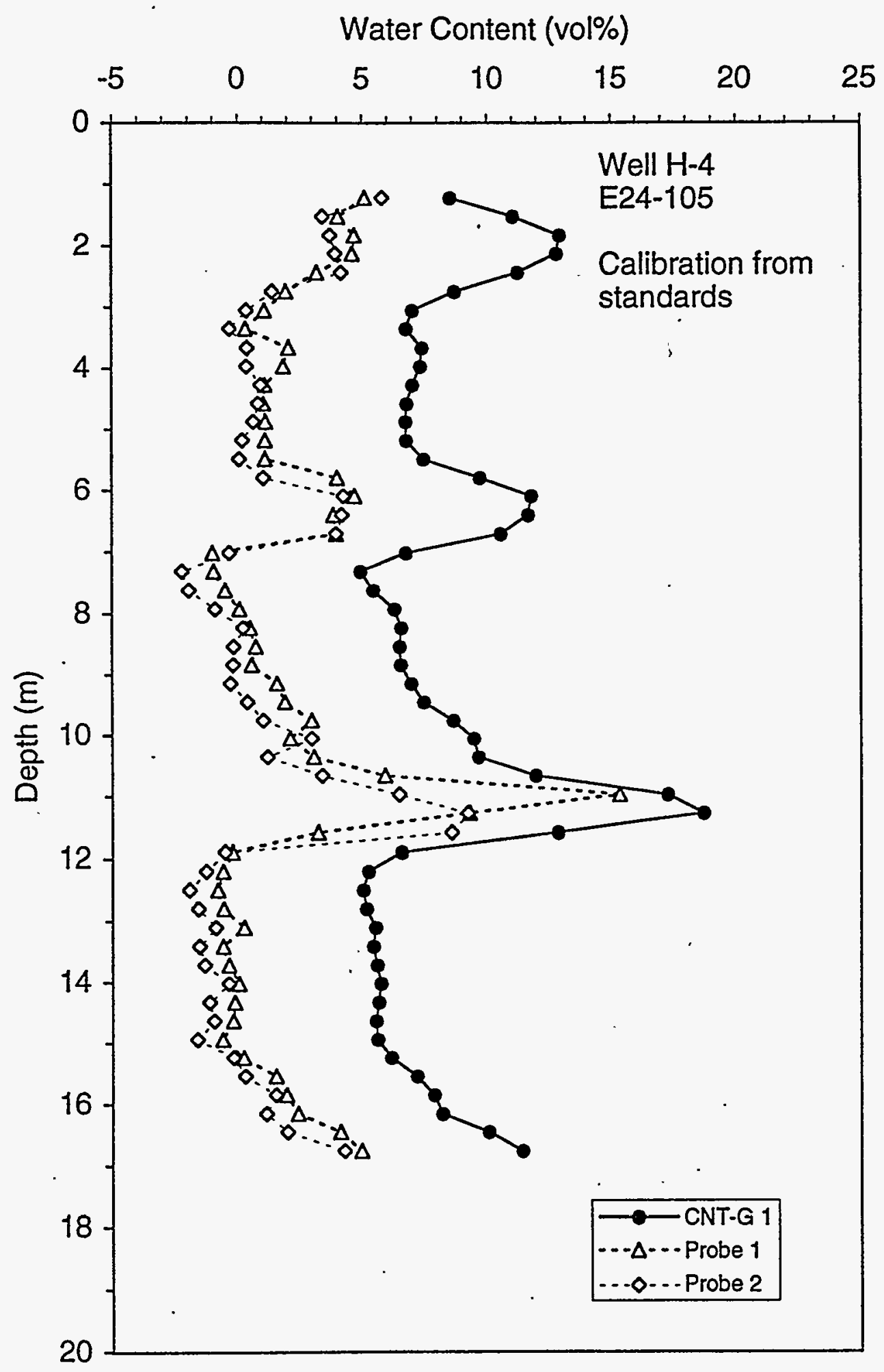

Figure 3.2. Water Content Profiles for the CNT-G Probe and the Two Neutron Probes Used in 1980. Equations based on the calibration standards were used to calculate water contents from the neutron probe data. 
Table 3.3. Identification of Data Set of Neutron Probe Counts (from Sisson and Lu 1984) Used to Cross-Calibrate Probe 3

\begin{tabular}{||c|c|c|c|c|}
\hline \hline Well ID & $\begin{array}{c}\text { Depth } \\
\text { Interval } \\
\text { [m (ft)] }\end{array}$ & Date & Time at Start of Readings (hhmm) \\
\cline { 3 - 5 } F-2 & $\begin{array}{c}9.8 \text { to } 13.7 \\
(32 \text { to } 45)\end{array}$ & 28 October 1980 & 1015 & 1307 \\
\hline G-1 & $\begin{array}{c}9.8 \text { to } 13.7 \\
(32 \text { to } 45)\end{array}$ & 28 October 1980 & 1033 & 1245 \\
\hline H-2 & $\begin{array}{c}9.8 \text { to } 12.2 \\
(32 \text { to } 40)\end{array}$ & 28 October 1980 & 1049 & 1158 \\
\hline H-4 & $\begin{array}{c}9.8 \text { to } 12.5 \\
(32 \text { to } 41)\end{array}$ & 27 October 1980 & 1210 & 1130 \\
\hline
\end{tabular}

Table 3.4. Fitting Statistics for Calibration of the Neutron Probes Using both the Calibration Standards and the CNT-G Data for Depths Between 1.2 and $16.8 \mathrm{~m}$ (4 and $56 \mathrm{ft}$ ) $(n=204)$. Readings at three depths in well E24-95 were not included in the regression because of poor correlation, possibly because of depth shifting or near-surface infiltration between the time of the CNT-G reading and the neutron probe readings. The hydroprobe (serial numbers starting with the letter $\mathrm{H}$ ) software converted all readings to a $16-\mathrm{s}$ basis.

\begin{tabular}{||l|c|c|c|c|c||}
\hline $\begin{array}{c}\text { Probe Serial } \\
\text { No. }\end{array}$ & Counting Time (s) & Slope & Intercept & $\begin{array}{c}\text { Standard } \\
\text { Error in Water } \\
\text { Content }\end{array}$ & $r^{2}$ \\
\hline D72024328 & 60 & 0.0115 & -4.85 & 2.1 & 0.778 \\
\hline D79102971 & 60 & 0.00479 & -4.03 & 1.0 & 0.898 \\
\hline H33115410 & 64, but reported as 16 & 0.0059 & -6.98 & 1.6 & 0.833 \\
\hline H38092510 & 64, but reported as 16 & 0.0171 & -3.82 & 1.6 & 0.829 \\
\hline
\end{tabular}

The counting times used in 1995 were much longer than in 1980 . The slopes of the calibration equations in Table 3.4 were corrected to yield slopes specific to the 15-s counting time that was used in 1980. Equations 3.3 to 3.5 are the final calibration equations that should be used to process the data from the 1980 experiment (Sisson and Lu 1984).

Probe 1:

Probe 2:

Probe 3:

$$
W C \stackrel{\circ}{=} 0.0182 \mathrm{H}^{3} 8 C_{15}-3.82
$$

$$
W C=0.0192{ }^{D} 79 C_{15}-4.03
$$

$$
W C=0.0202{ }^{\mathrm{H} 36} C_{15}-6.39
$$




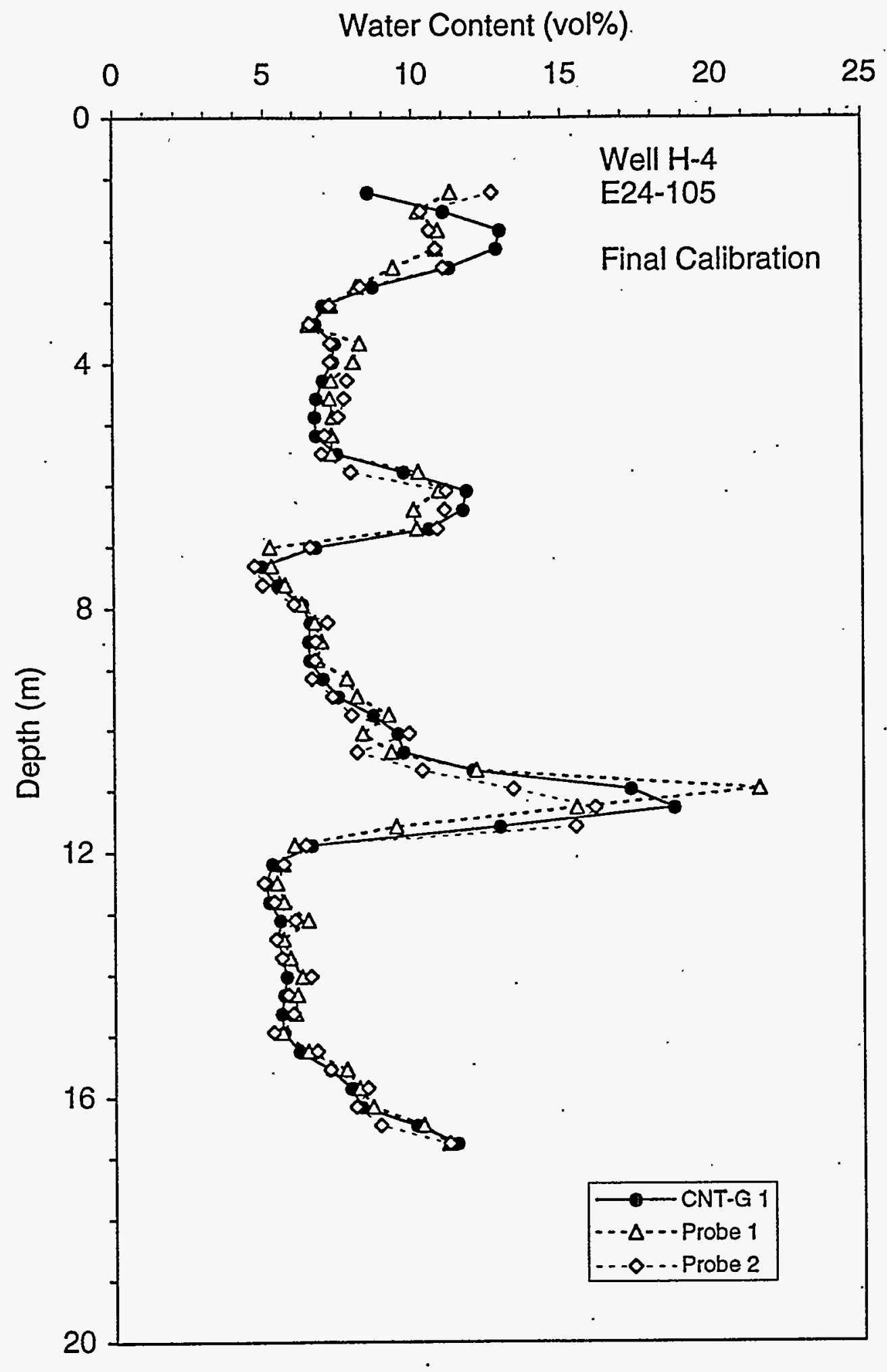

Figure 3.3. Comparison of Water Content Profiles from the CNT-G Tool and the Two Neutron Probes Used in 1980. Equations based on both the calibration standards and the field data were used to calculate water contents from the neutron probe data. 
Figure 3.4 shows the relationship of the three calibration equations to the original calibration equation used by Sisson and $\mathrm{Lu}(1984)$. The slopes of the three probe equations vary by no more than $10 \%$, but the intercepts vary by as much as $40 \%$. Equations 3.3 and 3.4 were determined using data from the eccentered probe position. A similar calibration process was used for data from the centered probe position. The resulting calibration equations yielded predicted water contents that were essentially identical in the dry range and differed by at most $1.4 \mathrm{vol} \%$ at a water content of $30 \mathrm{vol} \%$. These differences are less than the standard errors in Table 3.4 for $60-\mathrm{s}$ readings. The standard errors for the 1980 readings would be twice as great as in Table 3.4 because the counting times were only $15 \mathrm{~s}$. The error caused by the lateral probe position would likely double also. If an experiment with much longer counting times were conducted, the standard error could be lowered. Whether the error caused by the lateral probe position would then become more significant relative to the calibration error would have to be considered.

One concern was how the new calibration equations would alter the conclusions made in previous studies. A measure of the impact was determined by considering the differences from the original equation. Figure 3.5 shows the differences as a function of counts. Between counts of 600 and 1400 , where the bulk of the experimental values occurred, the new equations show that the water contents were 1.0 to 4.1 vol\% higher than predicted using the original equation. Some counts from the experiment were as high as 1800 . For counts this high, the new equations indicated that water contents were 2.7 to 4.7 vol\% lower than when using the original calibration.

Sisson and $\mathrm{Lu}(1984)$ and $\mathrm{Lu}$ and Khaleel (1993) reported qualitative comparisons of simulated and measured water contents. The change in probe calibrations shouldn't necessarily affect the conclusions of those studies. Smoot and Lu (1994) and Smoot (1995), however, used quantitative comparisons of simulated and measured water contents. Certainly, their measures of goodness-of-fit would have to be recalculated to determine whether their conclusions would change.

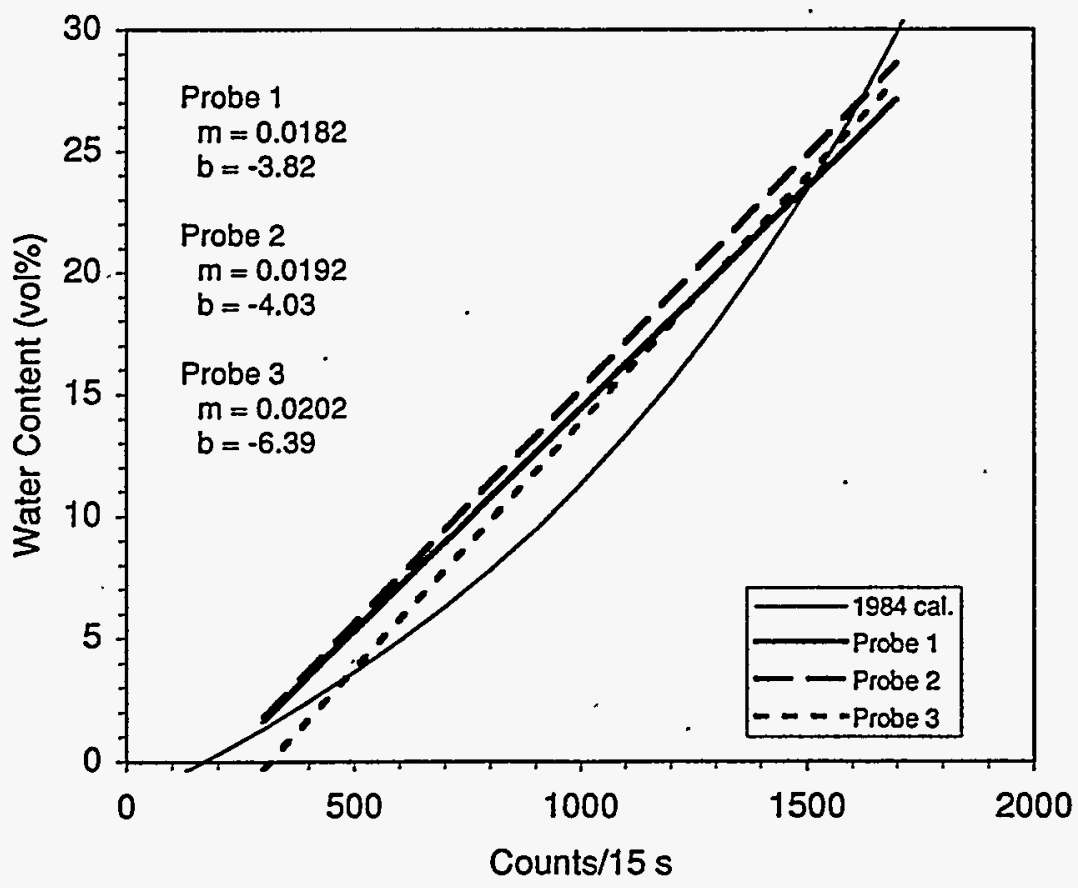

Figure 3.4. New Calibration Equations for the Neutron Probes 


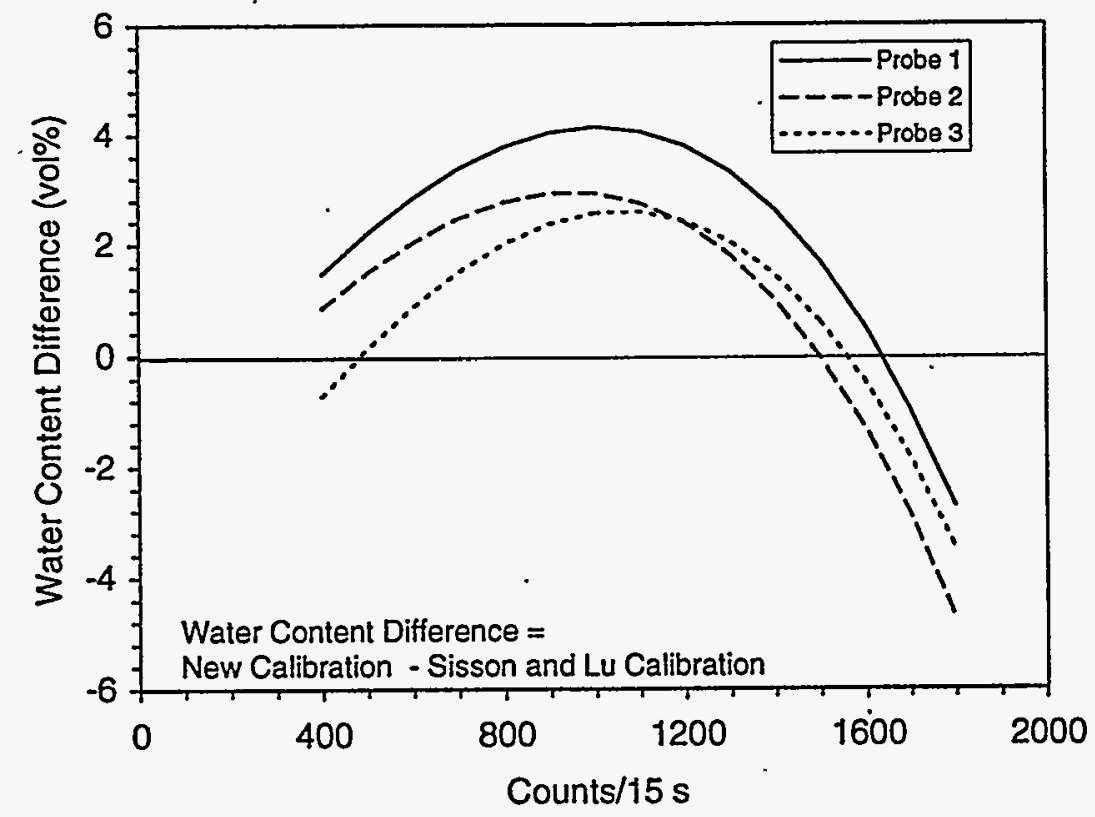

Figure 3.5. Water Content Differences Between the New Calibration Equations and the Original Equation as a Function of Probe Count

\subsection{Neutron-Neutron Logging Systems}

Two neutron-neutron logging systems (the CNT-G and APS) were used to measure the volume of moisture within the formation surrounding the Sisson and Lu boreholes. The systems are called neutron-neutron in reference to their mode of operation, which is to emit neutrons and detect the emitted neutrons after interaction with the formation. The neutron probes discussed in the previous section are neutron-neutron devices, but differ from the large truck-mounted devices in that they are smaller, have a much smaller source strength, and are hand operated.

\subsubsection{Description}

Neutron-neutron logging systems measure water content in a manner similar to neutron probes (i.e., detecting the presence of the hydrogen atom). High-energy neutrons are emitted from a source in the downhole instrument package known as a sonde. The neutrons collide elastically with nuclei of the formation and, with each collision, the neutrons lose some of their energy. The relative loss of energy is a function of the mass of the nuclei. The greatest loss occurs when a neutron strikes a nuclei of equal mass (i.e., a hydrogen atom). Collisions with heavy nuclei do not slow the neutron very much. Thus, the slowing of neutrons depends largely on the amount of hydrogen in the formation (Schlumberger 1989a).

Where the hydrogen concentration of the formation is large, most of the neutrons are slowed and captured by nuclei within a short distance of the source. If the hydrogen content is low, more neutrons will travel farther before they are captured. The neutron detector(s) are spaced at least $20 \mathrm{~cm}$ (7.9 in.) from the source (Hearst and Carlson 1994) and their count rate decreases as the 
hydrogen content increases. In contrast, neutron probes have a shorter source-detector spacing so that the probe responds to neutron reflection with an increasing count rate with increasing hydrogen content.

The nuclei of some elements are efficient absorbers of neutrons at thermal energies (i.e., below $0.1 \mathrm{eV}$ ). Examples of particularly efficient thermal absorbers include $\mathrm{B}, \mathrm{Cl}$, and $\mathrm{Fe}$. If sufficient quantities of thermal absorbers are present in the formation, then a neutron-neutron system that measures thermal neutrons will have fewer counts than anticipated and the moisture will be overestimated. Epithermal neutrons (energies from $0.1 \mathrm{eV}$ to $1 \mathrm{keV}$ ) are not nearly as affected by absorption. Thus, epithermal neutron logging systems remove this source of error. The population of epithermal neutrons, however, is typically much smaller than the population of thermal neutrons, so a large neutron source is used to ensure acceptable counting statistics.

Most neutron-neutron logging systems use at least two detectors, one detector close-spaced and one detector far-spaced. The close-spaced detector is used to provide compensation for borehole effects on the far-spaced detector by a simple ratio of counting rates (Ellis 1987).

A neutron-neutron logging system cannot differentiate between the hydrogen in water molecules and the hydrogen in hydrous minerals such as clays. The Hanford formation fortunately has very few hydrous minerals (Bjornstad 1990), so the neutron-neutron logging systems respond mostly to interstitial moisture.

The two neutron-neutron systems used at the Sisson and Lu site operate in fundamentally different ways. The CNT-G is a conventional neutron-neutron logging system. It uses a chemical source of $16 \mathrm{Ci} \mathrm{AmBe}$ that continuously emits approximately 4-MeV neutrons at a flux rate of about $4 \times 10^{7}$ neutrons per second (Tittman 1987). Figure 3.6 shows that the system employs both

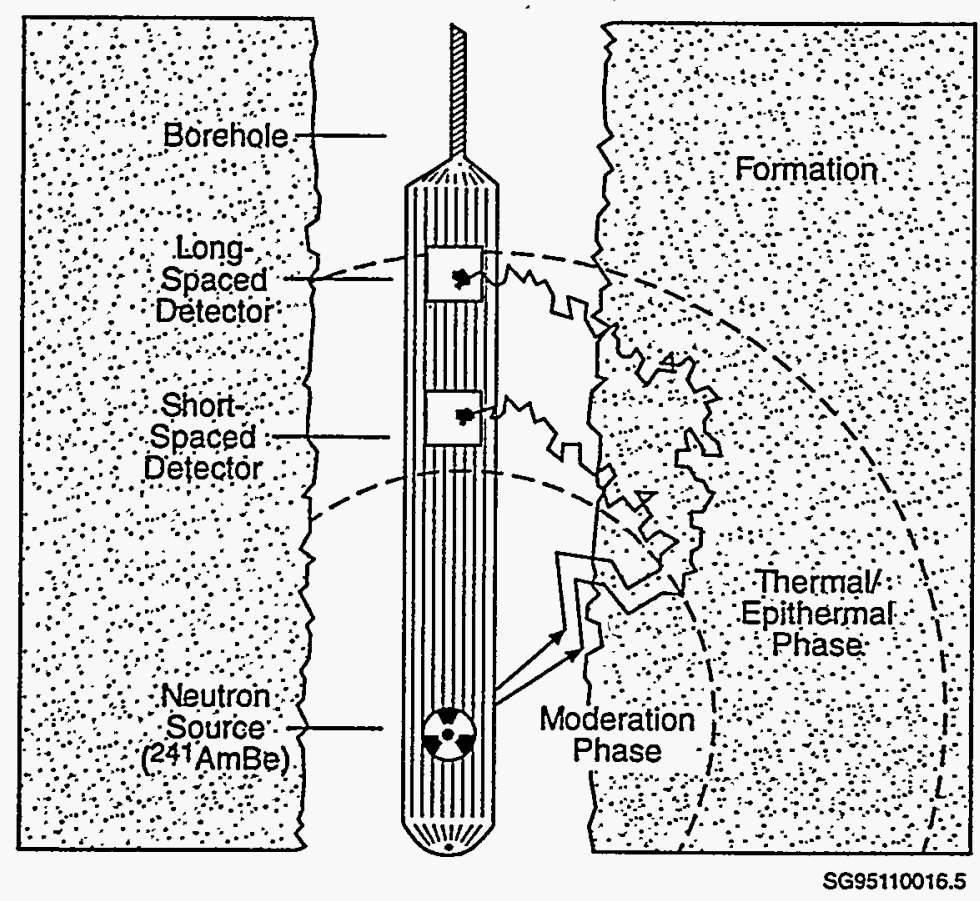

Figure 3.6. Schematic Diagram of the CNT-G Tool (after Ellis 1987) 
far-spaced and close-spaced epithermal detectors. The CNT-G has a vertical resolution of approximately $15 \mathrm{~cm}(6 \mathrm{in}$.) and an average depth of investigation of $25 \mathrm{~cm}$ (9.8 in.) (Schlumberger

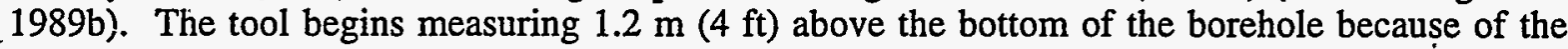
position of the detector on the tool.

The Accelerator Porosity Sonde (APS) uses an electronic neutron source that generates 14.1-MeV neutrons in a pulsed mode at a flux rate of about $3 \times 10^{8}$ neutrons per second (Scott et al. 1994). Figure 3.7 shows that this system employs four epithermal neutron detectors and one thermal neutron detector. One of the epithermal neutron detectors is far-spaced and is used to calculate the "near-far" moisture content in conjunction with the close-spaced epithermal detector. This measurement is similar to the moisture content determined with the CNT-G tool. The other two epithermal neutron detectors are medium-spaced and are used to measure the decay rate of epithermal neutrons that occurs subsequent to a neutron pulse. The decay rate is a function of the hydrogen concentration: the more hydrogen, the faster the decay (Mills et al. 1988). This "slowing-down" moisture measurement provides a better vertical resolution, approximately $7.5 \mathrm{~cm}$ ( 3 in.) (Ellis et al. 1995), at the expense of a smaller depth of investigation [roughly $6 \mathrm{~cm} \mathrm{(2.4} \mathrm{in.)].} \mathrm{The} \mathrm{resulting} \mathrm{moisture}$ measurement is independent of lithology (i.e., the concentration of thermal neutron absorbers).

The thermal neutron detector in the APS is used to calculate the decay rate of thermal neutrons subsequent to the neutron pulse. The decay is a function of the formation sigma $(\Sigma)$, the macroscopic thermal neutron absorption cross section. $\sum$ is a function of the types and quantities of thermal neutron absorbers present within the formation. The larger $\sum$ is, the faster the decay of the thermal neutron population. $\Sigma$ is typically measured in "capture units" (cu), a unit related to the mass-normalized thermal neutron cross section. Quartz has a $\sum$ of about $4 \mathrm{cu}$, fresh water has a $\sum$ of $22 \mathrm{cu}$. A comparison of $\sum$ and epithermal neutron porosity can differentiate zones within the formation that contain higher concentrations of thermal neutron absorbers, independent of moisture. Such zones could affect the functioning of tools like the neutron probes that rely solely on thermal neutron detection.

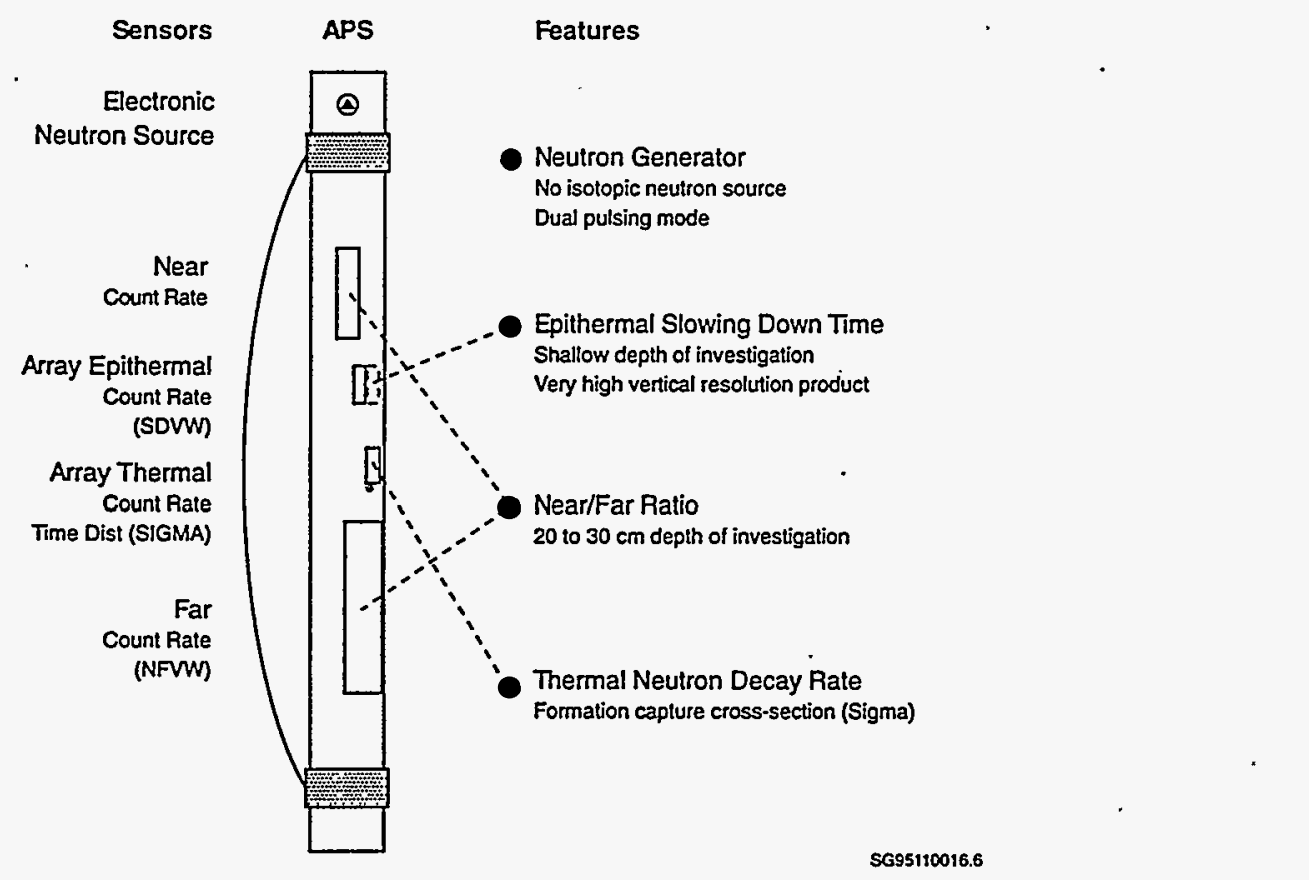

Figure 3.7. Schematic Diagram of the APS Tool (after Scott et al. 1994) 
The APS system begins measuring around $4 \mathrm{~m}(13.1 \mathrm{ft})$ above the bottom of the borehole. Because the CNT-G measures within $1.2 \mathrm{~m}(4 \mathrm{ft})$ of the borehole bottom and the Sisson and Lu boreholes were so shallow, the CNT-G was used for all 32 Sisson and Lu boreholes, even though the APS provides more data. The APS was run in three Sisson and Lu boreholes: A-7 (E24-79), E-1 (E24-92), and E-7 (E24-95).

\subsubsection{Calibration}

Schlumberger Well Services adapted both the CNT-G and APS services for Hanford borehole conditions as part of a Cooperative Research and Development Agreement (CRADA) with PNL and Westinghouse Hanford Company. Both logging systems were calibrated in moisture models built by Schlumberger (Ellis et al. 1995). The systems were subsequently tested in seven moisture models built by PNL as part of the CRADA (Engelman et al. 1995) to ensure the resulting measurements met Data Quality Objectives (DQOs) for precision and accuracy. Three of the models had 15-cm(6-in.-) diameter steel casing similar to that used in the Sisson and Lu.boreholes; the results are summarized in Table 3.5 .

Table 3.5. DQOs and Results for the Neutron-Neutron Moisture Logging Systems in Models with 15-cm- (6-in.-) ID Steel Casing

\begin{tabular}{|c|c|c|c|}
\hline . & DQOs & $\overline{\mathrm{APS}}$ & CNT-G \\
\hline Tool OD & & $\begin{array}{l}3.625 \mathrm{~cm} \\
(1.43 \mathrm{in} .)\end{array}$ & $\begin{array}{l}3.375 \mathrm{~cm} \\
(1.33 \mathrm{in} .)\end{array}$ \\
\hline Logging Speed & $1.5 \mathrm{~m} / \mathrm{min}(5 \mathrm{ft} / \mathrm{min})$ & & \\
\hline $\begin{array}{l}\text { Precision and Accuracy } \\
\text { Tolerances }\end{array}$ & one standard deviation & & \\
\hline Depth Precision & $\begin{array}{c} \pm 7.6 \mathrm{~cm}( \pm 3 \mathrm{in} .) \text { at a } \\
\text { depth of } 76.2 \mathrm{~m}(250 \mathrm{ft})\end{array}$ & & \\
\hline Distance Between Recordings & & $\begin{array}{c}\text { Continuous } \\
{[5 \mathrm{~cm}(2 \text { in. })]}\end{array}$ & $\begin{array}{c}\text { Continuous } \\
{[5 \mathrm{~cm}(2 \text { in. })]}\end{array}$ \\
\hline Recording Times (s) & & 3 & 2 \\
\hline \multicolumn{4}{|c|}{ Model F (5 vol\%) } \\
\hline Precision (vol\%) & \pm 1.0 & \pm 0.02 & \pm 0.03 \\
\hline Accuracy (vol\%) & $3.0-7.0$ & 5.62 & 5.17 \\
\hline \multicolumn{4}{|c|}{ Model E (12 vol\%) } \\
\hline Precision (vol\%) & \pm 1.2 & \pm 0.06 & \pm 0.07 \\
\hline Accuracy (vol\%) & $9.5-14.3$ & 11.45 & 12.2 \\
\hline \multicolumn{4}{|c|}{ Model G (20 vol\%) } \\
\hline Precision (vol\%) & \pm 2.0 & \pm 0.15 & \pm 0.30 \\
\hline Accuracy (vol\%) & $15.8-23.8$ & 18.55 & 19.72 \\
\hline
\end{tabular}


The posted APS results are for near-far moisture. Similar results were also realized for slowingdown time moisture. All results for both tools easily surpassed the DQOs.

The $\sum$ measurement has not been calibrated for Hanford boreholes. Measurements from the calibration models were higher than values calculated based on the model composition. The discrepancy is probably due to the enhanced diffusion of the neutron cloud in the low density of the calibration models, which accurately reflect the Hanford formation. Additional calibration is planned; until then, the $\sum$ data in this report should only be used for relative comparisons.

\subsection{Gamma-Gamma Density Logging System}

Gamma-gamma density. logging systems are used to measure the wet (or apparent) bulk density of the formation. If water content information is available, the wet bulk density can be used to calculate the dry bulk density and porosity of the formation. The Litho-Density Sonde (LDS) is the Schlumberger gamma-gamma service that was run in all 32 Sisson and Lu boreholes.

\subsubsection{Description}

Gamma-gamma density logging systems irradiate the formation with medium-energy gamma rays that collide with electrons in the formation. With each collision, a gamma ray loses some of its energy to electrons and continues with diminished energy. The reduced-energy gamma rays that reach the detector are counted as an indication of the electron density of the formation (Schlumberger 1989a), where fewer counts indicate a greater electron density. Several empirical relationships are used to convert the electron density into the apparent bulk density, which includes the contributions of the formation, in situ water content, air gap, and casing densities.

Gamma-gamma density logging systems have a shallow depth of investigation and their response is affected by borehole conditions (e.g., airgaps, steel casing). Most gamma-gamma density logging systems use dual detectors that allow the tool to correct for borehole effects (Figure 3.8). Based on the relationship between the counting rates for each detector, a density correction is applied to the apparent bulk to yield the in situ wet bulk density $\left(\rho_{b w}\right)$, sometimes called the compensated bulk density. 'The wet bulk density is the density of the formation outside the borehole at the in situ water content.

The porosity $(\phi)$ of the formation can be determined from the wet bulk density using an estimate of the sediment particle density $\left(\rho_{s}\right)$ and fluid density $\left(\rho_{f}\right)$ in the pore space:

$$
\phi=1-\frac{\rho_{\mathrm{bw}}-\rho_{f}}{\rho_{s}}
$$

The sediment particle density was assumed to be $2.69 \mathrm{~g} / \mathrm{cm}^{3}$ for the Hanford formation (Fayer et al. 1993). The fluid density is the product of the volumetric water content $(\theta)$, which was derived from the CNT-G log (Section 3.2), and the density of water (assumed to be $1 \mathrm{~g} / \mathrm{cm}^{3}$ ). The dry bulk density $\left(\rho_{b}\right)$ of the formation is simply $\rho_{b w}-\rho_{f}$.

The LDS system uses a gamma source of $1.7 \mathrm{Ci}$ of $137 \mathrm{Cs}$ and dual NaI(Tl) detectors that provide some spectral information. The LDS system has a vertical resolution of approximately $10 \mathrm{~cm}$ ( 3.9 in.) and a depth of investigation of 10 to $15 \mathrm{~cm}$ (3.9 in. to 6 in.). The tool is sensitive to changes in bulk density of $0.01 \mathrm{~g} / \mathrm{cm}^{3}$ (Flanagan et al. 1991). 


\subsubsection{Calibration}

Unlike the neutron tools discussed earlier, this tool has not yet been calibrated for Hanford unsaturated zone boreholes. The primary concerns are the presence of steel casing (this tool is usually run in uncased holes) and the effect of any air gaps between the casing and surrounding formation. These concerns are being addressed as part of a CRADA with Schlumberger during FY 1996.

The gamma-gamma density tool compensates for the presence of material between the gamma detectors and the formation (i.e., the steel casing in the wells logged at this site). The degree of compensation is expressed by a correction curve $(\Delta \rho)$. The correction is made to the apparent density seen by the log spacing detector. It is based on the discrepancy between the long and short spacing measurements and can be defined by the following equation:

$$
\Delta \rho \propto t_{s c}\left(\rho_{b w}-\rho_{s c}\right)
$$

where the correction is proportional to the product of the thickness of the steel casing $\left(t_{s c}\right)$ and the difference in density between the formation and casing (adapted from Ellis 1987). The correction is consistently negative because the casing has a greater density $\left(\rho_{s c}\right)$ than the formation $\left(\rho_{b}\right)$. Figure 3.8 shows that the density correction is linearly related to the wet (or compensated) bulk density. The linear trend suggests that the degree of compensation is primarily an inverse function of the wet bulk density and that casing thickness is fairly constant. This preliminary result indicates that the currently applied correction algorithm may compensate correctly for the presence of casing. Once adaptation of the LDS service is complete, the logs will be recomputed.

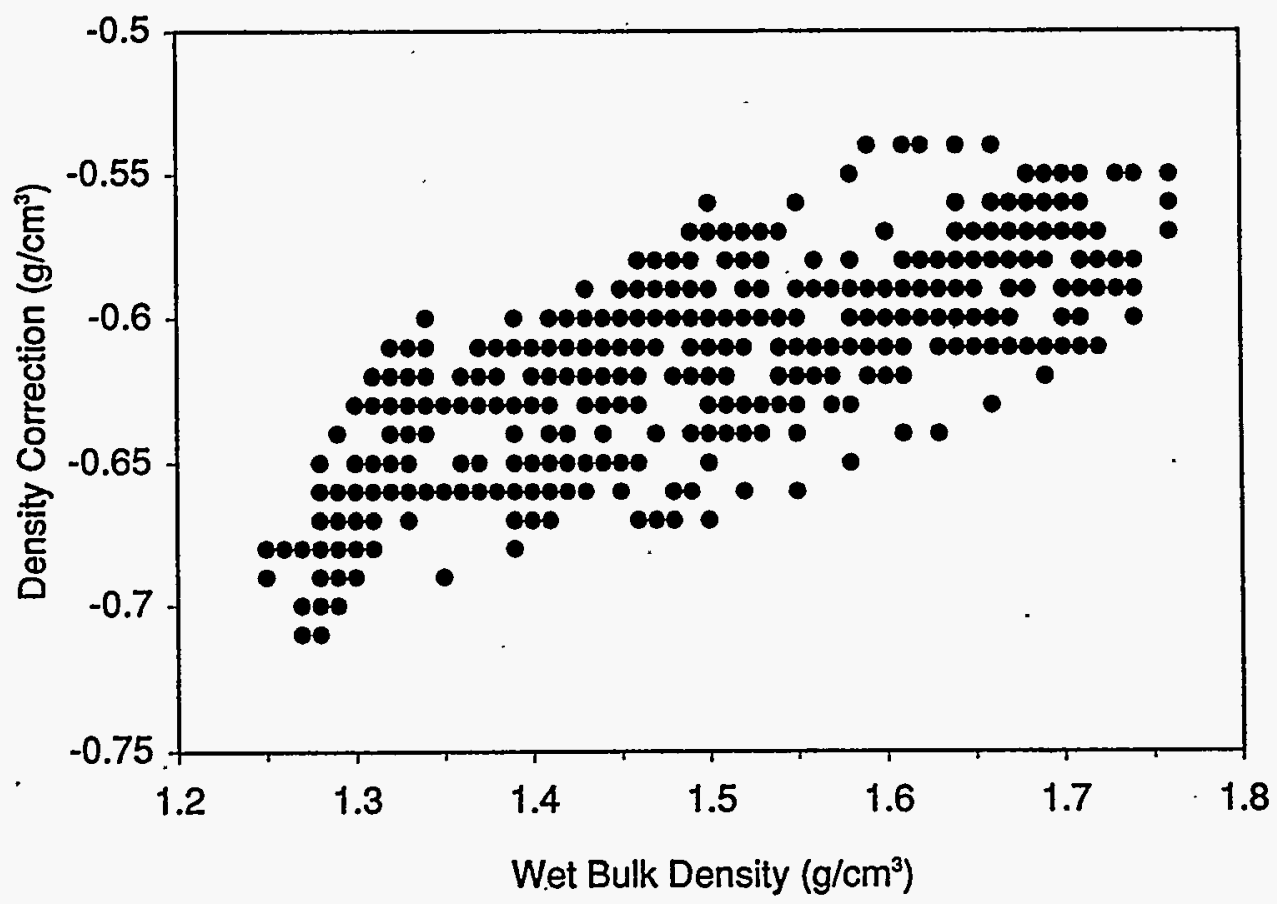

Figure 3.8. Density Correction as a Function of Compensated Bulk Density for Well E-1 


\subsection{Spectral Gamma Logging Systems}

Two spectral gamma logging systems [the Hostile Natural Gamma Spectroscopy (HNGS) System and the Radionuclide Logging System (RLS)] were used to measure the activities of gammaemitting radionuclides. The HNGS system was operated in all 32 wells by Schlumberger Well Services. The RLS system was operated in portions of three wells by WHC.

\subsubsection{Description}

Some radioactive elements within the formation, both naturally occurring (K, U, and $T h)$ and created (e.g., ${ }^{137} \mathrm{Cs},{ }^{60} \mathrm{Co}$ ), spontaneously emit gamma rays as they decay. The energies of the emitted gamma rays are distinctive for each element. A spectral gamma logging system measures the energy and intensity of incident gamma rays and computes the activity. In the Hanford formation, the naturally occurring radionuclides reside primarily in potassium feldspar, micas, and clay minerals.

There are two principal types of detectors used by spectral gamma logging systems: scintillation and solid state. Scintillators have been used for many years, while solid state detectors have seen limited commercial application. HPGe detectors provide a far superior spectral response at the expense of significantly decreased detector efficiency. Logging runs in a $25-\mathrm{m}-(82-\mathrm{ft}$ ) deep borehole with a scintillation detector take one-half hour, while those with a solid state detector may take 8 hours. HPGe detectors are more costly and must be operated at or near liquid nitrogen temperatures (Wilson 1981). Nevertheless, HPGe detectors do provide a very important advantage of being able to resolve many peaks in gamma-ray spectra, thereby allowing identification of numerous gamma-emitting radionuclides (Koizumi et al. 1994).

The two spectral gamma systems can be used in a complementary fashion. A scintillator system can be used to rapidly screen all boreholes and an HPGe system can be focused on any anomalous zones. This procedure was employed in this project. The scintillator system was run in all 32 boreholes during the course of two working days. Anomalous zones were detected in three boreholes, and an HPGe system was used during two working days to interpret these zones.

The scintillator system employed was the HNGS system, a service provided by Schlumberger Well Services. The HNGS was originally designed to identify and quantify naturally occurring radionuclides within oil wells. The HNGS was optimized to provide maximum sensitivity so that typical oil field logging speeds could be used while retaining effective counting statistics. To this end, the system uses two scintillators composed of bismuth germanate (BGO) (Figure 3.9). BGO has a high specific gravity (approximately $7 \mathrm{~g} / \mathrm{cm}^{3}$ ) which increases efficiency by promoting the capture of more (compared to most commonly employed scintillators) gamma rays that enter the detector. Two detectors are employed to increase the sensitivity without degrading the system's vertical resolution. Further technical information is in Flanagan et al. (1991).

The RLS, a service provided by Westinghouse Hanford Company, was the HPGe system run in the anomalous zones. The RLS used has an 18\%-efficient HPGe detector (Figure 3.10); other efficiencies are available. The RLS typically records data for $120 \mathrm{~s}$ at a fixed depth, generally at $15-\mathrm{cm}$ (6-in.) depth intervals. Longer recording times can be used where greater sensitivity is needed. Further technical information is described in Koizumi et al. (1994). 


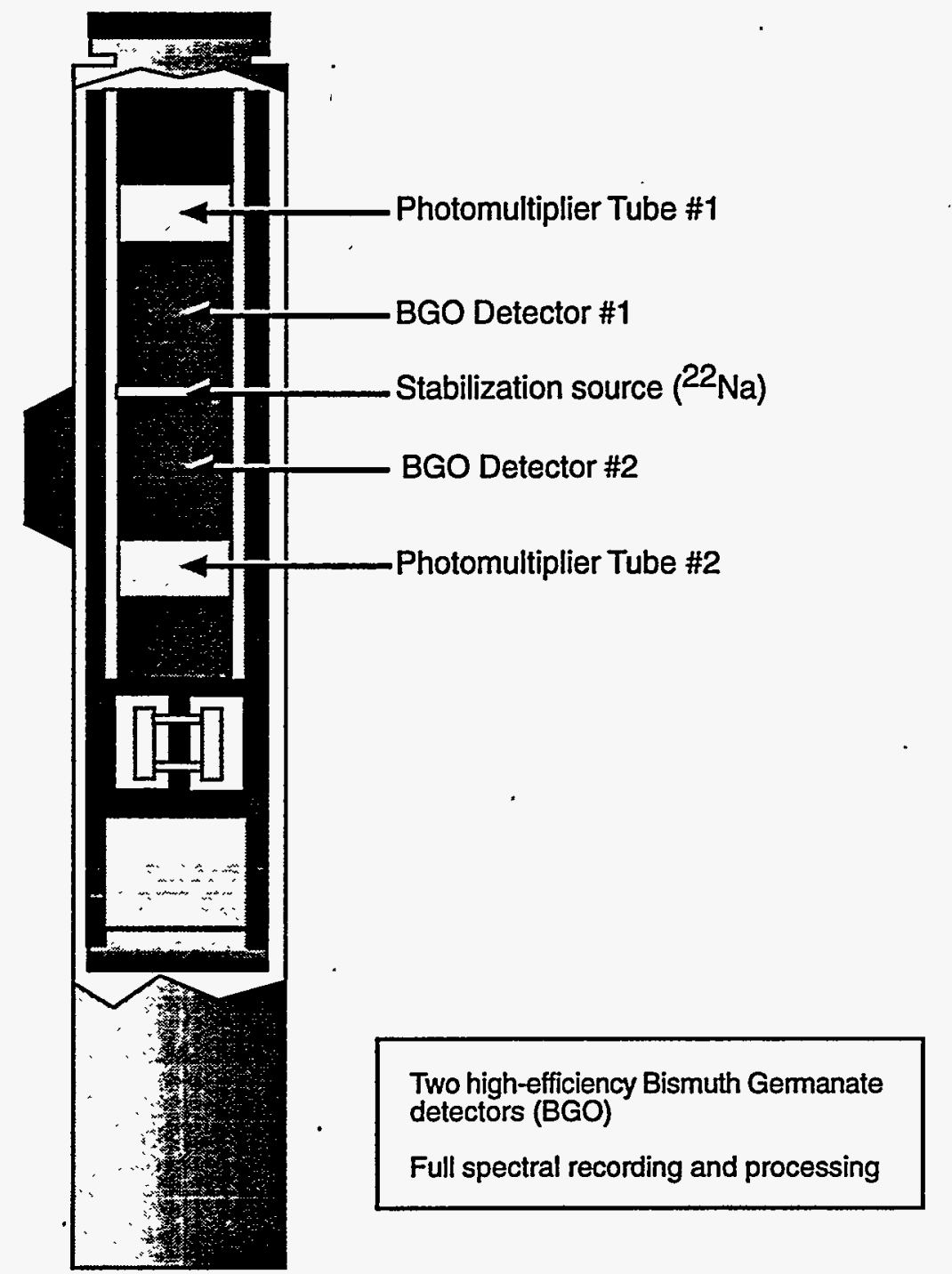

SG95110016.3

Figure 3.9. Schematic Diagram of the HNGS Tool (after Flanagan et al. 1991)

\subsubsection{Calibration}

Schlumberger Well Services adapted the HNGS service for Hanford borehole conditions as part of the same CRADA described in Section 3.2.2. A set of DQOs, primarily for accuracy and precision, were developed for scintillation spectral systems. Additional DQOs addressed which created radionuclides the system should identify, and the dynamic range for ${ }^{137} \mathrm{Cs}$ measurements. This system was tested for precision and accuracy in an existing set of calibration models (Steele and George 1986) built by the DOE-Grand Junction Project Office (DOE-GJPO) and now located at the Hanford Site. The four models contain known K, U(Ra), and Th concentrations. (Radium, 226Ra, is a surrogate of uranium because most gamma rays in the $U$ decay chain are emitted by the bismuth daughter, 214 $\mathrm{Bi}$, which is produced after $226 \mathrm{Ra}$ decays.) 


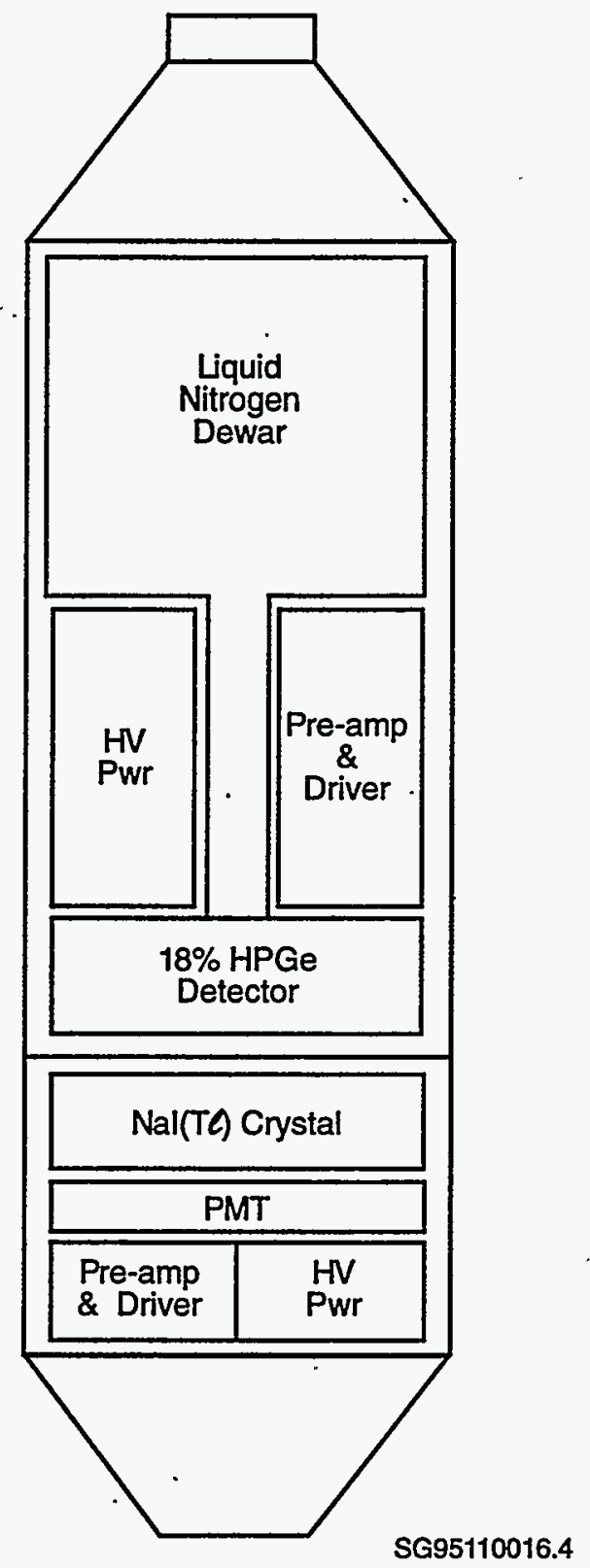

Figure 3.10. Schematic Diagram of the RLS Tool (after Koizumi et al. 1994)

Table 3.6 presents the results of the DQO tests for precision and accuracy of the naturally occurring radionuclides. These DQOs were met.

There were no calibration models for anthropogenic radionuclides (e.g., $60 \mathrm{Co},{ }^{137 \mathrm{Cs} \text { ). }}$ Schlumberger modeled the system response using small laboratory sources and gamma-ray transport computer codes (Ellis et al. 1995). 
Table 3.6. DQOs and Results for the Scintillation Spectral Gamma Logging System. A DQO for uranium was not provided because a suitable model was not available.

\begin{tabular}{||l|c|c||}
\hline \multicolumn{1}{|c|}{} & DQOs & HNGS Results \\
\hline Tool OD & & $\begin{array}{c}3.75 \mathrm{~cm} \\
(1.48 \mathrm{in} .)\end{array}$ \\
\hline Logging Speed & $1.5 \mathrm{~m} / \mathrm{min}(5 \mathrm{ft} / \mathrm{min})$ & \\
\hline Precision and Accuracy Tolerances & one standard deviation & $\cdot$ \\
\hline Depth Precision & $\begin{array}{c} \pm 7.6 \mathrm{~cm}( \pm 3 \mathrm{in} .) \text { at a } \\
\text { depth of } 76.2 \mathrm{~m}(250 \mathrm{ft})\end{array}$ & \\
\hline Distance Between Recordings & & $\begin{array}{c}\text { Continuous } \\
{[15 \mathrm{~cm}(6 \mathrm{in} .)]}\end{array}$ \\
\hline Recording Times (s) & & 6 \\
\hline Potassium Precision (pCi/g) & & \pm 0.27 \\
\hline Potassium Accuracy (pCi/g) & $48.5-60.5$ & 50.5 \\
\hline Uranium Precision (pCi/g) & \pm 0.7 & \pm 0.52 \\
\hline Thorium Precision (pCi/g) & \pm 0.2 & \pm 0.13 \\
\hline Thorium Accuracy (pCi/g) & $51.2-66.0$ & 51.6 \\
\hline \hline
\end{tabular}

The RLS has undergone extensive calibration at the Hanford Site and also at DOE-GJPO, where an extensive set of calibration models exists. The calibration of this system is discussed in general by Koizumi et al. (1994). Annual calibration reports (e.g., Koizumi et al. 1991, 1992) are also available. 



\subsection{Measurement Results}

The results of the 1995 data collection effort were used to understand the subsurface distribution of the variables water content, density, and sediment type as determined from gamma emissions, and the residual ${ }^{134} \mathrm{Cs}$ from the injection experiment. The results for each variable are described below. Example logs from well E-1 (E24-92) are provided in plates at the end of this report and interpreted in this section. The complete set of data is described in the Appendixes.

\subsection{Water Content}

Depth distributions of water content were determined in two wells using all three methods (neutron probe, CNT-G, and APS) and in one well using two methods (CNT-G and APS). The distributions were compared to highlight similarities and differences among the methods. The water content distributions in 1995 were then compared to the distributions just before and after the experiment to show changes that have occurred in the intervening 15 years.

\subsubsection{Comparison Among Tools}

All four tools for measuring water content were used in the two wells A-7 (E24-79) and E-7 (E24-95). In addition, both the CNT-G and APS tools were used in well E-1. In the remainder of the wells, only the CNT-G tool was used. The CNT-G and APS data were collected continuously. The CNT-G data were combined to give measurements every $0.15 \mathrm{~m}(6 \mathrm{in}$.$) . The APS data were$ combined to give measurements every $0.05 \mathrm{~m}$ ( 2 in.). The neutron probe data were collected every $0.3 \mathrm{~m}$ (12 in.). For the comparisons with the neutron probe, the CNT-G and APS data were depopulated to yield data at the same depth frequency as the neutron probe.

Figures 4.1 to 4.3 show the water content profiles for all tools. For most depths, the tools are remarkably similar. Depths where they are less similar are near the surface and near water content peaks that presumably coincide with finer textured sediment layers. As discussed in Section 3.3, the APS tool did not measure above $2 \mathrm{~m}(6.6 \mathrm{ft})$ or below $14.3 \mathrm{~m}(47 \mathrm{ft})$. Near-surface differences in water content may reflect a transient wetting front because two to three weeks separated the CNT-G and neutron probe measurements. In the vicinity of the water content peaks, all tools registered higher water contents, but the depth locations were sometimes different partly because of a slight shift in the datum. For example, in well E-7, Probe 1 and the APS indicated the peak was at $11.6 \mathrm{~m}$ ( $38 \mathrm{ft}$ ), whereas Probe 2 and the CNT-G indicated $11.9 \mathrm{~m}$ (39 ft).

Comparison of the water content profiles in Figures 4.1 to 4.3 reveals a subsurface complexity that will be more fully discussed later. Visually, each of the three wells has at least three dominant water content peaks at roughly similar depths. However, the depths and thicknesses of the peaks are

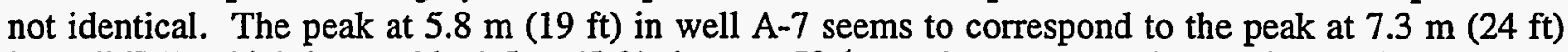

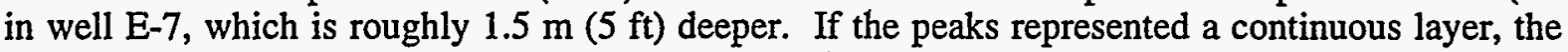

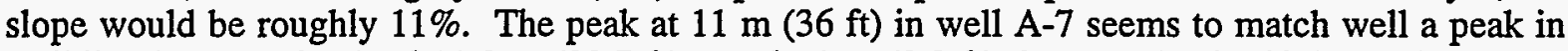
well E-7 but at a depth of $11.8 \mathrm{~m}(38.7 \mathrm{ft})$, nearly $1 \mathrm{~m}(3.3 \mathrm{ft})$ deeper. Again, if the peaks represented a continuous layer, the slope would be roughly $7 \%$. Also, the peak in well A-7 appears twice as broad and wetter by 4 to 5 vol\% water content. 


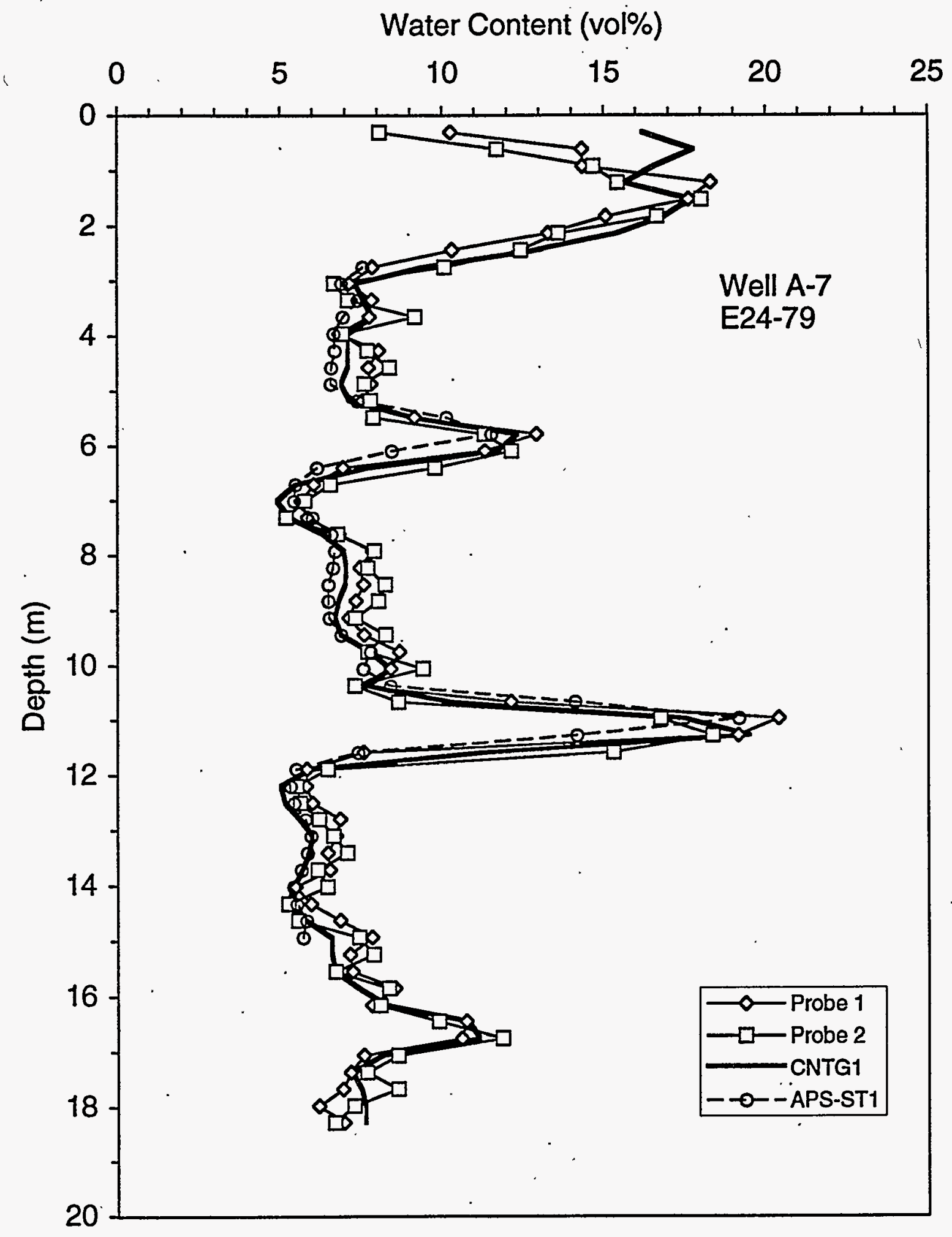

Figure 4.1. Comparison of Water Contents in Well A-7 (E24-79) Determined with Two Neutron Probes and the CNT-G and APS Tools in 1995 


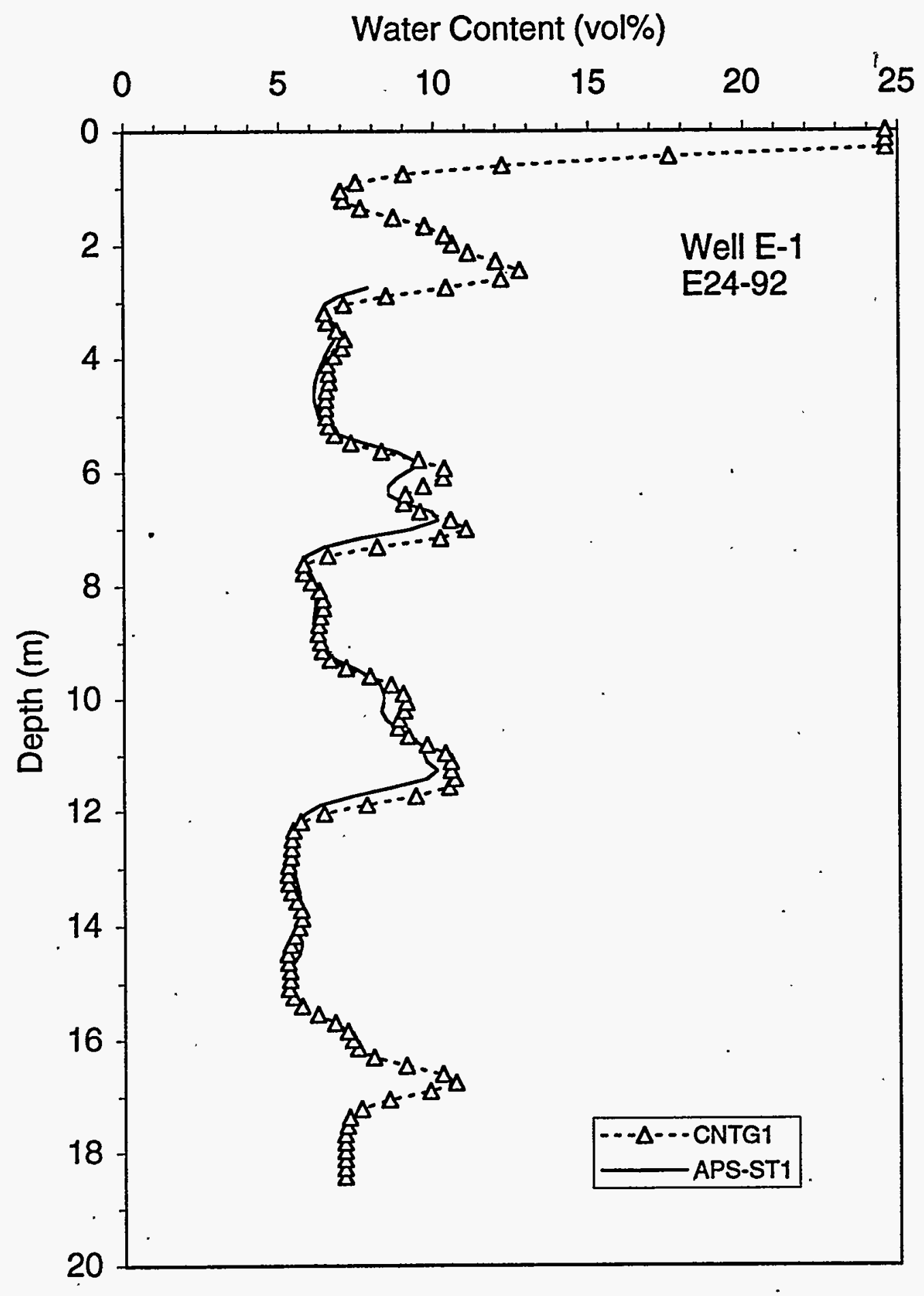

Figure 4.2. Comparison of Water Contents in Well E-1 (E24-92) Determined with the CNT-G and APS Tools in 1995 


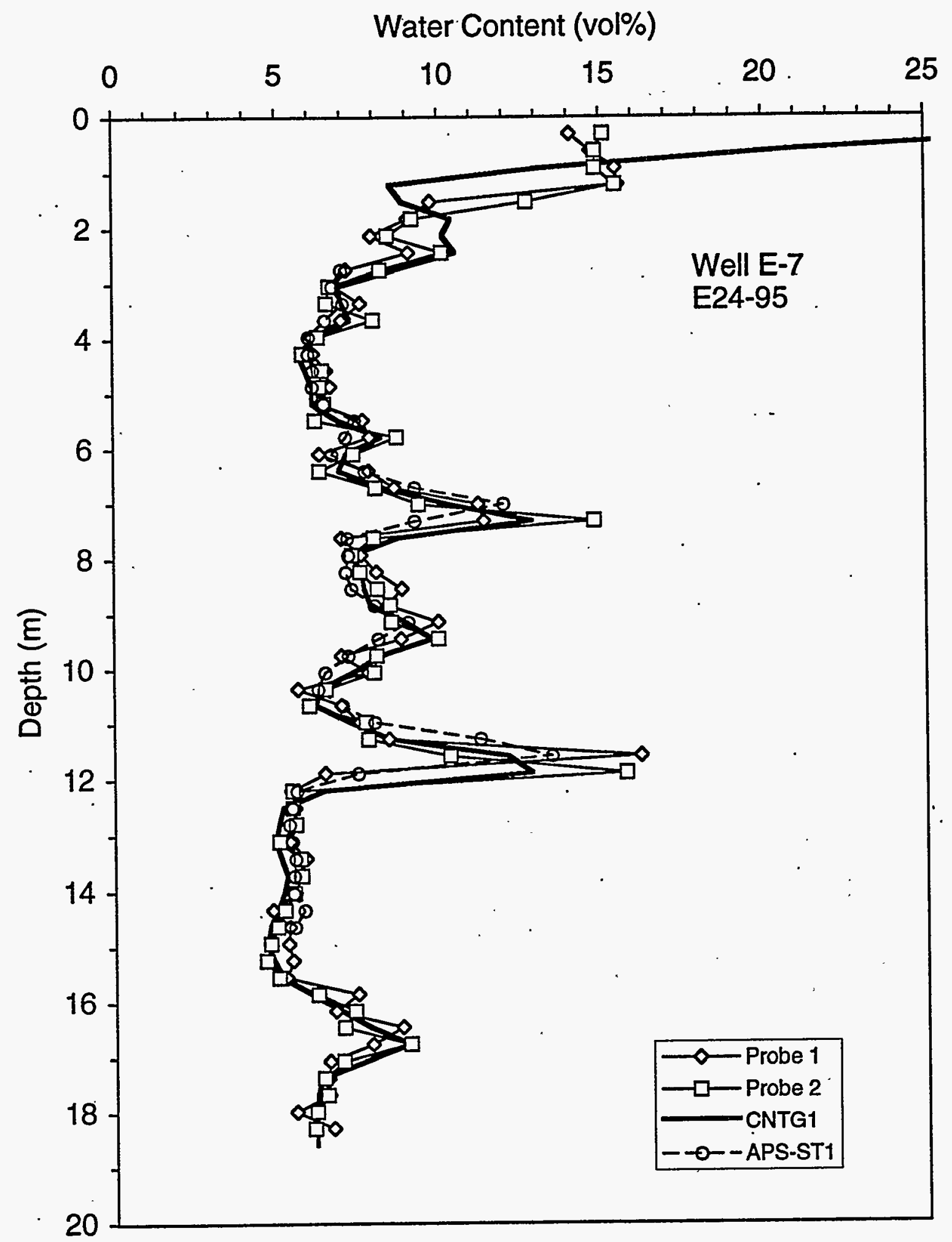

Figure 4.3. Comparison of Water Contents in Well E-7 (E24-95) Determined with Two Neutron Probes and the CNT-G and APS Tools in 1995 
Some of the water content peaks appear to be so thin that the $0.3-\mathrm{m}$ (12-in.) spacing of the neutron probe data probably was inadequate to resolve the water content of the thin layer accurately. Rather, the probe yields an average of the water contents of the layer and surrounding sediments. This problem is particularly noticeable for the peak in E-7 at $11.8 \mathrm{~m}(38.7 \mathrm{ft})$. A small depth shift in an instrument can register the peak at a different location (e.g., Probe 1 versus Probe 2). To see how thin some of the layers might be, the full APS data set for three wells is shown in Figure 4.4.

These three wells indicate the water content observations in an east-west cross-section, with well E-7 on the west end of the experiment, well E-1 near the center, and well A-7 on the east end. The results in Figure 4.4 show two major water content peaks in the three wells and a number of minor peaks. The results also show that some peaks coincide with others at the same depths but not the same water content, or they coincide in water content but not in depth, and that some depths are very thin, particularly $11.9 \mathrm{~m}$ (39 ft) in well E-7. Showing a thin peak at this resolution $[5 \mathrm{~cm}$ ( 2 in.)] indicates just how thin it is. A neutron probe operating at $0.3-\mathrm{m}$ (12-in.) spacing would definitely "smear" this high water content layer by averaging with nearby drier sediments, or worse, the probe might not even detect the layer.

\subsubsection{Comparison to 1980 Data}

The 1980 water content data were collected with Probe 1 in June 1980. Figures 4.5 to 4.8 show these pre-experiment water content profiles in the four wells that were monitored with the same neutron probe in 1995 . Figures 4.5 to 4.8 also include the post-experiment water content profiles in October 1981, which was roughly 8 months after the last injection. Finally, the figures show the 1995 water content profiles determined with the same neutron probe.

The most striking result is how closely the 1995 profiles match the pre-experiment profiles given the 15-year interval between measurements. At a majority of depths, the differences are less than $1 \mathrm{vol} \%$, which is smaller than the calibration error of the probe. The water contents are slightly higher in 1995. At depths with water content peaks, the differences are larger, the largest being $6 \mathrm{vol} \%$ in well $\mathrm{H}-4$ at a depth of $11 \mathrm{~m}(36 \mathrm{ft})$.

As shown in Figure 2.2, the four wells that were monitored with the neutron probes in 1995 were not near the center of the experiment where water contents were highest. Figure 4.9 shows water contents in well E-1, which was $1 \mathrm{~m}(3.3 \mathrm{ft}$ ) from the injection well. The CNT-G data in 1995 were used in lieu of neutron probe data. Figure 4.9 shows that the results are similar to those in Figures 4.5 to 4.8 , namely that the 1995 water contents are very nearly like the pre-experiment water contents measured in June 1980. Taken together, the data indicate that the sediments have attained some natural drained state beyond which further reductions in water content are minimal and may not be detectable. It may be that the June 1980 and the January and February 1995 water content profiles were in some sort of quasi-equilibrium with the recharge rate for the existing climate, soil, and vegetation conditions at the site. Previous modeling efforts were somewhat successful in matching these water content profiles only if the recharge rate was 20 to $50 \mathrm{~mm} / \mathrm{yr}(0.79$ to 1.97 in./yr) (e.g., Lu and Khaleel 1993; Smoot 1995). 


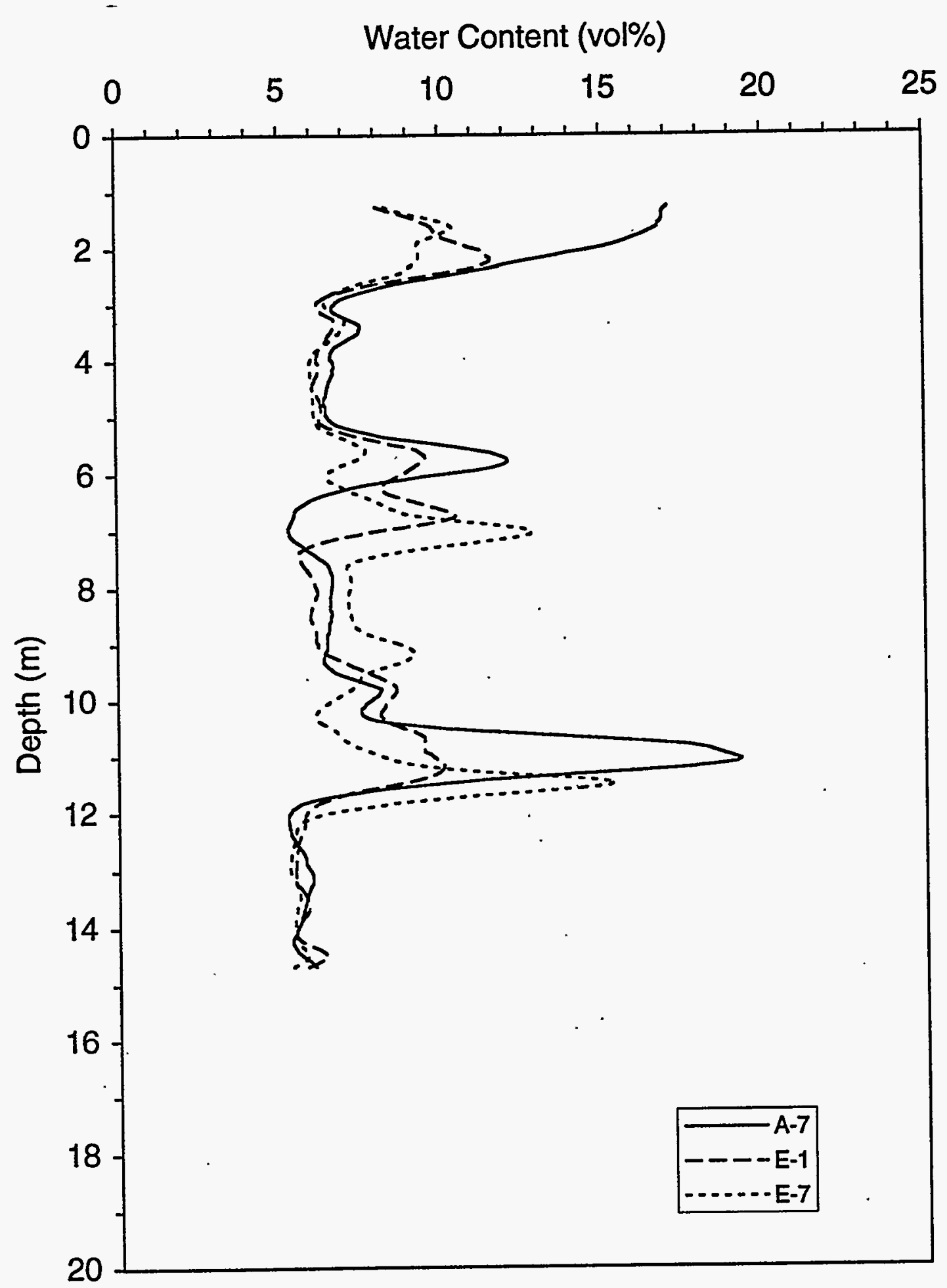

Figure 4.4. Comparison of Water Contents in Wells A-7, E-1, and E-7 Determined with the APS Operating at High Resolution Mode with a Value Every 0.05 m (1.9 in.) in 1995 


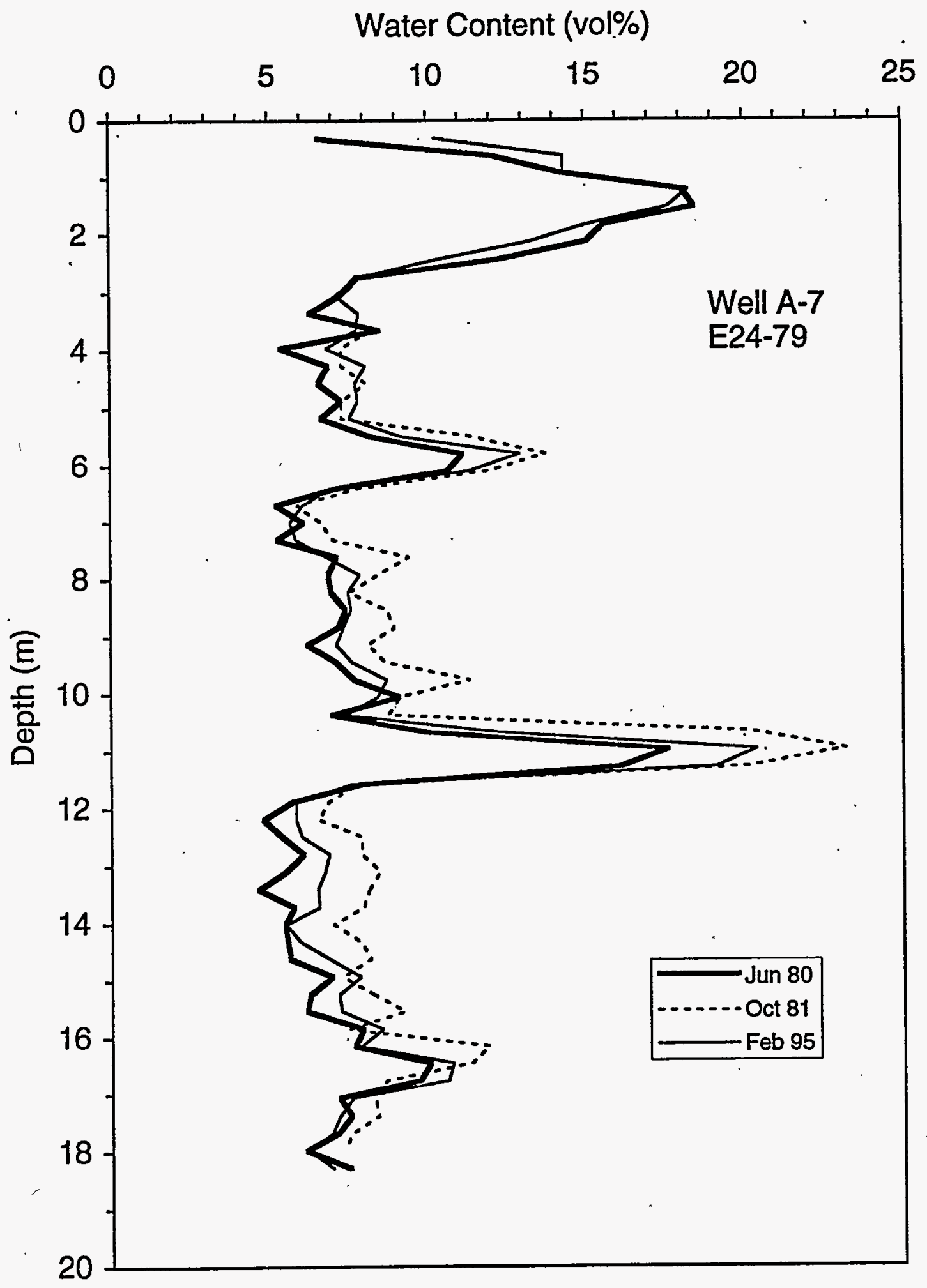

Figure 4.5. Comparison of Water Contents in Well A-7 Determined with Probe 1 in 1980, 1981, and 1995 


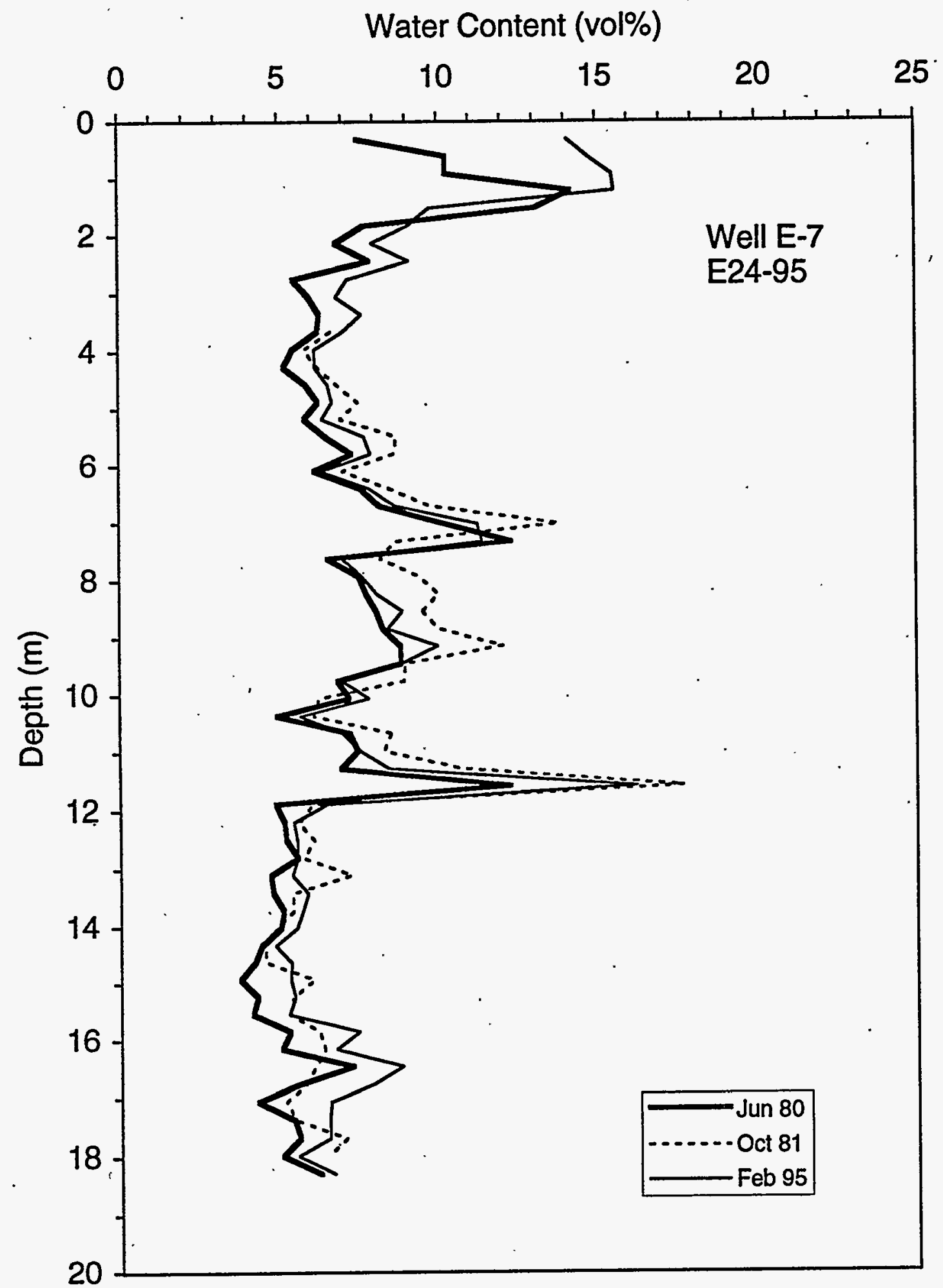

Figure 4.6. Comparison of Water Contents in Well E-7 Determined with Probe 1 in 1980, 1981, and 1995 


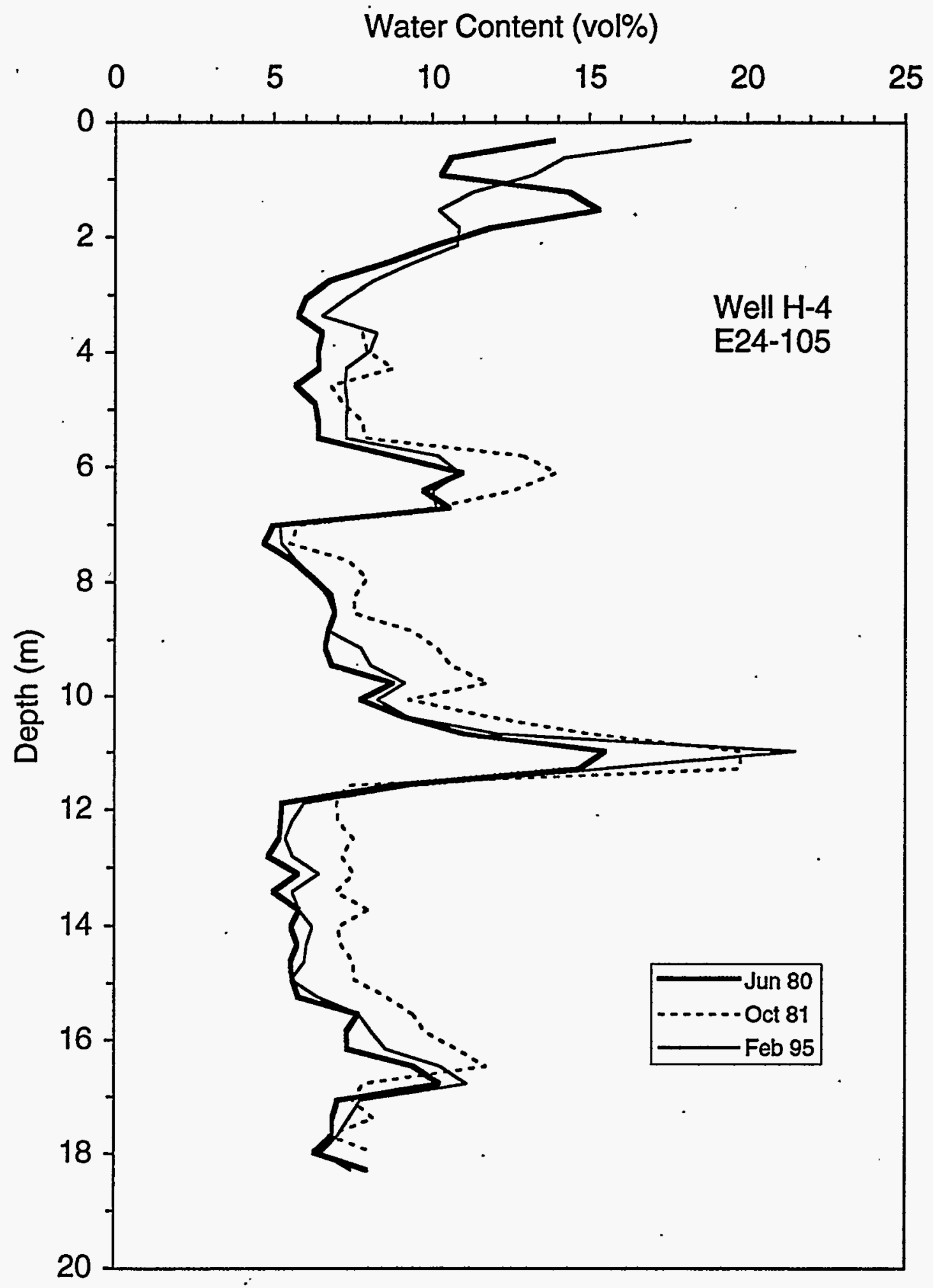

Figure 4.7. Comparison of Water Contents in Well H-4 Determined with Probe 1 in 1980, 1981, and 1995 


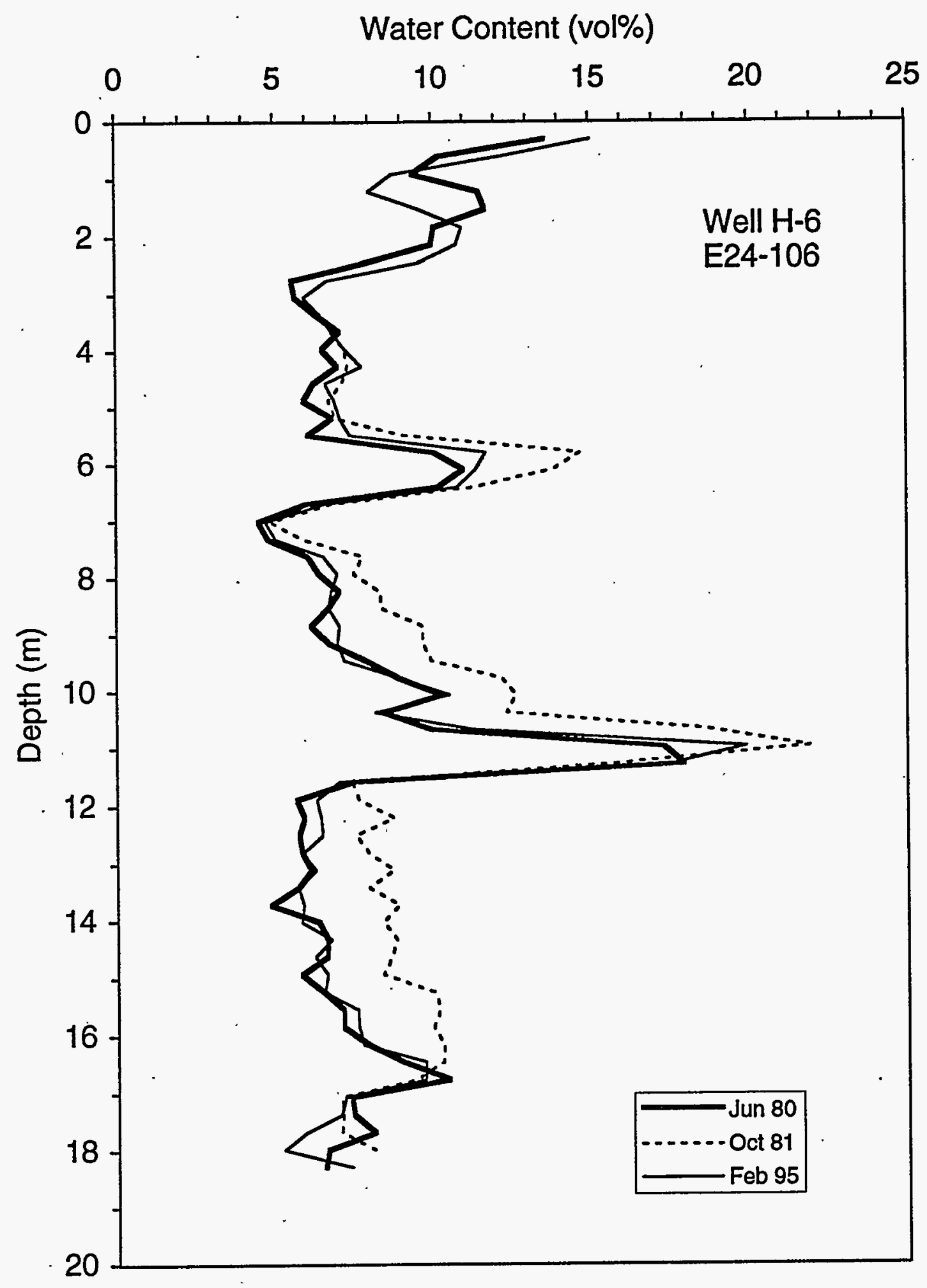

Figure 4.8. Comparison of Water Contents in Well H-6 Determined with Probe 1 in 1980, 1981, and 1995 


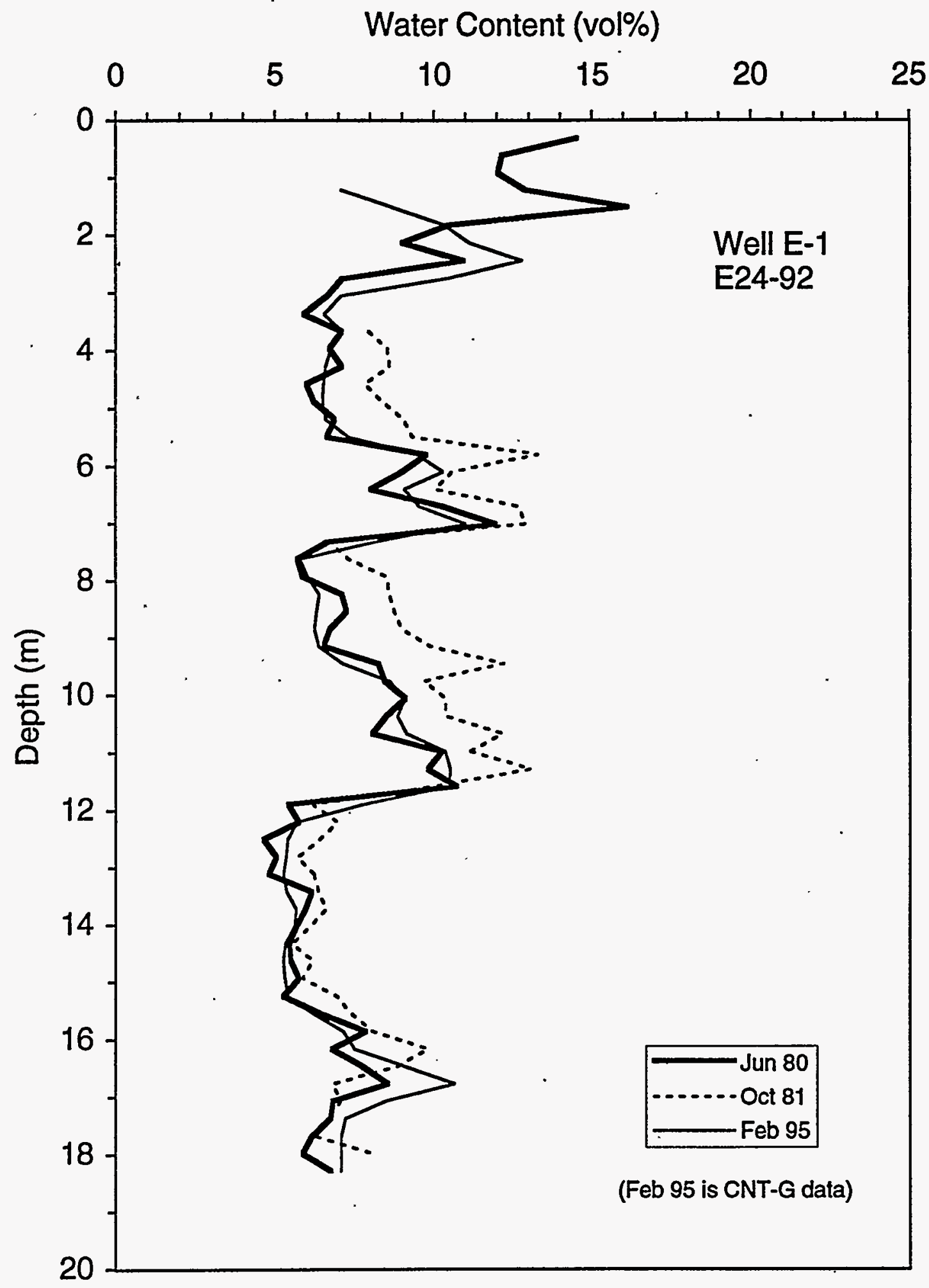

Figure 4.9. Comparison of Water Contents in Well E-1 Determined with Probe 1 in 1980 and 1981, and with the CNT-G in 1995 


\subsection{Density and Porosity}

Figure 4.10 shows the density and water content profiles for well E-1. Four high-density zones are apparent and they correlate one-to-one with the four high water content zones on the CNT-G log. This correlation indicates that the moisture is preferentially retained in the higher density zones. According to the CNT-G and APS logs, the maximum difference in moisture between the "dry" and "moist" zones is 6 vol\%. If the porosity for both zones is the same (e.g., 40 vol\%), this moisture difference equates to an increase in bulk density of only $0.06 \mathrm{~g} / \mathrm{cm}^{3}$, not the 0.20 to $0.35 \mathrm{~g} / \mathrm{cm}^{3}$ difference depicted on the log. Thus, the difference in density between the "dry" and "moist" zones must be primarily due to differences in porosity. Higher moisture in lower porosity zones is consistent with the increase in specific retention as the pores decrease in size and number.

Figure 4.11 compares water content and bulk density for each $0.15-\mathrm{m}(0.5-\mathrm{ft})$ interval from the CNT-G and LDS logs. The relationship between the two variables is linear and confirms the general relationship noted in the previous paragraph.

The physics of the gamma-gamma density tool permit finer vertical resolution than can be measured with any of the other logging systems used in the Sisson and Lu boreholes. Comparison of the APS and LDS logs in Figure 4.12 shows the enhanced vertical resolution of the LDS. The suggestion of a less moist bed at $1.8 \mathrm{~m}(6 \mathrm{ft}$ ) in the APS (see Section 3.3.3) is confirmed in the LDS where it . is shown as a lower density bed at $2.0 \mathrm{~m}(6.6 \mathrm{ft})$, where the depth discrepancy is due to slight shift in the datum for each log. In addition, the LDS shows a lower density bed at a depth of $2.4 \mathrm{~m}(8 \mathrm{ft})$.

\subsection{Lithology}

The lithology of the Hanford formation at the Sisson and Lu site can be partly inferred from changes in the activities of K, U, and Th. Examination of the HNGS data from well E-1 indicated that the activities of $U$ and Th were consistently very low $(<1 \mathrm{pCi} / \mathrm{g})$ and appeared to exhibit little variability. As Table 4.1 shows, however, the coefficient of variation $(\eta)$ was similar for all three elements. The coefficient of variation is a statistical measure of variability and was calculated using

$$
\eta=\frac{\sigma}{\mu}
$$

where $\sigma$ is the standard deviation and $\mu$ is the mean. The greater-than-anticipated variability of the $U$ and Th curves suggested that the activity scales for each should be expanded. However, comparison of the mean Th and $U$ activities to the precision listed in Table 3.6 suggested that $U$ and, to a lesser extent, Th, were present at activities low enough to be adversely affected by statistical variation in radioactive decay. Potassium activities, in contrast, were significantly greater than the precision of the measurement.

The average concentrations in the earth's crust are $2.6 \mathrm{wt} \%$ for potassium, $3 \mathrm{ppm}$ for uranium, and $12 \mathrm{ppm}$ for thorium (Schlumberger 1989a). Table 4.1 shows that the concentrations measured in well E-1 were all approximately one-half the crustal average. The relatively low activities of $U$ and Th are not surprising in light of the geochemistry of the Hanford formation. Uranium in uncontaminated clastic sediments is typically concentrated where total organic carbon (TOC) content is elevated. This is caused by the reduction of $\mathrm{U}^{6+}$ to $\mathrm{U}^{4+}$ and its subsequent precipitation as an insoluble phosphate or sulfide compound (Alloway 1990). The TOC content of the Hanford formation is variable although low, with maximum concentrations < $0.2 \mathrm{wt} \%$ (Bjornstad 1990). 


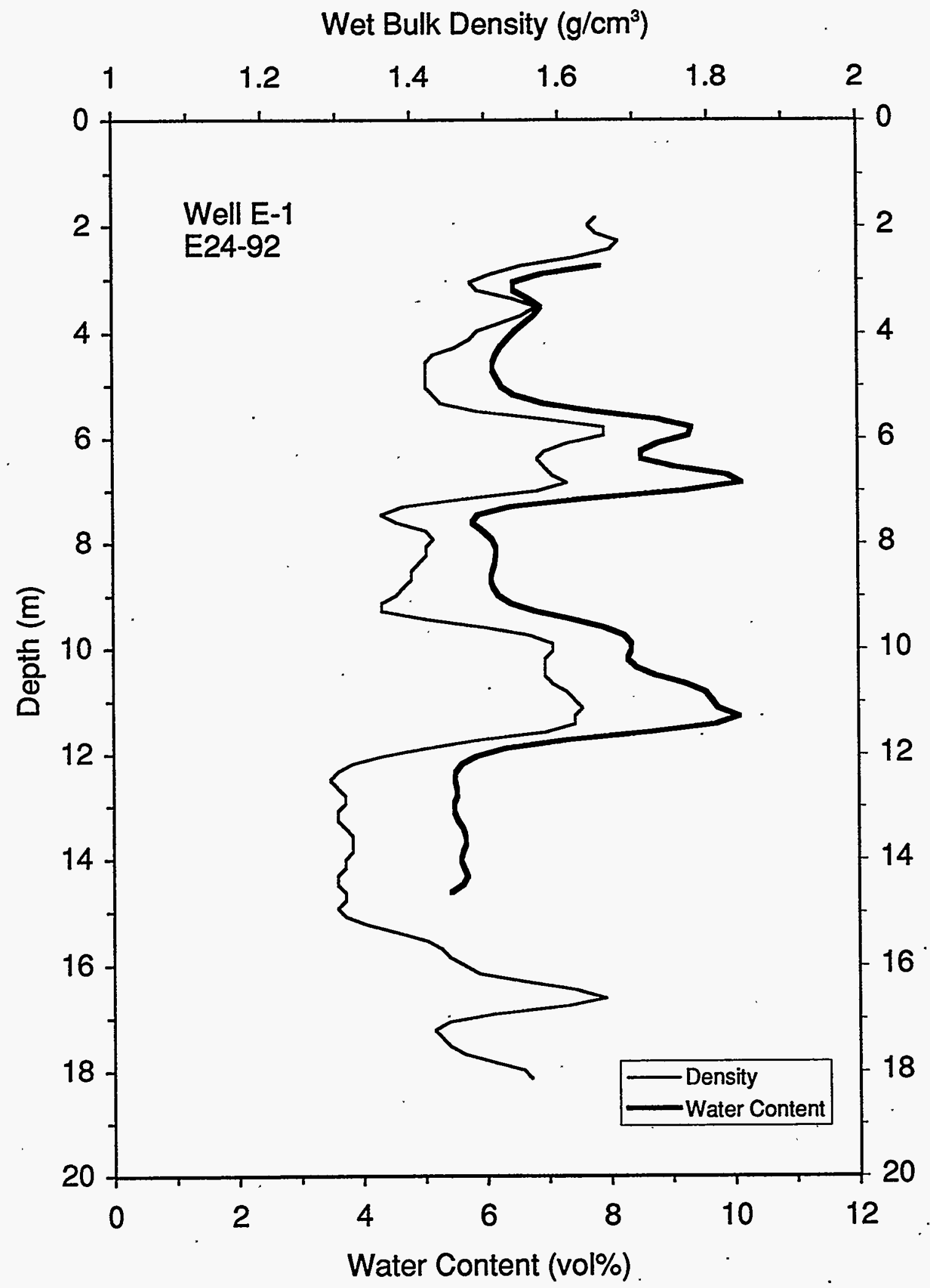

Figure 4.10. Depth Profiles of Wet Bulk Density and Water Content Measured with the LDS and CNT-G Tools at 0.15-m (5.9-in.) Intervals in Well E-1 


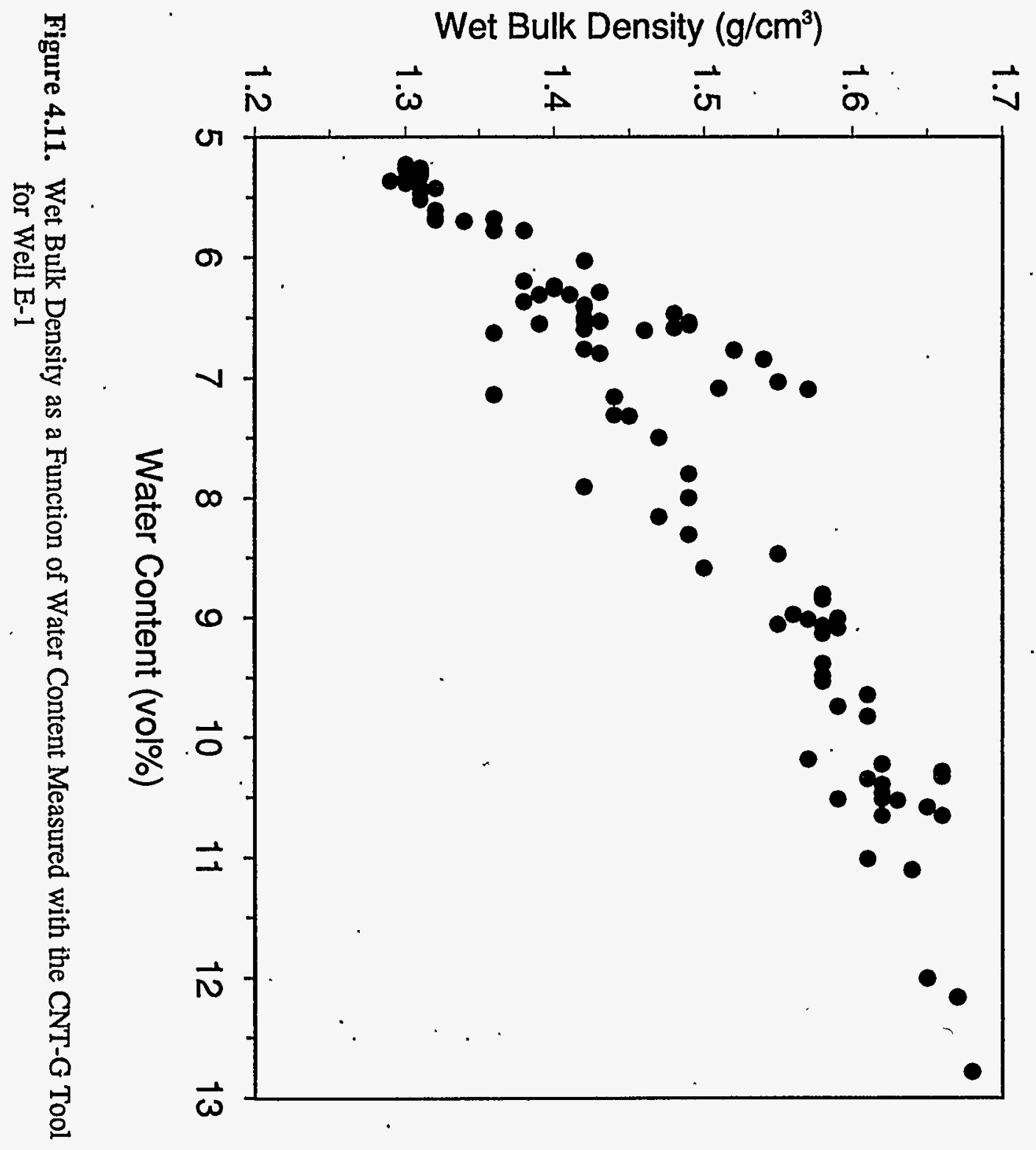




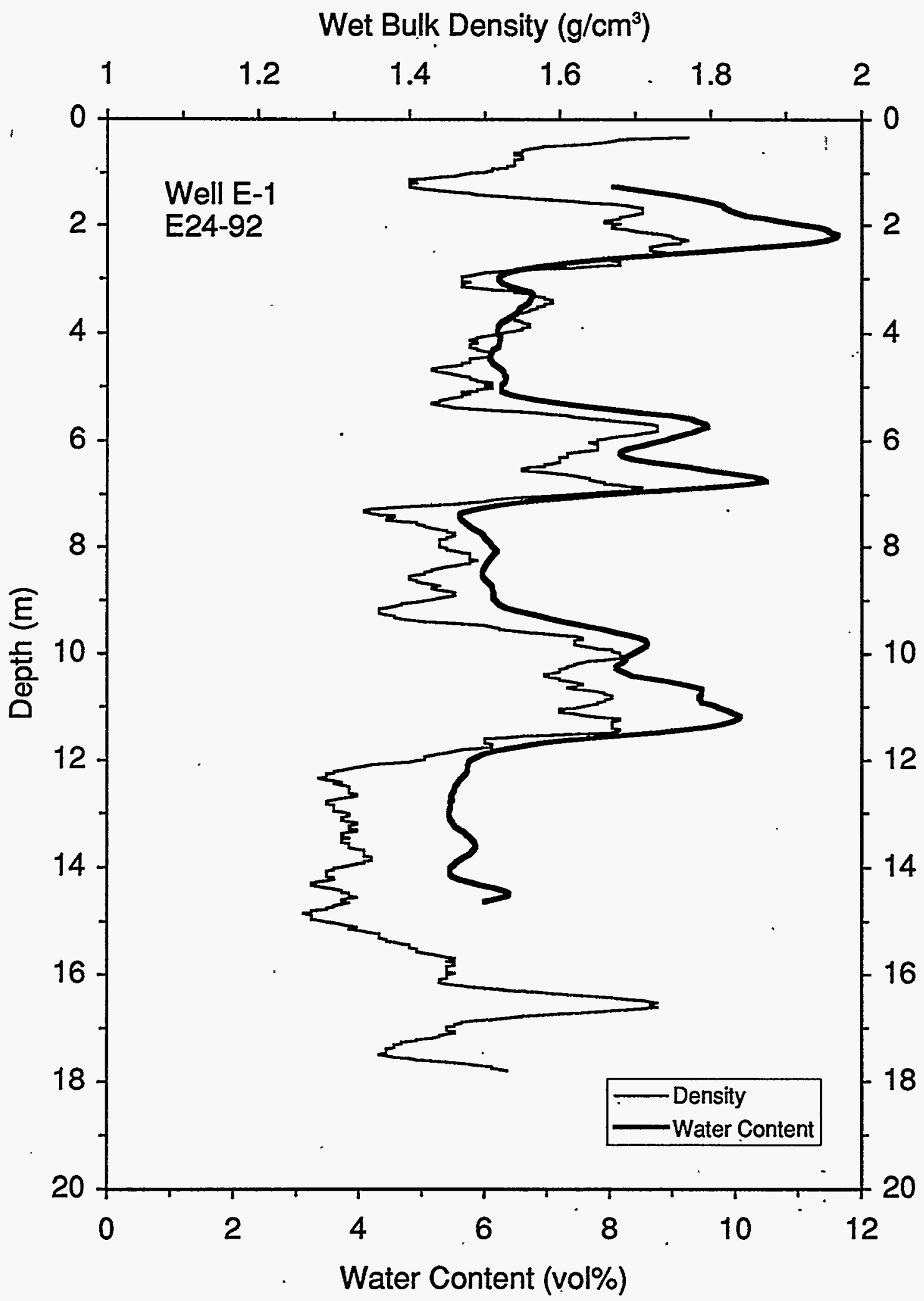

Figure 4.12. Depth Profiles of Bulk Density and Water Content Measured with the LDS Tool at 0.025-m (0.98-in.) Intervals and the APS Tool at 0.05-m (1.9-in.) Intervals in Well E-1 
Table 4.1. Statistical Parameters of Th, U, and $\mathrm{K}$ Data from HNGS Log of Well E-1

\begin{tabular}{||c|c|c|c|c|c||}
\hline \hline \multirow{2}{*}{ Element } & \multicolumn{3}{|c|}{ Mean } & $\begin{array}{c}\text { Standard } \\
\text { Deviation }\end{array}$ & \multirow{2}{*}{$\begin{array}{c}\text { Coefficient of } \\
\text { Variation }\end{array}$} \\
\cline { 2 - 6 } & $\mathrm{pCi} / \mathrm{g}$ & $\mathrm{ppm}$ & $\mathrm{wt} \%$ & $\mathrm{pCi} / \mathrm{g}$ & 0.10 \\
\hline Thorium & 0.75 & 6.8 & & 0.07 & 0.13 \\
\hline Uranium & 0.58 & 1.8 & & 0.08 & 0.11 \\
\hline Potassium & 13.07 & & 1.6 & 1.49 & 0.40 \\
\hline
\end{tabular}

Thorium activity, on the other hand, is typically associated with the specific clay minerals kaolinite and montmorillonite (Schlumberger 1991). The Hanford formation, which was rapidly. deposited by a series of high-energy floods, has been shown to have trace to low concentrations of clay minerals (Bjornstad 1980, 1990), supporting the low Th activity exhibited in this well log. More than half of the clay minerals within the Hanford formation, measured in wt\%, are from the montmorillonite and kaolinite groups. Because the mean Th activity is approximately three times greater than the precision, the variability of Th activity probably partially reflects changes in the concentrations of these clay minerals. Charts have been developed that identify minerals based on the ratio of Th and $\mathrm{K}$ concentrations (Ellis 1987); the mean Th and $\mathrm{K}$ concentrations for well E-1 plot in the montmorillonite field. This is consistent with Bjornstad (1990), who showed that montmorillonites are the most common clay minerals within the Hanford formation, accounting for $37 \%$ by weight of the combined clay fraction.

Potassium, in contrast, is present at measurable activities ranging from 8.3 to $14.4 \mathrm{pCi} / \mathrm{g}$. The average activity within the borehole is $13.1 \mathrm{pCi} / \mathrm{g}$. For comparison, Bjornstad (1990) reported that the Hanford formation has an average $\mathrm{K}_{2} \mathrm{O}$ concentration of $2.1 \mathrm{wt} \%$. This concentration is equivalent to an activity of $14.6 \mathrm{pCi} / \mathrm{g}$, which is fairly close to the mean activity in well E-1. Potassium is generally present in some clay minerals (e.g., illite), some micas (e.g., biotite and muscovite), and potassium feldspar. Bjornstad (1990) reported an average potassium feldspar volume of $3.92 \%$ and an average mica volume of $3.48 \%$ for the Hanford formation. Illite, in contrast, is only $10 \%$ of the clay fraction and would be present only at trace levels. If the mica is biotite, then potassium feldspar contributes three times as much $\mathrm{K}$ as the mica, and the reported $\mathrm{K}$ levels are in response primarily to potassium feldspar.

The gross gamma response was similar to the $\mathrm{K}$ response. This was expected because $\mathrm{K}$ is present at relatively high activities, whereas $U$ and $T h$ are not. Nevertheless, inspection of the digital data for well $\mathrm{E}-1$ indicates that $U$ and Th activities generally respond similarly to the $\mathrm{K}$ activity. That is, zones of elevated $\mathrm{K}$ activity typically have elevated $\mathrm{U}$ and $\mathrm{Th}$ activities, and their response does contribute to the gross gamma response. Nevertheless, the gross gamma response primarily reflects the variation in potassium feldspar concentrations and, to a lesser extent, mica concentrations. 
The gross gamma and potassium responses can be divided into two different vertical zones with a boundary at the 3-m (10-ft) depth. Above this depth, both measurements exhibit a low radioactivity zone at a depth of $2.1 \mathrm{~m}(7 \mathrm{ft})$. This zone has the lowest $\mathrm{K}$ and gross gamma activity encountered in the entire well, and it is present at the same depth in all of the other wells logged at this site. The same response was seen by the RLS system (Appendix C). This anomaly can be caused by 1 ) a geologic feature that contains a low $K$ concentration, 2) a soil horizon where $K$ has been leached out, or 3) a well completion feature. Resolution of this anomaly will require more data. The decrease in gross gamma and $\mathrm{K}$ activity from $0.6 \mathrm{~m}(2 \mathrm{ft})$ to the surface is simply due to the reduction in gamma activity as the detector nears the atmosphere, which basically contains no gamma emitters.

Below $3 \mathrm{~m}(10 \mathrm{ft})$, the gross gamma and $\mathrm{K}$ behave regularly except for a high activity zone at $4.5 \mathrm{~m}$ (15 ft). This zone has the highest gross gamma activity, but it does not have the highest $\mathrm{K}$ activity. Close examination of the HNGS log shows that there is a small anomaly at this depth, interpreted as ${ }^{137} \mathrm{Cs}$, that is responsible for the additional gamma activity. This anomaly is present from 3.8 to $5.6 \mathrm{~m}(12.5$ to $18.5 \mathrm{ft})$ and it was also in the repeat $\log$. The maximum activity is

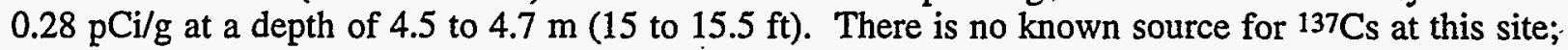
however, ${ }^{134} \mathrm{Cs}$ was injected as a tracer at a depth of $4.5 \mathrm{~m}(15 \mathrm{ft})$ in an injection well $1 \mathrm{~m}(3.3 \mathrm{ft})$ from this well (Fayer et al. 1993). A cumulative $89,162 \mu \mathrm{Ci}$ of ${ }^{134} \mathrm{Cs}$ were injected in eight separate events during 1980 . Approximately $0.81 \%$ of the $134 \mathrm{Cs}(723 \mu \mathrm{Ci})$ would not yet have decayed when this well was logged with the HNGS on January 13, 1995.

Cesium-134 has a half life of 2.05 years and it produces gamma rays primarily at two energies: $604.7 \mathrm{keV}$ and $795.8 \mathrm{keV}$ with yields of $98 \%$ and $88 \%$, respectively. Cesium-137, in contrast, produces a gamma ray of $661.6 \mathrm{keV}$ with a yield of $93 \%$. The proximity of the injection point, the potential for undecayed ${ }^{134} \mathrm{Cs}$, and the production of gamma rays of very similar energies by each radioisotope suggest that the HNGS misidentified the ${ }^{134} \mathrm{Cs}$ as ${ }^{137} \mathrm{Cs}$.

\subsection{Residual $134 \mathrm{Cs}$}

The RLS system has much better selectivity compared to the HNGS. Therefore, that system was employed to test the hypothesis that the gamma anomaly identified in Section 4.3 was ${ }^{134} \mathrm{Cs}$, and if present, to determine the activity. Well E-1 was logged by the RLS on February 24, 1995, using $120-\mathrm{s}$ measurements recorded every $15 \mathrm{~cm}$ (6 in.) with the highest efficiency detector (70\% HPGe) available. The RLS software used for routine logging was unable to identify ${ }^{134} \mathrm{Cs}$. However, subsequent analysis of the spectra from the anomalous intervals, as identified by the HNGS, allowed identification of ${ }^{134} \mathrm{Cs}$.

Figure 4.13 shows the portion of the gamma ray spectrum from 590 to $620 \mathrm{keV}$ for the $4.9 \mathrm{~m}$ (16 ft) depth. There are two photopeaks present, and each has been fit with a Gaussian distribution. According to the curve fit, the larger photopeak has an energy of $609.6 \mathrm{keV}$ (corresponding to a gamma ray of $609.3 \mathrm{keV}$ that is emitted from ${ }^{214} \mathrm{Bi}$, a member of the naturally occurring $238 \mathrm{U}$ decay series). The smaller photopeak has an energy of $605.2 \mathrm{keV}$ (corresponding to the $604.7 \mathrm{keV}$ gamma

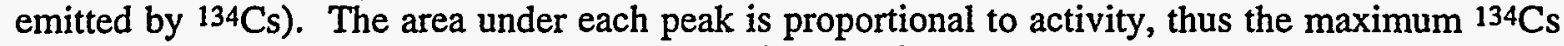
activity is $0.11 \pm 0.02 \mathrm{pCi} / \mathrm{g}$. Cesium-134 was detected from 4.6 to $5.2 \mathrm{~m}$ (15 to $17 \mathrm{ft}$ ). No other anthropogenic radionuclides were identified with the RLS in this well.

Figures 4.14 and 4.15 show that the HNGS logs identified similar, but lower activity anomalies, in two additional wells, C-1 (E24-84) and G-1 (E24-100). Like well E-1, well G-1 is $1 \mathrm{~m}$ from the injection well. The HNGS identified an anomaly from 4.4 to $5.3 \mathrm{~m}$ (14.5 to $17.5 \mathrm{ft}$ ), with a maximum activity (misidentified by the HNGS software as ${ }^{137} \mathrm{Cs}$ ) of $0.04 \mathrm{pCi} / \mathrm{g}$ at 5.0 to $5.2 \mathrm{~m}(16.5$ to 


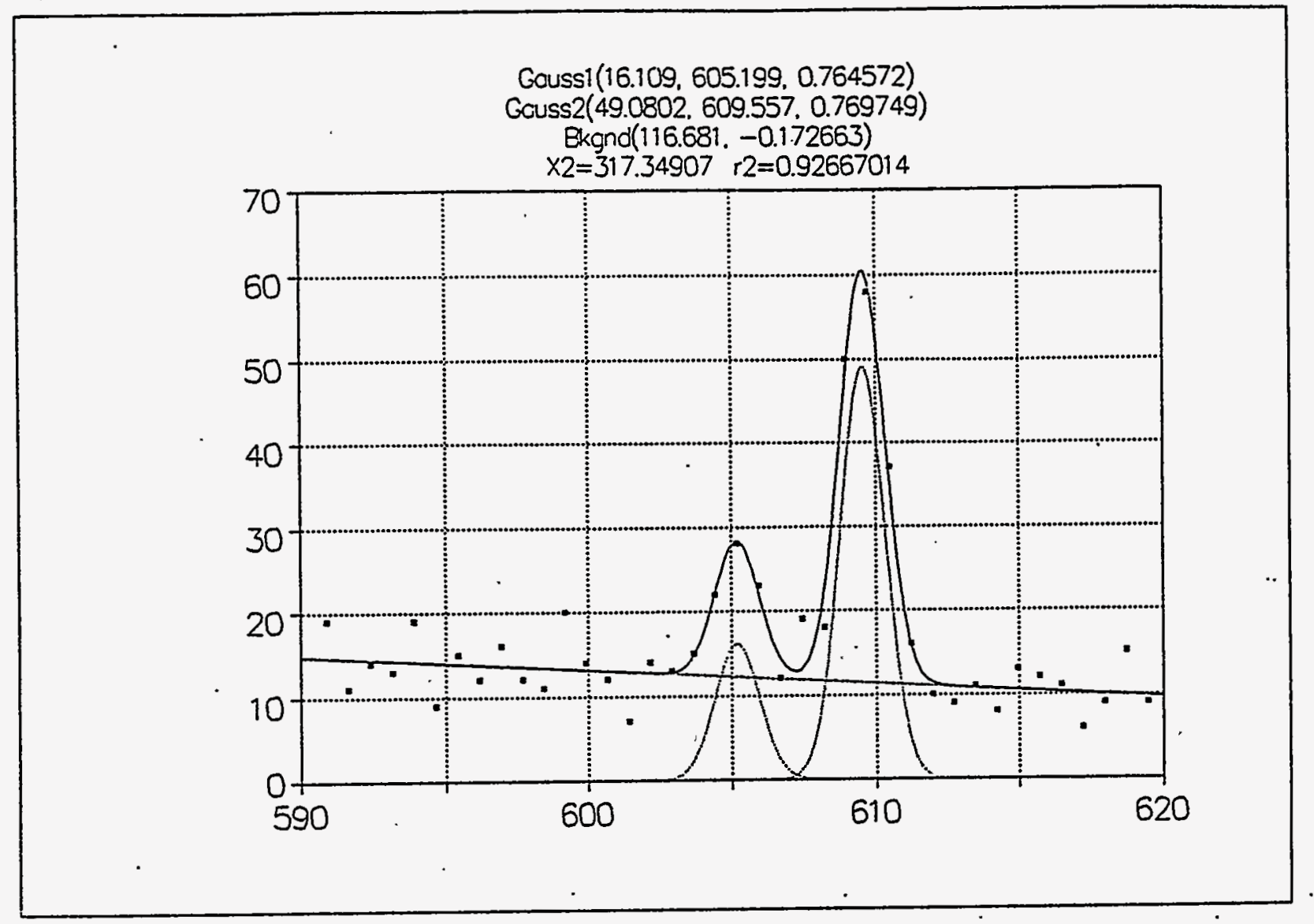

Figure 4.13. Spectral Gamma Data Collected with the RLS System in Well E-1 in 1995 


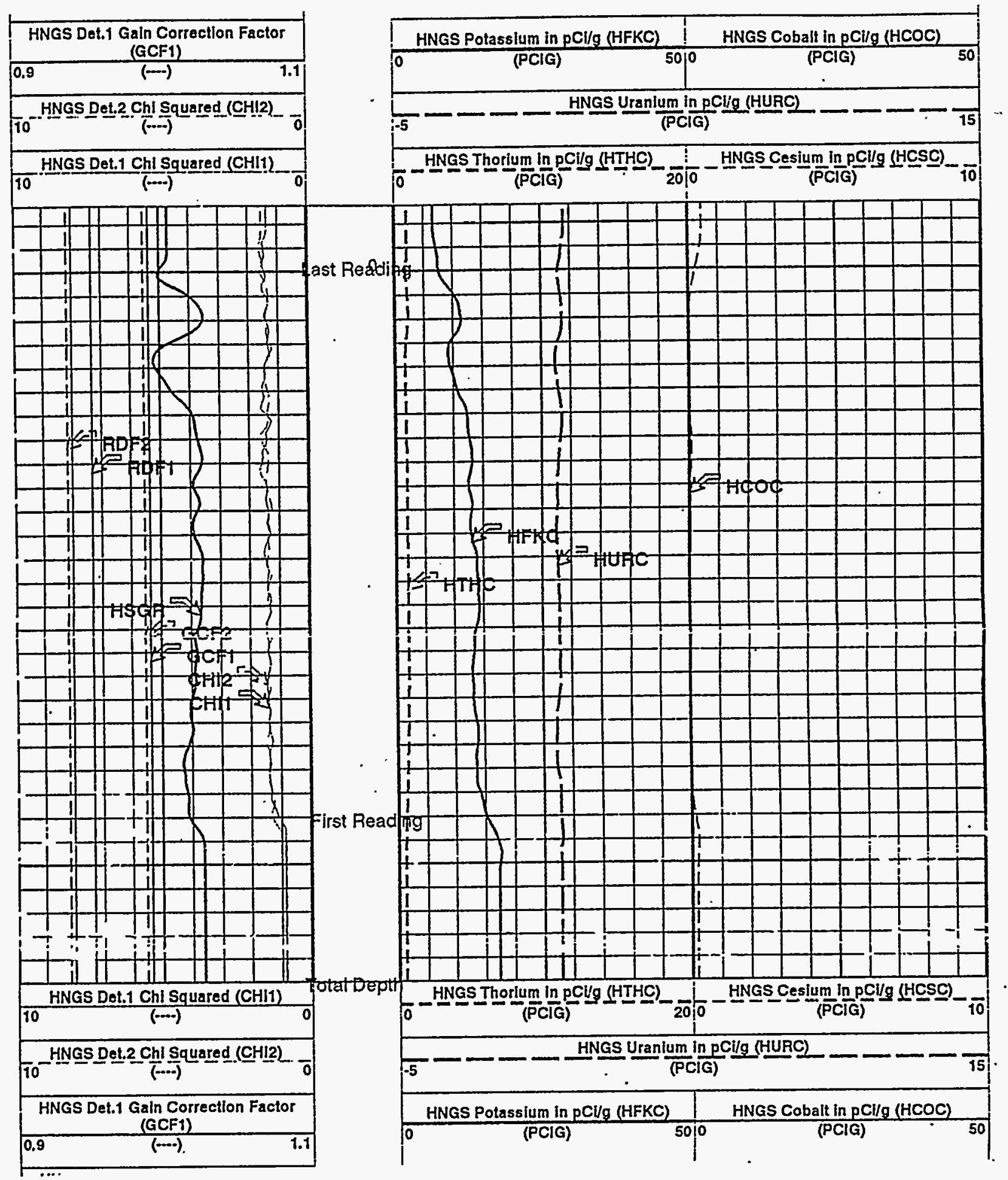

Figure 4.14. Gamma Data Collected with the HNGS Tool in Well C-1 in 1995 


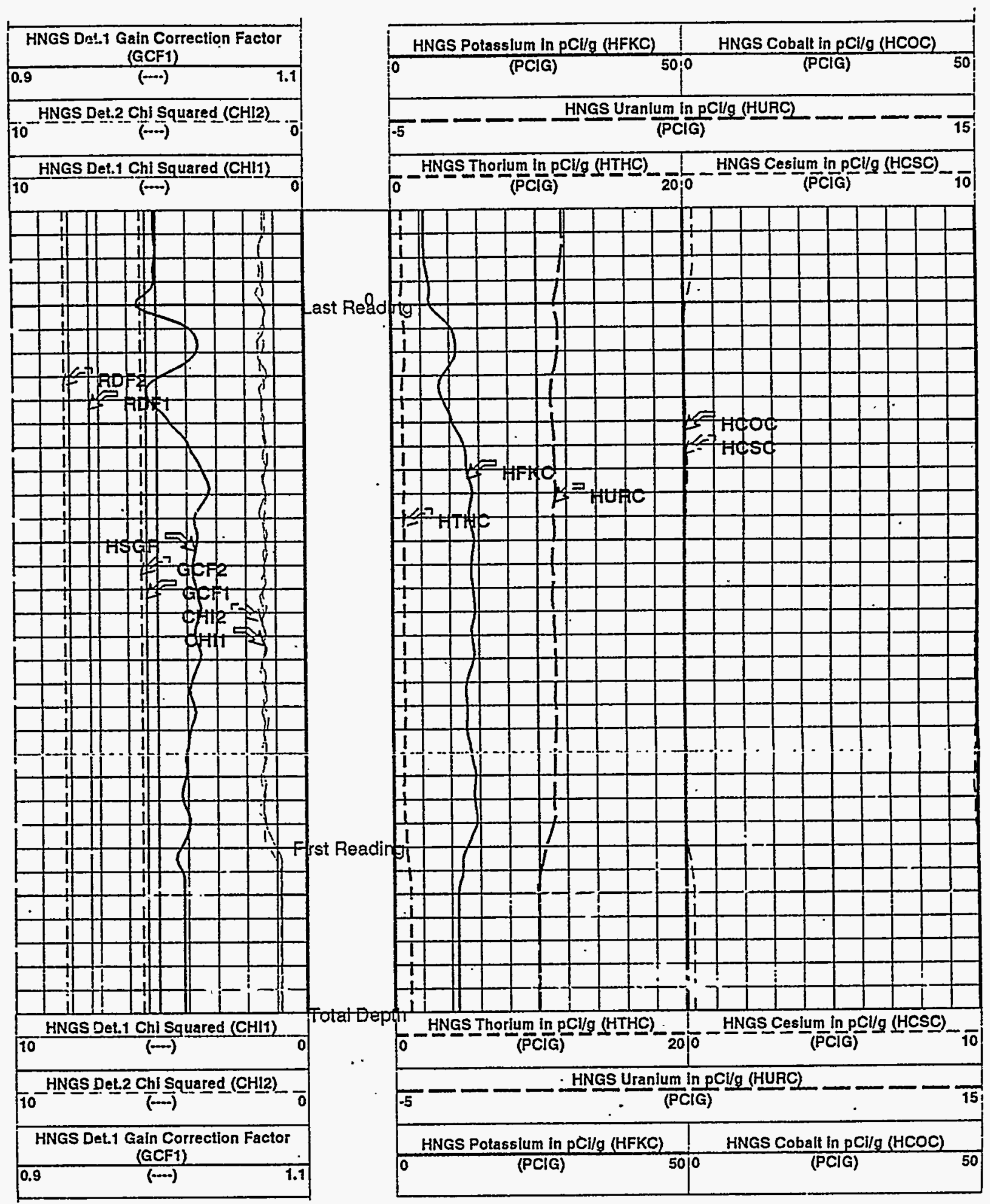

Figure 4.15. Gamma Data Collected with the HNGS Tool in Well G-1 in 1995 
$17 \mathrm{ft}$ ). The anomaly was also present in the repeat log. This well was subsequently logged with the RLS from 3.0 to $6.7 \mathrm{~m} \mathrm{(10} \mathrm{to} 22 \mathrm{ft}$ ) to resolve the anomaly. The $70 \% \mathrm{HPGe}$ detector and a longer measurement time of $440 \mathrm{~s}$ were used to enhance the sensitivity. Figure 4.16 shows that a small photopeak corresponding to ${ }^{134} \mathrm{Cs}$ was present at 4.7 and $4.9 \mathrm{~m}(15.5$ and $16 \mathrm{ft})$. However, the photopeak at $604.7 \mathrm{keV}$ could not be adequately resolved from the larger 214Bi photopeak. The ${ }_{134} \mathrm{Cs}$ gamma ray at $795.8 \mathrm{keV}$ was resolvable from a $794.8 \mathrm{keV}$ gamma emitted in the $232 \mathrm{Th}$ decay series. The maximum calculated $134 \mathrm{Cs}$ activity was a very low $0.056 \pm 0.05 \mathrm{pCi} / \mathrm{g}$. The anomaly in well C-1 was also logged with the RLS using the same acquisition parameters used for well G-1. An indication of a ${ }^{134} \mathrm{Cs}$ anomaly was visually identified at a system threshold level of $0.02 \mathrm{pCi} / \mathrm{g}$.

A total of three wells (C-1, E-1, and G-1) showed a minute amount of 134 Cs activity in 1995 . During the injection experiment in 1980 and $1981,{ }^{134} \mathrm{Cs}$ concentrations were provided for these three wells only. As mentioned in Section 2.3, Sisson and Lu (1984) did not indicate if other wells were sampled, and no ${ }^{134} \mathrm{Cs}$ was observed. The 1995 data seem to imply certainly that the highest quantities were in the same wells. Recently, a 1983 set of gross gamma logs for the 32 Sisson and Lu wells was discovered. These logs should be processed with the 1995 data to determine the ${ }^{134 \mathrm{Cs}}$ distribution in 1983. This information could reveal the true lateral and vertical extent of the ${ }^{134} \mathrm{Cs}$ plume and confirm whether the monitoring scheme used during the experiment was sufficient to capture the full ${ }^{134} \mathrm{Cs}$ plume. The 1983 data might present a unique opportunity to test the flow and transport model with a field estimate of the distribution coefficient for ${ }^{134} \mathrm{Cs}$.

An overall observation based on the HNGS data is that geophysical logging was able to locate a 15 -year-old ${ }^{134} \mathrm{Cs}$ plume and verify that the only detectable ${ }^{134} \mathrm{Cs}$ isotope remaining from the 1980 injection was located near the injection point. These findings were not surprising and indicate the value of noninvasive geophysical logging and radioactive tracers in experiments designed to test flow and transport models and to document subsurface flux rates. 


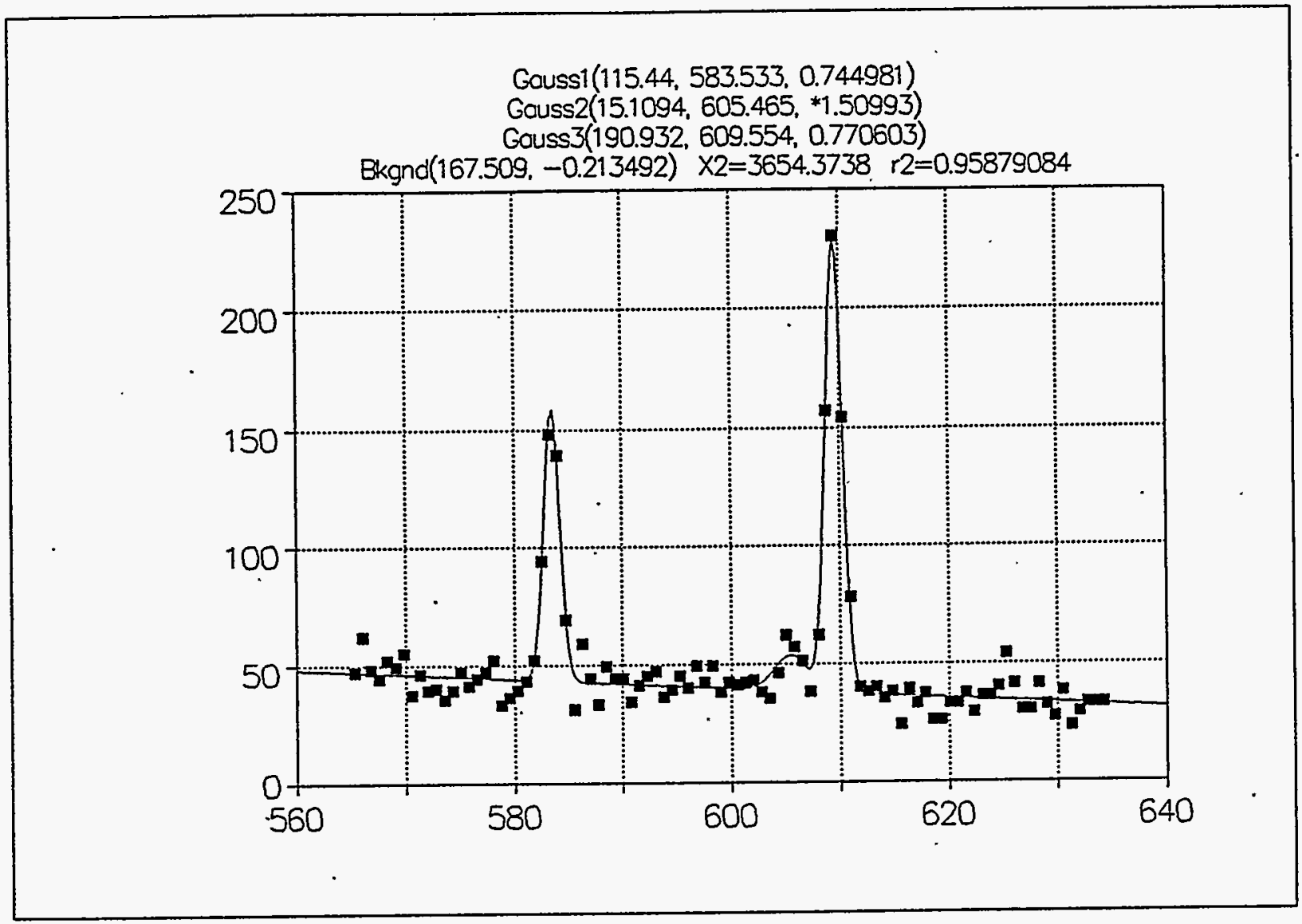

Figure 4.16. Spectral Gamma Data Collected with the RLS System in Well G-1 in 1995 


\subsection{Data Interpretation}

The data collected in 1995 were used to evaluate the 1980 injection experiment. Specific questions that were addressed included how well the neutron probe monitoring accounted for the mass of injected water; whether the sediment stratigraphy had detectable continuity, slope, and aspect; and whether the 1995 findings verify or refute the previous geologic models.

\subsection{Mass Balance Check}

In any experiment, an accurate accounting is required of the mass entering and leaving the experimental domain. Of interest in the injection experiment was whether the monitoring scheme was sufficient spatially and temporally to account for the injected volume of water with some accuracy. A complete accounting through the experiment was not possible because injected water definitely left the monitored domain before the end of the experiment. However, early in the experiment, it appears that the volume of injected water was within the monitored domain, and so a mass balance calculation during early times was considered feasible.

Water contents were calculated using Eq. 3.3, the updated calibration equation for Probe 1. This equation was used because it entailed the least effort and because Probe 1 was the probe used on most of the dates examined below. The equations for the other probes were similar, and we assumed that any differences would be minimal for our comparisons.

The change in the volume of water in the sediments was estimated for the experiment using the technique of Smoot (1995). The water contents determined with the neutron probes were interpolated onto the three-dimensional grid used by Smoot for model simulations. In that grid, the model domain consisted of 9216 cells, each $0.9 \mathrm{~m}$ in the $\mathrm{x}$ and $\mathrm{y}$ directions and $0.5 \mathrm{~m}(1.6 \mathrm{ft})$ in the $\mathrm{z}$ direction, for a total cell volume of $0.405 \mathrm{~m}^{3}(14.3 \mathrm{ft} 3)$. Vertically, the $0.3-\mathrm{m}$ (1-ft)-spaced neutron probe data were interpolated linearly to the cell centers using the two nearest probe data, one above and one below the cell center. Laterally, the cells were assigned according to the layout in Figure 5.1. Because of the cell dimensions, the well data were assigned to nearby cells, thus not preserving the exact lateral well spacing during the interpolation. Water contents were assigned to the remaining cells of the model domain by interpolating from the cells already assigned from the well data; interpolation was accomplished using a cubic spline function.

For any time interval, the change in the water content was multiplied by the cell volume to estimate the change in the volume of water. The total change in water volume over the model domain was just the summation of the changes in the individual cells. The error added by the interpolation scheme was not calculated.

Figure 5.2 shows that the estimated volume of injected water fairly well matched the volume calculated from the injection data. During the main part of the experiment from September 1980 to January 1981, the estimate ranged from $3000 \mathrm{~L}$ less to $4800 \mathrm{~L}$ more ( 795 to 1272 gal) than the injection data. This range is roughly equivalent to the volume of one injection event. In contrast to the earlier estimates, the estimate in July 1981 is about $18,000 \mathrm{~L}$ (4770 gal) higher than expected. On this date, Probe 2 was used in five wells (out of 32). If all wells carried equal weight, the error in using the equation from Probe 1 (rather than Probe 2) should have been no more than about $4500 \mathrm{~L}$ (1193 gal). On that date, the five wells monitored with Probe 2 were on the domain periphery: C-7, D-8, E-7, F-8, and G-7. These wells likely carry more weight in the interpolation scheme, and thus the difference in the probe equations could easily explain the over-estimate. 


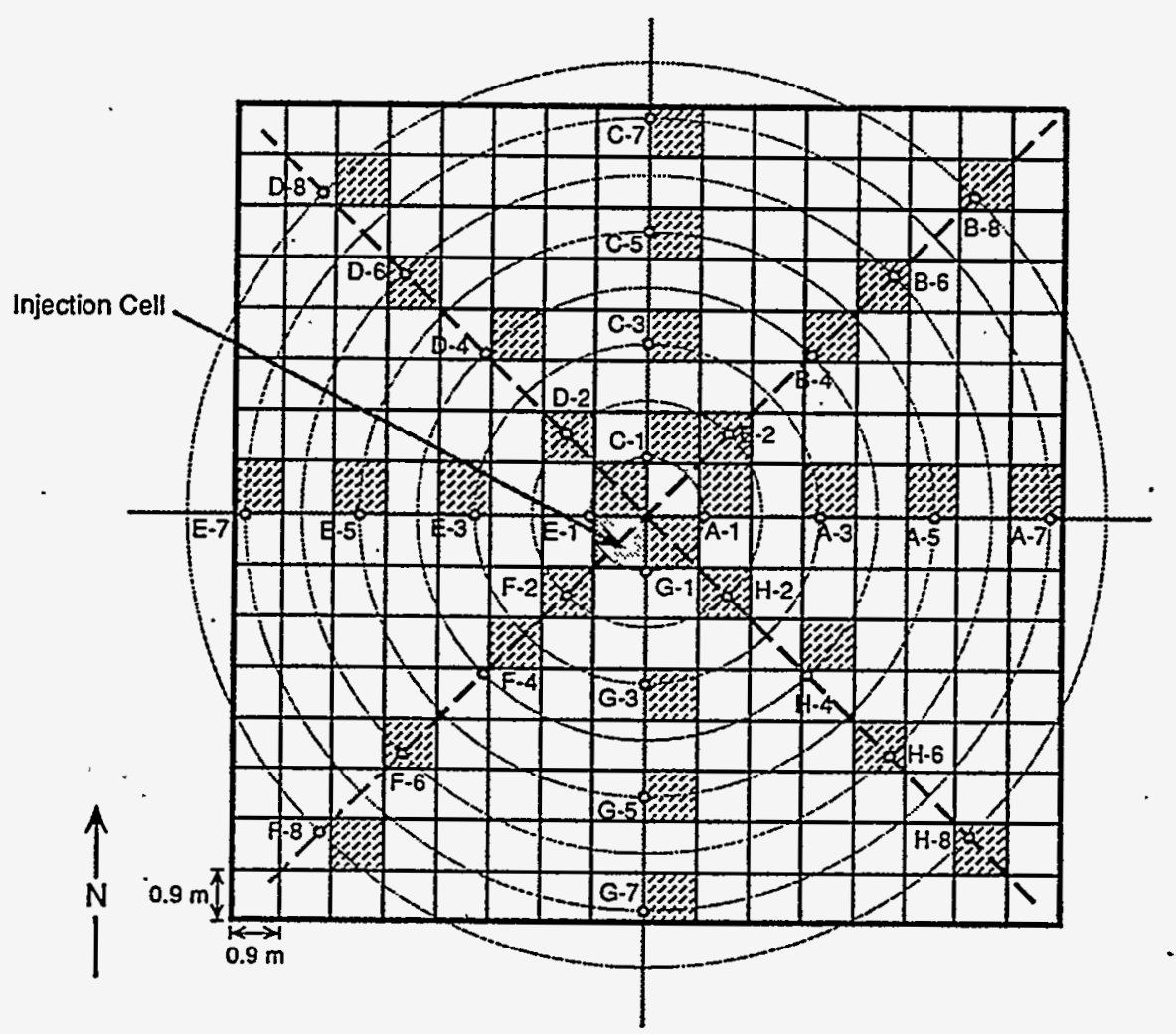

Figure 5.1. Plan View of Model Grid Showing Locations of Wells and Associated Cells

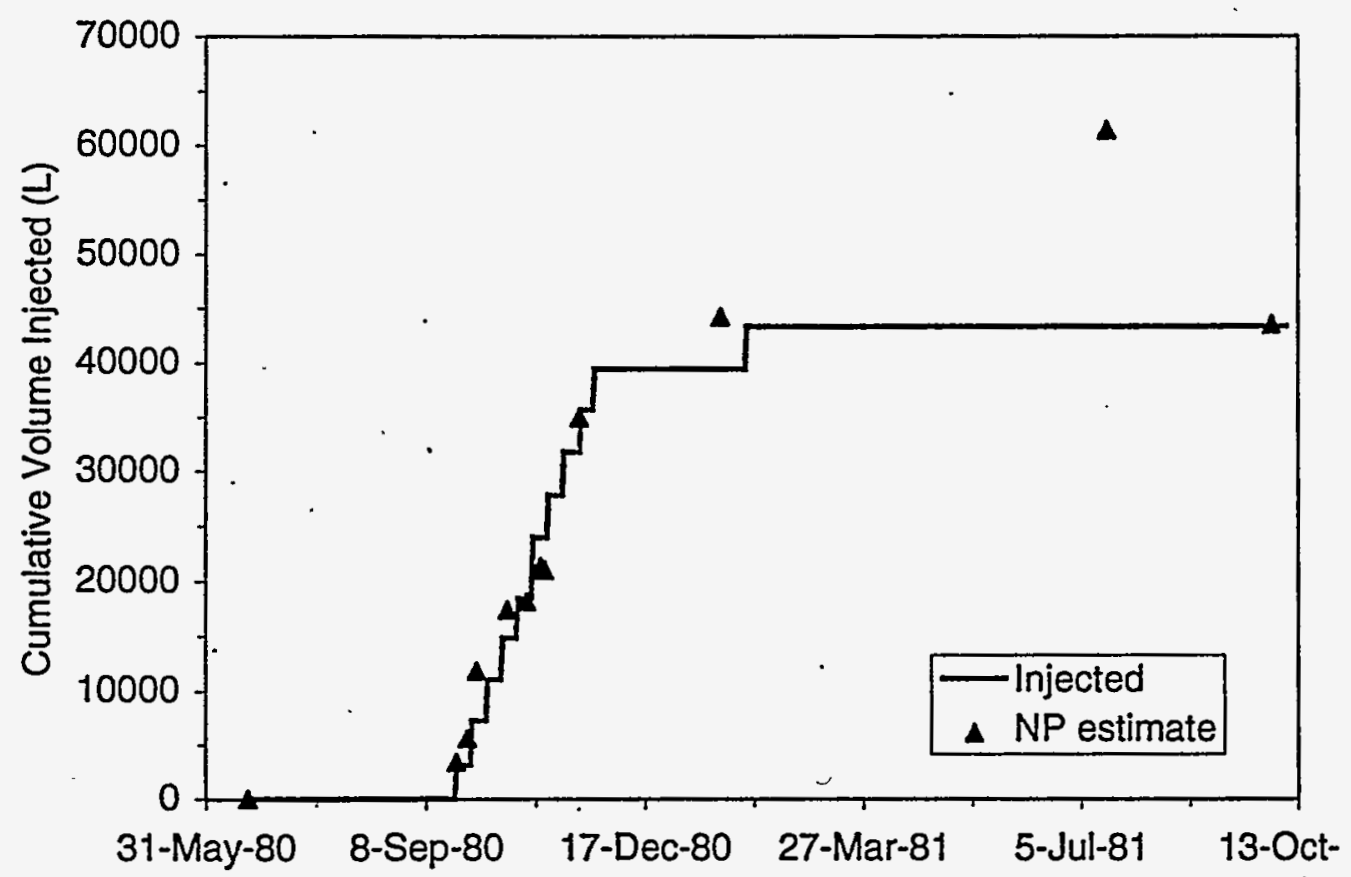

Figure 5.2. Comparison of Injected Volume of Water and the In Situ Increase in Water Content Detected with the Neutron Probe 
From October 15 to November 17, 1980, Probes 2 and 3 were used in some of the wells without significant impact on the comparison in Figure 5.2. However, the wells were mostly interior wells that would have had less influence in the interpolation scheme, and so the impact of using a single calibration equation may have been lessened.

In future analyses, two steps should be taken. First, the modeling grid should be chosen to coincide more closely with the spacing of the monitoring data. Second, probe-specific calibration equations should be used. With the large size of the modeling domain, a small difference in the calibration equation can significantly affect the estimation of the injection volumes.

\subsection{Stratigraphy, Slope, and Aspect}

A wealth of geophysical data were collected from 32 wells in 1995. Analyses of these data have only just begun, so definitive statements relative to the actual lithology and stratigraphy are premature. However, some ideas can be gleaned from the depth profiles of water content and potassium. Figure 5.3 shows distinct layering in the water content profiles. In some cases, the layers are thin [e.g., at $16.5 \mathrm{~m}(54.1 \mathrm{ft})$ ] and in others, thick. Between 12 and $15 \mathrm{~m} \mathrm{(39.4} \mathrm{and} 49.2 \mathrm{ft})$, the water contents indicate a single layer that is quite uniform. The water content range throughout this zone is $<2 \mathrm{vol} \%$. The range of variability appears to be much higher between depths of 10 and $12 \mathrm{~m}$ ( 32.8 and $39.4 \mathrm{ft}$ ), indicating that the layer may be less uniform and possibly dipping and/or discontinuous.

Figure 5.4 shows less layering in the potassium profiles compared to the water content profiles, but there still appears to be some structure that may indicate layering. For example, the drop in potassium at $11 \mathrm{~m}(36 \mathrm{ft}$ ) corresponds with the large peak in water content seen in Figure 5.3. Below $4 \mathrm{~m}(13.1 \mathrm{ft})$, the variability in the range of potassium values appears to remain constant with depth. Above $4 \mathrm{~m}(13.1 \mathrm{ft})$, there is a major decrease in potassium, with a minimum at about the 2-m (6.6-ft) depth that is $40 \%$ less than the average potassium concentration deeper in the profile. This minimum may indicate a major difference in sediment type or the impact of weathering or an ancient soil. Field samples will be needed to determine the reasons for this anomaly and, more importantly, to confirm the more general lithologic interpretations that will eventually emerge from the analyses of these data.

We have begun to analyze the data using three-dimensional visualization software. Figures 5.5, 5.6, and 5.7 show the distribution of water content, bulk density, and gross gamma along the plane that intersects the $A$ and $E$ wells (i.e., the wells aligned east-west). Quite visible in this vertical plane of Figure 5.5 are four zones of high water content. The uppermost zone is indicative of water that infiltrated during the winter (roughly October 1994 to January 1995) and not of a specific lithologic layer. The lower three zones of higher water content are most likely indicative of some lithologic control of water content. The zone at $12 \mathrm{~m}(39.4 \mathrm{ft})$ has both the highest and lowest water contents of the wet zones. This zone very dramatically demonstrates that these layers are not necessarily continuous and may pinch out in some regions.

At a coarse scale, the more clearly defined layers were briefly studied to determine if they had any slope and aspect. Dipping stratigraphic layers could alter the movement of water and tracers and would have to be addressed in simulations of flow and transport during the experiment. Visual inspection of images like those shown in Figures 5.5 to 5.7 did not reveal any significant slope except at the 12-m (39.4-ft) depth, but the scale of the plots may have been too large. There was some suggestion in Section 4.1.1 (Figure 4.4) of slopes as great as $7 \%$ to $11 \%$. A more rigorous measure . of slope can and should be performed using the three-dimensional software. 


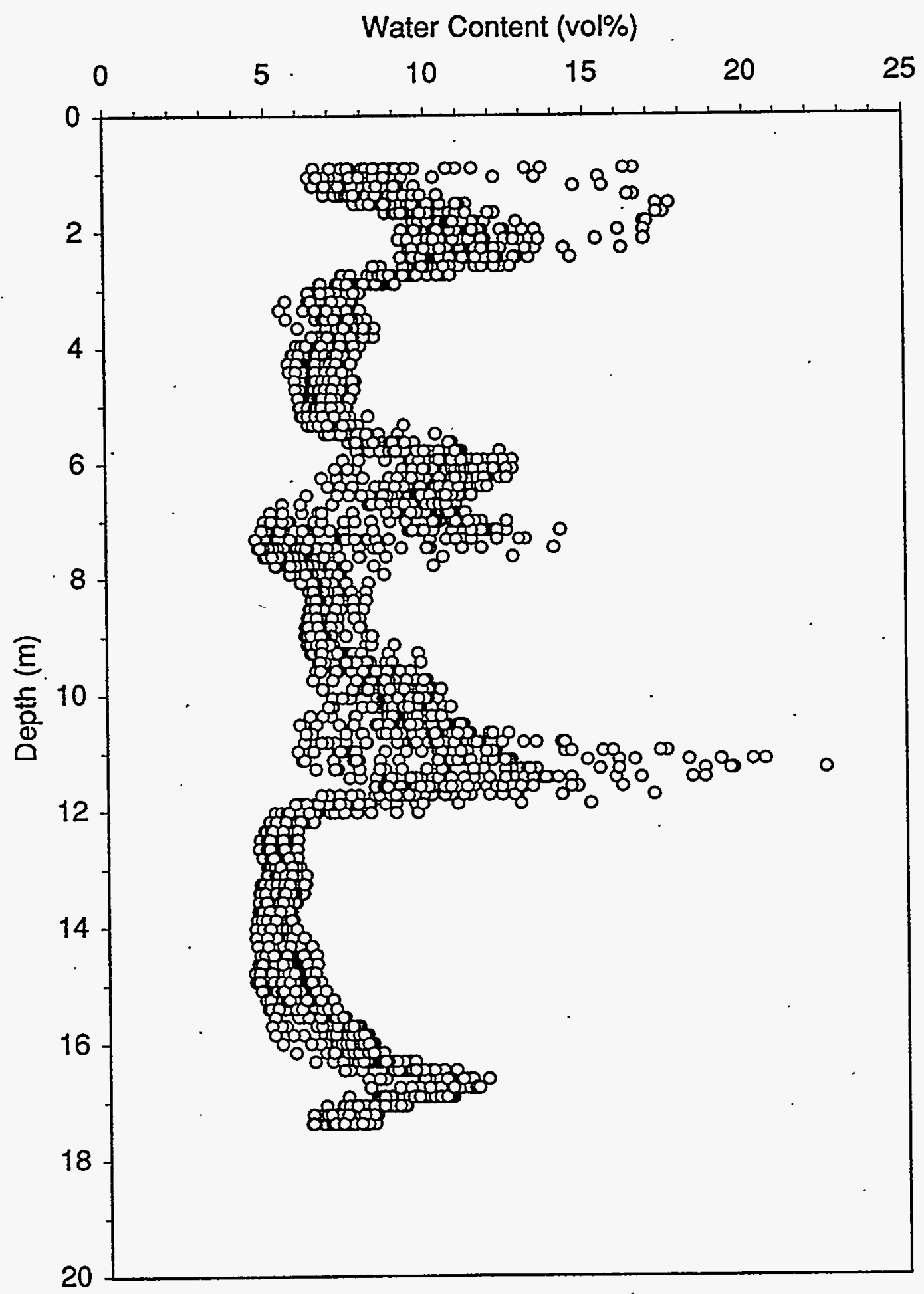

Figure 5.3. Water Content Profiles for all 32 Wells Using the 1995 CNT-G Data Every $15 \mathrm{~cm}$ (6 in.) 


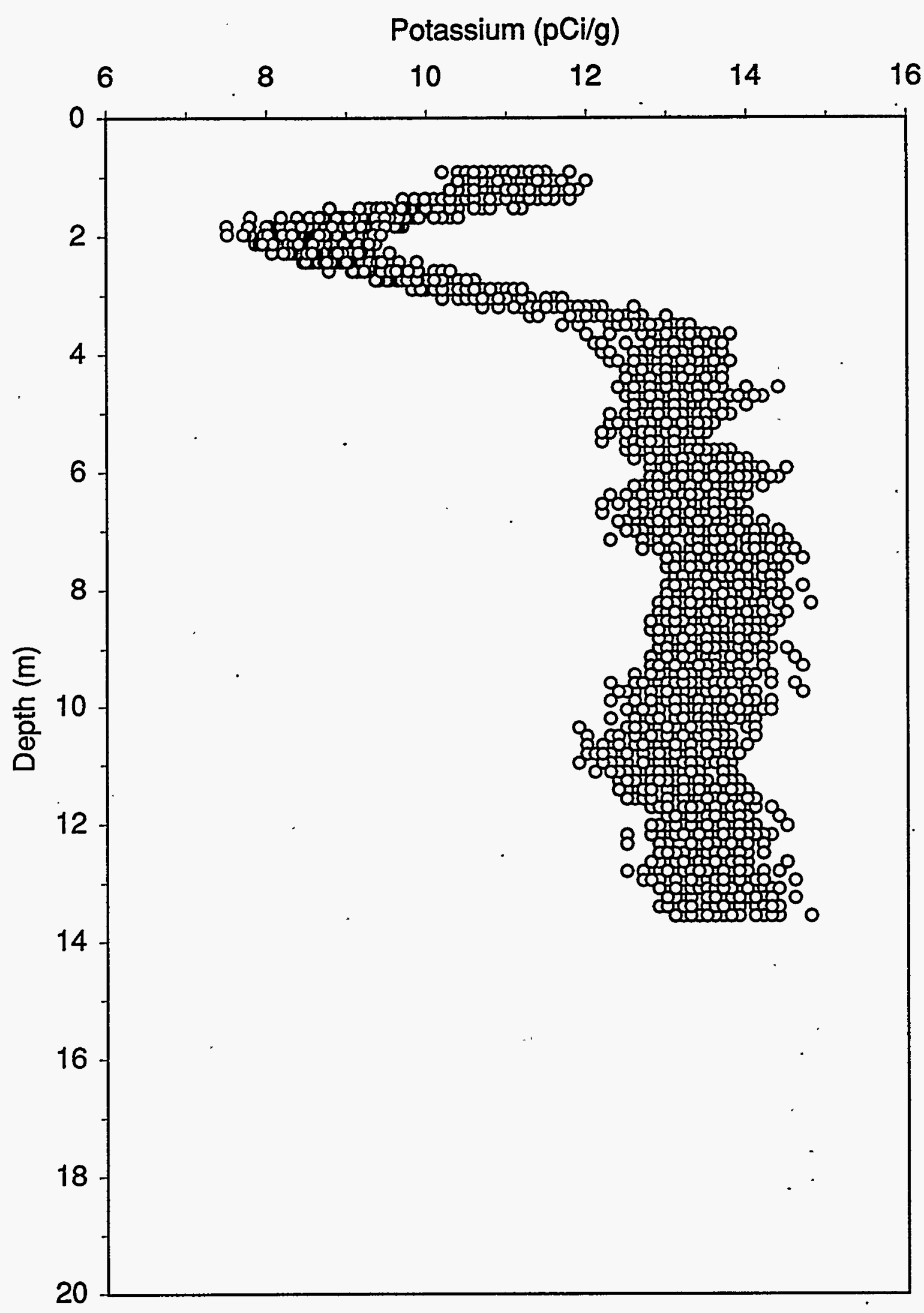

Figure 5.4. Potassium Profiles for all 32 Wells Using the 1995 HNGS Data Every $15 \mathrm{~cm}(6 \mathrm{in}$.) 



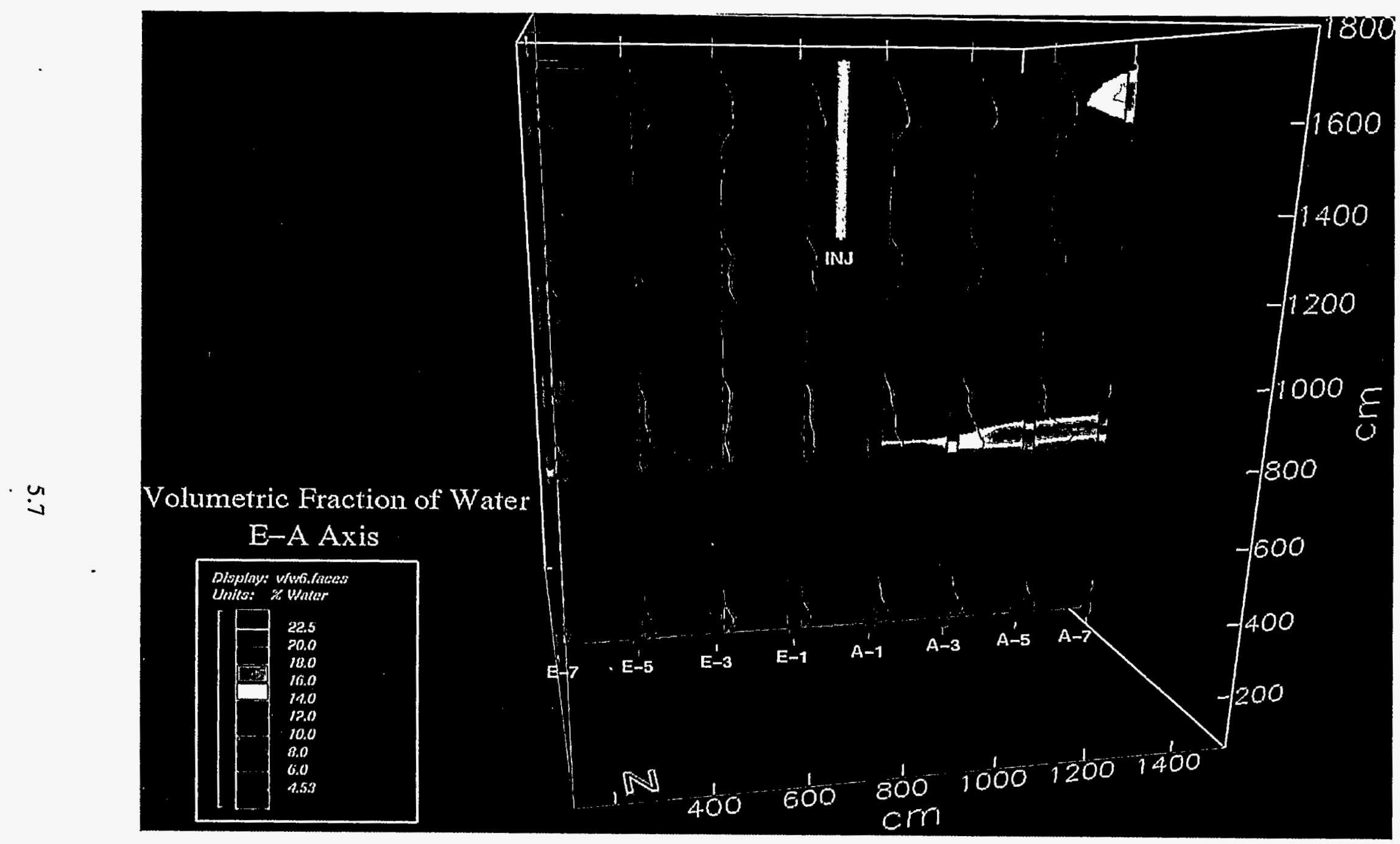

Figure 5.5. Three-Dimensional View of Water Content Using the 1995 CNT-G 15-cm (6-in.) Data Along a Transect Through the A and E Wells (east-west) 


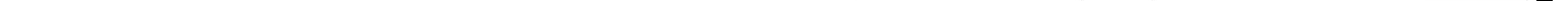




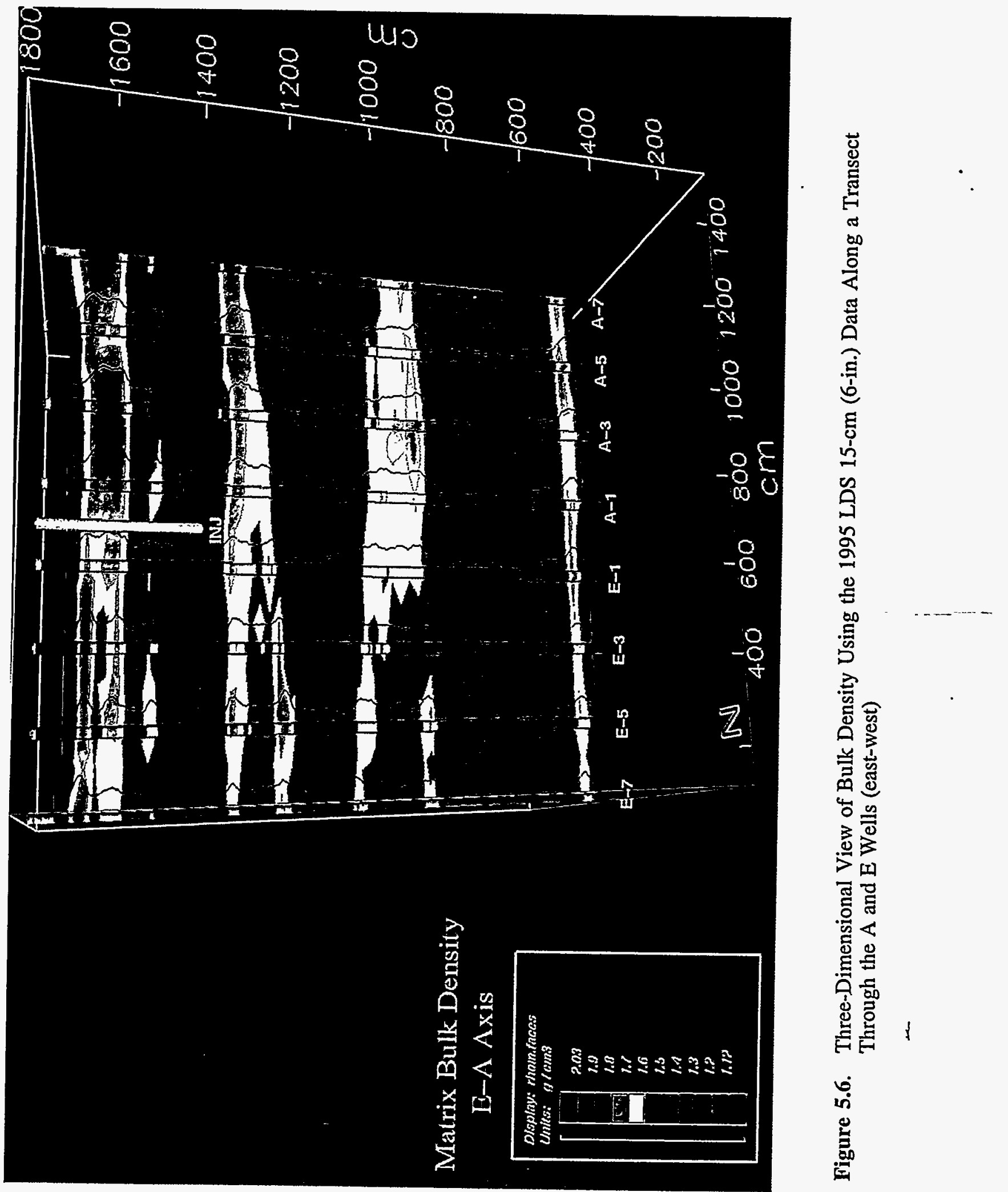




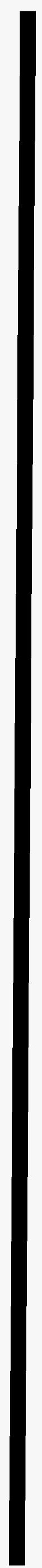




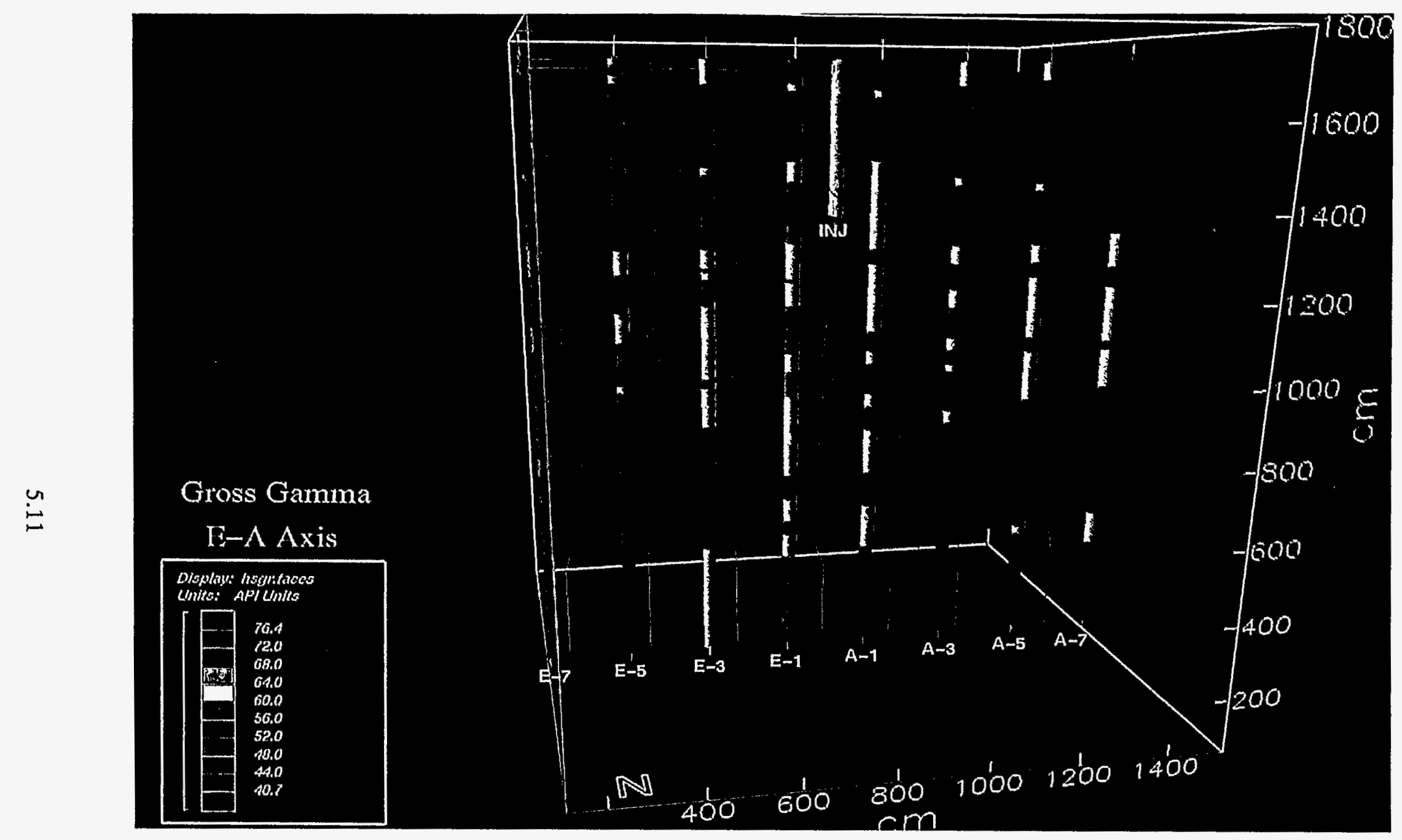

Figure 5.7. Three-Dimensional View of Gross Gamma Using the 1995 HNGS 15-cm (6-in.) Data Along a Transect Through the A and E Wells (east-west) 



\subsection{Findings Relative to Previous Geologic Models}

In the earlier geologic models of this site, the tendency was to use horizontal layers with uniform properties in each layer. These studies attempted to mimic the significant lateral spreading that was observed by incorporating anisotropy ratios. These ratios are an attempt to account for the fine detail (e.g., thin gravel layers) that usually is not represented in the coarse geologic model grids. The ratios were used in past studies to increase the horizontal conductivity by factors ranging from 2 to 8 relative to the vertical conductivity. Only Smoot and $\mathrm{Lu}$ (1994) and Smoot (1995) attempted to incorporate a truly three-dimensional geologic model, and they concluded that spreading was achieved without resorting to the imposition of anisotropy ratios.

The 1995 logging results partly confirmed both types of conceptual models. The logs showed a definite sequence of layers with similar properties across the site. The logs also showed that the properties within the layers were variable, which may also indicate that the depth intervals were not identical across the site. Table 5.1 shows that the distributions of four of the variables measured in 1995 are not similar. For example, the distribution of water content is positively skewed, while the distributions of potassium and total gamma counts are negatively skewed. Similar statistics for subzones or layers should be calculated.

Smoot and Lu (1994) and Smoot (1995) constructed their geologic model using geologic drawings prepared from the driller's logs. For this site, the driller's logs were based on a visual examination of sediment that was blown out of the borehole during the air-rotary drilling operation. The method of constructing geologic logs from driller's logs is common because the driller's logs are usually the only information available for most sites.

Table 5.1. Summary Statistics for all 32 Wells Using the 1995 Geophysical Data

\begin{tabular}{||c|c|c|c|c||}
\hline \hline & $\begin{array}{c}\text { Water Content } \\
(\mathrm{vol} \%)\end{array}$ & $\begin{array}{c}\text { Bulk Density } \\
\left(\mathrm{g} / \mathrm{cm}^{3}\right)\end{array}$ & $\begin{array}{c}\text { Potassium } \\
(\mathrm{wt} \%)\end{array}$ & $\begin{array}{c}\text { Total Gamma } \\
\text { Counts }\end{array}$ \\
\hline $\mathrm{N}$ & 3488 & 3488 & 2688 & 2688 \\
\hline Minimum & 4.53 & 1.21 & 7.50 & 40.70 \\
\hline Maximum & 22.50 & 1.93 & 14.80 & 76.40 \\
\hline Mean & 7.85 & 1.49 & 12.71 & 57.96 \\
\hline Variance & 5.17 & 0.02 & 2.23 & 21.21 \\
\hline Std. Dev. & 2.27 & 0.14 & 1.49 & 4.61 \\
\hline Skewness (G1) & 1.29 & 0.43 & -1.62 & -1.46 \\
\hline C.V. & 0.29 & 0.09 & 0.12 & 0.08 \\
\hline Median & 7.26 & 1.47 & 13.20 & 58.85 \\
\hline
\end{tabular}


In this case, the driller's logs were less valuable because of the mixing inherent in an air rotary operation and the imprecise estimate of the sample depth. Given the potential value of the Sisson and Lu experiment, an improvement of the geologic model is necessary.

The next step should be to take the 1995 geophysical logs and construct a more detailed geologic model for use in flow and transport simulations. Use of borehole geophysical data for this purpose is gaining acceptance. For example, Jorgensen and Petricola (1995) used borehole geophysics to determine geohydrologic properties in the Abu Dhabi Emirate. Murray (1994) described how to use geophysical logs and core data to construct a three-dimensional rock model for use in oil reservoir fluid-flow simulations. For the Sisson and $\mathrm{Lu}$ site, the quantity of data is sufficient to derive detailed horizontal and vertical spatial statistics with which to interpolate the well data to a modeling grid. For example, our preliminary analyses are revealing that the vertical variogram for water content is showing zero nugget and a significant hole effect at $5 \mathrm{~m}(16.4 \mathrm{ft})$. This variogram is better defined relative to the variogram used by Smoot (1995), and it remains to be seen what impact the change in variogram would have on the construction of a geologic model and its impact on flow simulations.

Ultimately, the value of increasingly detailed geologic 'conceptual models can be demonstrated with a series of flow simulations. Four geologic models should be used:

1. The original Sisson and $\mathrm{Lu}(1984)$ model

2. The Lu and Khaleel (1993) model

3. The Smoot and $\mathrm{Lu}(1994)$ and-Smoot (1995) model

4. A geologic model constructed from the 1995 geophysical logging data.

A single flow and transport model should be used to simulate the injection experiment using each of the above geologic conceptual models. A consistent set of statistical measures should be used to demonstrate the performance of the flow model for each geologic case. Only then will it be possible to determine whether increasing detail in the geologic conceptual model leads to an improved model fit and increased confidence in the model results.

The set of data from the Sisson and Lu site is one of most extensive data sets available for testing flow and transport models in the unsaturated zone. The planning, execution, and monitoring of the experiment were time consuming and labor intensive. The scales, roughly $8 \mathrm{~m}(26.2 \mathrm{ft}) \mathrm{from}$ the injection point and 15 years in duration, were much larger than laboratory tests and approach the scale of disposal facilities. Repeating this type of experiment at the same or larger scales would be very expensive. For disposal decisions that are being made now or in the near future, such an experiment may have little value because of the delay in learning the final results.

The potential of the Sisson and Lu data set for demonstrating model confidence has not yet been realized. Until it is, the best course of action is to exhaust the probative value of the experiment before proposing additional tests. The exceptions to this recommendation are those tests designed with objectives for which it is known the Sisson. and Lu experiment cannot address. 


\subsection{Conclusions}

A tremendous quantity of data were collected in 1995 at the Sisson and Lu injection site. Although the analysis of the data is incomplete, many conclusions have been drawn relative to the main objectives of this task, which were to 1) document the 1995 monitoring data, 2) interpret the water content and tracer data, and 3) recommend the appropriate course of action to complete this model testing task. The conclusions are presented below, along with recommendations for completing the analyses.

\subsection{Document Monitoring Data}

The first objective was to document the monitoring data. These data are described in the Appendixes and are available upon request. From the data, new calibration equations along with error estimates were calculated for all three neutron probes used during the experiment. The revised equations were significantly different from the original calibration equation, thereby affecting calculations from some past studies. Error estimates for the calibration equations are now available for the first time. For Probe 1 (the most frequently used probe), the estimated error in water content for the 15 -s readings in 1980 was 3.2 vol\%. The error in water content caused by probe positioning (i.e., centered versus eccentered) was estimated to be no more than $2.2 \mathrm{vol} \%$, somewhat less than the error in the calibration equations.

Neutron probe coverage of all wells at all depths and times did not occur. In future experiments, prior to each injection, the entire set of wells should be logged to serve as a baseline. Also, before, during, and after the experiment, all of the probes should be run in several wells for field verification.

The temporal spread of neutron probe measurements makes it difficult to analyze the experiment during and immediately after an injection when fluxes were highest, because essentially all measurements were taken at unique rather than uniform times. However, this may not be the most important time to analyze; performance assessment analyses are more concerned with what happens over many years rather than hours. Measurements several days after an injection could likely be treated as simultaneous occurrences because fluxes would have subsided, making changes during the measurement undetectable. Future experiments should focus the monitoring activity less on the actual injection and more on the long-term movement of the injected water and tracers.

In summarizing the tracer data, it was noted that the tracer profiles appeared incomplete because not all depths or wells were scanned. It is difficult to know where the tracers migrated given the data. A complete set of total gamma logs for these wells in 1983 was discovered. These logs should be digitized and processed with the total gamma emissions in 1995 to estimate the ${ }^{134} \mathrm{Cs}$ distribution in 1983. This information could be used to clarify whether the original tracer scans covered the entire ${ }^{134} \mathrm{Cs}$ plume or were incomplete.

A final source of error is the spatial location of the measurements. As analysts strive to discern details at $15 \mathrm{~cm}(6 \mathrm{in}$.) or shorter spacings, knowledge of the actual depth location of each measurement will be critical. For example, the cables on the neutron probes are known to stretch and the depth markers to shift. The centers of measurement for different geophysical tools can yield measurement discrepancies (e.g., see Section 4.2). Most of the 1995 logging was in reference to the tops of the casings. These casings should be surveyed to eliminate elevation differences during the data analyses. It is unclear what elevation reference was used during the 1980 experiment. In 
particular, the injection well location was referenced to the soil surface, but the well was removed after the experiment and the soil surface subsequently disturbed. Finally, well emplacement does not guarantee vertical insertion. With a 2-m $(2.5-\mathrm{ft})$ horizontal spacing and $18-\mathrm{m}(59-\mathrm{ft}) \mathrm{depth}$, the spacing at the well bottoms may differ from the spacing at the top. Also, three sample wells drilled subsequent to the experiment are close to several monitoring wells. If this site is considered for reuse, the eccentricity of the well placement should be estimated.

\subsection{Interpret Water and Tracer Data}

The second objective was to interpret the data relative to the mass of injected water, the original geologic conceptual model, and the predicted movement of water and ${ }^{134} \mathrm{Cs}$. A calculation of the volume of water in the domain during the experiment showed that the neutron probe data could track the injected volume within an amount roughly equivalent to one injection volume. This exercise also revealed that the calibration equation for each probe, rather than an average equation, should be used. It also revealed that data from the outer wells tended to carry more weight in the interpolation scheme.

Geophysical logging. data indicated that the injected $85 \mathrm{Sr}$ was not detected and the ${ }^{134} \mathrm{Cs}$ was barely detectable in three wells located less than $2 \cdot \mathrm{m}(6.6 \mathrm{ft})$ from the injection point. Given the 15 -year interval, the ${ }^{85 \mathrm{Sr}}$ had decayed to $<<0.01 \%$ of the original amount, while the ${ }^{134} \mathrm{Cs}$ had decayed to a little less than $1 \%$ of the original amount. The fact that ${ }^{134} \mathrm{Cs}$ was detected after 15 years only near the injection point is an indication of the high sorption potential of $134 \mathrm{Cs}$. The radioactive tracers were shown to be viable for in situ (nondestructive) measurements. These and similar tracers should be considered for use in future experiments. Because of the time needed to measure the tracers at a given depth, the experimental design should focus less on the actual injection and more on the subsequent long-term movement of the injected water and tracers, as was recommended earlier.

The geophysical data are undergoing analyses. To date, the results show strong horizontal features (i.e., layers) that aren't always truly horizontal, continuous, or of constant thickness. This variability is consistent with the attempts by Smoot and $\mathrm{Lu}$ (1994) and Smoot (1995) to incorporate three-dimensional features in their geologic model.

Tracer profiles constructed from 1980 data show steep vertical concentration gradients, sometimes with significant concentration differences over $0.15 \mathrm{~m}$ (6 in.). The short spacing of these differences implies that the detail of the geologic model may be important at a similar scale. Furthermore, the observation of steep concentration gradients indicates a need for more detail in the modeling grid. To date, the finest model detail has been a $0.5-\mathrm{m}(1.6-\mathrm{ft})$ vertical spacing. The 1995 geophysical data were collected at vertical spacings ranging from 0.025 to $0.15 \mathrm{~m}$ ( 1 to $6 \mathrm{in}$.). As these data are analyzed, similarly detailed geologic conceptual models can be generated and tested.

Some of the geophysical data can be used to infer the lithology of the sediments, but eventually better baseline data will be needed on sediment properties (e.g., grain size distribution, mineralogy, porosity, conductivity). A field sampling effort should be undertaken to collect sediment samples to verify the resulting lithologic model and to calibrate the geophysical logging tools. This sampling effort could be coordinated with the tracer task to optimize the investment in field sampling activities. 


\subsection{Recommendations}

The third objective was to determine the fruitfulness of continuing studies at the injection site, proposing studies at one or more new sites, or ceasing testing altogether. Based on the preliminary analyses, much remains to be learned from the Sisson and Lu experiment. Steps outlined earlier include these: 1) construct a geologic model that is consistent with the 1995 geophysical data, 2) define a modelling grid that is aligned well with the spatial orientation of the monitoring data, 3) determine measures of model goodness-of-fit, 4) use a flow and transport model to simulate the injection experiment using the multiple geologic conceptual models proposed during the past 15 years, 5) demonstrate the quantitative capability of the flow and transport model to reproduce the injection experiment, and 6) evaluate the benefits derived from using the progressively more detailed, expensive, and computationally intensive geologic models.

Until these recommendations are.acted upon, it is premature to decide the need for additional experiments at the same site or experiments at new sites, or if testing should cease altogether. 



\subsection{References}

Alloway, B. J. 1990. Heavy metals in soil. John Wiley and Sons, Inc., New York.

Bjornstad, B. N. 1980. Sedimentology and depositional environment of the Touchet Beds, Walla Walla Valley, South-Central Washington. M.S. Thesis, Eastern Washington University, Cheney, Washington.

Bjornstad, B. N. 1990. Geohydrology of the 218-W-5 burial ground. PNL-7336, Pacific Northwest Laboratory, Richland, Washington.

Bredehoeft, J. D. and L. F. Konikow. 1993. "Ground-water models: Validate or invalidate." - Ground Water 31:178-179.

Bredehoeft, J. D. and P. Hall. 1995. “Ground-water models." Ground Water 33:530-531.

CPN (Campbell Pacific Nuclear). 1984. 503 DR hydroprobe operating manual. Campbell Pacific Nuclear Corporation, Martinez, California.

DOE (see U.S. DOE)

Ellis, D. V. 1987. Well logging for earth scientists. Elsevier, New York.

Ellis, D. V., R. A. Perchonok, H. D. Scott, and C. Stoller. 1995. "Adapting wireline logging tools for environmental logging applications." Paper $\mathrm{X}$ in 36th annual logging symposium, transactions of the Society of Professional Well Log Analysts, Paris, France.

Engelman, R. E., R. E. Lewis, D. C. Stromsiwold, and J. R. Hearst. 1995. Calibration models for measuring moisture in unsaturated formations by neutron logging. PNL-10801, Pacific Northwest Laboratory, Richland, Washington.

Fayer, M. J., J. B. Sisson, W. A. Jordan, A. H. Lu, and P. R. Heller. 1993. Subsurface injection of radioactive tracers. PNL-8499, Pacific Northwest Laboratory, Richland, Washington.

Flanagan, W. D., R. L. Bramblett, J. E. Galford, R. C. Hertzog, R. E. Plasek, and J. R. Olsen. 1991. "A new generation nuclear logging service." Paper $\mathrm{Y}$ in 32nd annual logging symposium, transactions of the Society of Professional Well Log Analysts, Midland, Texas.

Goodspeed, M. J. 1981. "Neutron moisture meter theory." In Soil water assessment by the neutron method, E. L. Greacen (ed.), pp. 16-23, CSIRO Australia.

Greacen, E. L., R. L. Correll, R. B. Cunningham, G. G. Johns, and K. D. Nicolls. 1981.

"Calibration." In Soil water assessment by the neutron method, E. L. Greacen (ed.), pp. 50-81, CSIRO Australia.

Hajek, B. F. 1966. Soil survey Hanford project in Benton County Washington. BNWL-243, Pacific Northwest Laboratory, Richland, Washington. 
Hearst, J. R. and R. C. Carlson. 1994. "A comparison of the moisture gauge and the neutron log in air-filled holes." Nuclear Geophysics 8:165-172.

Hearst, J. R. and P. H. Nelson. 1985. Well logging for physical properties. McGraw-Hill, New York.

Hoitink, D. J. and K. W. Burk. 1994. Climatological data summary 1993 with historical data.

PNL-9809, Pacific Northwest Laboratory, Richland, Washington.

Jorgensen, D. G. and M. Petricola. 1995: "Research borehole-geophysical logging in determining geohydrologic properties." Ground Water 33:589-596.

Kaplan, D. I., R. J. Serne, and M. G. Piepho. 1995. Geochemical factors affecting radionuclide transport through near and far fields at a low-level waste disposal site. PNL-10379, Pacific Northwest Laboratory, Richland, Washington.

Khaleel, R. 1993. Vadose zone modeling workshop proceedings, March 29-30, 1993. R. Khaleel (ed.), WHC-MR-0420, Westinghouse Hanford Company, Richland, Washington.

Koizumi, C. J., J. K. Brodeur, W. H. Ulbricht, and R. K. Price. 1991. Calibration of the RLS HPGE spectral gamma ray logging system. WHC-EP-0464, Westinghouse Hanford Company, Richland, Washington:

Koizumi, C. J., R. K. Price, and R. D. Wilson. 1992. Calibration of the RLS HPGE system for 200 Area management study screening measurements. WHC-SD-EN-TRP-001, Westinghouse Hanford Company, Richland, Washington.

Koizumi, C. J., J. R. Brodeur, R. K. Price, J. E. Meisner, and D. C. Stromswold. 1994. "Highresolution gamma-ray logging for contaminant assessment." Nuclear Geophysics, 8(2):149-164.

Lu, A. H., and R. Khaleel. 1993. "Calibration/validation of VAM3D model using injection test data at Hanford." In Vadose zone modeling workshop proceedings, March 29-30, 1993, R. Khaleel (ed.), pp. 99-111, WHC-MR-0420, Westinghouse Hanford Company, Richland, Washington.

Mills, W. R., D. C. Stromswold, and L. S. Allen. 1988. "Pulsed neutron porosity logging based on epithermal neutron die-away." Nuclear Geophysics 2(2):81-93.

Murray, C. J. 1994. "Identification and 3-d modeling of petrophysical rock types." In Stochastic modeling and geostatistics, J. M. Yarus and R. L. Chambers (eds.), pp. 323-337, AAPG Computer Applications in Geology, No. 3. American Association of Petroleum Geologists, Tulsa, Oklahoma.

Schlumberger. 1989a. Log interpretation principles/applications. Schlumberger Educational Services, Houston, Texas.

Schlumberger. 1989b. Cased hole log interpretation principles/applications. Schlumberger Educational Services, Houston, Texas.

Schlumberger. 1991. Log interpretation charts: Schlumberger Educational Services, Houston, Texas. 
Scott, H. D., P. D. Wraight, J. L. Thornton, J. R. Olesen, R. C. Hertzog, D. C. McKeon, T. DasGupta, and I. J. Albertin. 1994. "Response of a multidetector pulsed neutron porosity tool." Paper J in 35th annual logging symposium, transactions of the Society of Professional Well Log Analysts, Tulsa, Oklahoma.

Serne, R. J. and M. I. Wood. 1990. Hanford waste-form release and sediment interaction: A status report with rationale and recommendations for additional studies. PNL-7297, Pacific Northwest Laboratory, Richland, Washington.

Shord, A. L. 1995. Tank waste remediation system complex site evaluation report.

WHC-SD-WM-SE-021, Rev. 0, Westinghouse Hanford Company, Richland, Washington.

Sisson, J. B. and A. H. Lu. 1984. Field calibration of computer models for application to buried liquid discharges: A status report. RHO-ST-46 P, Rockwell Hanford Operations, Richland, Washington.

Smoot, J. L. and A. H. Lu. 1994. "Interpretation and modeling of a subsurface injection test, 200 East Area, Hanford, Washington." In Proceedings of the thirty-third Hanford symposium on health and the environment: In situ remediation: Scientific basis for current and future technologies, G. W. Gee and N. R. Wing (eds.), pp. 1195-1213, Battelle Press, Columbus, Ohio.

Smoot, J. L. 1995. Development of a geostatistical accuracy assessment approach for modeling water content in unsaturated lithologic units. Ph.D. Dissertation, pp. 329, University of Idaho, Moscow, Idaho.

Steele, W. D. and D. C. George. 1986. Field calibration facilities for environmental measurement of radium, thorium and potassium. DOE Report No. GJ/TMC-01 (Second Edition), U.S. DOE Grand Junction Projects Office, Grand Junction, Colorado.

Tittman,'J. 1987. "Geophysical well logging." In Methods of experimental physics: Geophysics part $B$, field measurements. CG Sammis and TL Henyey (eds.), 24:441-615, Academic Press, New York.

U.S. DOE (Department of Energy). 1988. "Radioactive waste management." DOE Order 5820.2A.

U.S. DOE. 1991. Groundwater model development plan in support of risk assessment. DOE/RL-91-62, Decisional Draft, U.S. Department of Energy, Richland, Washington.

Williams, J., J. W. Holmes, B. G. Williams, and R. E. Winkworth. 1981. "Application in agriculture, forestry and environmental science." In Soil water assessment by the neutron method, E. L. Greacen (ed.), pp. 3-15, CSIRO Australia.

Wilson, R. D. 1981. Fundamentals of gamma-ray logging. Gamma-Ray Logging Workshop, Grand Junction, Colorado. 


\section{Appendix A}

\section{Neutron Probe Data}




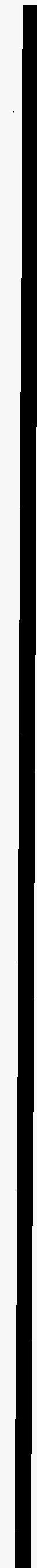




\section{Appendix A}

\section{Neutron Probe Data}

\section{A.1 Introduction}

A field injection experiment was performed in 1980 and 1981 to test the limits of model predictions of the movement of radioactive contaminants in the sediments beneath disposal facilities. The site of the injection test was roughly $305 \mathrm{~m}(1000 \mathrm{ft})$ west-southwest of the PUREX plant in the 200 East Area of the Hanford Site. The site consisted of 32 observation wells (see Figure 2.2) com-

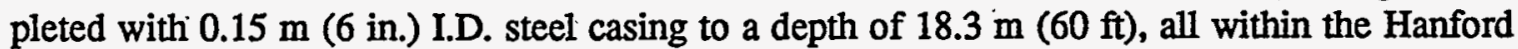
formation (unconsolidated fluvial sands with minor amounts of gravel). A full description of the experiment can be found in Sisson and Lu (1984) and Fayer et al. (1993).

Three Campbell-Pacific Nuclear (CPN) neutron probes were used to monitor the moisture in the formation surrounding the observation wells before, during, and after the injections. Fayer et al. (1993) expressed some concern about the calibration of these probes. In addition, the probes were less than $5 \mathrm{~cm}(2 \mathrm{in}$.) diameter, much smaller than the $15 \mathrm{~cm}(6 \mathrm{in}$.) diameter well casings. Varying amounts of air gap between the probes and the well casings may have introduced an uncertainty in the measured moisture content of the surrounding formation.

Schlumberger Well Services logged all 32 wells with a Compensated Neutron Logging Tool (CNT-G) in January 1995. This tool was calibrated at the Hanford Moisture Calibration Facility in August 1994 (Engelman et al. 1995). These data provided accurate moisture profiles for all 32 wells at the site.

\section{A.2 Purpose}

The purpose of this task was to evaluate the accuracy of the CPN probes to measure moisture. A secondary objective was to determine the degree of error that may have been introduced by the varying amounts of air gap between the well casing and the probe. Four wells were chosen for the study based on the volume fraction of water determined from the Schlumberger CNT-G logs. Measurements were then made in each of the four wells with four different moisture probes. The moisture probes were then calibrated at the Hanford Moisture Calibration Facility.

\section{A.3 Moisture Probe Description}

Four CPN moisture probes were used to measure water contents at the site. Two of the probes (D79102971 and H38092510) were used during the injection experiment in 1980. The other two probes were used by other projects at the Hanford Site.

Two of the probes (D72024328 and D79102971) were CPN 501 Depthprobes; D79102971 was Probe 2 in the Sisson and $\mathrm{Lu}(1984)$ report. These probes contained $50 \mathrm{mCi}$ of $241 \mathrm{AmBe}$ as a neutron source and $10 \mathrm{mCi}$ of ${ }^{137 \mathrm{Cs}}$ as a gamma-ray source (which was not used for this test or the injection experiment). The probe measures moisture by the neutron moderation technique: fast neutrons are emitted from the neutron source, they are slowed down by collisions with hydrogen, and the slowed "thermal" neutrons are then counted by the detector. The more neutrons that are

\section{A. 1}


counted by the detector the more hydrogen $\left(\mathrm{H}_{2} \mathrm{O}\right)$ in the formation. The heads for both of these probes could only display the total count for set time periods of $15,30,60$, or $120 \mathrm{~s}$. The counting time for all measurements made with these two probes was $60 \mathrm{~s}$. Each probe was $4.76 \mathrm{~cm}$ (1.875 in.) in diameter and $53.3 \mathrm{~cm}$ (21 in.) long. The moisture measurement point was located about $30 \mathrm{~cm}$ $(1 \mathrm{ft})$ above the bottom of the probe $(22.9 \mathrm{~cm}$ above the density measuring point). Both probes seemed to function properly although D72024328 made a "humming" sound which may have been from the high voltage components.

The third probe (H38092510) was a CPN 503 Hydroprobe; this was Probe 1 in the Sisson and $\mathrm{Lu}$ (1984) report. This probe contained just the $50 \mathrm{mCi}{ }^{241} \mathrm{AmBe}$ source to measure moisture. Moisture was measured by the same neutron moderation technique described above. Because the liquid crystal display on the head of this probe was damaged, the head from the fourth hydroprobe described below was used. This head was a direct reading head with many more functions than the two described above. The counting time was set to $64 \mathrm{~s}$ for all measurements, but this head normalized all readings to $16 \mathrm{~s}$. Only the total counts were recorded. The probe itself was $3.81 \mathrm{~cm}$ $(1.5 \mathrm{in}$.) in diameter and $30 \mathrm{~cm}$ (12 in.) long. The measurement point was located $7.62 \mathrm{~cm}(3 \mathrm{in}$.) above the bottom of the probes. The probe used an older $\mathrm{BF}_{3}$ (boron tri-fluoride) detector tube, which required a warm-up period. Some of the standard counts did not pass because the probe was not allowed to warm up. This did not seem to affect the field measurements because the probe reached its operating temperature during the standard counts taken before the field measurements.

The fourth probe (H33115140) was a CPN 503 DR Hydroprobe. It was nearly the same as the other hydroprobe, except that it used a direct reading head (also used on H33115140), had a newer detector (no warm-period), and was $4.76 \mathrm{~cm}$ (1.875 in.) diameter. The counting time was set to $64 \mathrm{~s}$, but again the head normalized all readings to $16 \mathrm{~s}$. This probe is currently being used by the Barriers Project.

\section{A.4 Subsurface Moisture Measurements}

Four wells at the Sisson and $\mathrm{Lu}$ Site were logged with the four probes between February 7 and February 16, 1995. The wells were A-7 (E24-79), E-7 (E24-95), H-4 (E24-105), and H-6 (E24-106). Measurements were made at 0.3-m (1-ft) intervals between $18 \mathrm{~m}(60 \mathrm{ft})$ and the surface.

Each probe was run in each well twice, once with the probe centralized and once with the probe eccentralized (i.e., pressed against the side of the casing). The centralizing device consisted of metal straps attached to two hose clamps fastened to the upper portion of the probe. The hose clamps were positioned so that the metal straps bowed out to the inside diameter of the well casing. The eccentralizing device consisted of one metal strap attached to two hose clamps fastened to the upper portion of the probe. The hose clamps were positioned so that the metal strap pushed the probe up against the side of the casing. No attempt was made to control which side of the well the probe was pressed against.

Standard counts were performed for each probe at the beginning and end of each day they were used. Each standard count was performed with the probes positioned on their cases. Depending on the probe, ten 60 or $64 \mathrm{~s}$ counts were taken. The average of the ten counts and the square root of the average were calculated and used to define acceptable limits within which a certain number of individual counts must fall. If 7 or more of the 10 counts were within these limits, the probe was considered functional. Due to time constraints, the probes were run even if the probes failed their standard count tests. During these times, the failure of the standard count appeared related to the first few readings taken during the warmup time rather than to a probe problem. 


\section{A.5 Moisture Calibration Measurements}

All four probes were run in three moisture calibration models at the Hanford Moisture Calibration Facility in Pasco, Washington, on February 17, 1995. Professional Ag Services was contracted to operate the probes at the Calibration Facility because PNL did not have a license to use radioactive materials off the Hanford Site.

The three models used (F, E, and G) represented water contents of 5,12 , and 20 vol\%, respectively. Each of the models utilized 15-cm (6-in.) diameter casing (the same as the wells at the Sisson and Lu Site).

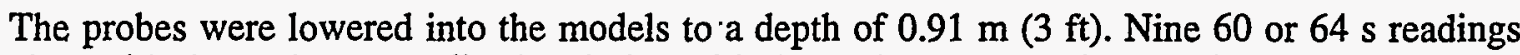
were taken with the probes centralized and nine with the probes eccentralized against the north side of the casing. The spacers used in the field were not used in the calibration standards. In this case, the probes were centralized by holding the cable in the center of the casing at the top of the model and eccentralized by holding the cable against the north side of the case. The probes' positions were confirmed visually.

Standard counts were performed for each probe prior to recording in the first model, between models, and after the last model. These standard counts were all performed in one central location at the facility. The same procedure was used as described above to perform these tests.

\section{A.6 Datá Files}

The complete set of data files is available on request. The data files contain all of the unprocessed data from the field and the calibration facility. The data files are in Macintosh Excel format in subdirectory NP_DATA. The files are described below.

DAT MODEL - This file contains the neutron probe counts in the moisture models.

DAT FIELD - This file contains the neutron probe counts in the four wells at the injection site.

STD FIELD - This subdirectory contains 10 files that contain the standard counts collected during the field monitoring of four wells at the injection site.

STD PASCO - This subdirectory contains 8 files that contain the standard counts collected during the calibration in the moisture models in Pasco, Washington.

\section{A.7 Impact of a Centered Probe}

The impact of centering the probe was evaluated in the moisture models. Table A.1 shows that the correlation between centered and eccentered positions was high $(>0.98)$ for all four probes. The correlations were not exactly 1 to 1 , indicating that a calibration equation derived for one probe position would introduce some error when applied to another probe position. However, this error is much lower than the standard error of the calibration.

The impact of centering the probe was also evaluated in the field. The correlation between centered and eccentered positions was strong $(>0.91)$, but not as high as in the moisture models. This result was expected because of the vertical variability in the field. If water contents also varied horizontally at a given depth, the eccentered probe position might present another source of variability 0 
Table A.1. Correlation of Neutron Probe Counts Between Centered and Eccentered Probe Positions in the Moisture Models

\begin{tabular}{||c|c|c|c|c||}
\hline $\begin{array}{c}\text { Probe Serial } \\
\text { Number }\end{array}$ & Slope & Intercept & $\begin{array}{c}\text { Standard Error in } \\
\text { Centered Probe } \\
\text { Count }\end{array}$ & $\mathrm{r}^{2}$ \\
\hline $\mathrm{D} 72024328$ & 0.990 & 37 & 67 & 0.985 \\
\hline $\mathrm{D} 79102971$ & 0.971 & 134 & 91 & 0.995 \\
\hline $\mathrm{H} 33115140$ & 0.956 & 138 & 49 & 0.998 \\
\hline $\mathrm{H} 38092510$ & 0.937 & 45 & 43 & 0.985 \\
\hline
\end{tabular}

Table A.2. Correlation of Neutron Probe Counts Between Centered and Eccentered Probe Positions in Four Wells at the Injection Site

\begin{tabular}{|c|c|c|c|c||}
\hline $\begin{array}{c}\text { Probe Serial } \\
\text { Number }\end{array}$ & Slope & Intercept & $\begin{array}{c}\text { Standard Error in } \\
\text { Centered Probe } \\
\text { Count }\end{array}$ & $\mathrm{r}^{2}$ \\
\hline D72024328 & 0.897 & 105 & 63 & 0.940 \\
\hline D79102971 & 0.959 & 116 & 91 & 0.977 \\
\hline H33115140 & 0.870 & 300 & 154 & 0.913 \\
\hline H38092510 & 0.922 & 39 & 30 & 0.969 \\
\hline
\end{tabular}

because there was no way to control against which side of the well casings the probe was pressed. More so than the moisture models, the field correlations were not exactly 1 to 1 , further supporting the observation that a calibration equation derived for one probe position would introduce some error when applied to another probe position. As discussed in Section 3.1, the error would range from 0 to a maximum of $1.4 \%$ at a water content of $30 \%$. These errors are less than the standard errors of the calibrations.

\section{A.8 References}

Engelman, R. E., R. E. Lewis, D. C. Stromswold, and J. R. Hearst. 1995. Calibration models for measuring moisture in unsaturated formations by neutron logging. PNL-10801, Pacific Northwest Laboratory, Richland, Washington.

Fayer, M. J., J. B. Sisson, W. A. Jordan, A. H. Lu, and P. R. Heller. 1993. Subsurface injection of radioactive tracers. PNL-8499, Pacific Northwest Laboratory, Richland, Washington.

Sisson, J. B. and A. H. Lu. 1984. Field calibration of computer models for application to buried liquid discharges: A status report. RHO-ST-46 P, Rockwell Hanford Operations, Richland, Washington. 
Appendix B

Schlumberger Data . 



\section{Appendix B}

\section{Schlumberger Data}

\section{B.1 Introduction}

The systems deployed in 1995 represent borehole geophysical logging (Ellis 1987, Hearst and Nelson 1985), a mature technology that has been used since the 1920s to support mineral exploration and provide geophysical data for the petroleum industry. Borehole geophysical technology consists of three major components as illustrated in Figure B.1: (1) a downhole instrument (or sonde) that measures one or more physical properties of the formation; (2) a cable that connects the sonde to the surface, conducting power downhole and transmitting data uphole; and (3) a logging truck that controls the sonde location in the borehole, provides power and houses a computer that controls sonde operation as well as processing and displaying the data real-time. The resulting data are shown on a continuous strip chart commonly called a $\log$ (because of its similarity to a well driller's $\log$ ). The data on the logs are in English units. The discussion below also uses English units to facilitate interpretation of the logs.

A log consists of four general sections: 1) header, 2) equipment description, 3) data section (which may be displayed twice at different vertical scales), and 4) calibration and check summary. The header provides general well information including well name, date logged, casing size, and datum used. The header is filled out by the logging engineer during the logging process. The equipment description presents a schematic of the logging equipment run into the borehole. It includes the serial numbers and dimensions of the tools. The data section presents the processed results, generally in three plots or tracks for each logging run. Track 1 is on the left. A narrow column containing the depth (in feet) is found between track 1 on the left and tracks 2 and 3 on the right. The latter two are generally contiguous. Each track is divided horizontally into 10 divisions. The tracks are divided vertically with a uniform grid of lines, with line spacings representing 2 - $\mathrm{ft}$ depth intervals. A subheading is placed at the top and bottom of each data section listing the codes and scales used for each measurement. The calibration and check summary depicts the calibration history for the logging tool in a table and also as a series of "trouble" indicators. Both representations include master calibration data, the results from pre- and post-logging checks, and the allowable tolerance.

\section{B.2 Log Interpretation}

The four plates provided with this report are field logs for well E-1 (E24-92). In the sections below, the $\log$ for each tool is briefly described. The digital data used to generate the logs are described in Section B.3. Schlumberger Well Services performs some data processing before reporting the results.

\section{B.2.1 CNT-G Tool}

Plate 1 in the back of this report is the log for the CNT-G tool for well E-1. The header gives the name of the well, the time and date logged (10:20 on 1/13/95), the internal diameter of the casing ( 6 in.), and the external diameter of the casing (reported as bit size at 6.375 in.). The calibration and check summary indicates that pre- and post-logging checks were within tolerance as defined by Schlumberger Well Service.

\section{B.1}




\section{BOREHOLE GEOPHYSICAL LOGGING}

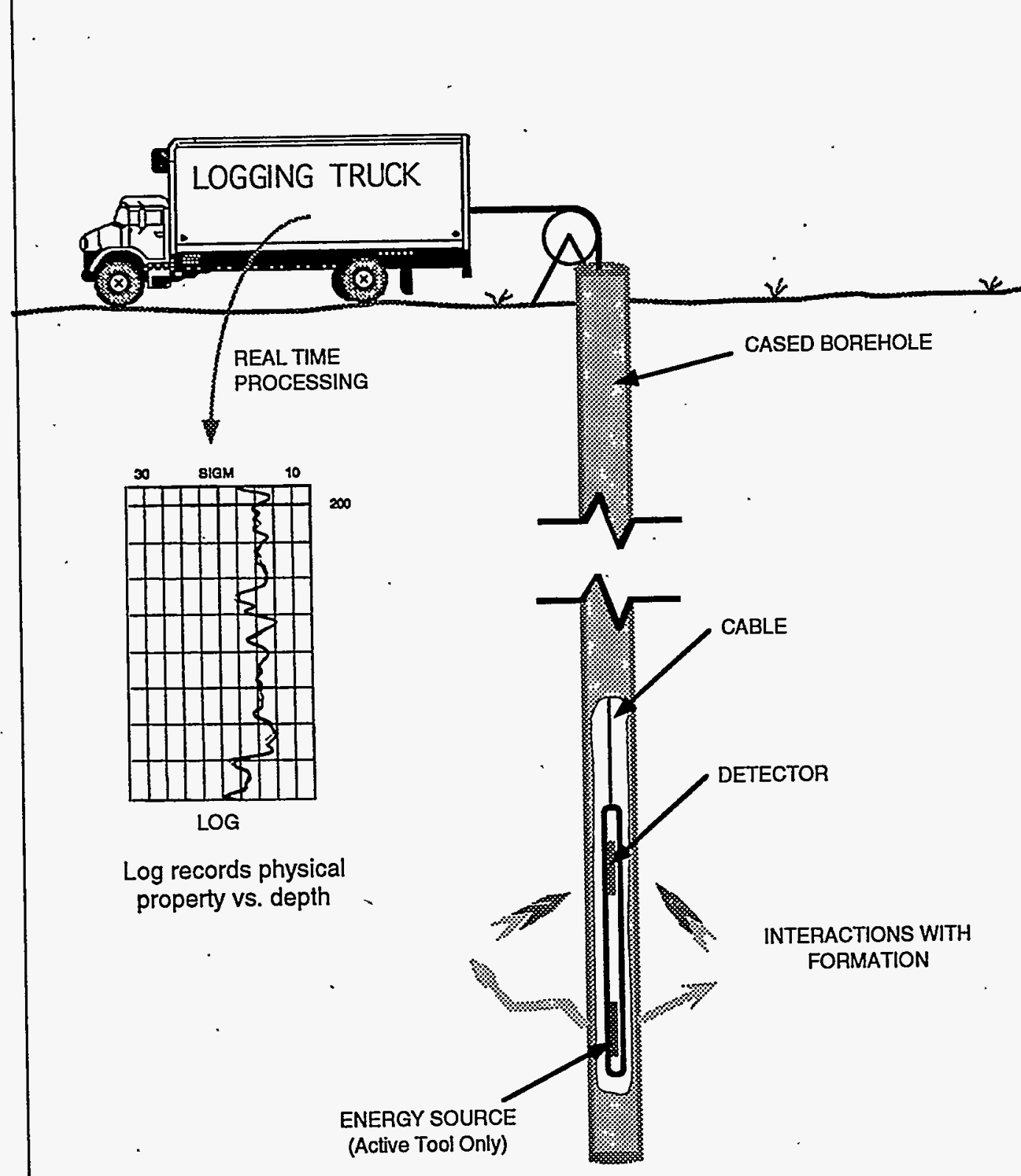

Figure B.1. Schematic of Borehole Logging System 
The $\log$ presents the results from two runs, a primary and a repeat. Repeats are commonly employed to check for adequate measurement precision. The results from the primary run are displayed at two different vertical scales, one at 5 in. equals $100 \mathrm{ft}$, and an expanded scale of $10 \mathrm{in}$. equals $100 \mathrm{ft}$. In both displays, each thin horizontal grid line indicates a 2-ft depth increment; thicker horizontal grid lines indicate 10-ft increments.

In the first data section, track 1 is blank. Track 2 displays the near/far ratio (LCO3) on a scale between 0 and 1 . This value was measured by the sonde and used to compute the VFW (LCO1) displayed on tracks 2 and 3. The VFW display is in "typical" oil-field fashion with moisture content decreasing to the right from a high of $60 \%$ VFW on the left. Each vertical grid line is equivalent to a VFW increment of $3 \%$. Much of the well is fairly dry at approximately $6 \%$ VFW.

There are four moist zones ( 5 to $10 \mathrm{ft}, 19$ to $24 \mathrm{ft}, 32$ to $39 \mathrm{ft}$, and 54 to $57 \mathrm{ft}$ ) that each have approximately $10 \%$ VFW. Because the vertical resolution of the CNT-G is around $15 \mathrm{~cm}$, finer features may not be recognized or only partially so. A possible example is the decrease in VFW at $22 \mathrm{ft}$ within a higher moisture zone. This may actually represent a thin (around $10 \mathrm{~cm}$ thick) low moisture zone. There is no way to tell with a CNT-G log.

The anomalous zone above $4 \mathrm{ft}$ is due to the interaction between the CNT-G system and the airrock interface. Because the source is above the epithermal neutron detectors, as the tool approaches the surface, progressively more of the neutrons emanating from the source migrate into the air from the borehole or formation. Once in the air, the mean path length between collisions of the neutrons increases significantly and, consequently, most escape detection. This progressive decrease in the number of epithermal neutrons reaching the detector is interpreted by the system as progressively higher moisture contents, thus the increasing VFW values at the surface.

The repeat log is plotted atop the primary log in the last display. As would be expected from the precision values measured in the calibration models (Table 3.1), the two curves are identical and plot atop one another.

\section{B.2.2 APS Tool}

Plate 2 is the log for the APS tool. The header is very similar to those discussed previously for the CNT-G logging system, although containing more information. The calibration and check summary indicates that pre- and post-logging checks were within Schlumberger tolerances. All APS checks were within tolerance.

Three passes were made with the APS, two at a standard resolution and one at a high resolution. The second standard resolution run is a repeat. The standard resolution uses a sampling interval of $15 \mathrm{~cm}$, and the high resolution uses a 5-cm interval. A high resolution pass is valid because of the greater vertical resolution of the slowing-down measurement in contrast to ratio measurements. The primary standard resolution and the high resolution passes are displayed at 5- and 10-in. scales.

Track 1 displays $\Sigma$ (SIGF). Tracks 2 and 3 display two different moisture measurements: near-far (NFVW) and slowing-down time (SDVW). For both curves, moisture content decreases to the right like the CNT-G display.

The two APS moisture curves do not overlie one another as they should. The near-far consistently has lower values. Table B.1 shows that this discrepancy is consistent with the results from the calibration models where the SDVW is lower than the NFVW by about 1 VFW. However, the difference in the data recorded is closer to 3 VFW. The source for this additional discrepancy is 
Table B.1. Calibration Results for the Accelerator Porosity Sonde

\begin{tabular}{||c|c|c||}
\hline \multirow{2}{*}{$\begin{array}{c}\text { Calculated } \\
\text { Water Content } \\
\text { (vol\%) }\end{array}$} & \multicolumn{2}{|c|}{$\begin{array}{c}\text { Measured Water } \\
\text { Content (vol\%) }\end{array}$} \\
\cline { 2 - 3 } & NFVW & SDVW \\
\hline 5.0 & 5.6 & 6.6 \\
\hline 11.9 & 11.5 & 12.4 \\
\hline 19.8 & 18.6 & 19.7 \\
\hline
\end{tabular}

unknown. The NFVW underwent much more rigorous calibration by Schlumberger (Ellis et al. 1995) wherein over 100 calibration points. were calculated with a Monte Carlo neutron transport code (Briesmeister 1991) and tied to the calibration model results. No computer modeling was performed for the slowing-down measurements. Aiso, the NFVW results and the CNT-G results are very similar. Therefore, we assumed that the NFVW measurements are more accurate than the SDVW. However, the SDVW values will still be used to delineate thinner features that cannot be resolved with the nearfar measurements.

Using the NFVW curve, three moist zones are again detected (the lowest zone logged in the CNT-G was not logged by the APS because of system configuration), and they have moisture values of around 10 VFW. The depths for each zone in the APS log are consistently around $1 \mathrm{ft}$ shallower than the corresponding ones in the CNT-G. This discrepancy is due to differences in the assignment of a datum during tool setup and is readily correctable. The SDVW curve does present more detail in the moisture profile. For example, the high moisture zone at 4 to $8 \mathrm{ft}$ can be resolved into two zones separated by a thin low-moisture bed at $6.5 \mathrm{ft}$. A similar feature is noted at $36 \mathrm{ft}$. The APS does not have anomalously high moisture at the top of the hole, like the CNT-G, because its neutron source was tumed off at a depth of $4 \mathrm{ft}$.

The $\sum$ curve shows little variability ( $\pm 6 \mathrm{cu}$ ), indicating that there is little change in the concentration of thermal neutron absorbers along the borehole. The most noticeable feature is from 4 to $8 \mathrm{ft}$, and it corresponds to a high moisture zone. Hydrogen is a thermal neutron absorber, and the elevation in its concentration will elevate $\Sigma$.

\section{B.2.3 LDS Tool}

Plate 3 is the log for the LDS tool from well E-1. The header is very similar to those discussed previously for the neutron-neutron logging systems. The calibration and check summary indicates that pre- and post-logging checks were within Schlumberger tolerances. Calibration for this system in Hanford boreholes has not been completed; all numerical values displayed in the log may be inaccurate.

The log presents the results from three runs: a standard resolution run, a high resolution run, and a high resolution repeat run. Standard resolution used a sampling interval of $15 \mathrm{~cm}$; high resolution used a sampling interval of $2.5 \mathrm{~cm}$. 
Track 1 contains two curves: a caliper measurement (LCAL) that records the inner diameter of the casing and a bulk density correction (DRH). The latter is the correction curve mentioned in Section 3.3.1 that compensates for the presence of material between the gamma detectors and the formation, i.e., the steel casing in the wells logged at this site.

Tracks 2 and 3 display the measured bulk density (RHOM) and calculated density porosity (DPO). The density porosity was calculated using a grain density of $2.69 \mathrm{~g} / \mathrm{cm}^{3}$ (Fayer et al. 1993). Following oil-field convention, both displays show lower density (higher porosity) zones as. excursions to the left.

The repeat $\log$ is plotted atop the primary $\log$ in the last display. The two curves are identical and plot atop one another.

\section{B.2.4 HNGS Tool}

Plate 4 is the log for the HNGS tool in well E-1. The header for the HNGS is similar to the other logs discussed previously. The calibration and check summary indicates that pre- and postlogging checks were within tolerance as defined by Schlumberger Well Service.

The log presents the results from two runs, a primary and a repeat. The results from the primary run are displayed at $5 \mathrm{in}$. equals $100 \mathrm{ft}$ and an expanded scale of 10 in. equals $100 \mathrm{ft}$. The repeat is shown as an overlay at the 5-in. scale. The repeat overlay, although very good, is not as impressive as those displayed for the other logging systems. This is primarily a function of the lower number of counts that a passive system (i.e., no active source of subatomic particles) deals with and . the resulting lower precision. The statistics of radioactive decay can be accurately expressed as a Poisson distribution in which the fractional uncertainty (precision or $f$ ) can be expressed as

$$
f \propto \frac{1}{\sqrt{Q t}}
$$

where $Q$ is the source strength and $t$ is the time of observation (Ellis 1987). The activity of naturally occurring gamma-emitting radionuclides is much lower $(<100 \mathrm{pCi})$ than the activity of the sources used in the other logging tools ( $>1.0 \mathrm{Ci}$ ); thus, the resulting precision should be lower.

Track 1 includes the gross gamma count (HSGR) in API units and a chi square curve for each detector (CHI1 and CHI2). The American Petroleum Institute (API) established calibration standards for gross gamma ray logging systems used in the petroleum industry. The definition of the API units of radioactivity is based on system response in a calibration model that has about twice the radioactivity of the typical shale, defined to be 200 API units (Ellis 1987). The chi square $\left(\chi^{2}\right)$ is a statistical measure of the goodness-of-fit of the weighted least squares algorithm used to deconvolve the gamma ray spectrum into its components, typically $\mathrm{K}, \mathrm{U}$, and $T h$. A $\chi^{2}$ value of about 1 indicates a good fit. If the value increases significantly above one, this may indicate the presence of other unresolved gamma-emitters; that is, created radionuclides for which HNGS spectra have not been . calculated. The $\chi^{2}$ values in this well averaged 1.45, indicating acceptable goodness-of-fit.

Track 2 includes the activities of $\mathrm{K}$ (HFKC) and Th (HTHC). Unlike oil-field log displays, this $\log$ reports activities in $\mathrm{pCi} / \mathrm{g}$ rather than concentration in wt \% $(\mathrm{K})$ or $\mathrm{ppm}$ (Th and $\mathrm{U})$. Track 3 includes the activities of two created radionuclides: ${ }^{137} \mathrm{Cs}$ and $60 \mathrm{Co}$. Uranium activity is shown on track 2 and 3 so that anticipated activities will not overplot on either the $K$ and Th tracks. 


\section{B.3 Data Files}

The complete set of data files is available on request. The data files contain all of the field data from Schlumberger Well Services. The data files are in Macintosh Excel format in subdirectory SCH_DATA. Within that subdirectory, there is a subdirectory for each of the 32 wells. The file naming convention is to use the Hanford well identification number (e.g., E24-92). Within each of these 32 subdirectories, there is a separate file for the data from each tool. The files are described below.

\section{B.3.1 CNT-G Files}

The two file names are CNTG1 and CNTG2. These files contain the CNTG data. The number refers to the number of the logging pass (some wells were logged twice). Table B.2 lists the column headings in the files.

\section{B.3.2 APS Files}

The three file names are APS1, APS-ST1, and APS-ST2. These files contain the APS data. APS1 refers to the high resolution log. APS-ST1 and APS-ST2 refer to the low resolution passes (some wells were logged twice). Table B.3 lists the column headings in the files.

\section{B.3.3 LDS Files}

The four file names are LDS1, LDS2, LDS-ST1, and LDS-ST2. These files contain the LDS data. LDS1 and LDS2 refer to the high resolution logs. LDS-ST1 and LDS-ST2 refer to the low resolution logs (some wells were logged twice at one or both resolutions). Table B.4 lists the column headings in the files.

\section{B.3.4 HNGS Files}

The three file names are HNGS, HNGS2, and HNGS3. These files contain the HNGS data. The number refers to the number of the logging pass (some wells were logged more than once).

Table B.5 lists the column headings in the files.

Table B.2. Description of Variables in the CNT-G Files

\begin{tabular}{||c|c|c|c||}
\hline \hline \multirow{2}{*}{$\begin{array}{c}\text { Column } \\
\text { No. }\end{array}$} & Name & Units & \multicolumn{1}{|c||}{ Description } \\
\cline { 2 - 4 } & DEPTH & $\mathrm{ft}$ & Depth below the top of the casing \\
\hline 1 & VFW6 & vol\% & Water content for 6-in. casing \\
\hline 2 & VFW8 & vol\% & Water content for 8-in. casing \\
\hline 3 & ENRA & -- & Epithermal neutron ratio \\
\hline 4 & &
\end{tabular}


Table B.3. Description of Variables in the APS Files

\begin{tabular}{||c|c|c|l||}
\hline \multirow{2}{*}{$\begin{array}{c}\text { Column } \\
\text { No. }\end{array}$} & \multicolumn{2}{|c|}{ Variable } \\
\cline { 2 - 4 } & Name & Units & \multicolumn{1}{|c|}{ Description } \\
\hline 1 & DEPTH & $\mathrm{ft}$ & Depth below the top of the casing \\
\hline 2 & NAVW & vol\% & Near array water content \\
\hline 3 & NFVW & vol\% & Far detector water content \\
\hline 4 & SDVW & vol\% & Slowing down water content \\
\hline 5 & ENAR & ratio & Epithermal near-array ratio \\
\hline 6 & ENFR & ratio & Epithermal near-far ratio \\
\hline 7 & SIGF & capture units & $\begin{array}{l}\text { Macroscopic thermal neutron absorption cross } \\
\text { section }\end{array}$ \\
\hline 8 & STTM & $\mu s$ & Slowing-down time \\
\hline
\end{tabular}

Table B.4. Description of Variables in the LDS Files

\begin{tabular}{|c|c|c|l||}
\hline \multirow{2}{*}{$\begin{array}{c}\text { Column } \\
\text { No. }\end{array}$} & \multicolumn{3}{|c||}{ Variable } \\
\cline { 2 - 4 } & Name & Units & \multicolumn{1}{|c||}{ Description } \\
\hline 1 & DEPTH & $\mathrm{ft}$ & Depth below the top of the casing \\
\hline 2 & RHOM & $\mathrm{g} / \mathrm{cm}^{3}$ & Apparent bulk density \\
\hline 3 & RHS4 & $\mathrm{g} / \mathrm{cm}^{3} \cdot$ & $\begin{array}{l}\text { Apparent bulk density from the short-spaced } \\
\text { detector only }\end{array}$ \\
\hline 4 & RHL & $\mathrm{g} / \mathrm{cm}^{3}$ & $\begin{array}{l}\text { Apparent bulk density from the long-spaced } \\
\text { detector only }\end{array}$ \\
\hline 5 & PEFL & $\begin{array}{c}\text { barns/ } \\
\text { electron }\end{array}$ & Photoelectric effect \\
\hline 6 & LCAL & in. & Caliper internal diameter of casing \\
\hline 7 & DRH & g/cm 3 & Correction curve \\
\hline 8 & DPO & $\mathrm{g} / \mathrm{cm}^{3}$ & $\begin{array}{l}\text { Density porosity calculated using a grain density } \\
\text { of } 2.69 \text { g/cm } 3\end{array}$ \\
\hline
\end{tabular}


Table B.5. Description of Variables in the HNGS Files

\begin{tabular}{||c|c|c|l||}
\hline \multirow{2}{*}{$\begin{array}{c}\text { Column } \\
\text { No. }\end{array}$} & \multicolumn{2}{|c||}{ Variable } \\
\cline { 2 - 4 } & Name & Units & \multicolumn{1}{|c||}{ Description } \\
\hline 1 & DEPTH & $\mathrm{ft}$ & Depth below the top of the casing \\
\hline 2 & HTHC & $\mathrm{pCi} / \mathrm{g}$ & Thorium activity \\
\hline 3 & HURC & $\mathrm{pCi} / \mathrm{g}$ & Uranium activity \\
\hline 4 & HFKC & $\mathrm{pCi} / \mathrm{g}$ & Potassium activity \\
\hline 5 & HCSC & $\mathrm{pCi} / \mathrm{g}$ & Cs-137 activity \\
\hline 6 & HCOC & $\mathrm{pCi} / \mathrm{g}$ & Co-60 activity \\
\hline 7 & HSGR & API & Gross gamma activity \\
\hline 8 & CHI1 & -- & Goodness-of-fit statistic on first detector \\
\hline 9 & CHI2 & -- & Goodness-of-fit statistic on second detector \\
\hline
\end{tabular}

\section{B.4 References}

Briesmeister, J. F., ed. 1991. MCNP 4, Monte Carlo neutron and photon transport code. Radiation Shielding Information Center Report No. CCC-200A/B, Oak Ridge National Laboratory, Oak Ridge, Tennessee.

Ellis, D. V. 1987. Well logging for earth scientists. Elsevier, New York.

Ellis, D. V., R. A. Perchonok, H. D. Scott, and C. Stoller. 1995. "Adapting wireline logging tools for environmental logging applications." Paper X in 36th annual logging symposium, transactions of the Society of Professional Well Log Analysts, Paris, France.

Fayer, M. J., J. B. Sisson, W. A. Jordon, A. H. Lu, and P. R. Heller. 1993. Subsurface injection of radioactive tracers. PNL-8499, Pacific Northwest Laboratory, Richland, Washington.

Hearst, J. R. and P. H. Nelson. 1985. Well logging for physical properties. McGraw-Hill, New York. 
Appendix C

RLS Data 



\section{Appendix C}

\section{RLS Data}

\section{C.1 Introduction}

While logging the Sisson and Lu boreholes in January 1995, Schlumberger Well Services detected the presence of an unknown gamma emitter. As explained in Section 4.3, the primary candidate isotope was $134 \mathrm{Cs}$, which was injected in 1980 during the original experiment (Sisson and Lu 1984). Westinghouse Hanford Company (WHC) was contracted to log three wells that had the highest response to unknown gamma rays.

\section{C.2 Methods}

WHC used the Radioactive Logging System (RLS) to identify the isotopes and quantify their amounts. The entire depth of well E-1 (E24-92) from 0 to $18.3 \mathrm{~m}$ (0 to $60 \mathrm{ft}$ ) was logged on February 24,1995 , using the $70 \%$ efficiency detector and 120 -s counting times at each $0.15-\mathrm{m}$ $(0 . \dot{5}-\mathrm{ft})$ depth. The results include activities of $\mathrm{K}, \mathrm{Th}, \mathrm{U}$, and ${ }^{134 \mathrm{Cs}}$, as well as total gamma response. Two other wells were logged with the same detector but with longer counting times $(440 \mathrm{~s})$ to enhance their sensitivity to detect low amounts of ${ }^{134} \mathrm{Cs}$. Well C-1 (E24-84) was logged from 3.4 to $6.7 \mathrm{~m}$ (11 to $22 \mathrm{ft}$ ) and well G-1 (E24-100) was logged from 3 to $6.7 \mathrm{~m}$ (10 to $22 \mathrm{ft}$ ) on March 16, 1995. Readings in all three wells were corrected for a casing thickness of $0.64 \mathrm{~cm}(0.25 \mathrm{in}$.) before reporting.

\section{C.3 Results}

Figures C. 1 to C.4 show the RLS estimate of $K$, Th, $U$, and total gamma response. As expected, $\mathrm{K}$ is the dominant source of gamma energy. Generally, total gamma mimics $\mathrm{K}$. However, around $4.6 \mathrm{~m}(15 \mathrm{ft})$, that doesn't occur and is an indication of one or more other isotopes (as also concluded in Section 4.3). Also included Figures C.1 to C.4 are the Schlumberger estimates. For K, $\mathrm{Th}$, and $\mathrm{U}$, the RLS estimates are roughly $10 \%$ higher than the Schlumberger estimates and they are more variable.

In Figure C.4, the total gamma response from the two instruments was quite similar. Both indicated a peak gamma response at roughly $4.6 \mathrm{~m}(15 \mathrm{ft})$. Both showed an unexplained minimum response at $2.1 \mathrm{~m}(7 \mathrm{ft})$ as discussed in Section 4.3 .

Figure C.5 shows the ${ }^{134} \mathrm{Cs}$ anomaly detected by Schlumberger and the RLS estimate of the .${ }^{134} \mathrm{Cs}$ activity. The peak values of ${ }^{134} \mathrm{Cs}$ were at 4.9 and $5 \mathrm{~m}$ (16 and.16.5 ft). Sisson and Lu (1984) reported ${ }^{134 \mathrm{Cs}}$ at depths from 4.0 to $4.7 \mathrm{~m} \mathrm{(13}$ to $15.5 \mathrm{ft}$ ) throughout the experiment. They also reported ${ }^{134} \mathrm{Cs}$ at $4.9 \mathrm{~m}(16 \mathrm{ft})$, but only for the first three weeks. They reported no values of ${ }^{134 \mathrm{Cs}}$ deeper than $4.9 \mathrm{~m}(16 \mathrm{ft})$. Either they missed the Cs peak with their monitoring scheme, or there was a slow downward migration of $\mathrm{Cs}$ with the recharge flux in the intervening years. Section 2.3 contains sufficient information to demonstrate insufficient monitoring. Even if the peaks had been well defined, there is enough uncertainty in the depth measurements and zero datums to state that there is insufficient evidence to verify ${ }^{134} \mathrm{Cs}$ migration. 


\section{C.4 Files}

The complete set of data files is available on request. Two data files are provided in the subdirectory RLS_DATA. The data files are in Macintosh Excel format. The files are:

1. E24-92R This file contains data from well E-1: the RLS estimates of $K$, Th, $U$, and ${ }^{134 C s}$ activities, error estimates, and total gamma response. Complete header information including units is contained in the file.

2. E24-92S This file contains the spectrum of gamma energy detected in well E-1 at a depth of $4.9 \mathrm{~m}(16 \mathrm{ft})$ below the top of the casing. The first column of data represent the energy level in $\mathrm{KeV}$. The second column contains the number of counts received in $120 \mathrm{~s}$.

\section{C.5 Reference}

Sisson, J. B. and A. H. Lu. 1984. Field calibration of computer models for application to buried liquid discharges: A status report. RHO-ST-46 P, Rockwell Hanford Operations, Richland, Washington. 


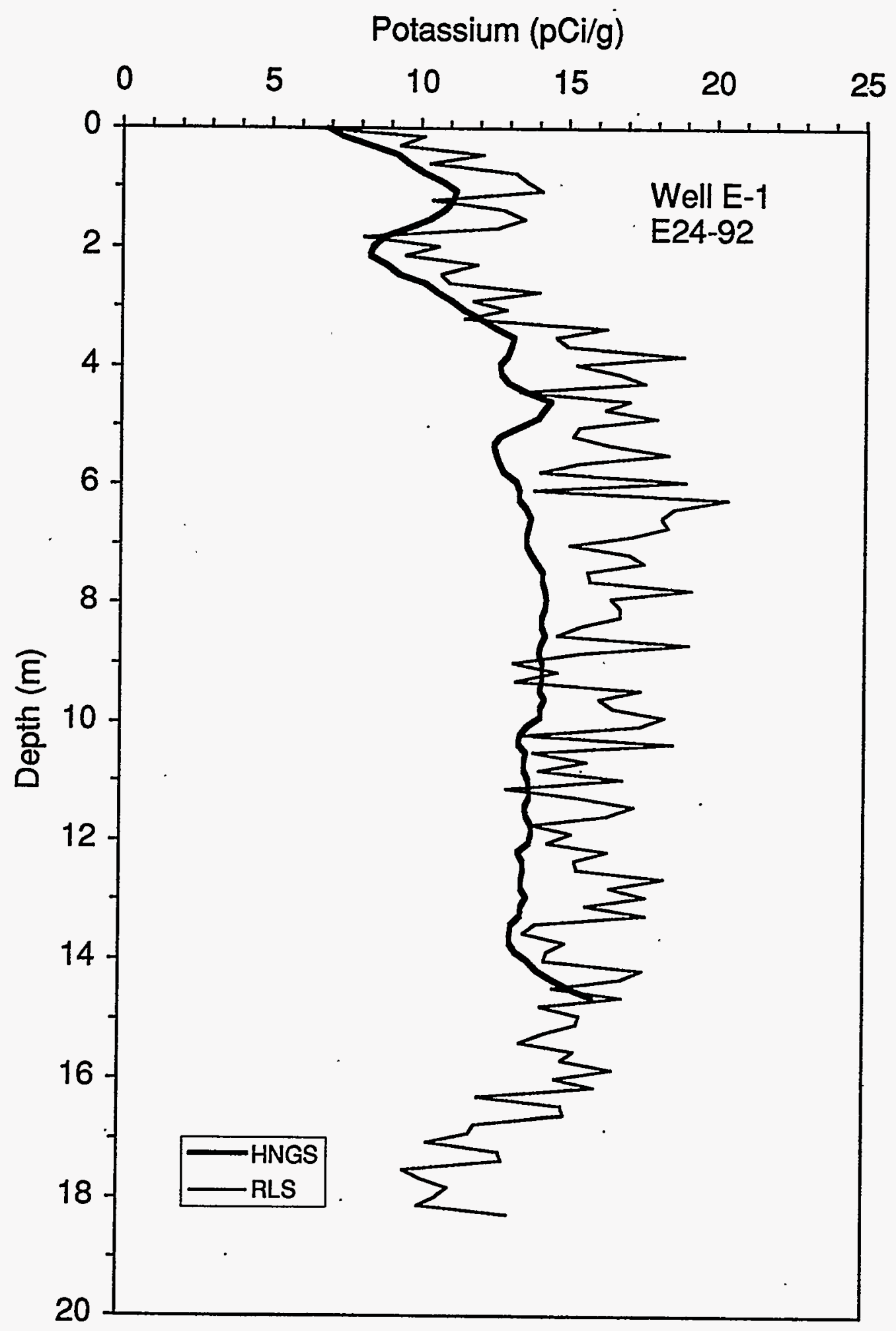

Figure C.1. Potassium Activity in Well E-1 on February 24, 1995

C. 3 


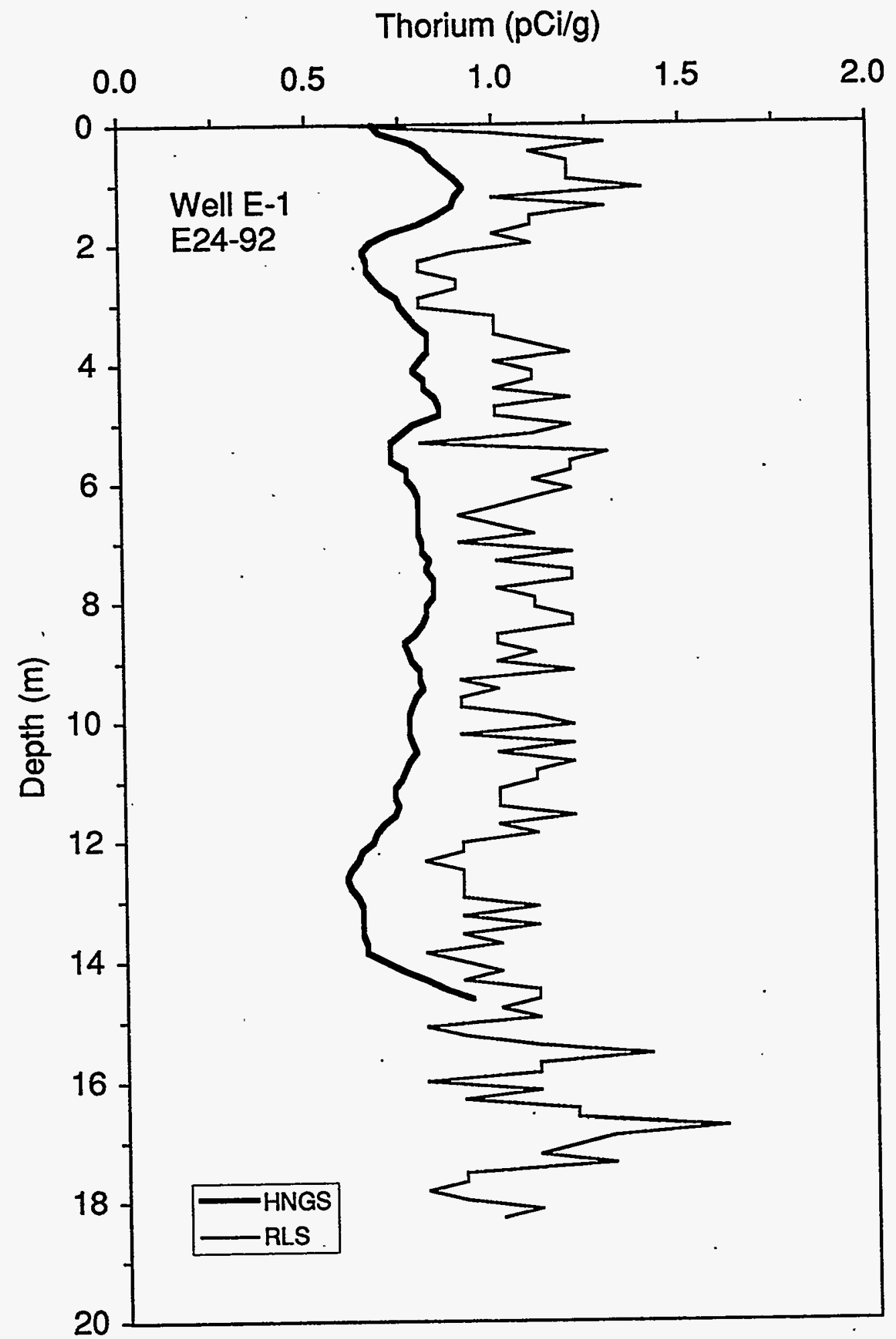

Figure C.2. Thorium Activity in Well E-1 on February 24, 1995 


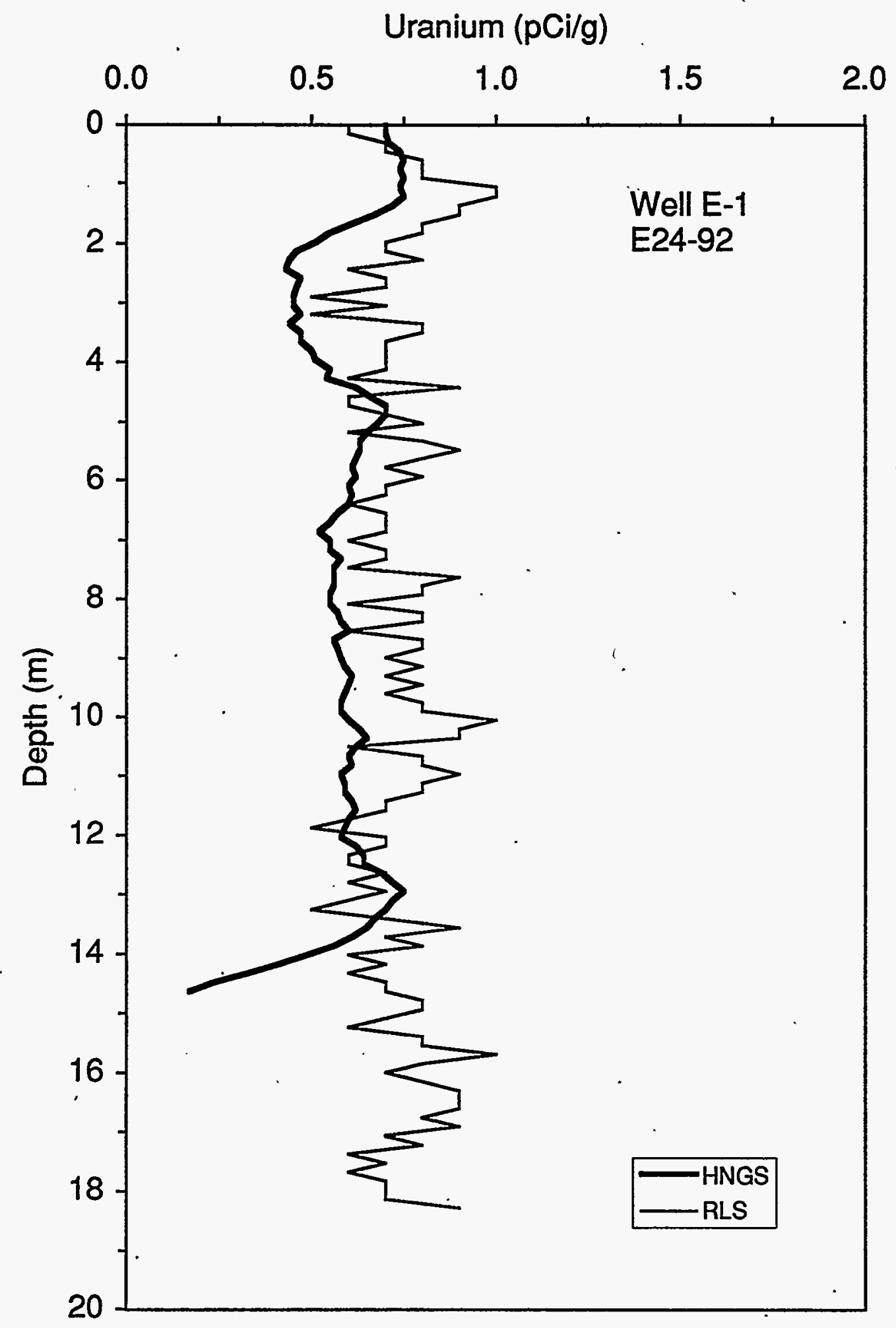

Figure C.3. Uranium Activity in Well E-1 on February 24, 1995 


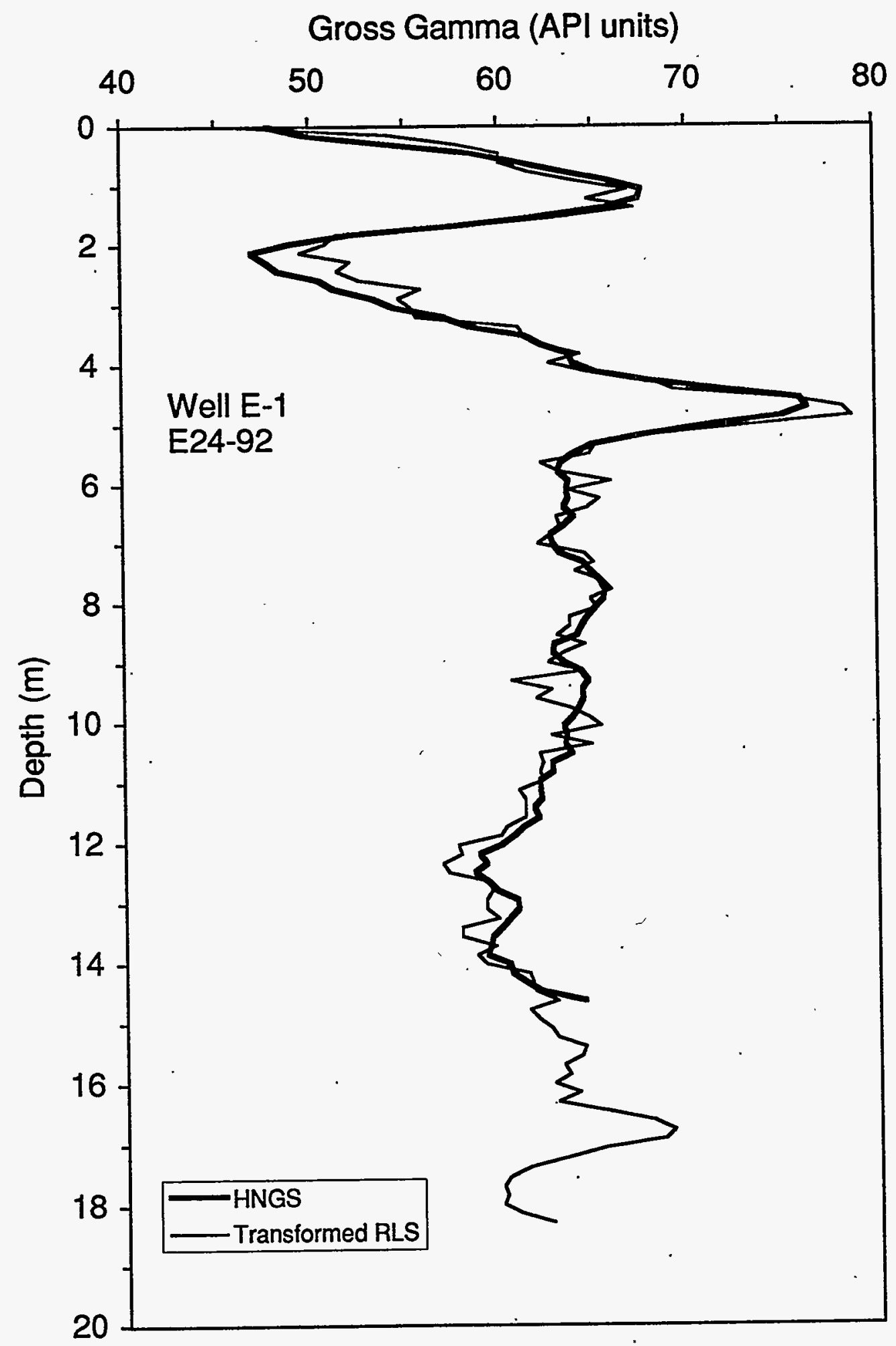

Figure C.4. Total Gamma Response in Well E-1 on February 24, 1995. The RLS data (in units of counts/s) were transformed to API units for direct comparison with the HNGS data. The transformation involved linear regression of the data from 0.3 to $14.0 \mathrm{~m}$ $(11.8$ to $45.9 \mathrm{ft})$. 


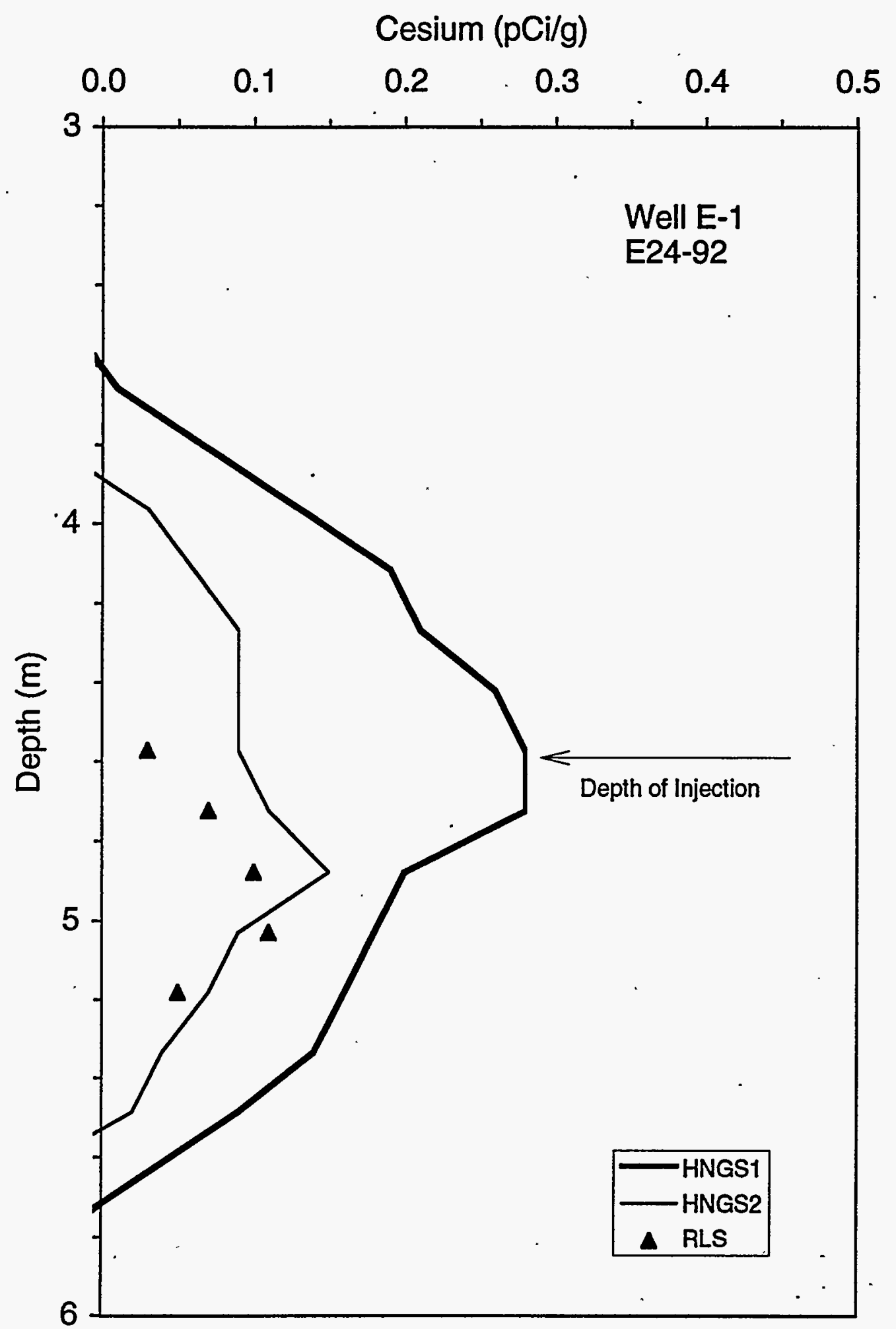

Figure C.5. ${ }^{134}$ Cs Activity in Well E-1 on February 24. The HNGS data do not actually represent ${ }^{134} \mathrm{Cs}$. The Schlumberger software interpreted the ${ }^{134} \mathrm{Cs}$ gamma energy peaks as $137 \mathrm{Cs}$, for which the HNGS system was calibrated. Schlumberger did not have a ${ }^{134} \mathrm{Cs}$ calibration when they logged the site. 



\section{Distribution}

No. of

Copies

\section{OFFSITE}

B. Drost

U.S. Geological Survey

1201 Pacific Avenue, Suite 600

Tacoma, WA 98402

M. M. Dunkleman

Washington State Department of

Health

Division of Radiation Protection

Airdustrial Center

Building 5, M.S. L-13

Olympia, WA 98503

4 Washington State Department of Ecology

P.O. Box 1386

Richland, WA 99352

Attn:
C. Cline
D. Goswami
D. Lundstrom
N. H. Uziemblo

R. G. Hills

Department of Mechanical Engineering

Box 30001, Department 3450

New Mexico State University

Las Cruces, NM 88003

T. J. Nicholson

U.S. Nuclear Regulatory Commission Office of Nuclear Regulatory Research Mail Stop NL-005

Washington, DC 20555

R. R. Randall

Three Rivers Scientific

3659 Grant Court

W. Richland, WA 99353

Schlumberger-Doll Research

P.O. Box 307

Ridgefield, CT 06877

Attn: D.V. Ellis
No. of

Copies

Schlumberger Wireline and Testing 225 Industrial Boulevard

Sugarland, TX 77478

Attn: H. D. Scott

J. B. Sisson

Lockheed-Martin

P.O. Box 1625, MS 2107

Idaho Falls, ID 83415

S. W. Tyler

Desert Research Institute

P.O. Box 60220

Reno, NV 89506

M. Th. Van Genuchten

U.S. Salinity Lab - USDA

4500 Glenwood Drive

Riverside, CA 92501

W. H. Wegener

Hoquiam High School

Hoquiam, WA

\section{FOREIGN}

M. Sheppard

Head, Ecological Research

Whiteshell Laboratories

Pinawa, Manitoba

Canada, ROE 1LO

\section{ONSITE}

\section{DOE Richland Operations Office}

D. H. Alexander. S7-51

N. R. Brown

K6-51

A. K. Crowell

S7-55

B. L. Foley

H4-83

M. J. Furman

R3-81

J. D. Goodenough

H4 -83

J. P. Hanson

K8-50

R. D. Hildebrand

H4-83

Distr.1 
No. of Copies
L. A. Huffman
K6-51
P. E. Lamont
S7-53
C. O. Ruud
S7-54
R. K. Stewart
H4-83
K. M. Thompson
H4-83
D. Wanek
H4-83

7 Bechtel Hanford, Inc.

K. R. Fecht

H4-80

G. L. Kasza

H6-04

A. J. Knepp

H4-85

D. R. Myers

H6-07

R. W. Ovink

H4-92

L. C. Swanson

H6-04

S. J. Trent

H6-02

$4 \quad$ U.S. Environmental Protection Agency

P. R. Beaver

B5-01

L. E. Gadbois

B5-01

P. S. Innis

B5-01

D. R. Sherwood

B5-01

26 Westinghouse Hanford Company

D. B. Barnett

K. C. Burgard

H6-06

L. B. Collard

C. R. Eiholzer

J. W. Fassett

J. G. Field

G6-13

H6-30

HO-36

H6-06

H6-30

E. A. Fredenburg

S4-53

R. L. Gibby

H5-27

M. J. Hartman

H6-06

V. G. Johnson

R. Khaleel

H6-06

N. W. Kline

H0-36

H0-36

D. W. Langford
No. of

Copies
A. H. Lu
$\mathrm{H} 0-36$
F. M. Mann
H0-36
J. E. Meisner
N1-55
R. J. Murkowski
G6-13
R. K. Price
H6-06
S. P. Reidel
J. S. Schmid
F. A. Schmittroth
H6-06
H6-06
A. M. Tallman
$\mathrm{HO}-35$
J. A. Voogd
H5-57
G6-13
B. A. Williams
G. F. Williamson
H6-06
M. I. Wood
G6-13
T4-02

42 Pacific Northwest National Laboratory

M. P. Bergeron

K9-33

K. A. Blanchard

$\mathrm{K} 2-47$

J. M. Creer

K9-80

R. E. Engelman

K9-33

G. W. Gee

K9-33.

M. J. Fayer (10)

K9-33

M. D. Freshley

K9-36

G. R. Holdren

K6-81

D. I. Kaplan

C. T. Kincaid

K6-81

R. R. Kirkham

K9-33

R. E. Lewis (5)

P. E. Long

K9-33

K9-33

K9-48

B. P. McGrail

E. M. Murphy

C. J. Murray

K2-38

K3-61

M. L. Rockhold

K9-33

K9-33

R. J. Serne

K6-81

J. L. Smoot

J. H. Westsik Jr.

G. A. Wyatt

K9-80

Information Release Office (7) K1-11

Public Reading Room

H2-05 


\section{SISSON/LU INJECTION SITE}

\section{BENTON STATE: WASHINGTON}

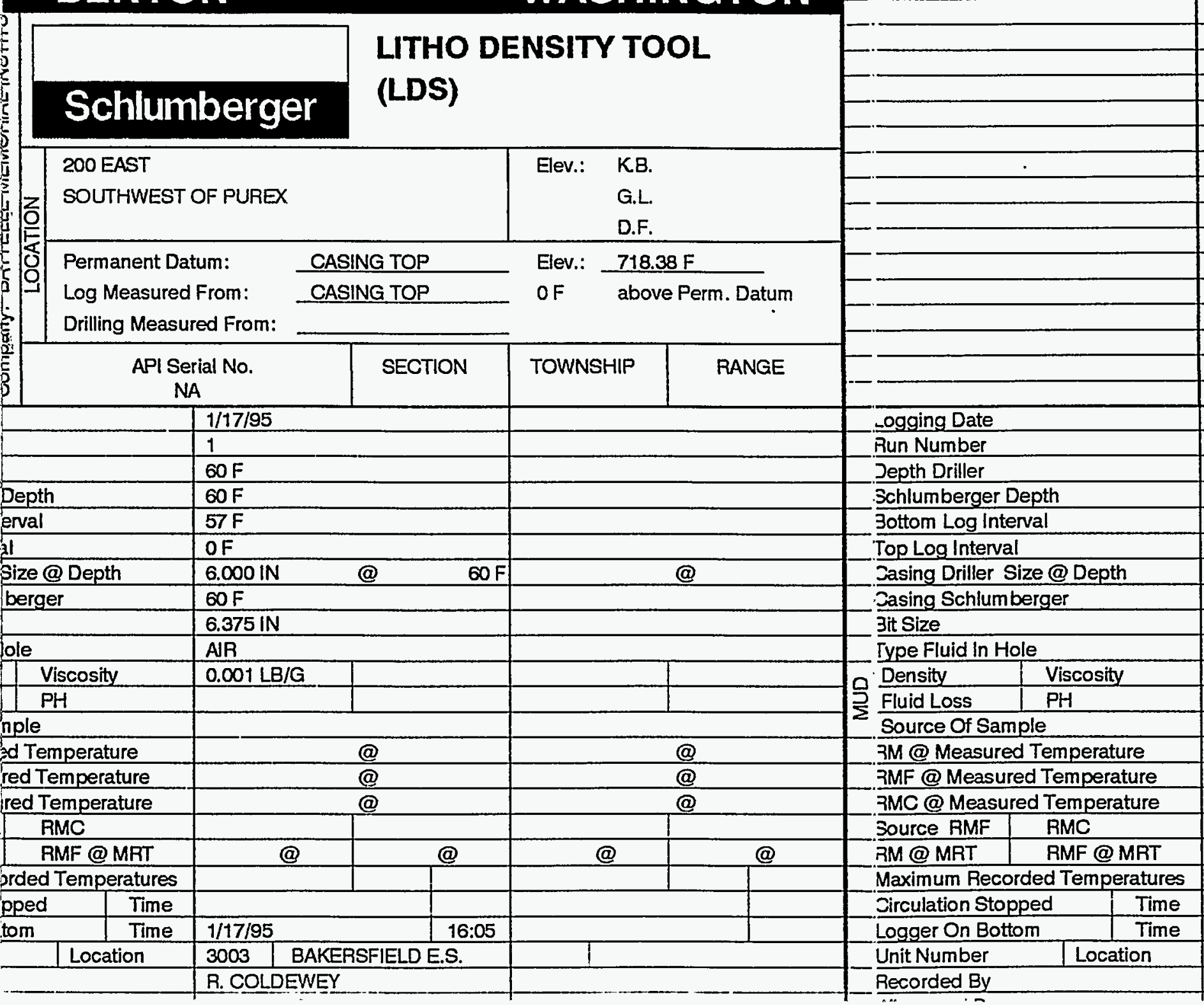

\begin{tabular}{|c|c|c|c|}
\hline Run 1 & Run 2 & Run 3 & $\mathrm{R}$ \\
\hline & & & \\
\hline & & & \\
\hline & & & \\
\hline & & & \\
\hline & & & \\
\hline & & & \\
\hline & & & \\
\hline & & & \\
\hline & & & \\
\hline & & & \\
\hline & & & \\
\hline & & & \\
\hline & & & \\
\hline & & & \\
\hline & & & \\
\hline & & & \\
\hline & & & \\
\hline & & & \\
\hline & & & \\
\hline & & & \\
\hline & & & \\
\hline & & & \\
\hline & & . & \\
\hline & & & @ \\
\hline & & & \\
\hline & & & \\
\hline & & & \\
\hline & & & \\
\hline & & & $@$ \\
\hline & & & @ \\
\hline & & & $@$ \\
\hline @ & @ & @ & \\
\hline & & & \\
\hline & & & \\
\hline & & & \\
\hline
\end{tabular}




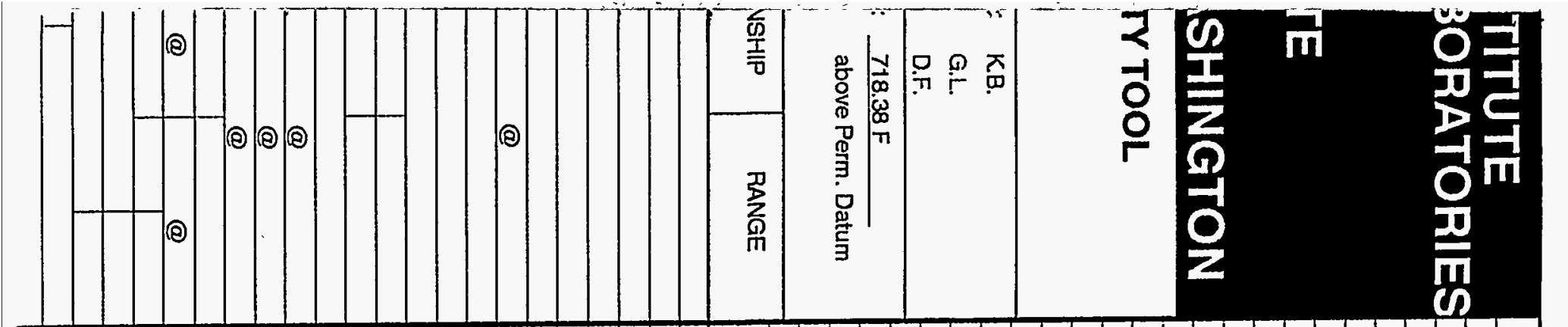

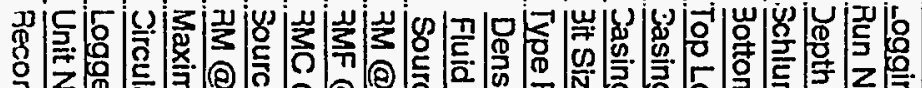

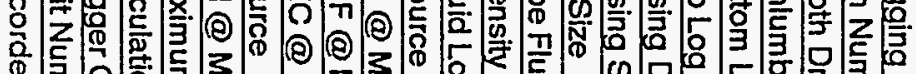

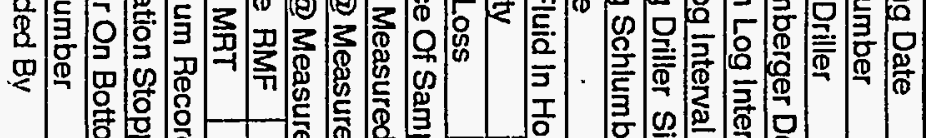

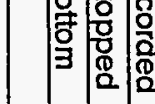

年

(5)

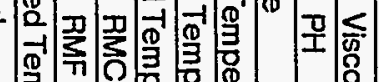

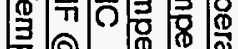

马-

AI.I. INTERPRETATIONS ARE OPINIONS BASED ON INFERENCES FROM ELECTRICAL OR OTHER MEASUREMENTS AND WE CANNOT AND DO NOT GUARANTEE THE ACCUHACY UHCOHHELINESS UP ANY INTERPRETATIONS, AND WE SHALL NOT, EXCEPT IN THE CASE OF GROSS OR WILLFUL NEG IGENCE ON OUR PART BE LIABLE OR 'RESPONSIBLE FOR ANY LOSS, COSTS, DAMAGES OR EXPENSES INCURRED OR SUSTAINED BY ANYONE RESULTING FROM ANY INTERPRETATION MADE BY ANYOF OUR OFFICERS, AGENTS OR EMPLOYEES. THESE INTERPRETATIONS ARE ALSO SUBJECT TO CLAUSE 4 OF OUR GENERAL TERMS AND CONDITIONS AS SET OUT IN OUR CURRENT PRICE SCHEDULE.

\section{OTHER SERVICES1}

DS1: HNGS

JS2: LDS

2S3: CNTG

JS4: APS

JS5:
OTHER SERVICES2

OS1:

OS2:

OS3:

OS4:

OS5:

REMARKS: RUN NUMBER2



.

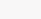





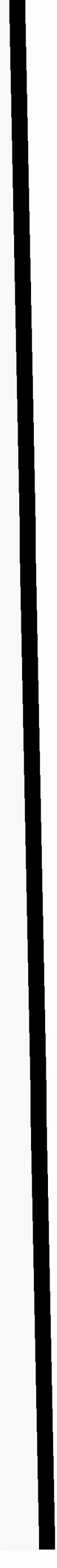





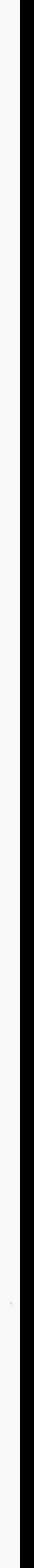





\section{OP System Version: 7C0-427}

HPCAX-326

Time Mark Every $60 \mathrm{~S}$

LDS Caliper (LCAL)

(IN)

14

LDS Bu!k Density Correction (DRH)

(G/C̄ö)
PIP SUMMARY

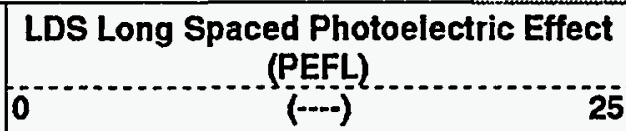

\begin{tabular}{|l|}
\hline \multicolumn{2}{|c|}{ LDS Bulk Density (RHOM) } \\
\hline 1 \\
\hline $60-1 \mathrm{G} 3)$ \\
\hline
\end{tabular}

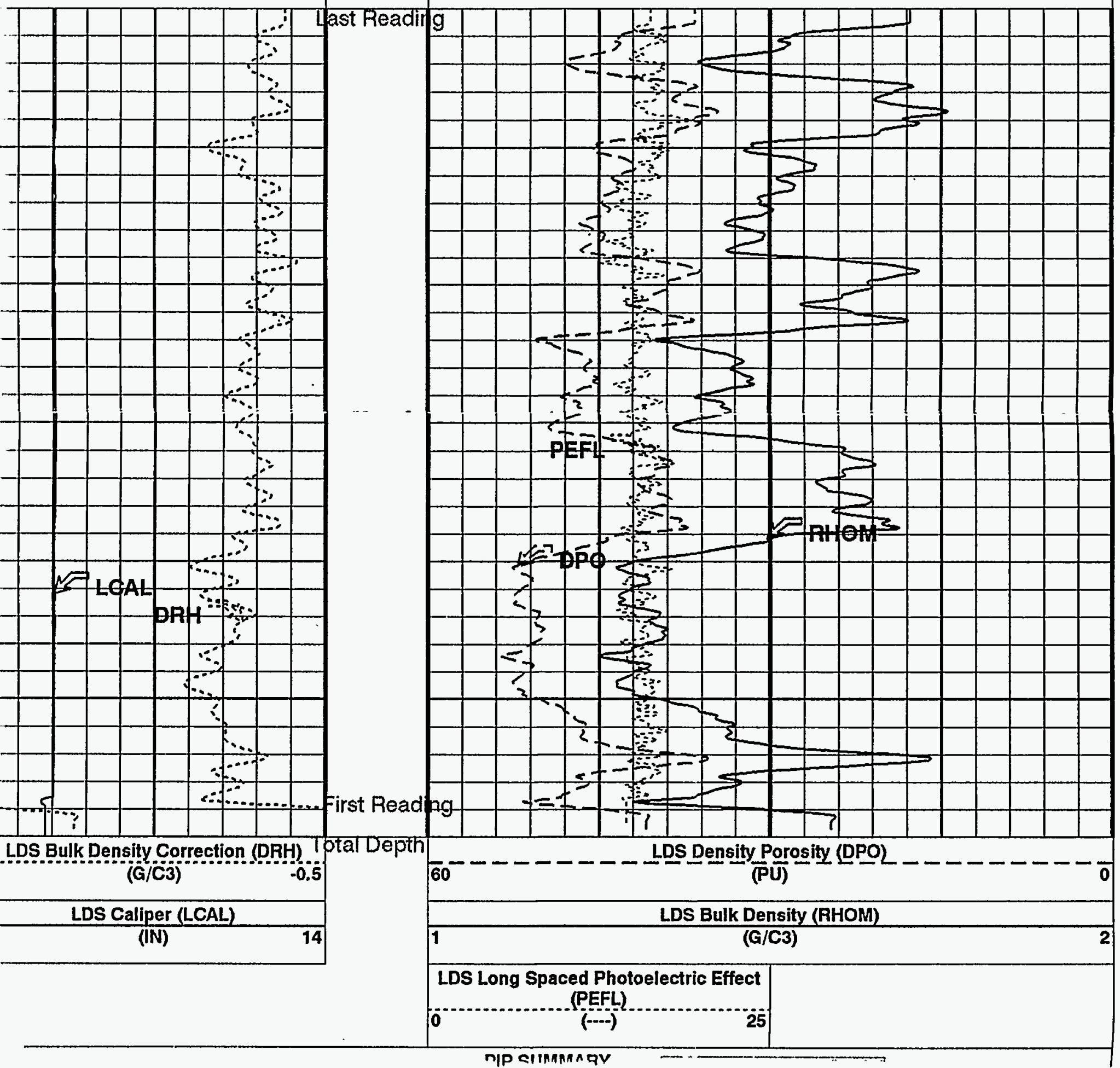




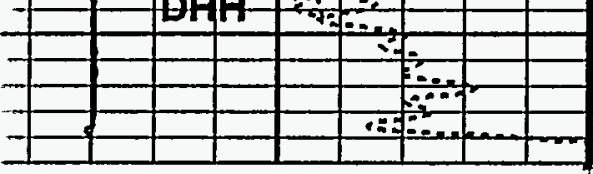

LDS Bulk Density Correction (DRH)

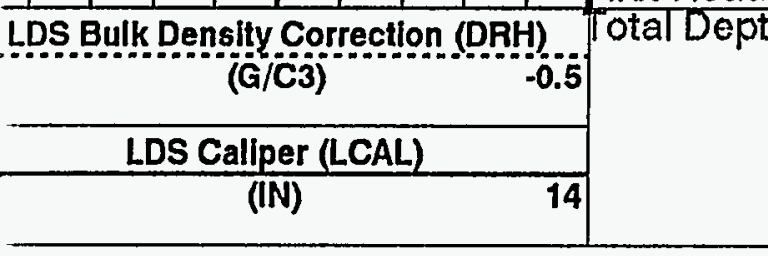

Time Mark Every $60 \mathrm{~s}$

\section{Parameters}

\section{DLIS Name}

Bs

DFD

$\mathrm{DHC}$

DO

DPPM

FD

LATC

LRSP

MDEN $\mathrm{PP}$
Description

Rit Size

Drilling Fluidá Density

Density Hole Correction

Depth Offset

Density Porosity Processing Mode

Fluid Density

LDS Activation Correction Switch

LDS Calibrated with DRS Switch

Matrix Density

Playback Processing
LDS Density Porosity (DPO)

LDS Bulk Density (RHOM)

(G/C3)
(PU)

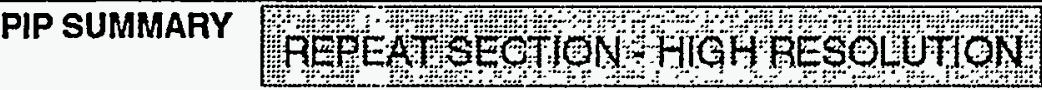

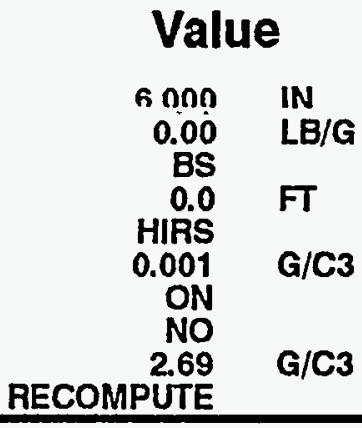

Graphics File Created: 23-JAN-1995 11:56

\section{OP System Version: 7C0-427 MBM}

\section{Input DLIS Files}
DEFAULT
LDS .186
FN:280
FIELD
16-JAN-1995 10:11
$60.0 \mathrm{FT}$
DEFAULT
LDS .295
FN:15
FIELD
23-JAN-1995 11:56
LDS_RED
LDS .295
FN:16
CUST
23-JAN-1995 11:56

Calibration and Check Summary

Measurement

Nominal

Master

Before

After

Change

Limit

Units

itho-Density Sonde Wellsite Calibration - Detector Calibration

Master: Jan 6 12:50 1995 Before: Jan 16 09:04 1995 After: Jan 16 19:43 1995

SS Total Countrate Background

$\begin{array}{lll}1645 & 1587 & 1581\end{array}$

SS HV Measured Background

SS Cs Centroid Background

SS Cs Resolution Background

LS Total Countrate Background

1100

893.6

911.6

661.0

661.4

9.000

8.069

1645

1449

1100

939.9

651.0

660.9

8.139

661.4

8.156

1446

is Ce Centroid Backeround

9.000

957.5

661.4

7.961

1585
894.5
661.5
8.009
1440
943.3
661.3
7.948

3.199

$-17.13$

0.1190

.0 .1467

$-5.990$

$-14.13$

. กำ1?웅

$-0.01259$

80.00
80.00
1.500
1.800
80.00
80.00
1500
1.800

CPS

$V$

KEV

$\%$

CPS

$V$

ho-Density Sonde Wellsite Calibration - Caliper Calibration

Before: Calibration not done

LDS Caliper Small Ring

LDS Caliper Large Ring

8.000
12.00

N/A

N/A

N/A

N/A

N/A

N/A

N/A

N/A

N/A

IN

IN 
Primary Equipment:

Powered Gamma Detector

PGD - K

Gamma Source Radioactive

GSR - J

1952

Auxiliary Equipment:

Density Resistivity Sonde

DRS - C

4838

Powered Detector Housing

$\mathrm{PDH} \cdot \mathrm{L}$

5737

Litho-Density Sonde Wellsite Calibration Detector Calibration

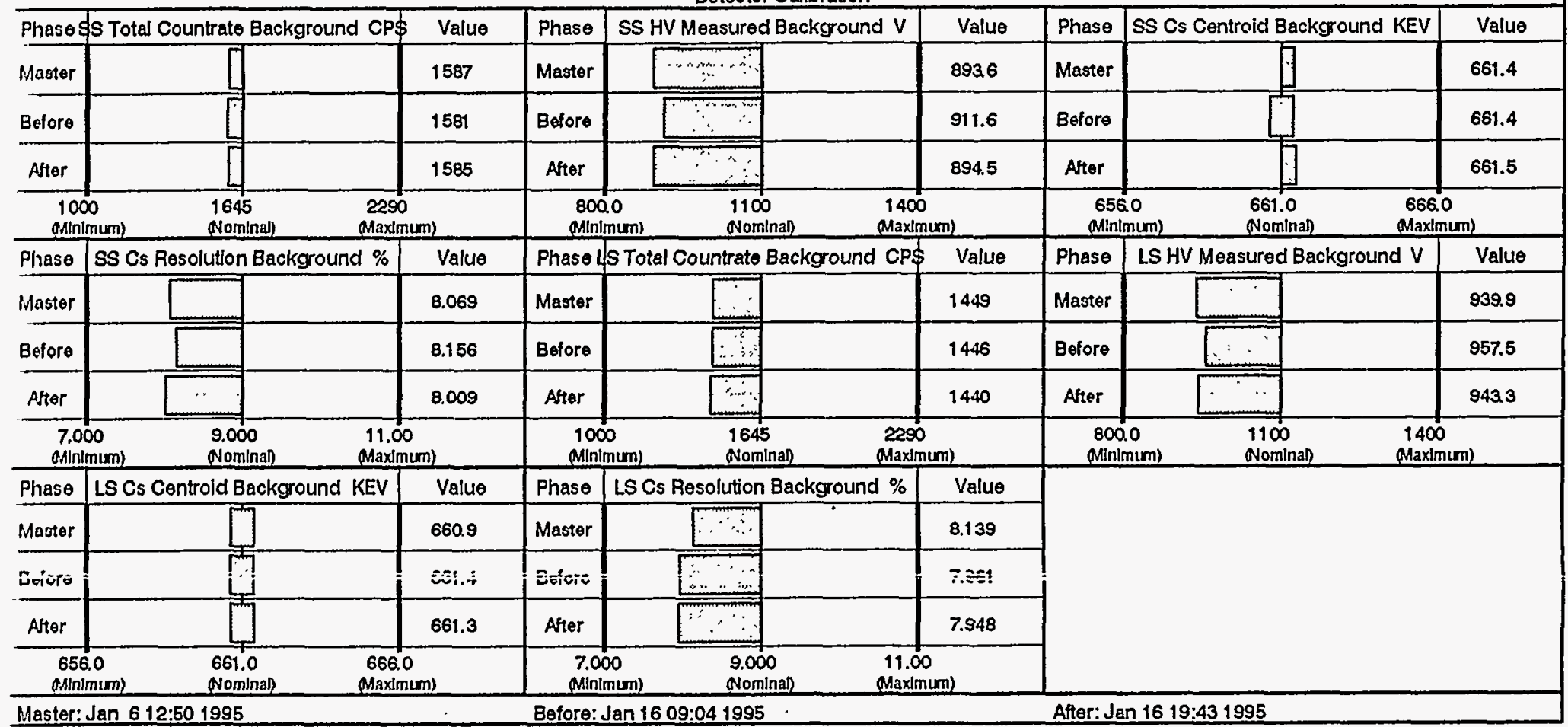

SOMPANY:

FIELD:

gOUNTY:

STATE:
BATTELLE MEMORIAL INSTITUTE

PACIFIC NORTHWEST LABORATORIES

299-E24-92

SISSON/LU INJECTION SITE

BENTON

WASHINGTON

\begin{tabular}{l|l}
\hline BOTTOM LOG INTERVAL & $57 \mathrm{~F}$ \\
\hline SCHLUMBERGER DEPTH & $60 \mathrm{~F}$ \\
\hline DEPTH DRILLER & $60 \mathrm{~F}$ \\
\hline KELLY BUSHING & \\
\hline DRILL FLOOR & \\
\hline GROUND LEVEL & \\
\hline
\end{tabular}

\section{Schlumberger}

\section{LITHO DENSITY TOOL \\ (LDS)}



PACIFIC NORTHWEST LABORATORIES 299-E24-92

\section{SISSON/LU INJECTION SITE}

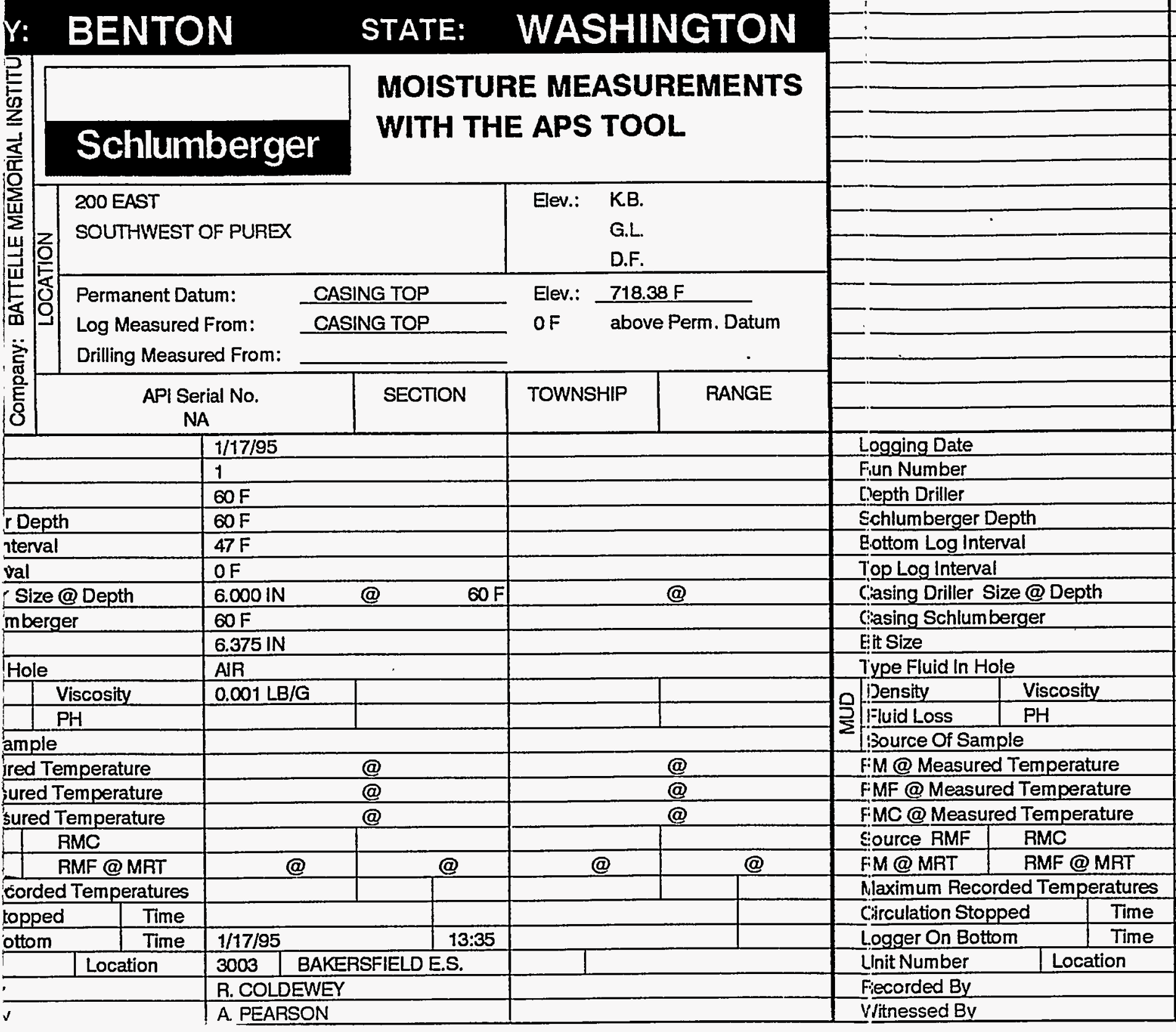

\begin{tabular}{|l|l|l|}
\hline Run 1 & \multicolumn{1}{|c|}{ Run 2 } \\
\hline & \\
\hline & \\
\hline & \\
\hline & \\
\hline & \\
\hline & \\
\hline & & \\
\hline & & \\
\hline & & \\
\hline & & \\
\hline & & \\
\hline & & \\
\hline & \\
\hline
\end{tabular}

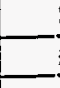

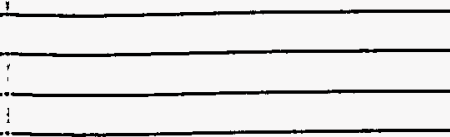

Logging Date

chlumberger Depth

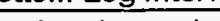

lasing Driller Size @ Depth

asing Schlumberger

Tize

Type Fidu lin Hole viscosity

\begin{tabular}{l|l}
\hline Fluid Loss & $\mathrm{PH}$ \\
\hline
\end{tabular}

Source Of Sample

M @ Measured Temperature

\begin{tabular}{ll}
\hline$M @ M R T$ & RMF @ MRT
\end{tabular}

Mlaximum Recorded Temperatures

Circulation Stopped $\quad$ Time

ogger On Bottom

R. COLDEWEY
A. PEARSON

itnessed By 
ALL INTERPRETATIONS ARE OPINIONS BASED ON INFERENCES FROM ELECTRICAL OR OTHER

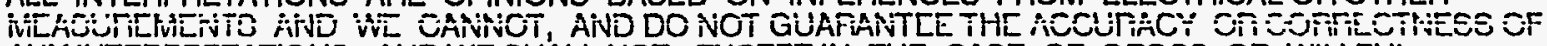
ANY INTERPRETATIONS, AND WE SHALL NOT, EXCEPT IN THE CASE OF GROSS OR WILLFUL NEGLIGENCE ON OUR PART, BE LIABLE OR RESPONSIBLE FOR ANY LOSS, COSTS, DAMAGES OR EXPENSES INCURRED OR SUSTAINED BY ANYONE RESULTING FROM ANY INTERPRETATION MADE BY ANY OF OUR OFFICERS, AGENTS OR EMPLOYEES. THESE INTERPRETATIONS ARE ALSO SUBJECT TO CLAUSE 4 OF OUR GENERAL TERMS AND CONDITIONS AS SET OUT IN OUR CURRENT PRICE SCHEDULE.

\section{OTHER SERVICES1}

OS1: HNGS

OS2: LDS

OS3: CNTG

OS4: APS

OS5:

REMARKS: RUN NUMBER 1

PASS 1 AND 2 AT STANDARD RESOLUTION

PASS 3 AT HIGH RESOLUTION

THE APS CALIBRATION STANDARDS WERE DEVELOPED USING DATA COLLECTED IN THE HANFORD MOISTURE MODELS DURING AUGUST, 1994.

\section{OTHER SERVICES2}

OS1:

OS2:

OS3:

OS4:

OS5:

REMARKS: RUN NUMBER2
SERVICE ORDER \#: PROGRAM VERSION: FLUID LEVEL:
LOGGED INTERVAL 
LEH-Q

LEH-Q

DTC-A

ECH-KN 391

DTC-A 20
$\mathrm{AH}-178$

$\mathrm{AH}-178$

APS-BA APS-BA 45 APH-AC 45 MNTR-F 4311 EME-F
NPLC-B

NPLC-B 53

$\mathrm{NPH}-\mathrm{B} 52$

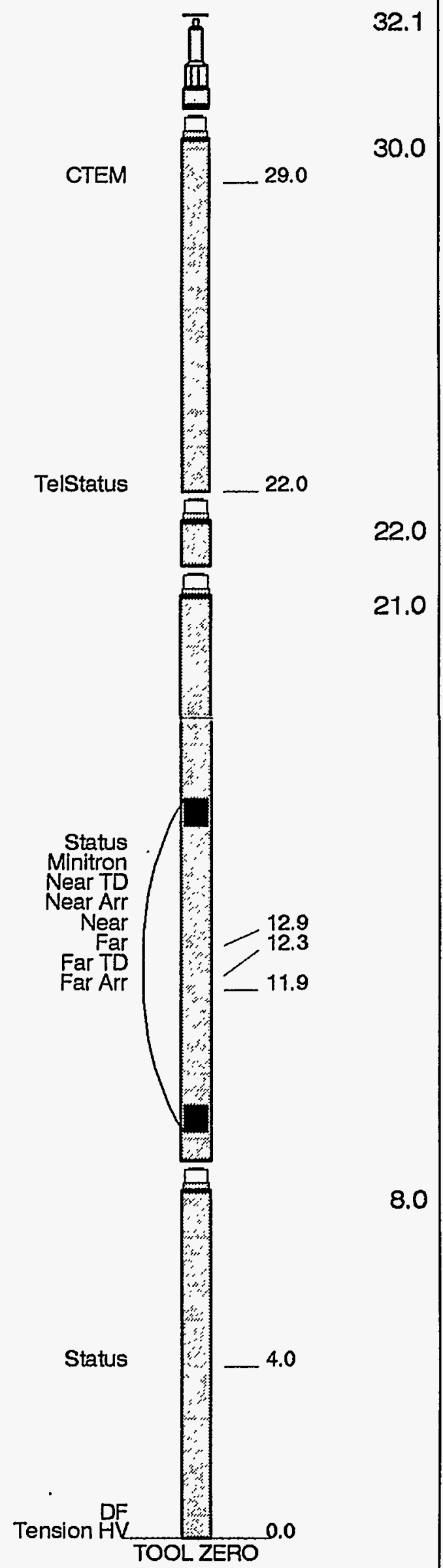




\section{Output DLIS Files}

$\begin{array}{lllllll}\text { DEFAULT } & \text { NPLB } .270 & \text { FN:413 } & \text { FIELD } & \text { 17-JAN-1995 14:09 } & 60.0 \mathrm{FT} & \\ \text { APS_RED } & \text { NPLB .270 } & \text { FN:414 } & \text { CUST } & \text { 17-JAN-1995 14:09 } & & 0.2 \mathrm{FT}\end{array}$

\section{OP System Version: 7C0-427}

NPLC-B

HPCAX-326

APS-BA

HPCAX-326

PIP SUMMARY

Time Mark Every $60 \mathrm{~S}$

APS Slowing Down Time Volume Fraction of Water (SDVW)

PASS 3 HIGLRESOLUTION

60

(\%)

APS Formation Capture Cross-Section (SIGF)

so

(CU)

APS Near/Far Volume Fraction of Water (NFVW)

$60--1 \%)$

$60---1$ APS Near/Array Volume Fraction of Water (NAVW

(U)

$\overline{20}$

0

st Readin

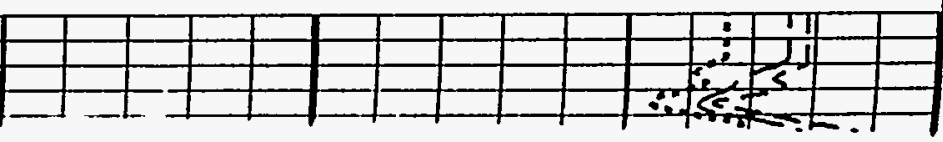


GCSE

GDEV

GTSE

NARC

NFRC

SHT

TD
Generalized Caliper Selection

Average Angular Deviation of Borehole from Normal

Generalized Temperature Selection

APS Near/Array Calibration Ratio

APS Near/Far Calibration Ratio

Surface Hole Temperature

Total Depth $\begin{aligned} \text { LINEAR_ESTIMATE } & \text { DEG } \\ 1.06234 & \\ 0.930565 & \\ 68 & \text { DEGF } \\ 60 & \text { FT }\end{aligned}$

Vertical Scale: $10^{\prime \prime}$ per $100^{\prime}$

Graphics File Created: 17-JAN-1995 14:09

\section{OP System Version: 7C0-427}

HPCAX-326

APS-BA

HPCAX-326

\section{Output DLIS Files}

\begin{tabular}{|c|c|c|c|c|}
\hline DEFAULT & NPLB .270 & FN:413 & FIELD & 17-JAN-1995 14:09 \\
\hline AिTS_FEẼ & ñFîL̃ & Fivi:äia & CUST & ī-JĀ̄̃-i \\
\hline
\end{tabular}

\section{Output DLIS Files}

$\begin{array}{llllll}\text { DEFAULT } & \text { NPLB .269 } & \text { FN:411 } & \text { FIELD } & \text { 17-JAN-1995 13:53 } & 60.0 \text { FT } \\ \text { APS_RED } & \text { NPLB .269 } & \text { FN:412 } & \text { CUST } & \text { 17-JAN-1995 13:53 } & 60.0 \text { FT }\end{array}$

NPLC-B

HPCAX-326

OP System Version: 7C0-427

Time Mark Every $60 \mathrm{~S}$

APS-BA

HPCAX-326

PIP SUMMARY

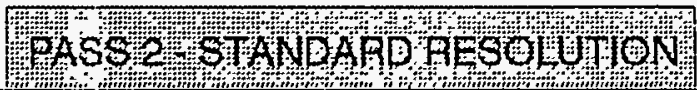

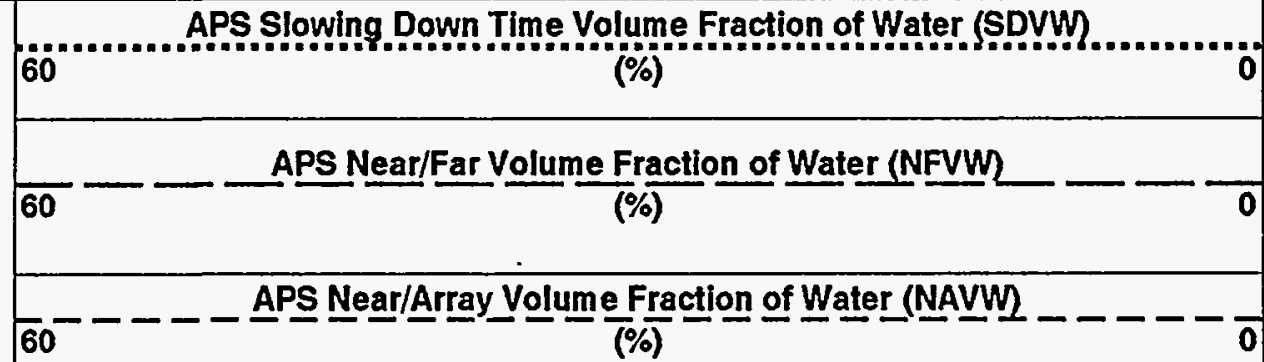

0

(SIGF)

(CU) 0

0

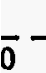

APS Slowing Down Time (STTM)

(U)

$2 \overline{0}$

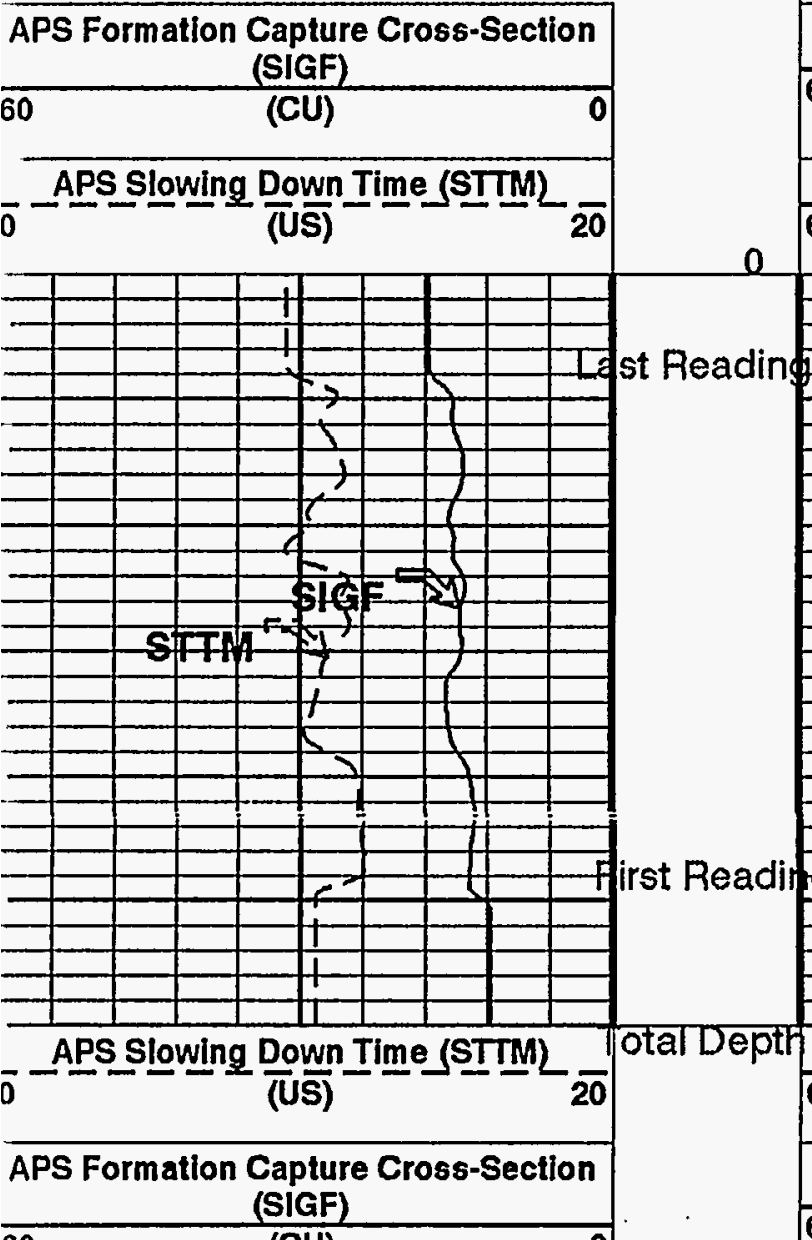

$$
\frac{}{\mathrm{AP}}
$$

APS Slowing Down Time (STTM) Total Depth

$\frac{\text { Down Time (STTM) }}{20}$
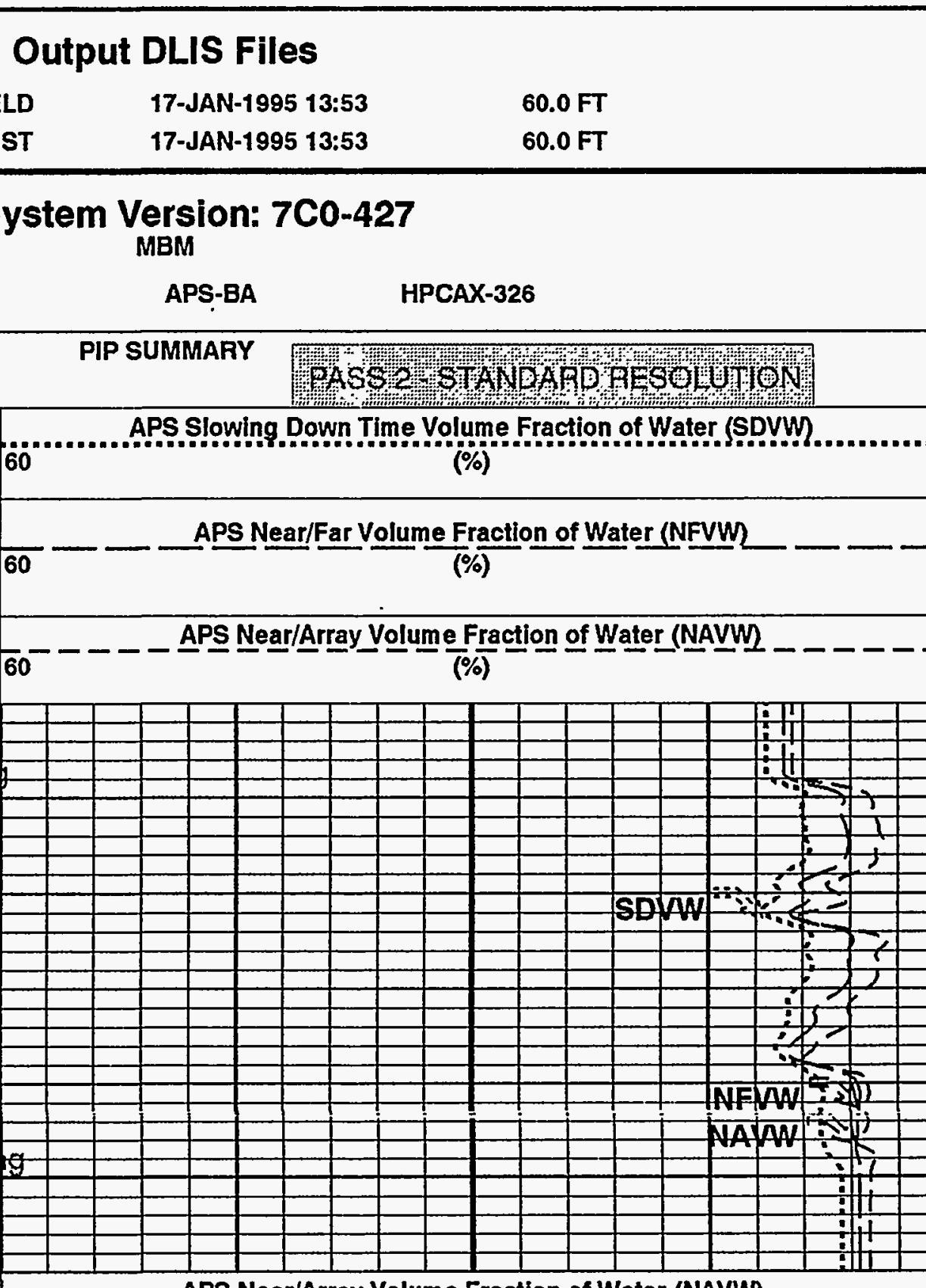

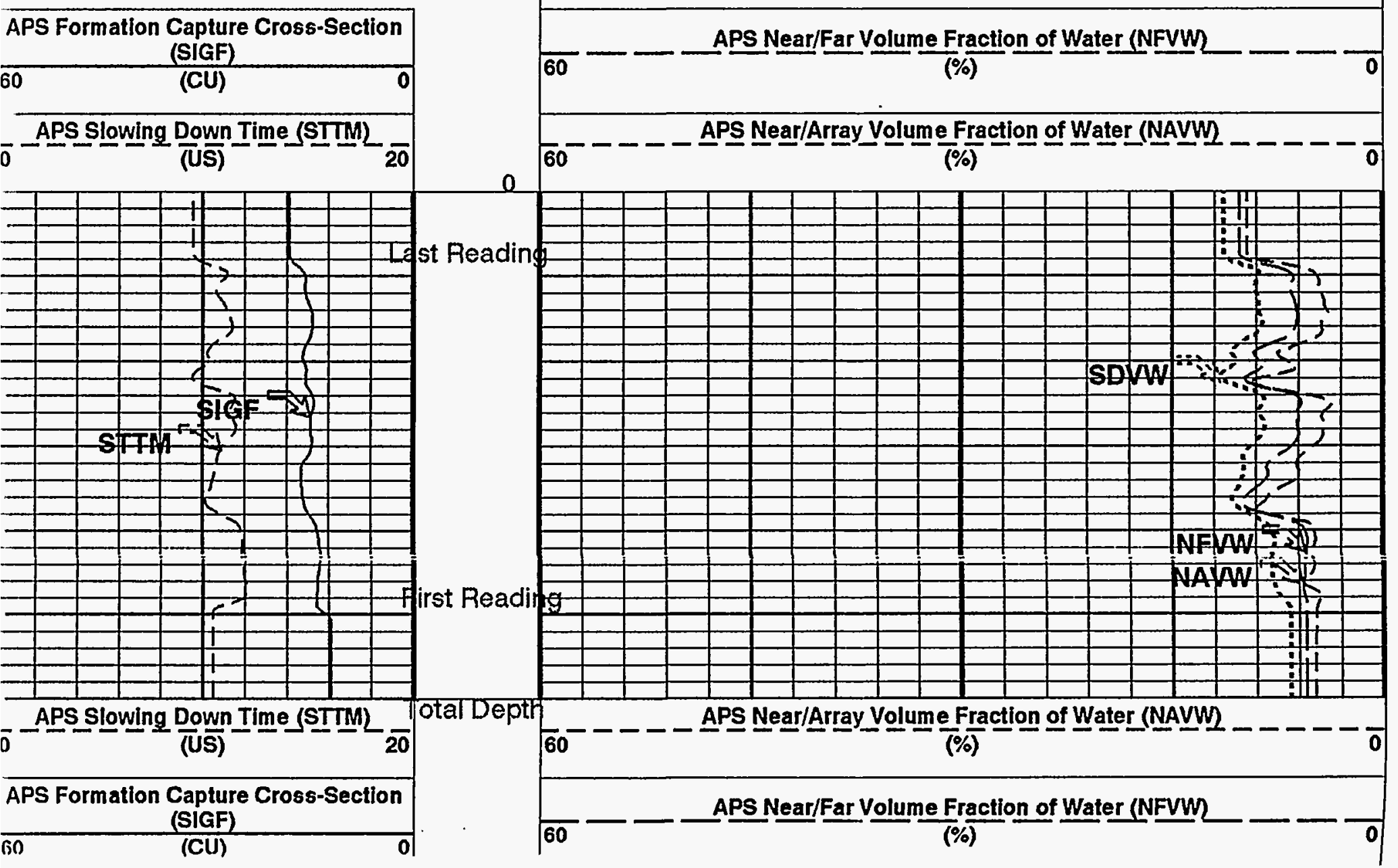




\section{Parameters}

\section{DLIS Name}
ABOS
ACID
ADSO
AHCS
AHSS
AMTY
ASOS
ATSS
AVWT
BHT
BS
BSAL
DFD
DOAL
DPPM
FSAL
GCSE
GDEV
GTSE
NARC
MFRC
SHT
TD

\section{Description}

APS Neutron Burst-Off Background Subtraction Switch

APS Casing Inner Diameter

APS Array Detectors Data Source Switch

APS Holesize Correction Source

APS Holesize Correction Switch

APS Environmental Corrections Mud Type

APS Standoff Correction Switch

APS Temperature-Pressure-Salinity Correction Switch

APS Volume Fraction of Water Transform

Bottom Hole Temperature (used in calculations)

Bit Size

Borehole Salinity

Drilling Fluid Density

Depth Offset Repeat Analysis

Density Porosity Processing Mode

Formation Salinity

Generalized Caliper Selection

Average Angular Deviation of Borehole from Normal

Generalized Temperature Selection

APS Near/Array Calibration Ratio

APS Near/Far Calibration Ratic

Surface Hole Temperature

Total Depth

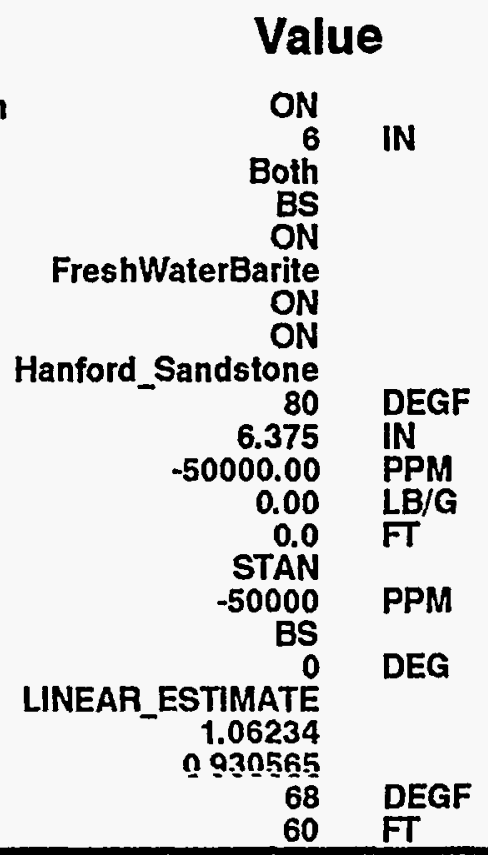

Graphics File Created: 17-JAN-1995 13:53

Format: APSEnvLog

Vertical Scale: $5^{\prime \prime}$ per $100^{\prime}$

\section{OP System Version: $7 \mathrm{CO}-427$}

$\begin{array}{llll}\text { NPLC-B HPCAX-326 HPS-BA } & \text { HPCAX-326 }\end{array}$

\section{Output DLIS Files}

$\begin{array}{lllll}\text { DEFAULT } & \text { NPLB .269 } & \text { FN:411 } & \text { FIELD } & \text { 17-JAN-1995 13:53 } \\ \text { APS_RED } & \text { NPLB } .269 & \text { FN:412 } & \text { CUST } & \text { 17-JAN-1995 13:53 }\end{array}$

\section{Output DLIS Files}

$\begin{array}{llllll}\text { DEFAULT } & \text { NPLB .269 } & \text { FN:411 } & \text { FIELD } & \text { 17-JAN-1995 13:53 } & 60.0 \mathrm{FT} \\ \text { APS_RED } & \text { NPLB .269 } & \text { FN:412 } & \text { CUST } & \text { 17-JAN-1995 13:53 } & 60.0 \mathrm{FT}\end{array}$

\section{OP System Version: 7C0-427}

NPLC-B

HPCAX-326

APS-BA

HPCAX-326

Time Mark Every $60 \mathrm{~S}$

PIP SUMMARY

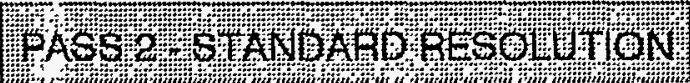

APS Slowing Down Tíme Volume Fraction of Water (SDVW)

60

(\%)

APS Formation Capture Cross-Section (SIGF)

APS Near/Far Volume Fraction of Water (NFVW)

(CU) 0

60

(\%)

60

5

APS Slowing Down Time (STTM)

(U) $\bar{S}$ ) $-\overline{20}$

-

0

$60---0-7$
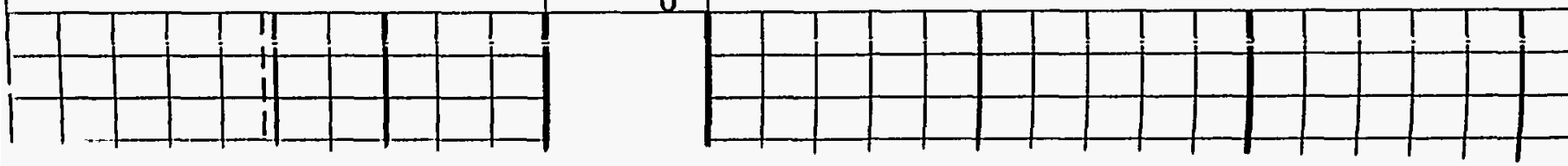


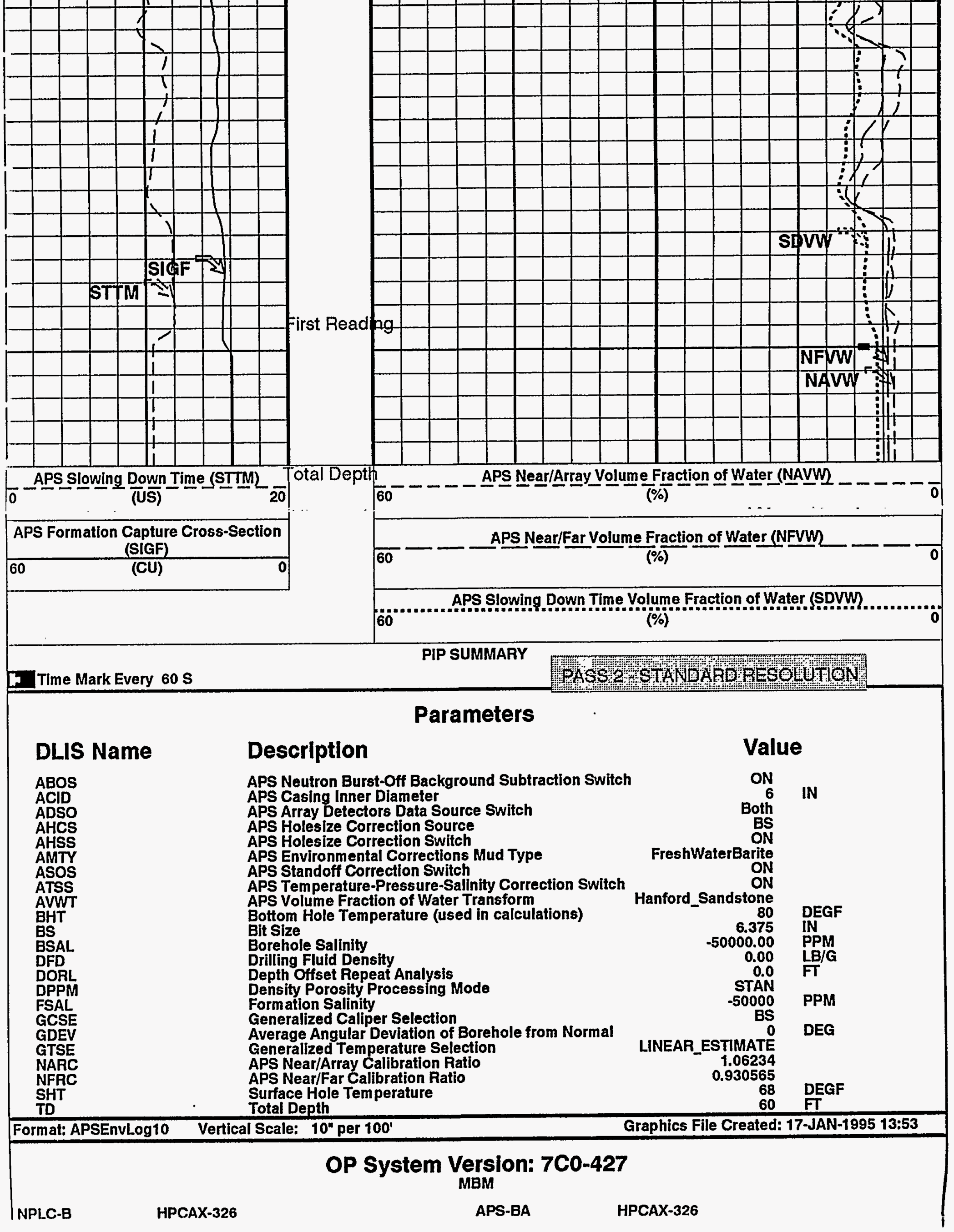




\section{Input DLIS Files}

$\begin{array}{llllll}\text { DEFAULT NPLB .267 FN:407 FIELD } & \text { 17-JAN-1995 13:30 } & \text { 60.0 FT }\end{array}$

\section{Output DLIS Files}

$\begin{array}{lllll}\text { DEFAULT } & \text { NPLB .269 } & \text { FN:411 } & \text { FIELD } & \text { 17-JAN-1995 13:53 } \\ \text { APS_RED } & \text { NPLB .269 } & \text { FN:412 } & \text { CUST } & \text { 17-JAN-1995 13:53 }\end{array}$

\section{OP System Version: $7 \mathrm{CO}-427$}

NPLC-B HPCAX-326

Time Mark Every $60 \mathrm{~S}$

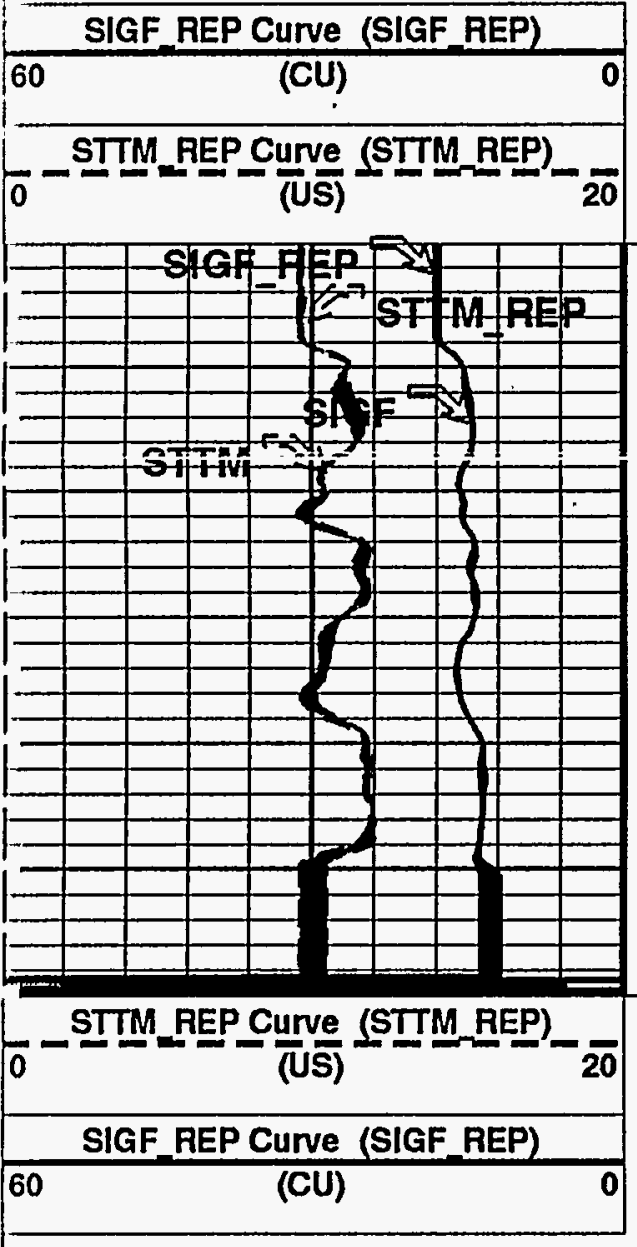

Time Mark Every $60 \mathrm{~s}$

\section{DLIS Name}

ABOS

$A C I D$

ADSO
APS-BA

HPCAX-326

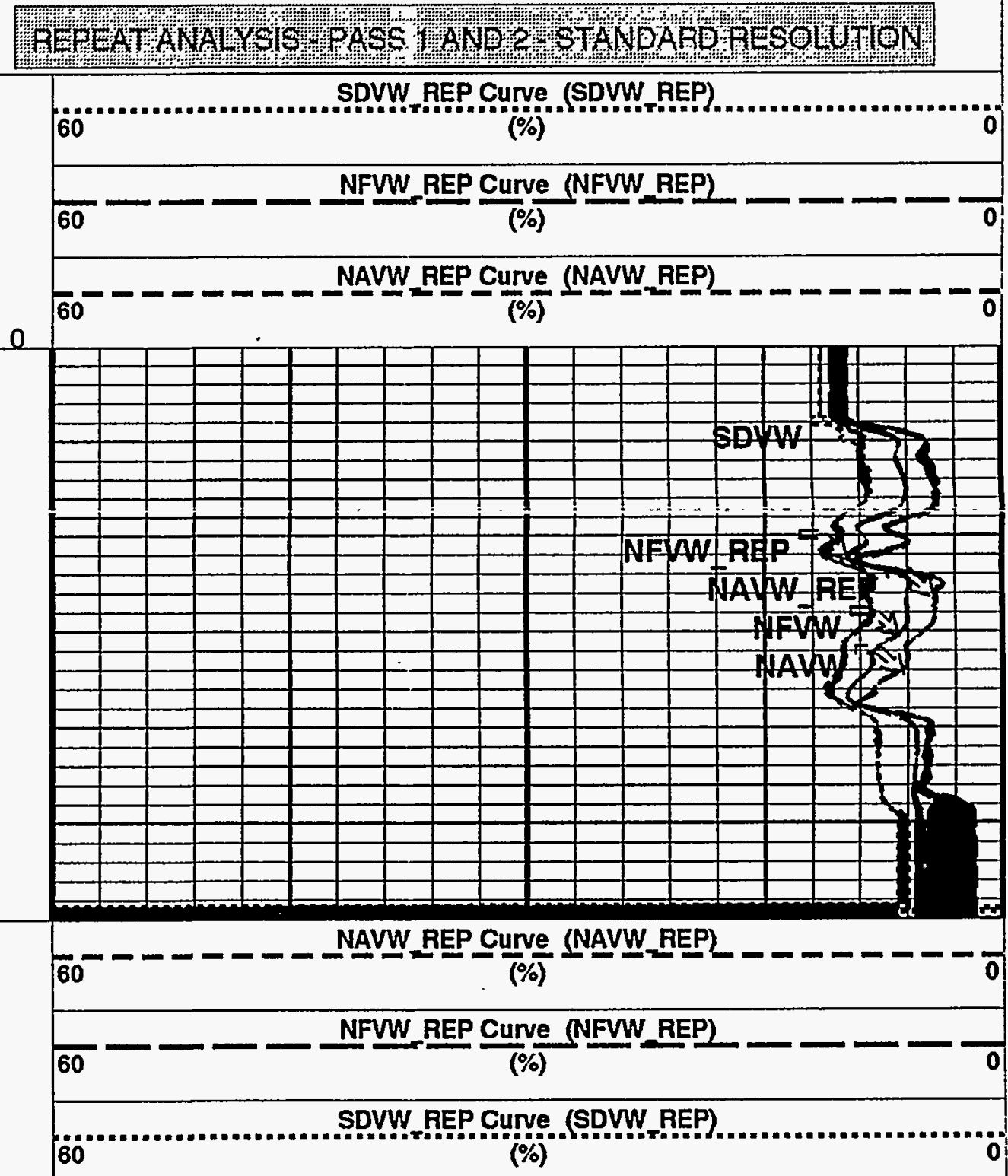

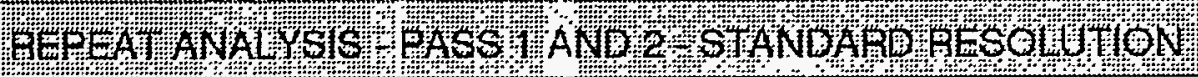

\section{Parameters}

Description

APS Neutron Burst-Off Background Subtraction Switch

APS Casing Inner Diameter

APS Array Detectors Data Source Switch

\section{Value}

ON

6 IN 


\begin{tabular}{|c|}
\hline SIGF REP Curve (SIGF_REP) \\
\hline 60
\end{tabular}

\section{Parameters}

\section{DLIS Name}

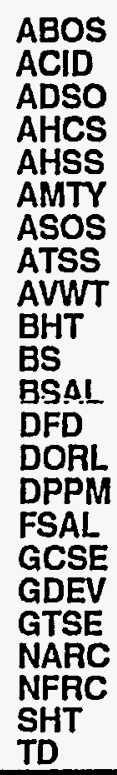

\section{Description}

APS Neutron Burst-Off Background Subtraction Switch

APS Casing Inner Diameter

APS Array Detectors Data Source Switch

APS Holesize Correction Source

APS Holesize Correction Switch

APS Environmental Corrections Mud Type

APS Standoff Correction Switch

APS Temperature-Pressure-Salinity Correction Switch

APS Volume Fraction of Water Transform

Bottom Hole Temperature (used in calculations)

Bit Size

Borehole Salinity

Drilling Fluid Density

Depth Offset Repeat Analysis

Density Porosity Processing Mode

Formation Salinity

Generalized Caliper Selection

Average Angular Deviation of Borehole from Normal

Generalized Temperature Selection

APS Near/Array Calibration Ratio .

APS Near/Far Calibration Ratio

Surface Hole Temperature

Total Depth

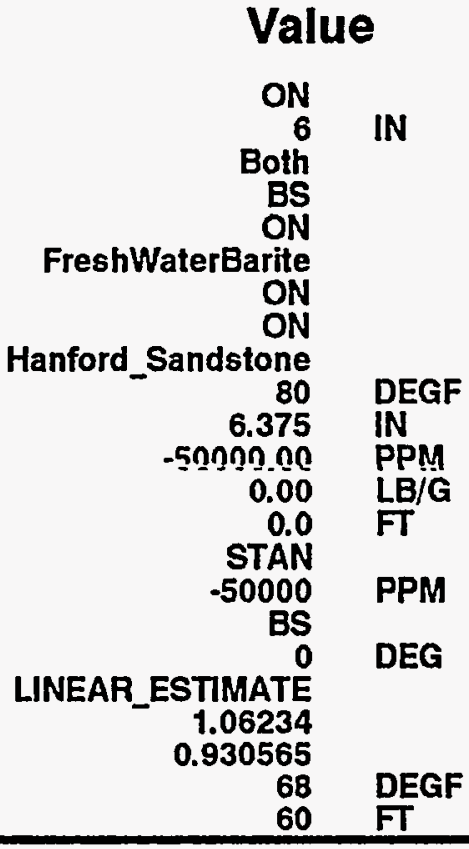

Graphics File Created: 17-JAN-1995 13:53

Format: APSEnvLog_REP Vertical Scale: $5^{n}$ per $100^{\prime \prime}$

\section{OP System Version: 7C0-427}

$\begin{array}{llll}\text { NPLC-B } & \text { HPCAX-326 } & \text { APS-BA } & \text { HPCAX-326 }\end{array}$

\section{Input DLIS Files}

$\begin{array}{lllll}\text { DEFAULT NPLB .267 FN:407 FIELD 17-JAN-1995 13:30 } & \text { 60.0 FT }\end{array}$

\section{Output DLIS Files}

$\begin{array}{lllll}\text { DEFAULT } & \text { NPLB .269 } & \text { FN:411 } & \text { FIELD } & \text { 17-JAN-1995 13:53 } \\ \text { APS_RED } & \text { NPLB .269 } & \text { FN:412 } & \text { CUST } & \text { 17-JAN-1995 13:53 }\end{array}$

Calibration and Check Summary

Measurement

Nominal

Master

Before

After

Change

Limit

Units

Accelerator-Porosity Sonde Wellsite Calibration - Detector Background

Master: Jan 6 14:51 1995 Before: Jan 17 12:20 1995 After: Jan 17 15:09 1995

Near Detector HV Background

Far Detector HV Background

Array Detector HV Background

1650

1730
2020

1728

2017

1954

1729
2019
1955

1.664

1.137

0.7418

20.00

20.00

20.00

V
V
V 
Primary Equipment:

Accelerator-Porosity Sonde

APS Minitron

Auxillary Equipment:

Accelerator-Porosity Housing

APS Calibration Water Tank

APS Aluminium Callbrator Sleeve $\begin{array}{ll}\text { APS - BA } & 45 \\ \text { MNTR - F } & 4311\end{array}$

APH $\cdot$ AC $\quad 45$

SFT. $178 \quad 20$

SFT - $281 \quad 7$

Accelerator-Porosity Sonde Wellsite Calibration Detector Background

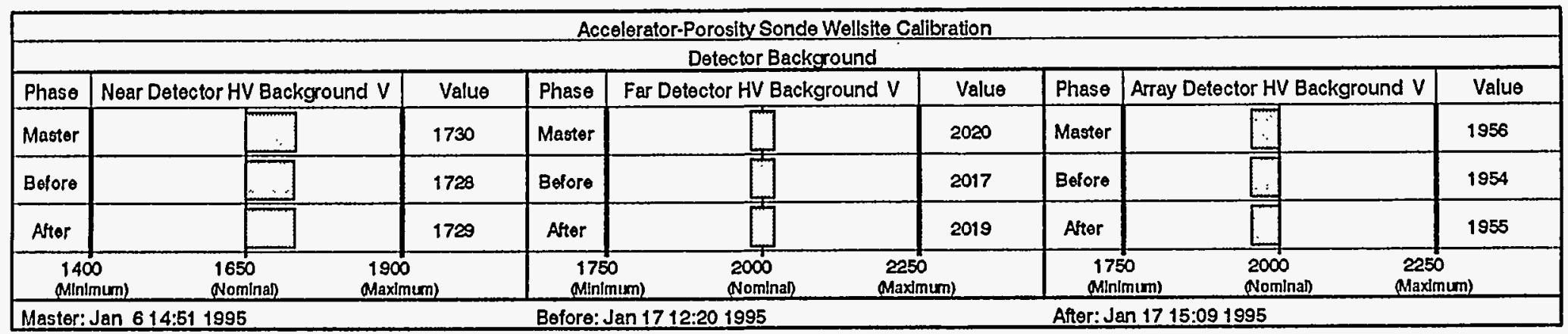

\section{COMPANY: \\ BATTELLE MEMORIAL INSTITUTE \\ WELL: \\ FIELD: \\ COUNTY: \\ STATE: 299-E24-92 \\ SISSON/LU INJECTION SITE BENTON WASHINGTON} PACIFIC NORTHWEST LABORATORIES

\begin{tabular}{|l|l|}
\hline BOTTOM LOG INTERVAL & $47 \mathrm{~F}$ \\
\hline SCHLUMBERGER DEPTH & $60 \mathrm{~F}$ \\
\hline DEPTH DRILLER & $60 \mathrm{~F}$ \\
\hline KELLY BUSHING & \\
\hline DRILL FLOOR & \\
\hline GROUND LEVVEL & \\
\hline
\end{tabular}

\section{MOISTURE MEASUREMENTS WITH THE APS TOOL}

Schlumberger 
ANY INTERPRETATIONS, AND WE SHALL NOT, EXCEPT IN THE CASE OF GROSS OR WILLFUL

NEGLIGENCE ON OUR PART, BE LIABLE OR RESPONSIBLE FOR ANY LOSS, COSTS, DAMAGES OR

EXPENSES INCURRED OR SUUSTAINED BY ANYONE RESULTING FROM ANY INTERPRETATION MADE BY

ANY OF OUR OFFICERS, AGENTS OR EMPLOYEES. THESE INTERPRETATIONS ARE ALSO SUBJECT TO

CLAUSE 4 OF OUR GENERAL TERMS AND CONDITIONS AS SET OUT IN OUR CURRENT PRICE SCHEDULE.

\section{OTHER SERVICES1}

OS1: HNGS

OS2: LDS

OS3: CNTG

OS4: APS

OS5:

REMARKS: RUN NUMBEA 1

THE CNTG EPITHERMAL NEUTRON CALIBRATION STANDARDS WERE

DEVELOPED USING DATA COLLECTED IN THE PASCO MOISTURE

CALIBRATION FACILITY DURING AUGUST, 1994.

\section{OTHER SERVICES2}

OS1:

OS2:

OS3:

OS4:

OS5:

REMARKS: RUN NUMBER2
SERVICE ORDER \#:

PROGRAM VERSION:

FLUID LEVEL:

LOGGED INTERVAL
RUN 1

657025

$7 \mathrm{C0}-427$
SERVICE ORDER \#:

PROGRAM VERSION

FLUID LEVEL:
RUN 2 LOGGED INTERVAL

\begin{tabular}{|l|l|l|}
\hline START & STOP \\
\hline & & \\
\hline & & \\
\hline & & \\
\hline
\end{tabular}

\section{EQUIPINENT DESCRIPTION}

RUN 1

RUN 2

CNB-AB 4321

NCT-B 507

NCS-VB

TCM-AB 465

\section{SURFACE EQUIPMENT}

STOP

\section{DOWNHOLE EQUIPMENT}


LEH-Q

LEH-Q

TCC-B

ECH-KC 289

TCC-B 591
CNT-G

CND-NA

NLS-KL 2559

NSR-F 2559

CNC-GA 180

CNH-G 189

BOW-SPR

$\mathrm{NPV}-\mathrm{N}$
17.3

15.1

12.1

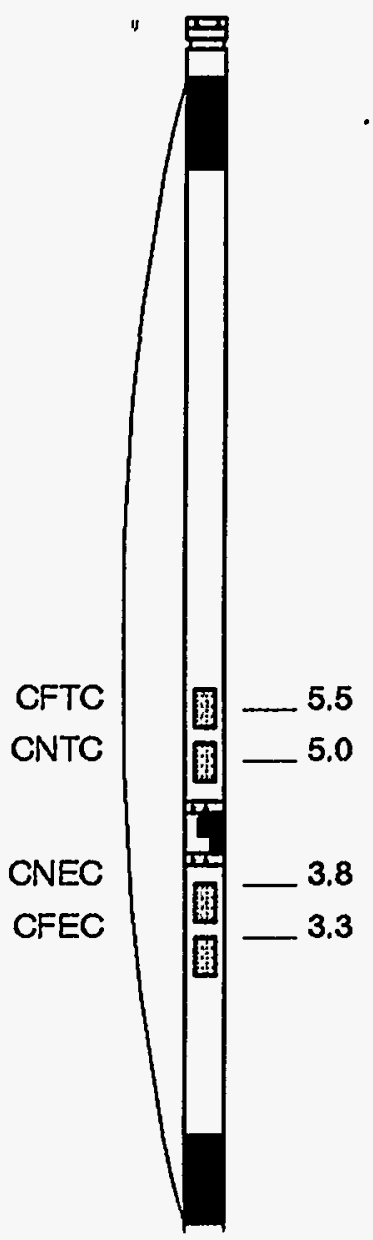

12.1

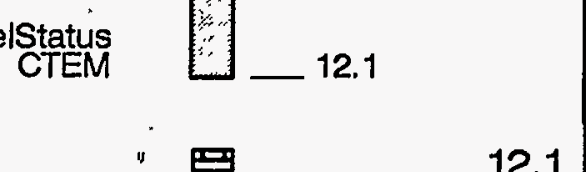

(2.1 


\section{Output DLIS Files}

$\begin{array}{cccccc}\text { DEFAULT } & \text { CNTG .095 } & \text { FN:137 } & \text { FIELD } & \text { 13-JAN-1995 10:34 } & 60.0 \mathrm{FT} \\ \text { CNTG_RED } & \text { CNTG .095 } & \text { FN:138 } & \text { FIELD } & \text { 13-JAN-1995 10:34 } & 60.0 \mathrm{FT}\end{array}$

\section{OP System Version: 7C0-427} MBM
PIP SUMMARY

$$
\text { NEAR/FAR RATIO (LCO3) }
$$

$$
\frac{1}{(-\cdots)}-\left(\frac{1}{1}\right.
$$




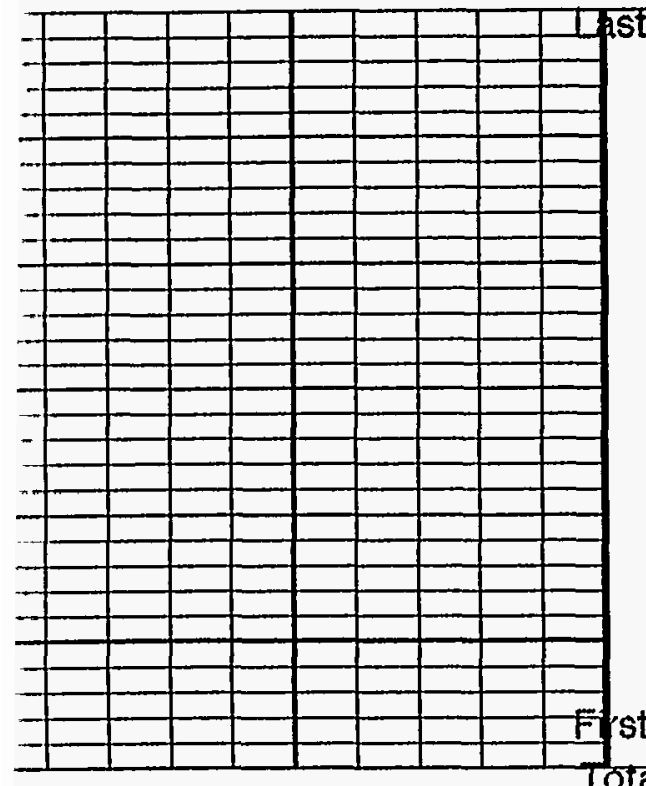

Total Deptis
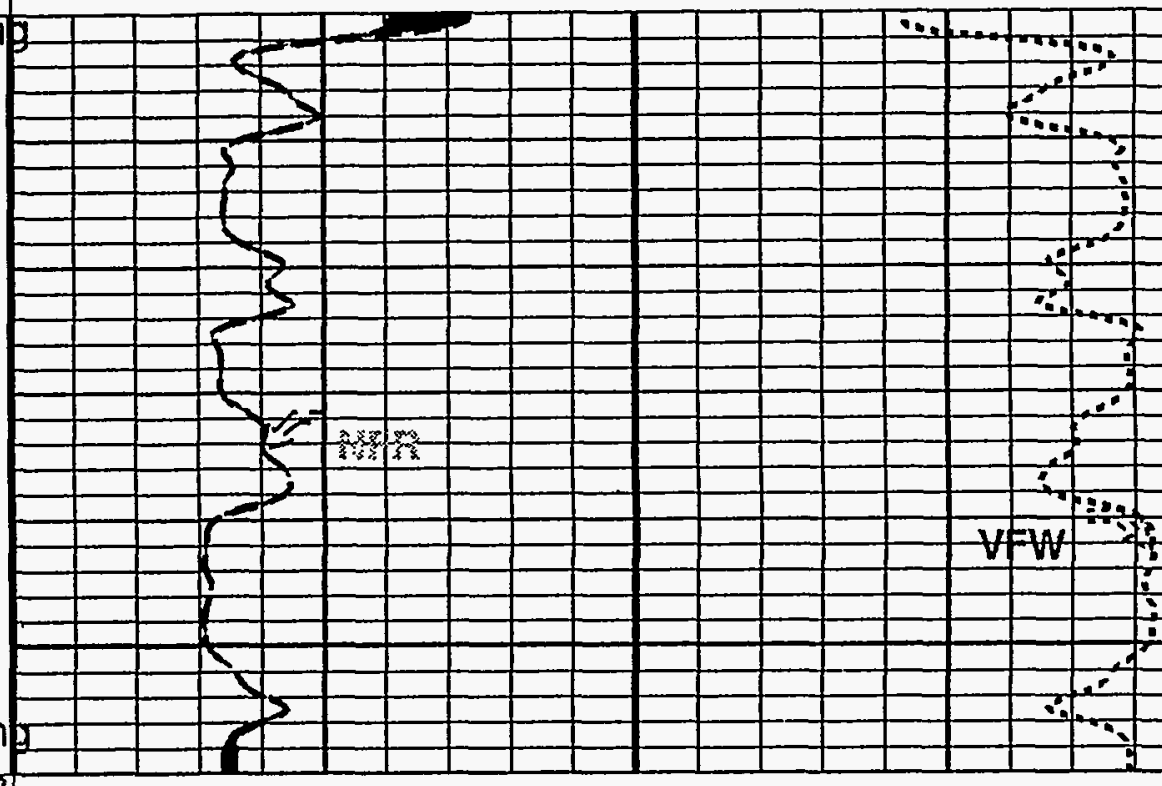

60

УOLUME FRACJIOU RE.WAJER. 6". SASED AIR BOBEHPLE(LCOU) $(---)$

\section{Parameters}

\begin{tabular}{llll} 
DLIS Name & Description $\ldots \ldots$ & $\ldots$ & \multicolumn{2}{c}{ Value } \\
DORL & Depth Offset Repeat Analysis & $\ldots .0$ FT
\end{tabular}
ormat: CNTG_REP Vertical Scale: $5^{\prime \prime}$ per 100'

\section{OP System Version: 7C0-427 MBM}

\section{Input DLIS Files}

$\begin{array}{llllll}\text { DEFAULT CNTG } & 094 & \text { FN:135 FIELD 13-JAN-1995 10:20 } & \text { 60.5 FT }\end{array}$

\section{Output DLIS Files}

\begin{tabular}{|c|c|c|c|c|c|c|c|}
\hline \multicolumn{8}{|c|}{ Callbration and Check Summary } \\
\hline Measurement & Nominal & Master & Before & After & Change & Limit & Units \\
\hline $\begin{array}{l}\text { Compensated Neutron = } \\
\text { Master: Jan } 5 \text { 16:11 } 1985 \\
\text { CNTC Background } \\
\text { CFTC Background } \\
\text { CNEC Background } \\
\text { CFEC Background }\end{array}$ & $\begin{array}{l}\text { Zero Mee } \\
21995 \mathrm{~A} \\
1.000 \\
0 \\
1.000 \\
0\end{array}$ & $\begin{array}{l}\text { int } \\
1319: 0 \\
0.2594 \\
0.2593 \\
0 \\
0.2593\end{array}$ & $\begin{array}{l}0 \\
0 \\
0 \\
0\end{array}$ & $\begin{array}{l}0.8054 \\
2.956 \\
0 \\
0.5377\end{array}$ & $\begin{array}{l}0.8054 \\
2.956 \\
0 \\
0.5377\end{array}$ & $\begin{array}{l}\text { N/A } \\
\text { N/A } \\
\text { N/A } \\
\text { N/A }\end{array}$ & $\begin{array}{l}\text { CPS } \\
\text { CPS } \\
\text { CPS } \\
\text { CPS }\end{array}$ \\
\hline $\begin{array}{l}\text { Compensated Neutron - } \\
\text { Master: Jan } 5 \text { 17:52 } 1995 \\
\text { CNTC Jig } \\
\text { CFTC Jig } \\
\text { CNTC/CFTC (Jig) }\end{array}$ & $\begin{array}{l}\text { Jig Meas } \\
71995 \text { A } \\
3046 \\
1258 \\
2.420\end{array}$ & $\begin{array}{l}\text { nt } \\
1319: 0 \\
3046 \\
1258 \\
2.420\end{array}$ & $\begin{array}{l}3039 \\
1241 \\
2.449\end{array}$ & $\begin{array}{l}3021 \\
1239 \\
2.438\end{array}$ & $\begin{array}{l}-18.12 \\
-2.092 \\
-0.01049\end{array}$ & $\begin{array}{l}N / A \\
N / A \\
N / A \\
\cdots \cdots\end{array}$ & $\begin{array}{l}\text { CPS } \\
\text { CPS } \\
\end{array}$ \\
\hline
\end{tabular}


BATTELLE MEMORIAL INSTITUTE PACIFIC NORTHWEST LABORATORIES 299-E24-92

\section{SISSON/LU INJECTION SITE}

\section{BENTON STATE: WASHINGTON}

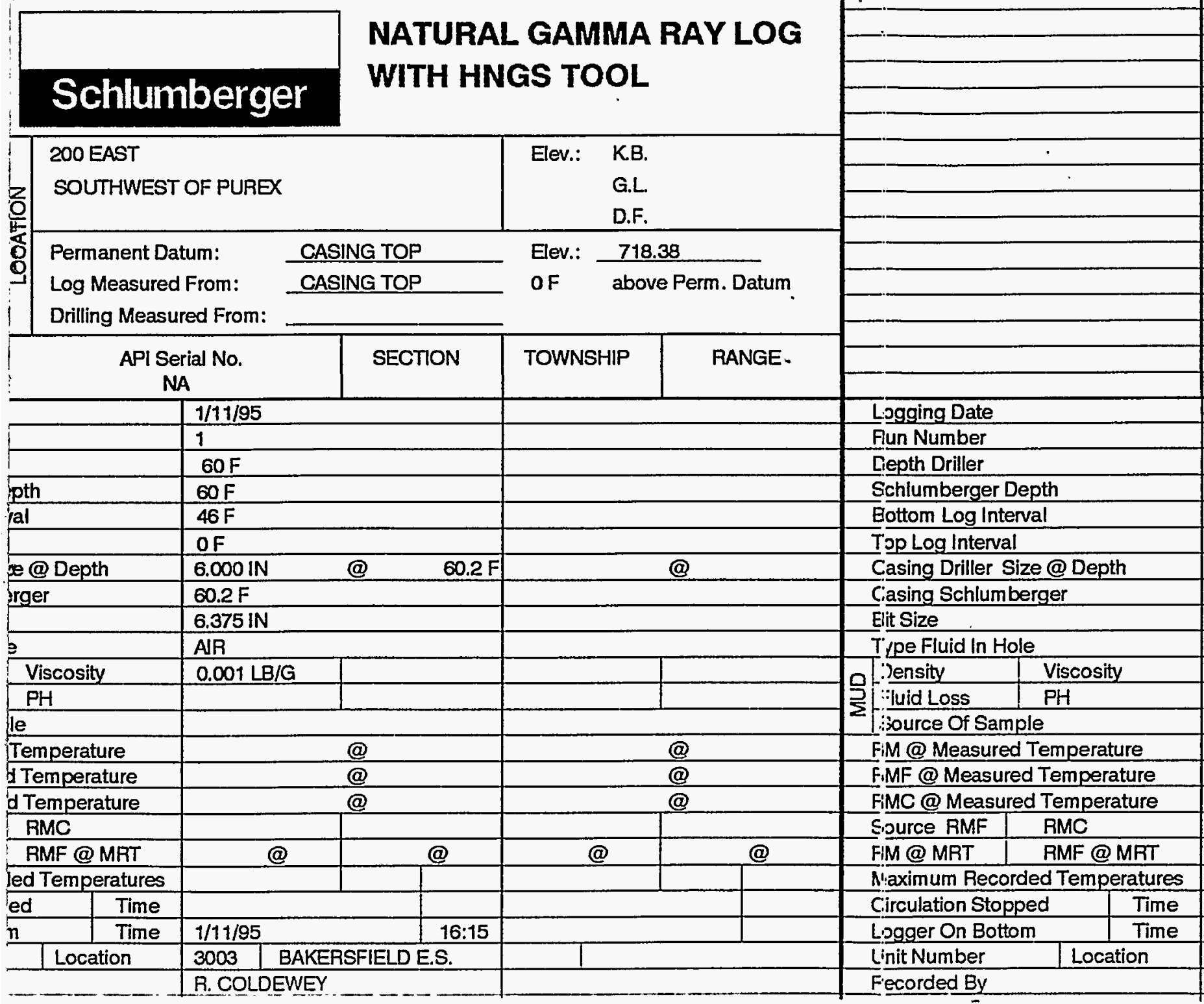

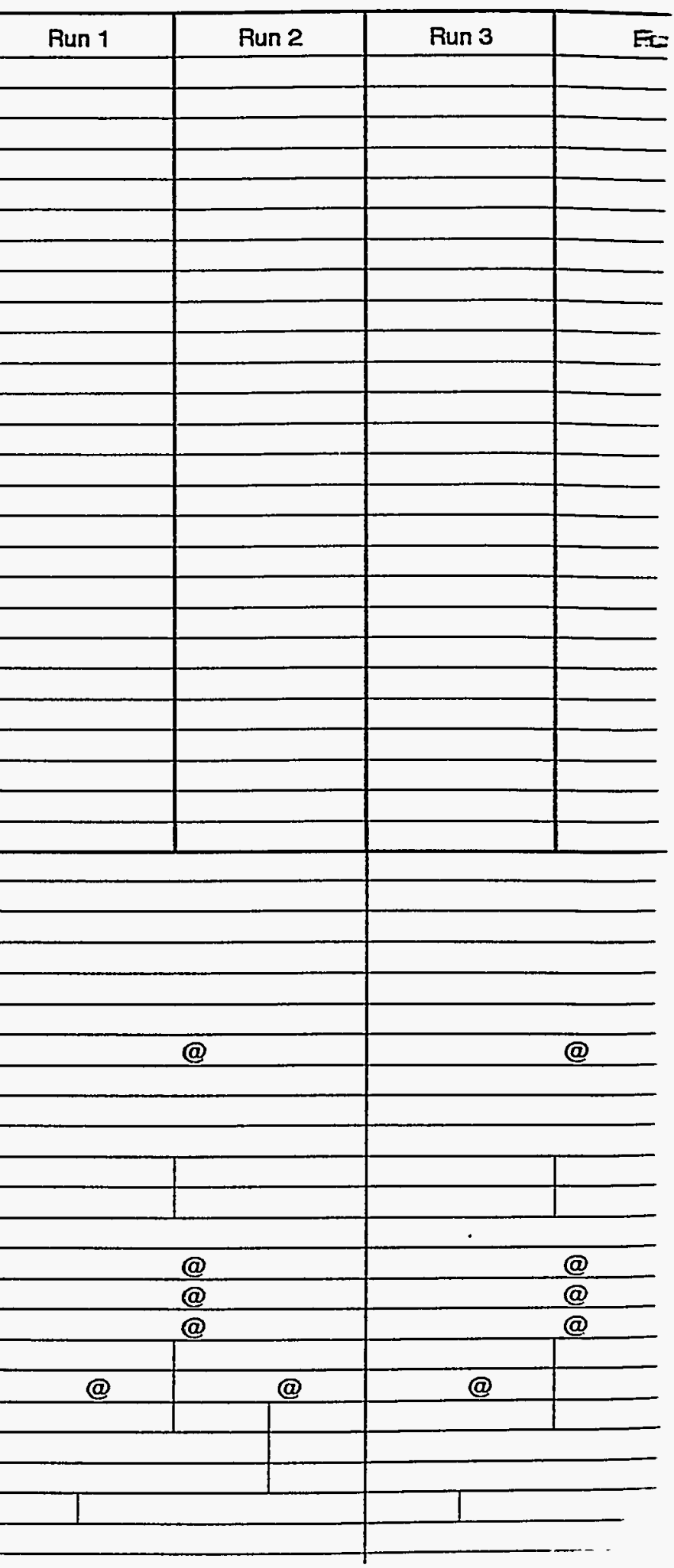




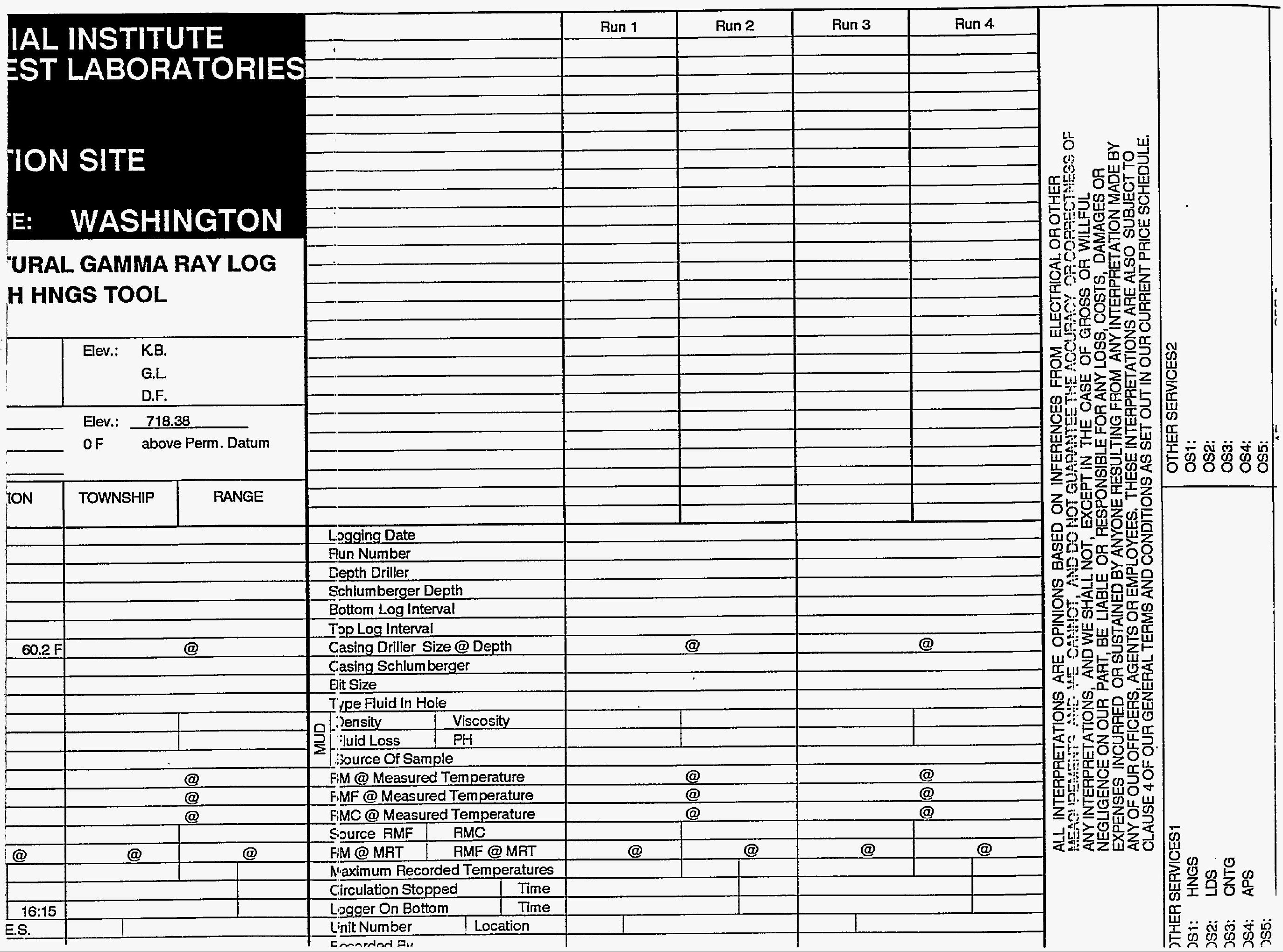


SERVICE ORDER \#:

PROGRAM VERSION:

FLUID LEVEL:

LOGGED INTERVAL
RUN 1

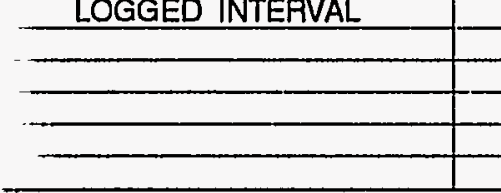

RUN 1
SERVICE ORDER \#:

PROGRAM VERSION:

FLUID LEVEL:
RUN 2

STOP LOGGED INTERVAL

\section{EQUIPMENT DESCRIPTION}

JTM-B 8216

\section{DOWNHOLE EQUIPMENT}

TTC-A

$\mathrm{CH}-\mathrm{KN} 391$

TTC-A 20

$\mathrm{EH}-\mathrm{Q}$

$\mathrm{EH}-\mathrm{Q}$

NGS-BA

INGS-BA 12

INSH-BA 12

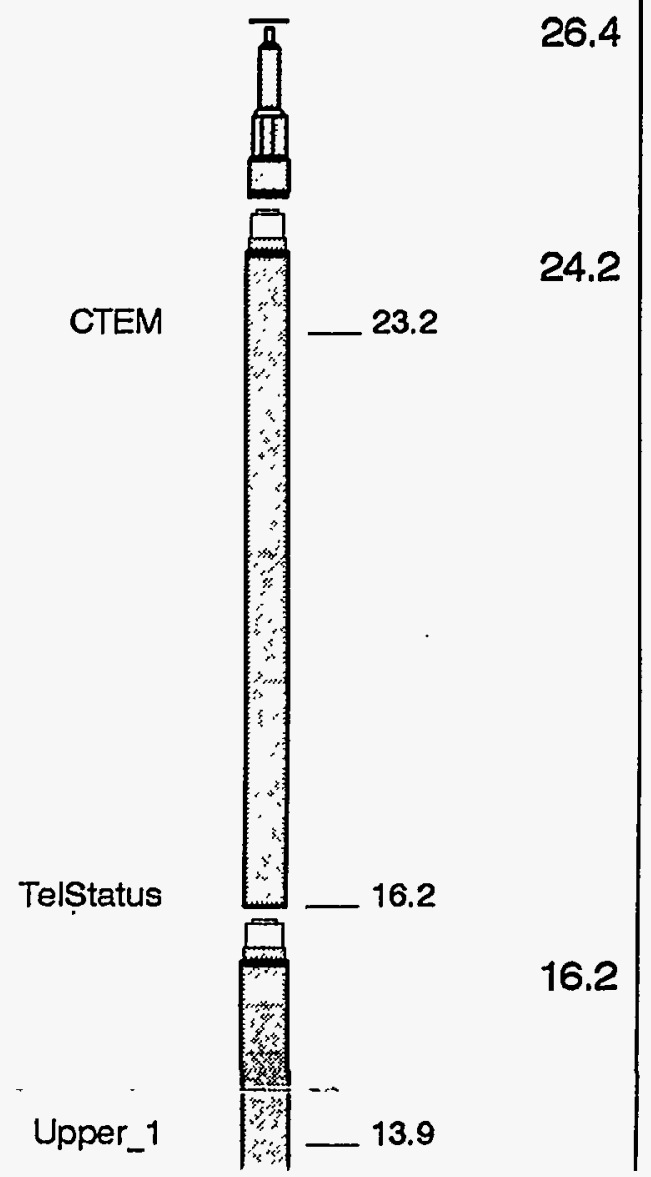


HNGS-BA

HPCAX-326

PIP SUMMARY

Time Mark Every $60 \mathrm{~S}$

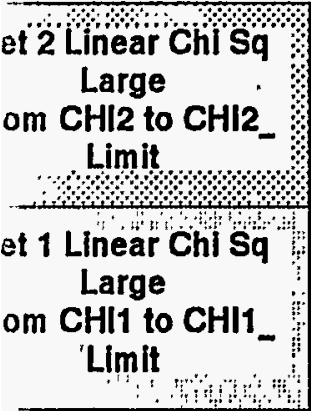

INGS Spectroscopy Gamma Ray (HSGA)

(GAPI)

VGS Det.2 Resolution Degradation

--- Factor (RDF2) $--\cdots)--\frac{1}{10}$

$$
\frac{1}{(--)}-2---\frac{1}{10}
$$

VGS Det.1 Resolution Degradation Factor (RDF1)

$(--)$

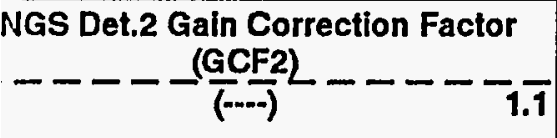

NGS Det.1 Gain Correction Factor (GCF́1)

$(\ldots-$.

1.1

HNGS Det.2 Chi Squared (CHI2)

(-...)

HNGS Det.1 Chi Squared (CHI1)

(---)

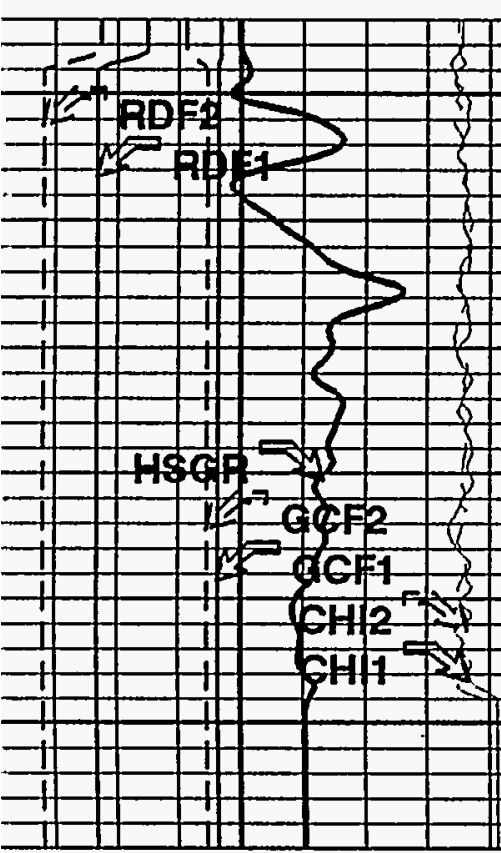

HNGS Det.1 Chi Squared (CHI1)

(---)

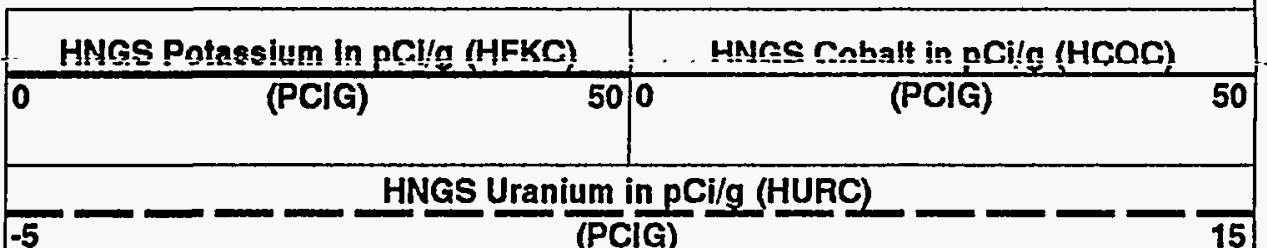

HNGS Thorlum in pCi/g (HTHC) _ _ _ HNGS Cesium in pCi/g (HCSC)

$0-(\overline{P C I G})-(\overline{P C I G})-2010$

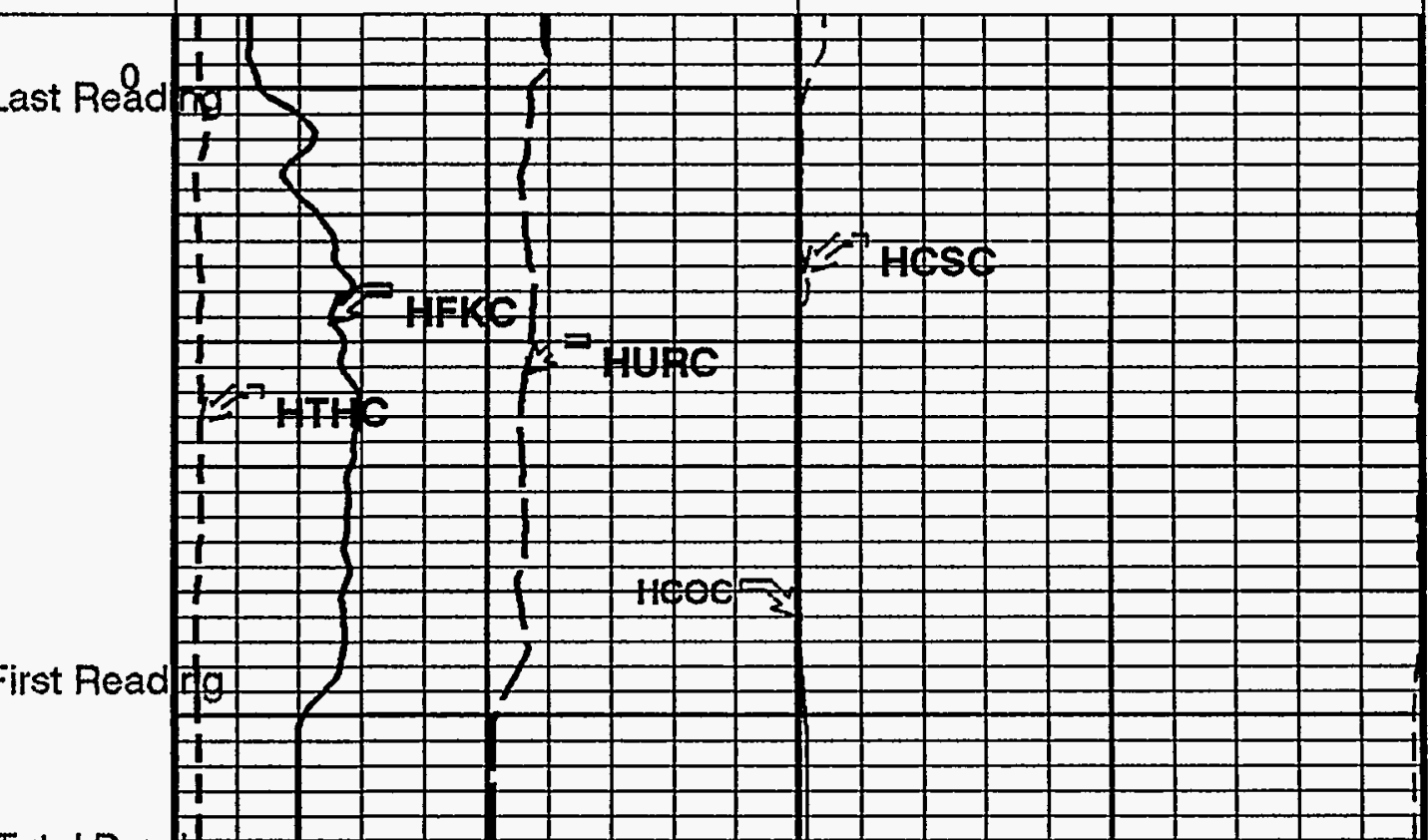

Total Dept

- HNGS Thorlum in $\mathrm{pCi} / \mathrm{g}$ (HTHC)

0 HNGS Cesium in $\mathrm{pC} i / g$ (HCSC) 


\section{D1TL}

D2PR

D2TC

D2TL

DBCC

DFD

Dẫil

GCF1_START

GCF2-START

GCSE

H1P

H2P

HABK

HALF

HATIM

HCAB

HMWM

HNPE

HSLV

HSVN

MAAQ START

RDF1_START

RDF2_START

S1BI

S1NA

S1NG

S2BI

S2NA

S2NG

SABK

SGRC

TPOS

VBA1

VBA2
HNGS Detector 1 Calibration Thorlum Peak Location

HNGS Detector 2 Callbration Thorlum Peak Resolution

HNGS Detector 2 Callbration Temperature

HNGS Detector 2 Callbration Thorlum Peak Location

HNGS Barite Constant Correctlon Flag

Drilling Fluid Densily

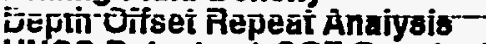

HNGS Detector 1 GCF Constant

HNGS Detector 2 GCF Constant

Generalized Caliper Selection

HNGS Detector 1 Allow/Disallow In Processing

HNGS Detector 2 Allow/Disallow In Processing

HNGS Borehole Potassium Running Average

HNGS Alpha Filter Length

HNGS Marquardt Accumulation Time

HNGS Apply Borehole Potassium Correction

Mud Weighting Material

HNGS Processing Enable

HNGS Borehole Fluid Excluder Sleeve Status

HNGS Spectral Standards Verslon Number

HNGS Marquardt Start-up Mode

HNGS Detector 1 RDF Constant

HNGS Detector 2 RDF Constant

HNGS Detector 1 Callbratlon Bismuth Count Rate

HNGS Detector 1 Callbration Sodlum Count Rate

HNGS Detector 1 Callbration End-On / Side-On Gain Ratio

HNGS Detector 2 Calibration Bismuth Count Rate

HNGS Detector 2 Calibration Sodium Count Rate

HNGS Detector 2 Calibration End-On / Side-On Gain Ratio

HNGS Statistical Uncertainty in Borehole Potassium Running Average

HNGS Standard Gamma-Ray Correctlon Flag

Tool Position

HNGS Detector 1 Variable Barite Factor Running Average

HNGS Detector 2 Variable Barlte Factor Running Average
$\%$

DEGF

66.3654

209.404

NONE

0.00

LB/G

IT

ALLOW

ALLOW

$-0.0236624$

60

600

NONE

NATU

YES

NO

INTERNAL

IN

$\mathbf{S}$

0.00282244

0.929226

0.940435

Jrmat: HNGSEnvLog10 Vertical Scale: $10^{\prime \prime}$ per 100'

Graphics File Created: 11-JAN-1995 16:18

\section{OP System Version: 7C0-427}
PLC-B
HPCAX-326
HNGS-BA
HPCAX-326

\section{Output DLIS Files}

$\begin{array}{ccccc}\text { DEFAULT } & \text { NPLB .004 } & \text { FN:5 } & \text { FIELD } & \text { 11-JAN-1995 16:18 } \\ \text { HNGS_RED } & \text { NPLB .004 } & \text { FN:6 } & \text { CUST } & \text { 11-JAN-1995 16:18 }\end{array}$

Input DLIS Files

$\begin{array}{llllll}\text { DEFAULT NPLB .003 FN:3 FIELD } & \text { 11-JAN-1995 16:00 } & 60.0 \mathrm{FT} & -6.0 \mathrm{FT}\end{array}$

\section{Output DLIS Files}

$\begin{array}{ccccc}\text { DEFAULT } & \text { NPLB .004 } & \text { FN:5 } & \text { FIELD } & \text { 11-JAN-1995 16:18 } \\ \text { HNGS_RED } & \text { NPLB .004 } & \text { FN:6 } & \text { CUST } & \text { 11-JAN-1995 16:18 }\end{array}$

\section{OP System Verslon: 7C0-427 \\ MBM}

JLC-B

HPCAX-326

HNGS-BA

HPCAX-326

Time Mark Every $60 \mathrm{~s}$

Jet 2 Linear Chi Sq
Large
rom CHl2 to CHI2
Llimit

Jet 1 Linear Chi Sq

Large 


\section{Large}

From CHI1 to CHI1_

Limit

P.?

- RDF2 REP Curve (RDF2-REP) $-\frac{10}{(-\cdots)}$

RDF1 REP Curve (RDF1 REP)

$(-\cdots)$

HSGR REP Curve (HSGR REP)

(GAPI) 100

GCF2 REP Curve (GCF2 REP)

$9-1.1$

GCF1 REP Curve (GCF1 REP)

$\frac{(-\cdots)}{(-\cdots) \text { REP Curve (CHI2 REP) }}$

CHI1 REP Curve (CHI1 REP)

$(-\cdots)$

0

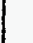

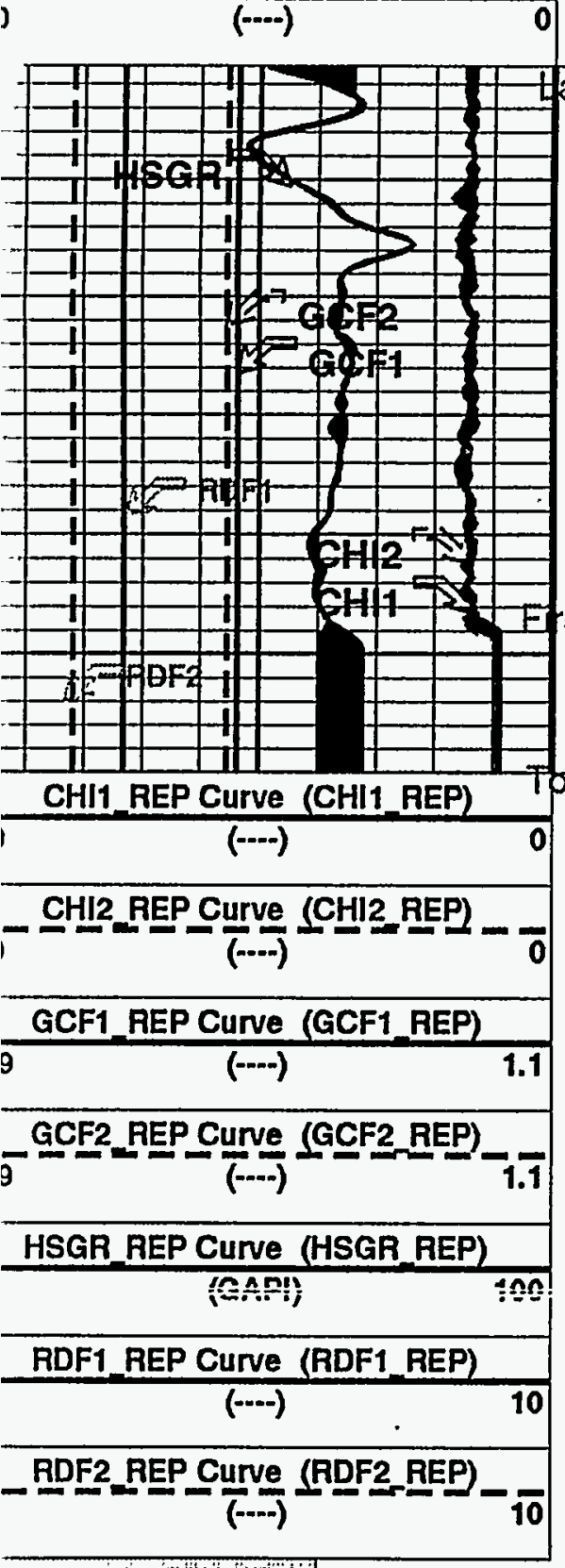

Det 1 Linear Chi Sq

st Readin
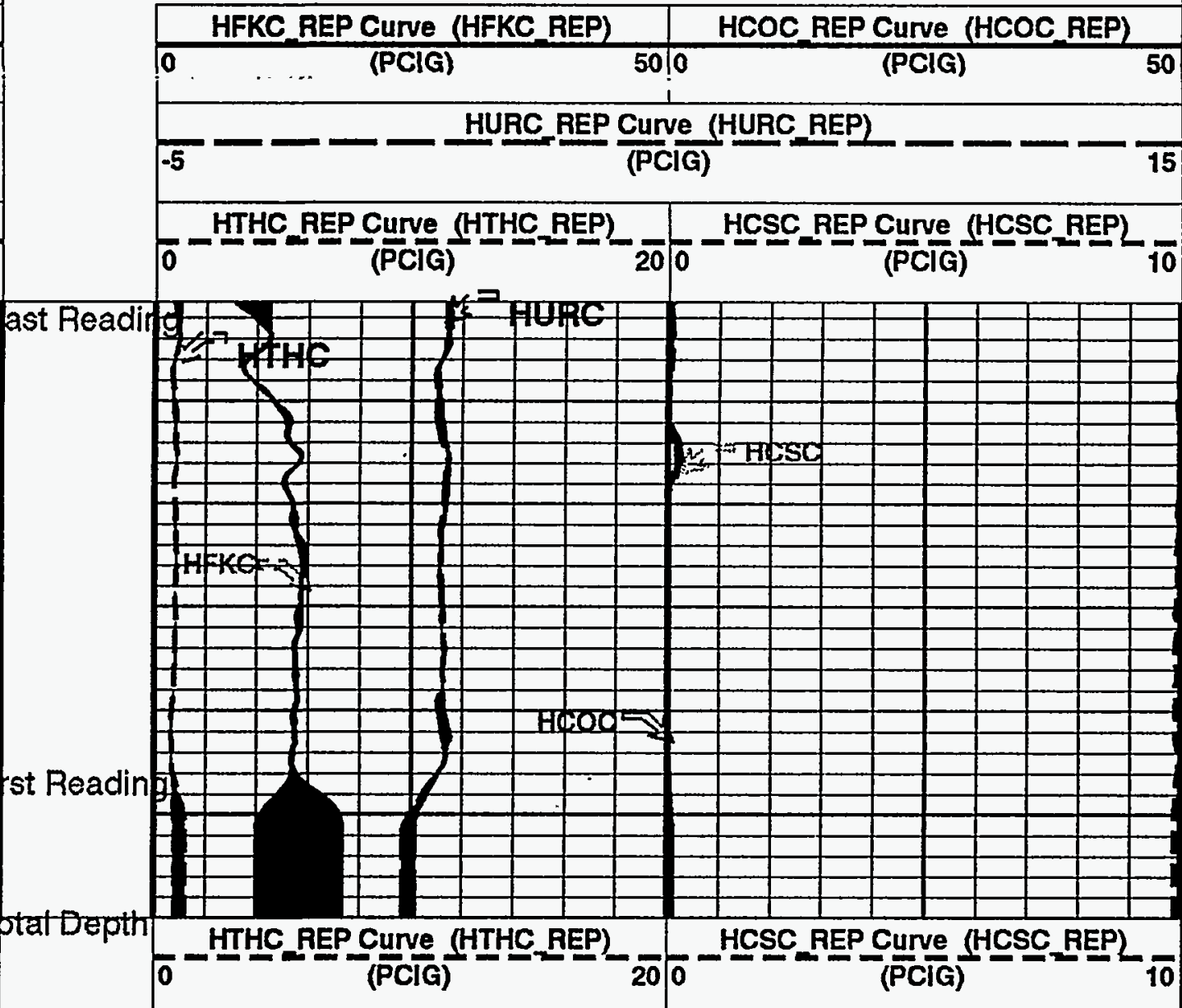

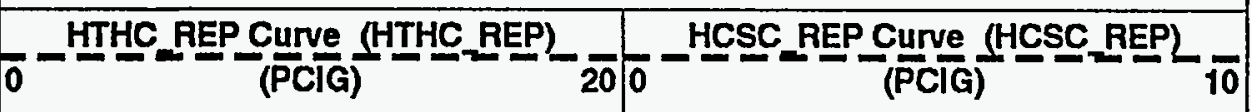

Frnm $\mathrm{CH} 11$ to $\mathrm{CHI}$ 


\section{Parameters}

\section{DLIS Name}

BAR1

BAR2

BHK

BHS

BKSF

BKSH

BKSL

BS

CSD1

CSD2

CSW1

CSW2

D1PR

D1TC

D1TL

D2PR

D2TC

D2TL

DBCC

DFD

DORL

GCF1 START

GCF2_START

GCSE

H1P

$\mathrm{H} 2 \mathrm{P}$

HABK

HALF

HATIM

HCAB

HMWM

HNPE

HSLV

HSVN

MARQ STAAT

RDF1_START

RDF2-START

S1BI

S1NA

SING

S2BI

S2NA

S2NG

SABK

SGRC

TPOS

VBA1

VBA2

\section{Description}

HNGS Detector 1 Barite Constant

HNGS Detector 2 Barite Constant

HNGS Borehole Potassium Correction Concentration

Bore Hole Status

HNGS Borehole Fluid Excluder Sleeve Algorithm Factor

HNGS Borehole Fluid Excluder Sleeve Algorithm High Channel

HNGS Borehole Fluld Excluder Sleeve Algorithm Low Channel

Bit Size

Inner Casing Outer Diameter

Outer Casing Outer Dlameter

Inner Casing Welght

Outer Casing Weight

HNGS Detector 1 Callbration Thorlum Peak Resolution

HNGS Detector 1 Callbration Temperature

HNGS Detector 1 Calibration Thorium Peak Location

HNGS Detector 2 Calibration Thorium Peak Resolution

HNGS Detector 2 Calibration Temperature

HNGS Detector 2 Calibration Thorium Peak Location

hiNG Sa Earite Cônstant Correction Fíag

Drilling Fluld Density

Depth Offset Repeat Analysis

HNGS Detector 1 GCF Constant

HNGS Detector 2 GCF Constant

Generalized Caliper Selection

HNGS Detector 1 Allow/Disallow In Processing

HNGS Detector 2 Allow/Disallow In Processing

HNGS Borehole Potassium Running Average

HNGS Alpha Filter Length

HNGS Marquardt Accumulation TIme

HNGS Apply Borehole Potasslum Correction

Mud Welghting Material

HNGS Processing Enable

HNGS Borehole Fluld Excluder Sleeve Status

HNGS Spectral Standards Version Number

HNGS Marquardt Start-up Mode

HNGS Detector 1 RDF Constant

HNGS Detector 2 RDF Constant

HNGS Detector 1 Calibration Bismuth Count Rate

HNGS Detector 1 Calibration Sodium Count Rate

HNGS Detector 1 Calibration End-On / Side-On Gain Ratio

HNGS Detector 2 Calibration Bismuth Count Rate

HNGS Detector 2 Calibration Sodium Count Rate

HNGS Detector 2 Callibration End-On / Side-On Gain Ratio

HNGS Statistical Uncertainty in Borehole Potassium Running Average

HNGS Standard Gamma-Ray Correction Flag

Tool Position

HNGS Detector 1 Variable Barite Factor Running Average

HNGS Detector 2 Variable Barite Factor Running Average

\section{Value}

1

1

OPEN

1

245

6.375

6

IN

IN

IN

LB/F

LB/F

7.95108

$\%$

68.1123

210.186

7.22512

66.3654

209.404

Bंजivi

0.00

0.0

FT

DEGF

ALLOW

ALLOW

$-0.0236624$

60

600

NONE

NATU

YES

NO

INTERNAL

IN

S

CPS

33.439 CPS

0.983299

2.8

33.7118

CPS

CPS

rmat: HNGSEnvLog_REP Vertical Scale: 5" per 100" 0.940435

\section{OP System Version: 7C0-427 \\ MBM}

JLC-B HPCAX-326 HNGS-BA HPCAX-326

Input DLIS Files

$\begin{array}{lllll}\text { DEFAULT NPLB .003 FN:3 FIELD } & 11-J A N-199516: 00 & 60.0 \text { FT }\end{array}$

Output DLIS Files 


\begin{tabular}{|c|c|c|c|}
\hline \multirow{2}{*}{\multicolumn{4}{|c|}{$\begin{array}{c}\text { Hostile Natural Gamma Ray Sondo Wellsite Calibratio } \\
\text { Ratio Of Detector } 1 \text { To Detector } 2\end{array}$}} \\
\hline & & & \\
\hline \multirow{2}{*}{ Thase } & \multicolumn{2}{|c|}{ Colncidence Count Rate Ratio } & \multirow{2}{*}{$\frac{\text { Value }}{0.9957}$} \\
\hline & & & \\
\hline jefore & & & 0.9858 \\
\hline After & & & 0.9946 \\
\hline \multicolumn{2}{|c|}{$\begin{array}{c}0.9500 \\
\text { d.1(1nIm(m) }\end{array}$} & $\begin{array}{l}1.000 \\
\text { Nom(na) }\end{array}$ & \\
\hline \multicolumn{4}{|c|}{ Aaster: Jan $622: 131995$} \\
\hline \multicolumn{4}{|c|}{ Aofore: Jan 11 16:12 1995} \\
\hline \multicolumn{4}{|c|}{ fter: Jan 11 18:52 1995} \\
\hline
\end{tabular}

\begin{tabular}{|c|c|c|c|}
\hline \multirow{2}{*}{ GMPANY: } & BATTELLE MEMORIAL INSTITUTE & BOTTOM LOG INTERVAL & $46 \mathrm{~F}$ \\
\hline & PACIFIC NQRIHWEST LABORATORIES & SCHLUMBERGER DEPTH & $60 \mathrm{~F}$ \\
\hline 耻: & $299-E 24-92$ & DEPTH DRILLER & $60 \mathrm{~F}$ \\
\hline FP: & SISSON/LU INJECTION SITE & KELLY BUSHING & \\
\hline QUNTY: & BENTON & DRILL FLOOR & \\
\hline ATE: & WASHINGTON & GROUND LEVEL & \\
\hline Schlur & $\begin{array}{l}\text { NATURAL C } \\
\text { WITH HNGS }\end{array}$ & RAY LOG & \\
\hline
\end{tabular}

期-

FP:

ATE

Schlumberger
NATURAL GAMMA RAY LOG

WITH HNGS TOOL 